Departamento de Ciencias Biológicas - Facultad de Ciencias Exactas Universidad Nacional de La Plata

\title{
"CARACTERIZACIÓN Y ROL FUNCIONAL DE CANALES IÓNICOS EN CÉLULAS DE MÚSCULO LISO VASCULAR HUMANO"
}

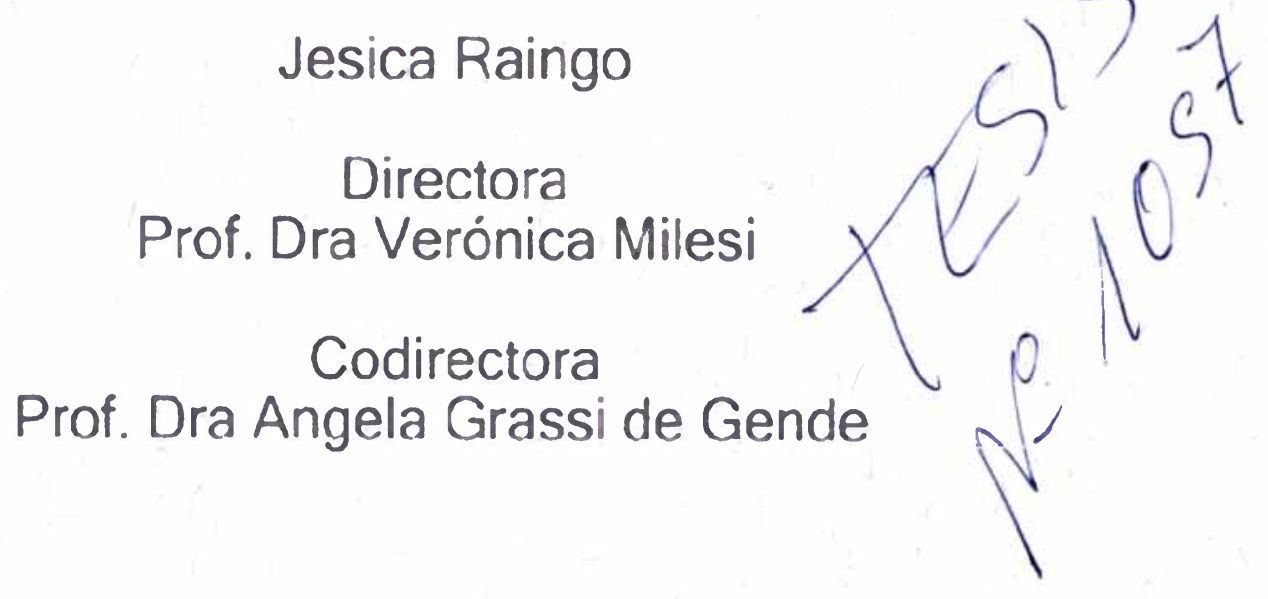

Tesis Doctoral

- 2004 -

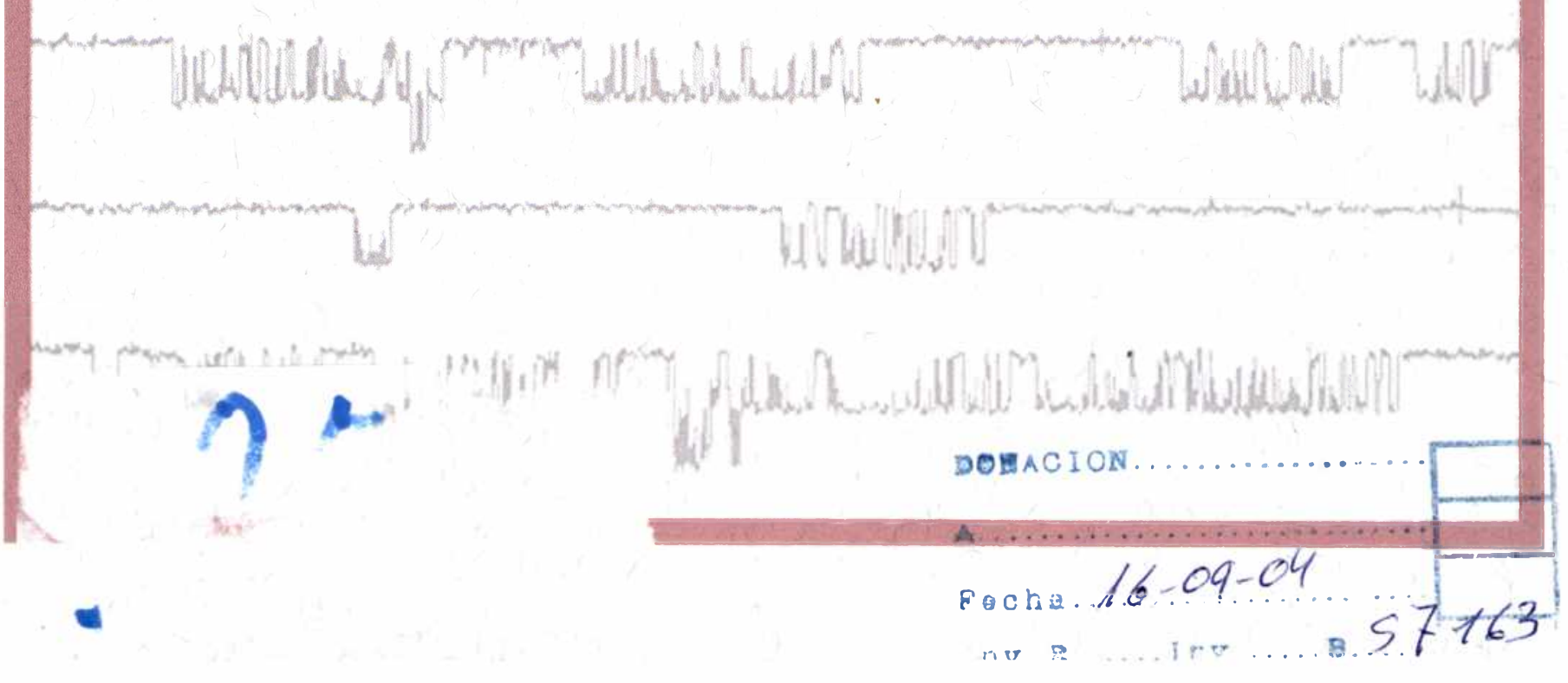




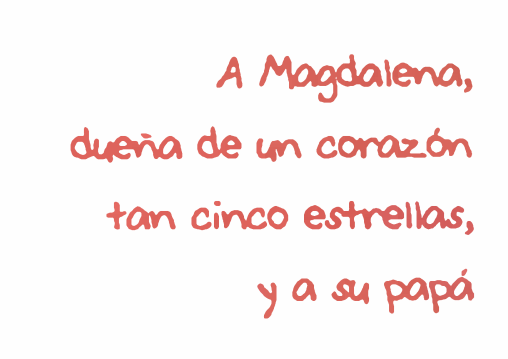

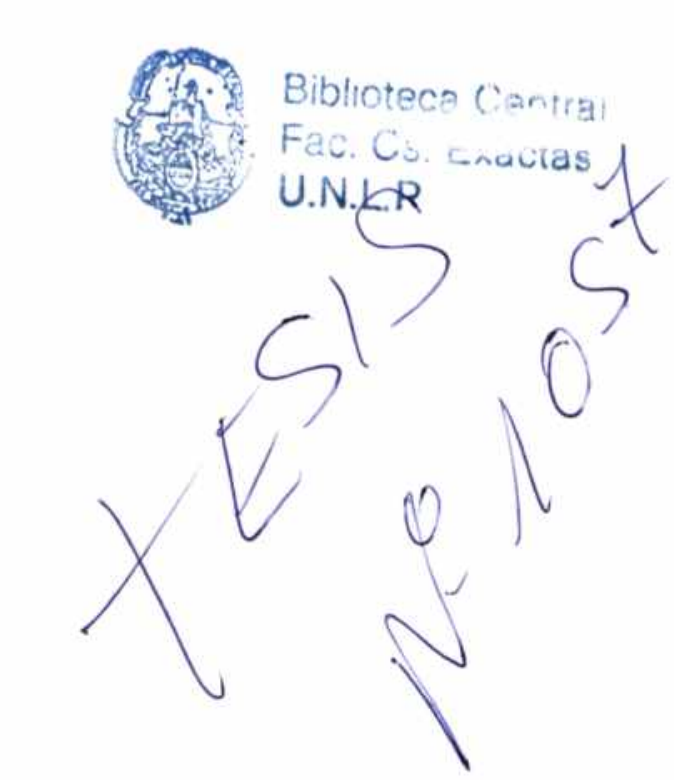

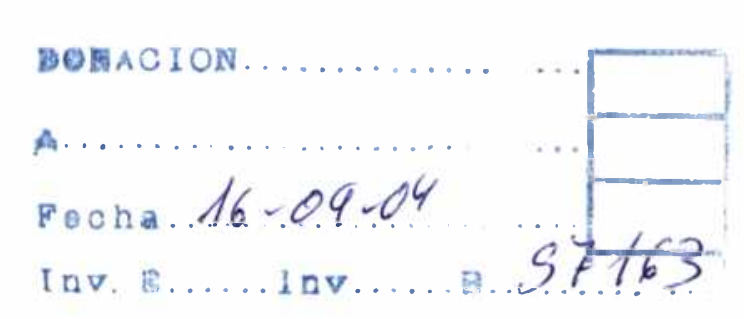




\section{GRACIAS}

A Verónica por su apoyo constante, por escuchar todas mis dudas, por permitirme trabajar en forma independiente, por alentarme a tener confianza en mi misma, por su predisposición para la discusión, por mostrarme que la ciencia es divertida, que nada es tan dificil, por guiarme en el aprendizaje de una disciplina tan fascinante y compleja como la electrofisiología y, por sobre todas las cosas, por enseñarme a hacer "patch", porque es una muestra de la dedicación y el entusiasmo con que se involucra en la formación de sus becarios.

A Angela por su inmensa generosidad, por su predisposición, por confiar siempre en mí, por alentarme y enseñarme tantas cosas. También por permitirme trabajar en el laboratorio de la Cátedra de Fisiología, la cual nació y creció a partir de sus infinitas ganas de hacer cosas y en la que cada uno de nosotros pudo encontrar un lugar excelente para formarse, trabajar y desarrollar con total libertad sus ideas.

A Alejandro por haberme enseñado tanto y estar siempre dispuesto a solucionar todos los inconvenientes que se me presentaron (siempre de índole tan variada), por haber funcionado como traductor, profesor, enciclopedia, diccionario de inglés (y castellano) y manual de "Windows", entre otras cosas. Por el compañerismo y la infinita paciencia que tuvo conmigo en el día a día, porque si bien somos muy distintos nos divertimos mucho trabajando juntos.

A Silvia, a Francisco, a Florencia, a Alicia por el compañerismo, por los buenos momentos, por la ayuda, por los consejos, por los mates, por la música y por tolerar mis malos días cargados de exigencias, a veces sin sentido.

A Gustavo Rinaldi por colaborar y ayudarme tanto con mi trabajo, por dedicar tiempo a la discusión de resultados y estar siempre dispuesto a ayudarme. También por todo lo que me enseñó.

A la Facultad de Ciencias Exactas por permitirme desarrollar este trabajo de Tesis Doctoral, por darme un espacio para aprender, enseñar y discutir ideas, por permitirme ser parte de un centro académico de excelencia que me llena de orgullo y a la Universidad Nacional de La Plata, por confiar en mí y por financiarme ininterrumpidamente todos estos años.

A mis amigos y compañeros: A Micha, a Grace, a Gracielita, a Euge, a Ana, a Manuel, a Leti, a Martín, a Cecilia, a Mauro, a Vero, a Griselda y a Bamba por 
los buenos momentos, los viajes compartidos, por aconsejarme y escucharme cada vez que lo necesité y a Male porque la adoro.

A mis padres y a mis hermanos: A mamá porque me dio herramientas que me servirán toda la vida y por el esfuerzo que puso en criarnos; a papá por el aliento constante, por los consejos y por escucharme; a los dos, por confiar en mi y permitirme venir a estudiar a La Plata. A Fede y a Pao por estar ahí cuando los necesito y por estar siempre tan orgullosos de mí.

A mi abuela Beba por preocuparse por mí y por estar siempre dispuesta a ayudar. Por todo lo que me cocinó cuando estudiaba y por todo lo que renegó cuando llegaba tarde. Por llorar conmigo cuando desaprobé mi primer final y por ponerse tan contenta cuando cada vez que me fue bien.

A toda mi familia: a mis tíos Osvaldo, Graciela, Graciela, Coca, Lilian, y Edgardo y a todos mis primos por la ayuda en los primeros tiempos en La Plata, por los consejos y por hacerme sentir en familia cada vez que estamos juntos.

A Mario, simplemente por ser mi compañero de ruta y mi mejor amigo, por querernos tanto a mi y a Magui, porque los mejores momentos siempre lo involucran, por demostrarme con hechos que siempre-todo-se-puede y por apretar el botón de "on" todos los días de mi vida.

A Magui por adaptarse a nuestra vida, porque verla feliz me llena de ganas de hacer cosas y por la hermosa corriente $\mathrm{BK}_{\mathrm{Ca}}$ de su arteria umbilical que ilustra la portada de esta Tesis. 


\section{INDICE}

\section{INTRODUCCIÓN}

- Presión Arterial (PA), irrigación sanguínea y

músculo liso vascular

- Función contráctil del músculo liso

- Canales iónicos y propiedades bioeléctricas de las células

de músculo liso vascular

- Canales de $\mathrm{K}^{+}$

- Canales catiónicos no selectivos

OBJETIVOS

- Determinaciones electrofisiológicas mediante

la técnica de patch-clamp

- Determinación de fuerza isométrica

en anillos vasculares intactos

- Determinación de presión de perfusión

en segmentos vasculares intactos

- Drogas y reactivos utilizados 
- Caracterización electrofisiológica de células

de músculo liso aisladas de arteria umbilical humana

71

-Registros de corrientes iónicas macroscópicas

71

- Registros de canal único

88

- Estudio de la función contráctil de la arteria umbilical humana

97

-Caracterización del canal $\mathrm{BK}_{\mathrm{Ca}}$ en células de músculo liso

aisladas de arteria mamaria interna humana

- Participación del canal BK $\mathrm{Ca}_{\mathrm{C}}$ en la respuesta contráctil

inducida por cambios de $\mathrm{pH}$ en la arteria mamaria interna humana

119

DISCUSIÓN Y CONCLUSIONES

-Conclusiones finales 


\section{INTRODUCCIÓN}

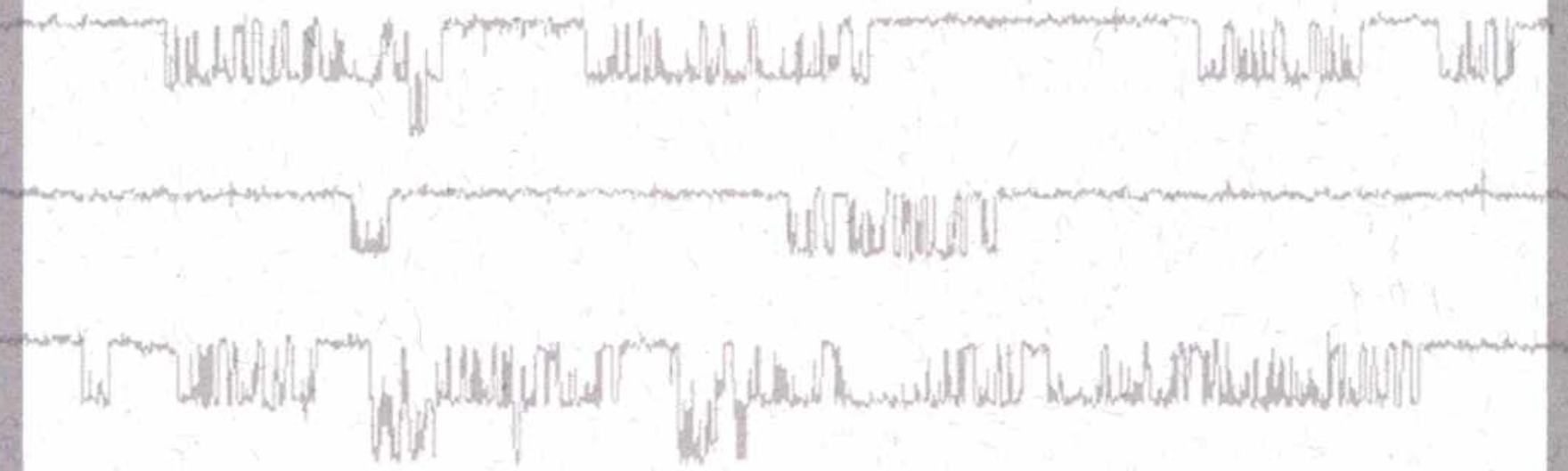




\section{INTRODUCCIÓN}

El aparato circulatorio, integrado por el corazón y los vasos sanguíneos, posee la función principal de proveer oxigeno, sustancias nutritivas, vitaminas y hormonas a las células del organismo, así como la de eliminar productos de desecho metabólico producidos por las mismas. Estos procesos se llevan a cabo, en los organismos adultos, mediante la circulación de la sangre por dos circuitos en serie. El circuito mayor formado por la aorta que da origen a todas las arterias sistémicas, las cuales se subdividen en arterias de calibre medio hasta dar origen a las arteriolas y, finalmente a los capilares, cuya pared está formada sólo por una capa de células endoteliales que permite el intercambio de gases y sustancias con los tejidos. Las células endoteliales de los capilares sintetizan colágeno no fibrilar, glicoproteínas, laminina y fibronectina que forman una membrana basal que lo vincula con el intersticio del tejido que irrigan (1).

Luego del intercambio de sustancias entre la sangre y los tejidos a nivel capilar, la sangre drena en las vénulas, las cuales poseen mayor diámetro a medida que se alejan del lecho capilar, para regresar al corazón a través de las venas cavas superior e inferior que llevan la sangre a la aurícula derecha. El ventrículo derecho impulsa la sangre a través del circuito menor formado por la arteria pulmonar que se ramifica permitiendo que la sangre se oxigene y elimine el $\mathrm{CO}_{2}$ al nivel de los capilares pulmonares, luego de lo cual la sangre regresa a la aurícula izquierda por las venas pulmonares (2).

La pared de los vasos sanguíneos se ajusta a una organización histológica general, donde se distinguen tres capas: intima, media y adventicia (3).

La estructura de la capa adventicia es compleja; y contiene una red de fibras de elastina y colágeno entremezcladas. Posee células inmersas y terminales nerviosas, siendo su función fisiológica mejor conocida la de mediar la inervación de la pared del vaso (4). Sin embargo, recientemente se ha demostrado que la capa adventicia modifica las propiedades mecánicas de las arterias carótida e iliaca de rata en forma independiente de la actividad de las terminales nerviosas (5). Esta capa se encuentra irrigada por vasos microscópicos denominados "vasa vasorum" los cuales pueden llegar a la zona periférica de la capa media. 
Entre la capa adventicia y la capa media de los vasos que reciben inervación se ubica un plexo de grandes nervios perivasculares cuya porción terminal presenta engrosamientos a nivel de los cuales se liberan neurotransmisores (3).

La capa media se compone principalmente de células de músculo liso en disposición helicoidal; la cantidad de células que forman esta capa varía a lo largo del árbol vascular. Las células musculares lisas se encuentran inmersas en una matriz extracelular formada por elastina, colágeno, glicoproteinas y proteoglicanos, cuya proporción varía en los distintos vasos. Las venas de calibre pequeño o mediano poseen una capa media mucho más delgada que las arterias que las acompañan de similar calibre, formada generalmente por una única lámina circular de células de músculo liso, donde hay más fibras de colágeno y menos células musculares que en las arterias. Las paredes de las venas son distensibles y no poseen componentes elásticos. Esto permite que las venas alojen un gran volumen sanguineo por lo que se denominan vasos de capacitancia. En las arterias musculares existen dos láminas elásticas, una externa entre la capa adventicia y la media y otra interna, entre la capa media y la intima.

La capa intima está formada por una capa de tejido conectivo (subendotelio), una membrana basal y una monocapa de células especializadas que recubren la superficie interna del vaso denominada endotelio.

En la pared de los vasos puede existir comunicación entre distintas células, la cual está mediada por uniones estrechas (o del inglés "gap junctions") formadas por proteinas denominadas conexinas que comunican el citoplasma de dos células adyacentes permitiendo el paso selectivo de determinadas sustancias. Estas proteínas se pueden encontrar entre dos células musculares, entre dos células endoteliales e incluso comunicando células endoteliales con células musculares (6). Estas uniones mio-endoteliales son caracteristicas de las arteriolas, donde las células endoteliales presentan crestas que atraviesan la membrana basal y se comunican asi con las células musculares (1).

\section{Presión Arterial (PA), irriqación sanquínea v músculo liso vascular}

Los valores de PA máximos considerados normales en adultos de 18 años o más, son $139 \mathrm{mmHg}$ para la presión sistólica y $89 \mathrm{mmHg}$ para la diastólica (7). Estos valores de presión se mantienen casi constantes durante todo el ciclo 
cardíaco, aunque el corazón eyecta sangre en forma intermitente. Las arterias de mayor calibre, como la aorta, poseen como función principal conservar constante la presión sanguínea diastólica. En estas arterias de gran diámetro la gran proporción de componentes elásticos en su pared permite que durante la sístole ventricular la pared se distienda y almacene parte del volumen eyectado y el retroceso elástico de sus paredes mantiene el flujo hacia los capilares durante la diástole ventricular (8). Las arterias de calibre medio y pequeño y las arteriolas cumplen un rol importante en la regulación de la presión arterial de un organismo porque dependiendo del estado contraído o relajado de sus células poseerán distinto diámetro determinando el volumen de sangre que queda alojado en el sistema arterial. Desde un punto de vista hemodinámico, la presión arterial depende del volumen minuto, el cual se define como el caudal de sangre que circula por cualquier sección transversal total del árbol circulatorio, y de la resistencia periférica. Mediante las siguientes ecuaciones derivadas de la ley de Poiseuille es posible relacionar la presión arterial con la viscosidad de la sangre y el radio del vaso, dos factores que determinan el valor de resistencia periférica (9):

$$
P A=V M \cdot R p \quad R p=8 \eta L / \pi r^{4}
$$

Donde

$\mathrm{PA}=$ presión arterial media

$\mathrm{VM}=$ volumen minuto cardíaco

$\mathrm{Rp}=$ resistencia periférica total

$\eta=$ es la viscosidad de la sangre

$\mathrm{L}=$ longitud total del sistema

$r=$ radio del vaso

En el lecho vascular no existen grandes variaciones de la viscosidad de la sangre, sin embargo el radio de los vasos puede variar mucho y en poco tiempo. El estado contráctil de las células musculares lisas que forman la pared de las arterias de calibre medio y pequeño $(4-0.5 \mathrm{~mm})$ y de las arteriolas $(35-30 \mu \mathrm{m})$ es fundamental en la determinación del diámetro de estos vasos, por lo que la contracción o relajación de las células de músculo liso de estos vasos producirá una disminución o aumento de la luz del vaso, modificando la resistencia periférica y la presión arterial. Un aumento en la resistencia periférica constituye un 
desorden hemodinámico fundamental en la hipertensión arterial. Esta patologia caracterizada por el aumento de la presión arterial por encima de los valores normales, es el mayor factor de riesgo para accidentes cardiovasculares (accidente cerebro-vascular e infarto de miocardio). Si bien, en la mayoría de los casos, se desconoce la etiologia de la hipertensión arterial, muchos autores han observado cambios en las propiedades contráctiles de las células de músculo liso provenientes de organismos hipertensos animales y humanos (10).

La pared de los vasos en los individuos hipertensos sufre cambios estructurales importantes que aumentan el grosor de la pared y reducen la luz del vaso contribuyendo asi al aumento de la resistencia periférica. La literatura muestra controversias sobre si estos cambios son consecuencia o parte de las causas del aumento de la presión arterial (10).

En este trabajo de Tesis, uno de los vasos estudiados fue la arteria mamaria interna humana (AMIH), la cual pertenece al grupo de arterias de calibre medio y transcurre a lo largo del tórax, irrigando principalmente el músculo esquelético. Esta arteria sistémica es una rama de la arteria subclavia y en su transcurso da origen a las siguientes arterias colaterales: pericardiofrénica, mediastínica, tímica, esternal, perforante e intercostal anterior; y en la zona terminal, se divide en las arterias musculofrénica y epigástrica superior (11). La AMIH es utilizada en la cirugia de revascularización miocárdica como puente aorto-coronario para restablecer el flujo sanguíneo en el miocardio. Se comenzó a utilizar en reemplazo de la vena safena humana y es actualmente el vaso de primera elección por la alta permeabilidad que presenta a largo plazo, la cual es de un 90 a $100 \%$ en un plazo de 5 años (12).

Por otro lado, en un organismo, los volúmenes de sangre requeridos por los distintos tejidos varian en el tiempo dependiendo principalmente de la actividad metabólica de las células. Las arterias, denominadas musculares, de calibre medio poseen en su capa media una gran proporción de células de músculo liso organizadas en varias capas que responden a estímulos locales, mecánicos, hormonales y nerviosos; regulan el estado contráctil del vaso, permitiendo la variación de su diámetro y garantizando la llegada de un volumen de sangre adecuado a las necesidades de los distintos tejidos en cada momento. Alteraciones en dichos mecanismos como la hiperreactividad de los vasos a determinados estimulos contráctiles pueden alterar la irrigación de los diferentes 
tejidos generando algunas situaciones patológicas como la enfermedad de Raynaud o la acrocianosis (13).

Algunos vasos sanguineos poseen la capacidad de generar una respuesta denominada miogénica por medio de la cual responden a un aumento de la presión transmural con una vasoconstricción, y a una disminución de la misma con una vasodilatación. Esta respuesta ha sido demostrada en arteriolas, arterias de diámetro medio y pequeño asi como también en vénulas, venas y vasos linfáticos $(14,15,16)$. El tono miogénico ha sido ampliamente observado en el músculo liso vascular y en este tejido se desarrolla en forma independiente de influencias endoteliales, neuronales, hormonales o metabólicas. Su descripción original fue realizada por Bayliss en el año 1902 (17), si bien habia sido esbozada previamente por otros autores. Este mecanismo juega un rol importante en la regulación del flujo sanguíneo en forma local (autorregulación), previniendo o atenuando un aumento de la irrigación del tejido cuando aumenta la presión y facilitando la misma cuando la presión disminuye; además de proveer a los vasos de un tono basal para responder ante distintos estímulos neurohumorales, especialmente a aquellos que inducen vasodilatación (18). En relación con este tema, en este trabajo de Tesis Doctoral se realizó la caracterización del tono miogénico en la arteria umbilical humana $(A \cup H)$, una arteria de calibre pequeño involucrada en la circulación feto-placentaria humana. En el feto, la oxigenación de la sangre y la eliminación de $\mathrm{CO}_{2}$ tienen lugar en la placenta, mientras que los pulmones no poseen función de intercambio gaseoso hasta el momento del nacimiento.

La aorta fetal posee dos ramas colaterales de baja resistencia que son las arterias umbilicales, las cuales transportan sangre pobremente oxigenada $\left(\mathrm{PO}_{2}=\right.$ $21 \mathrm{~mm} \mathrm{Hg}$ ) (19) hacia los senos venosos placentarios. Las arterias umbilicales se ramifican varias veces y se dilatan en asas capilares dentro de los senos placentarios; desde la madre, la sangre llega hasta la placenta por ramas de la arteria uterina que dan origen a las arterias espirales. Con el aumento de la edad gestacional, las arterias espirales remodeladas por la acción del sincitiotrofoblasto disminuyen su resistencia, permitiendo que la sangre materna bañe los senos placentarios donde se realiza el intercambio gaseoso materno-fetal. La sangre de los senos retorna a la circulación materna por las venas uterinas y la sangre fetal oxigenada vuelve a la circulación fetal mediante la vena umbilical. 
Los vasos del cordón umbilical tienen un rol fundamental en el transporte de nutrientes vitales para el desarrollo del feto y el estado contráctil de sus células contribuye en la determinación del flujo feto-placentario. Estos vasos no poseen inervación nerviosa autónoma (20), de forma que su tono está regulado por factores liberados en forma local (por células endoteliales, de músculo liso) o que alcanzan las células de músculo liso a través del flujo sanguineo. Por otro lado, en el año 1993, Umans y colaboradores mostraron que la AUH presenta un tono dependiente de la concentración de calcio externo, al cual estos autores denominaron "espontáneo" (21).

Durante el embarazo ocurren cambios hemodinámicos y cardiovasculares para poder satisfacer las necesidades metabólicas de la madre y del feto. Entre estos cambios, en la madre se observa una disminución importante de la resistencia vascular total y de la presión arterial. Estos cambios no ocurren en mujeres que desarrollan preeclampsia, en las cuales la resistencia vascular y la presión arterial se ven aumentadas abruptamente. Asociada a esta patologia se ha observado una inadecuada invasión del sincitiotrofoblasto sobre las arterias espirales uterinas y una disminución del flujo utero-placentario. Se ha postulado que la alteración morfológica de las arterias podría ser la causa de la reducción del flujo utero-placentario determinando en la placenta un estado de hipoxia o isquemia que induce a la misma a liberar distintos factores como citoquinas y especies de oxigeno reactivas, entre otros. En esta hipótesis, dichos factores serian los que inician una cascada de eventos celulares y moleculares que conducirian a la disfunción de las células endoteliales y musculares lisas de las arterias maternas, provocando las alteraciones hemodinámicas características de la patologia y el retardo de crecimiento fetal que ocurre en estos casos (22). Esta disfunción es exclusiva de los seres humanos y si bien, para estudiar las consecuencias de este desorden, se han generado modelos en ratas de hipertensión durante la gestación, el estudio de los vasos umbilicales y placentanios humanos resulta importante para tratar de dilucidar el mecanismo de desarrollo de esta enfermedad que se encuentra entre las primeras causas de morbimortalidad fetal y materna (22). 


\section{Función contráctil del músculo liso}

\section{Descripción y función de las estructuras que participan en el mecanismo de contracción y relajación del músculo liso}

Las células musculares lisas son células fusiformes de unos 100 a $500 \mu \mathrm{m}$ de largo y 2 a $6 \mu \mathrm{m}$ de diámetro con una gran proporción superficie / volumen; esta relación se debe en parte a las invaginaciones que presenta la membrana llamadas cavéolas $(23,24)$.

Las proteínas contráctiles presentes en el citosol, actina y miosina, forman parte de los filamentos finos y gruesos del aparato contráctil que participa en el mecanismo de contracción muscular (25). Los filamentos gruesos están compuestos principalmente por miosina la cual a su vez está compuesta por dos subunidades pesadas y dos pares de subunidades livianas. Las cadenas pesadas están enrolladas entre sí, constituyendo el núcleo del filamento, y terminan en dos porciones de naturaleza globular capaces de hidrolizar ATP que sobresalen del mismo a intervalos regulares. Sobre cada cabeza de miosina se disponen dos tipos de cadenas livianas, una de ellas se denomina cadena liviana reguladora 0 MLC20 (del ingles "miosine light chain $20 \mathrm{kDa}$ ") y posee un sitio de fosforilación importante para la regulación de la contracción en el aminoácido serina 19.

La actina es el principal constituyente de los filamentos finos. Está formada por monómeros globulares de G-actina que se disponen formando un polímero filamentoso helicoidal de doble cadena de 1-2 $\mu \mathrm{m}$ de longitud denominado F-actina y en los surcos de esta proteína se dispone a intervalos regulares una molécula de la proteína fibrilar denominada tropomiosina $(23,24)$.

La proteína reguladora calponina se une a la actina y a la tropomiosina. El caldesmón es otra proteína reguladora que se ubica en el aparato contráctil interaccionando tanto con la actina como con la miosina. Los filamentos contráctiles del músculo liso se organizan en unidades de tres a cinco filamentos gruesos rodeados de varios filamentos finos, los cuales se fijan a estructuras proteicas denominadas cuerpos densos que están anclados a proteínas del citoesqueleto celular $(26,25)$. 
En estado de reposo, la concentración de $\mathrm{Ca}^{2+}$ libre en el citosol de la célula muscular lisa está comprendida en el rango de valores de 120 a $170 \mathrm{nM}$, y tiene un rol fundamental en la regulación del estado contráctil del músculo liso (27). Un aumento global en la concentración del ion $\mathrm{Ca}^{2+}$ intracelular a niveles de 500 a $700 \mathrm{nM}$ activa el aparato contráctil celular mediante el mecanismo que se esquematiza en la figura $I$.

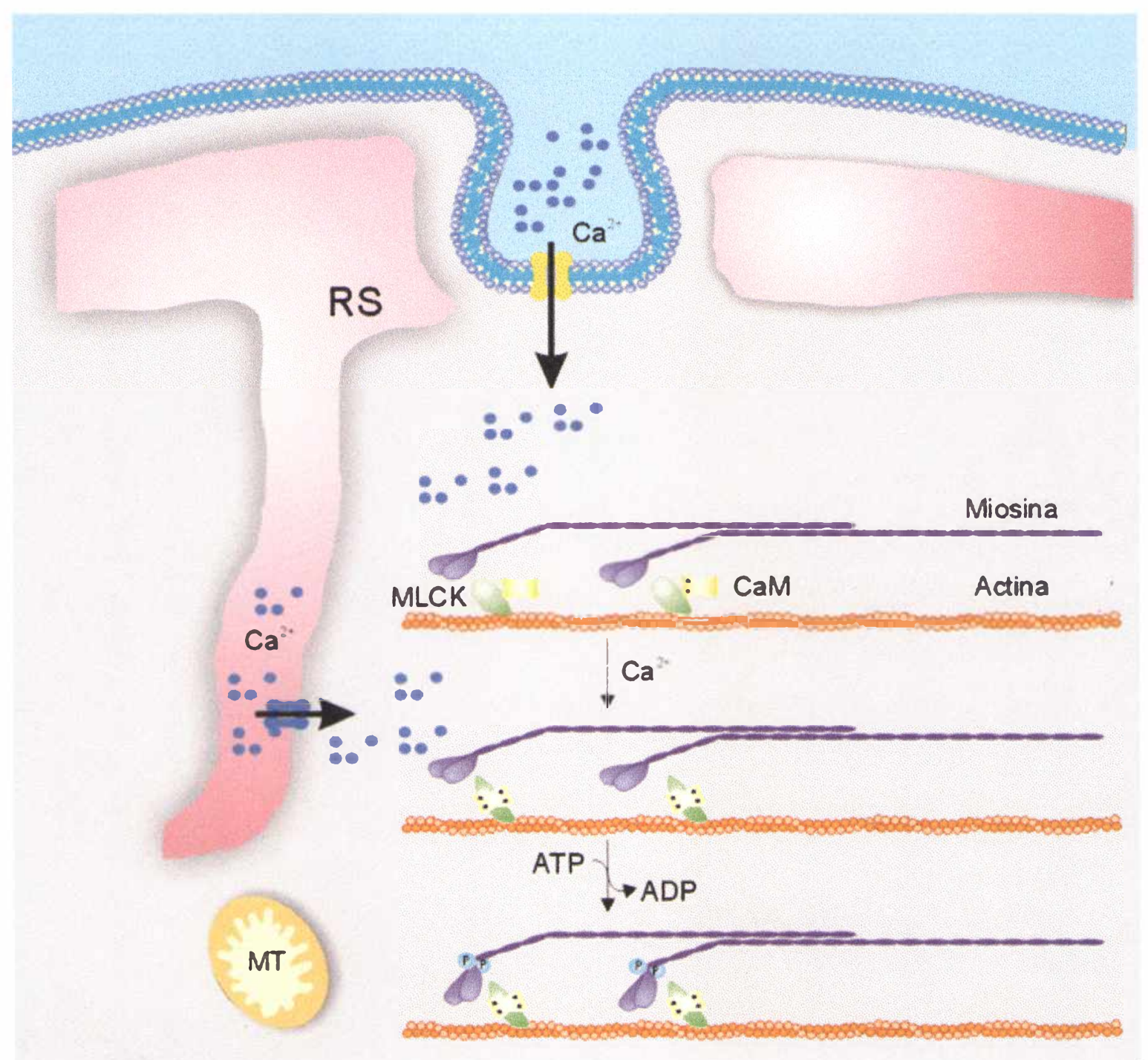

Figura I: esquema del mecanismo de activación de la contracción en la células de músculo liso. CaM, calmodulina, MLCK, proteína quinasa de la cadena liviana de la miosina, RS, retículo sarcoplásmico, MT, mitocondria. (31)

$\mathrm{El} \mathrm{Ca}{ }^{2+}$ se une a una proteína citoplasmática denominada calmodulina que posee afinidad por el $\mathrm{Ca}^{2+}$. La calmodulina posee cuatro sitios de unión para iones $\mathrm{Ca}^{2+}$. El complejo $\mathrm{Ca}^{2+}$-calmodulina (4 iones $\mathrm{Ca}^{2+}$ unidos a una molécula de 
calmodulina) activa a la proteina quinasa de la cadena liviana de la miosina o MLCK (del inglés "miosine light chain kinase"). Esta quinasa puede estar ligada a los filamentos finos a través de su extremo $\mathrm{N}$ terminal y cuando es activada fosforila a la proteina MLC20 $(28,29,30)$. Esta reacción desencadena un ciclo, durante el cual ocurre el corrimiento de las cabezas de miosina desplazando los filamentos de actina mediante el gasto de energía metabólica a través de la actividad ATPasica del complejo actomiosínico. Este mecanismo conduce a acortamiento de la estructura contráctil y desarrollo de fuerza. Recientemente se ha descripto que una fracción del total de proteinas calmodulina estaria unida a la MLCK, aún a concentraciones de $\mathrm{Ca}^{2+}$ de reposo (31), de esta forma el $\mathrm{Ca}^{2+}$, al aumentar su concentración en el citosol, se uniria a los sitios libres restantes de la calmodulina, activando la contracción.

Las proteinas reguladoras calponina y caldesmón tienen la propiedad de inhibir la actividad ATPasica del complejo actomiosínico sin afectar la fosforilación de la MLC20. Esta inhibición es removida por la unión de estas proteinas al complejo $\mathrm{Ca}^{2+}$-calmodulina o por fosforilación de las mismas. Este mecanismo se ha demostrado que sería el responsable de que en algunos casos la fuerza desarrollada no se corresponda con la proporción de MLC20 fosforilada (32).

El ciclo de la contracción se lleva a cabo hasta que el $\mathrm{Ca}^{2+}$ vuelve a disminuir a la concentración de reposo, a la cual la MLCK se inactiva y se interrumpe la fosforilación de la miosina. La miosina se desfosforila por acción de una fosfatasa de la miosina (MLCP) independiente del $\mathrm{Ca}^{2+}$ y esto lleva a la relajación de la célula.

Diversos estímulos fisiológicos como la acción de agonistas, cambios en el valor del potencial de membrana de las células de músculo liso, entre otros, pueden determinar un aumento de la concentración de $\mathrm{Ca}^{2+}$ intracelular en forma local o global mediante la generación de flujos de $\mathrm{Ca}^{2+}$ desde el espacio extracelular 0 desde organelas intracelulares y por lo tanto alterar el estado contráctil de las células. A continuación se detallan las estructuras involucradas en la génesis de dichos flujos de $\mathrm{Ca}^{2+}$ :

Canales de $\mathrm{Ca}^{2+}$ operados por voltaie o VOC (del inglés "voltage operated channels"): son canales iónicos selectivos al ión $\mathrm{Ca}^{2+}$ cuya actividad es sensible a los cambios del potencial eléctrico de la membrana celular. Se han identificado y 
caracterizado en diferentes tipos de músculo liso y se clasifican en canales de $\mathrm{Ca}^{2+}$ de tipo $\mathrm{L}$ (de inactivación lenta), sensibles a las dihidropiridinas y de tipo $\mathrm{T}$ (de inactivación rápida), inhibidos por el mibefradil, si bien la selectividad de este compuesto ha sido cuestionada. Ambos tipos de canales poseen la capacidad de inactivarse en forma dependiente del tiempo. Sin embargo, la dependencia del voltaje de la cinética de activación e inactivación de los canales tipo L es tal que la inactivación es incompleta en un determinado rango de potencial de membrana (aproximadamente entre -60 y $-20 \mathrm{mV}$ ) denominado ventana de corriente en el cual la activación de estos canales es baja pero significativa (33). Por lo tanto, las células de músculo liso de tipo tónico con valores de potencial de membrana dentro de dicho rango, tienen un influjo de $\mathrm{Ca}^{2+}$ constante y pequeñas variaciones del potencial son capaces de alterar significativamente la concentración de $\mathrm{Ca}^{2+}$ intracelular (34). Se ha informado la existencia de canales tipo $L$ que pueden ser activados por ligandos como NA, angiotensina II, serotonina y endotelina sin variaciones del potencial de membrana celular (35). Los canales tipo T se encuentran menos expresados en células de músculo liso, aunque en algunos casos pueden ser importantes en la regulación de la concentración de $\mathrm{Ca}^{2+}$ en este tipo celular $(36,37)$. La activación de este tipo de canal estaría en relación con la promoción del crecimiento celular en la pared de los vasos (38).

Canales catiónicos no selectivos (CNS): en los últimos años se ha comenzado a estudiar la presencia de este tipo de canales en la membrana plasmática. Estos canales iónicos son permeables a cationes monovalentes presentes en las soluciones fisiológicas como $\mathrm{Na}^{+}, \mathrm{K}^{+}$y según el tipo o subtipo de canal son permeables también a cationes divalentes como el $\mathrm{Ca}^{2+}$. En el músculo liso este tipo de canales puede constituir una vía importante de entrada de $\mathrm{Ca}^{2+}$ contribuyendo a la contracción muscular. Como se explicará en detalle más adelante, estos canales se encuentran regulados por factores muy diversos como estiramiento de la membrana plasmática y depleción de los depósitos intracelulares de $\mathrm{Ca}^{2+}$, entre otros (39).

Canales de $\mathrm{Ca}^{2+}$ presentes en las membranas del reticulo sarcoplásmico: estos canales permiten liberación de $\mathrm{Ca}^{2+}$ acumulado en depósitos intracelulares hacia el citosol determinando así un aumento del $\mathrm{Ca}^{2+}$ citoplasmático. En las membranas del retículo sarcoplásmico se han descripto dos tipos de canales de $\mathrm{Ca}^{2+}$ el canal activado por inositol trifosfato $\left(\mathrm{IP}_{3}\right)$ y el denominado receptor de 
rianodina $(27,40)$. La activación de los canales sensibles a $\mathbb{I P}_{3}$ se verifica cuando determinados agonistas se unen a sus receptores ubicados en el lado extracelular de la membrana plasmática activando a la enzima fosfolipasa $C$, la cual hidroliza fosfatidilinositol 4,5 bifosfato, presente en la membrana plasmática celular, produciendo $\mathrm{IP}_{3}$ y diacilglicerol. $E \mathrm{EI} \mathrm{IP}_{3}$ es un segundo mensajero que activa canales $\mathrm{IP}_{3}$ sensibles produciendo un flujo de $\mathrm{Ca}^{2+}$ desde el retículo sarcoplásmico hacia el citosol. La concentración citoplasmática de $\mathrm{Ca}^{2+}$ modifica la activación de estos canales ya que hasta $300 \mu \mathrm{M} \mathrm{el} \mathrm{Ca}{ }^{2+}$ aumenta la sensibilidad del canal al IP 3 y a concentraciones más altas la disminuye $(41,42,43)$. Con respecto a los canales receptores de rianodina, se sabe que pueden ser activados por concentraciones micromolares de $\mathrm{Ca}^{2+}$, iniciando así el mecanismo de liberación de $\mathrm{Ca}^{2+}$ inducido por $\mathrm{Ca}^{2+}(44)$.

Intercambiador $\mathrm{Na} / \mathrm{Ca}$ o $\mathrm{NCX}$ (del inalés " $\mathrm{Na} / \mathrm{Ca}$ exchanger"): es una proteína de membrana que transporta $\mathrm{Ca}^{2+}$ y $\mathrm{Na}^{+}$en direcciones opuestas. El sentido del transporte depende del valor de los potenciales electroquímicos de los iones $\mathrm{Na}^{+}$y $\mathrm{Ca}^{2+}$. La dependencia de su actividad con el potencial de membrana de la célula depende, a su vez, de la estequiometría de funcionamiento el NCX: si transporta carga neta (transportador electrogénico) o si no lo hace (transportador electroneutro). Esta proteína ha sido intensamente estudiada en músculo cardíaco pero es poca la información disponible sobre sus características y rol funcional en el músculo liso $(45,46,47)$. En determinadas condiciones funciona en el modo de entrada de $\mathrm{Ca}^{2+}$ (modo reverso) transportando $\mathrm{Ca}^{2+}$ hacia el interior celular y $\mathrm{Na}^{+}$ hacia el exterior. En algunos tipos de músculo liso se ha demostrado que ante determinados estímulos, como la disminución de la concentración de $\mathrm{Na}^{+}$ extracelular o la presencia de bloqueantes de la bomba Na/K, el NCX funcionando en modo reverso produce un influjo considerable de $\mathrm{Ca}^{2+}(48)$. Se ha descripto también en células de músculo liso la colocalización del NCX y zonas del retículo sarcoplásmico, sugiriendo un acoplamiento funcional entre ambas estructuras (49, 50). Un ejemplo de esto es el trabajo de Momose y colaboradores que demuestra que, en células en cultivo de músculo liso intestinal de cobayo, la disminución del $\mathrm{Na}^{+}$extracelular estimula el modo reverso del $\mathrm{NCX}$ generando un pequeño influjo de $\mathrm{Ca}^{2+}$ que induce la la liberación de $\mathrm{Ca}^{2+}$ desde depósitos intracelulares al citosol (liberación de $\mathrm{Ca}^{2+}$ inducida por $\left.\mathrm{Ca}^{2+}\right)(51,52)$. También se ha descripto que el aumento de la concentración de $\mathrm{Na}^{+}$en la zona subsarcolemal del 
citoplasma (ver más adelante), generado por flujos iónicos mediados por canales CNS, influencia la actividad del NCX activando su modo reverso de entrada de $\mathrm{Ca}^{2+}(53)$.

Como se mencionó antes, la función del NCX puede ser regulada por cambios en la actividad de la bomba $\mathrm{Na} / \mathrm{K}$, ya que ésta produce cambios en el gradiente de $\mathrm{Na}^{+}$a ambos lados de la membrana plasmática. En la arteria umbilical humana (54) y en vasos placentarios humanos (55) se ha descripto que el inhibidor de la bomba $\mathrm{Na}^{+} / \mathrm{K}^{+}$, ouabaina, produce contracción.

Entre los factores que regulan el NCX en el músculo liso vascular se sabe que el pH puede afectar su actividad. La acidificación extra como intracelular, inhiben su actividad dando como resultado una menor extrusión de $\mathrm{Ca}^{2+}$ de la célula y contribuyendo así a un aumento del tono contráctil (56). En músculo liso se ha encontrado que el NCX puede ser estimulado por GMPc (57), norepinefrina (58) y ésteres de forbol (59). Además, Wakabayashi y colaboradores demostraron en células de músculo liso vascular que el NCX es activado por factores de crecimiento a través de fosforilaciones mediadas por proteína quinasa $C$ (PKC) (60).

La disminución de la concentración de $\mathrm{Ca}^{2+}$ intracelular a través del flujo de $\mathrm{Ca}^{2+}$ hacia el medio extracelular y/o la recaptación de $\mathrm{Ca}^{2+}$ por organelas intracelulares dan inicio al mecanismo de relajación del músculo liso en el cual las siguientes estructuras cumplen un rol importante:

Ca-ATPasa de la membrana plasmática: transporta $\mathrm{Ca}^{2+}$ desde el citosol al espacio extracelular en contra de su gradiente a expensas del gasto de ATP. EI mecanismo de transporte mediado por la Ca-ATPasa es electroneutro ya que intercambia un ion $\mathrm{Ca}^{2+}$ por dos iones $\mathrm{H}^{+}$hacia el interior celular. Así, su estimulación disminuye el $\mathrm{pH}$ intracelular (pHi) (56) y se ha demostrado que cambios en el pHi o extracelular (pHe) pueden afectar su actividad. En arterias coronarias se ha encontrado que cambios en la actividad de la bomba contribuyen al efecto contráctil observado al aumentar el pHe (contracción) y al disminuirlo (relajación) (56). Además, la Ca-ATPasa es activada por la unión de calmodulina a su extremo carboxilo terminal (32). 
Ca-ATPasa de la membrana del retículo sarcoplásmico: también denominada SERCA del inglés "sarcoplasmic reticulum $\mathrm{Ca}^{2+}$ ATPase", esta proteina localizada en las membranas del retículo sarcoplásmico permite la captación de $\mathrm{Ca}^{2+}$ cuando este ion aumenta su concentración en el citosol. Utiliza la energía metabólica del ATP para funcionar y el $\mathrm{Ca}^{2+}$ que ingresa al retículo sarcoplásmico en contra de su gradiente electroquimico es captado por proteinas que unen $\mathrm{Ca}^{2+}$ como la calsecuestrina y la calreticulina; estas proteinas permiten que la concentración total de $\mathrm{Ca}^{2+}$ en el retículo sarcoplásmico alcance valores de 10-15 mM (61). Esta Ca-ATPasa es regulada por una proteína de transmembrana denominada fosfolamban que se une a ella inhibiéndola. Esta unión puede ser liberada por la fosforilación de fosfolamban por proteinas quinasas de tipo $G \circ$ A. Algunos agonistas que aumentan el AMPc $\circ$ el GMPc en las células de músculo liso producen relajación por activación de la Ca-ATPasa a través de fosforilación de fosfolamban (62). La Ca-ATPasa intercambia iones $\mathrm{Ca}^{2+}$ hacia el interior del retículo por iones $\mathrm{H}^{+}$hacia el citoplasma. Se han descripto dos estequiometrías posibles para esta intercambio, $1 \mathrm{H}^{+}: 1 \mathrm{Ca}^{2+}$ y $3 \mathrm{H}^{+}: 2 \mathrm{Ca}^{2+}(56)$.

Intercambiador $\mathrm{Na} / \mathrm{Ca}$ : cuando este intercambiador funciona en su modo directo utiliza el gradiente de $\mathrm{Na}^{+}$a través de la membrana plasmática para generar un influjo de $\mathrm{Na}^{+}$y un flujo de $\mathrm{Ca}^{2+}$ hacia el medio extracelular. EI intercambiador $\mathrm{Na} / \mathrm{Ca}$, en general, posee baja afinidad por el $\mathrm{Ca}^{2+}$ y altas concentraciones locales intracelulares de $\mathrm{Ca}^{2+}$ pueden activarlo.

Mitocondrias $v$ núcleo celular: las mitocondrias y el núcleo celular también pueden acumular $\mathrm{Ca}^{2+}$ cuando éste aumenta su concentración en zonas cercanas a estas organelas intracelulares. Se han descripto conductancias al $\mathrm{Ca}^{2+}$ en la membrana de la mitocondria, éste ingresa impulsado por la polaridad negativa que posee el lado interno de la membrana de la mitocondria establecido por la extrusión de $\mathrm{H}^{+}$en la cadena transportadora de electrones (33). También se ha descripto al intercambiador $\mathrm{Na} / \mathrm{Ca}$ en las mitocondrias, pero es poca la información sobre esta estructura y su función (63). Estas dos organelas celulares poseen diferentes estructuras dependientes del $\mathrm{Ca}^{2+}$, y la concentración de este ion puede modificar importantes funciones como la sintesis de ATP en las mitocondrias y la expresión de distintos genes en el núcleo (64). 
En los últimos años se ha estudiado la distribución en el citoplasma de las distintas estructuras involucradas en el mecanismo de contracción y relajación del músculo liso. Con respecto a esto se ha descripto que en el citoplasma de las células de músculo liso vascular existe una zona de 200-300 nm de ancho adyacente a la membrana plasmática libre de proteínas contráctiles denominado espacio pobre en miosina y otra zona central donde se encuentran ubicadas las proteínas contráctiles denominada espacio rico en miosina. Se postula además que los canales de $\mathrm{Ca}^{2+}$ de tipo $\mathrm{L}$ están ubicados en los ápices de las caveolas de la membrana plasmática y que el influjo de $\mathrm{Ca}^{2+}$ mediado por estos canales sería el responsable de elevar la concentración de $\mathrm{Ca}^{2+}$ en la zona central de las células (64). Esta distribución de las estructuras que participan en el mecanismo de contracción es coherente con el requisito de un aumento masivo en la concentración de $\mathrm{Ca}^{2+}$ para que pueda ser activado el aparato contráctil de las células (33). También se ha descripto que el retículo sarcoplásmico posee una distribución característica en las células de músculo liso vascular. Algunas zonas de la membrana plasmática están ubicadas muy cerca $(15-20 \mathrm{~nm})$ de la membrana del retículo sarcoplásmico y conforman la denominada barrera buffer superficial. Este nuevo concepto estructural determina que el $\mathrm{Ca}^{2+}$ que ingresa a la célula puede ser amortiguado por captación por el retículo sarcoplásmico o por generación de un flujo hacia el exterior a través de algún transportador. Asi esta nueva teoría sugiere que pueden existir flujos de $\mathrm{Ca}^{2+}$ entre el retículo sarcoplásmico, el citoplasma y el exterior celular que regulen la concentración efectiva de este ion capaz de ser censada por las proteínas contráctiles de la célula.

La liberación de $\mathrm{Ca}^{2+}$ desde el retículo sarcoplásmico a través de receptores de rianodina ubicados en zonas de la membrana del retículo cercanas a las proteinas contráctiles contribuye a la activación de la contracción (64). Sin embargo estos canales también producen flujos de $\mathrm{Ca}^{2+}$ en zonas muy cercanas a la membrana plasmática, denominados sparks de $\mathrm{Ca}^{2+}$, los cuales aumentan la concentración de este ión en forma localizada y modifican la actividad de estructuras de membrana dependientes de $\mathrm{Ca}^{2+}(31)$. Se ha estimado que los sparks de $\mathrm{Ca}^{2+}$ pueden aumentar la concentración de $\mathrm{Ca}^{2+}$ hasta $10 \mu \mathrm{M}$ en la zona de liberación. También se ha descripto la existencia de aumentos locales de $\mathrm{Ca}^{2+}$ 
por liberación a través de receptores de $\mathrm{IP}_{3}$, los cuales se han denominado puffs de $\mathrm{Ca}^{2+}(65,66)$.

La figura 3 resume las estructuras y posibles mecanismos involucrados en la homeostasis del $\mathrm{Ca}^{2+}$ en una célula de músculo liso vascular.

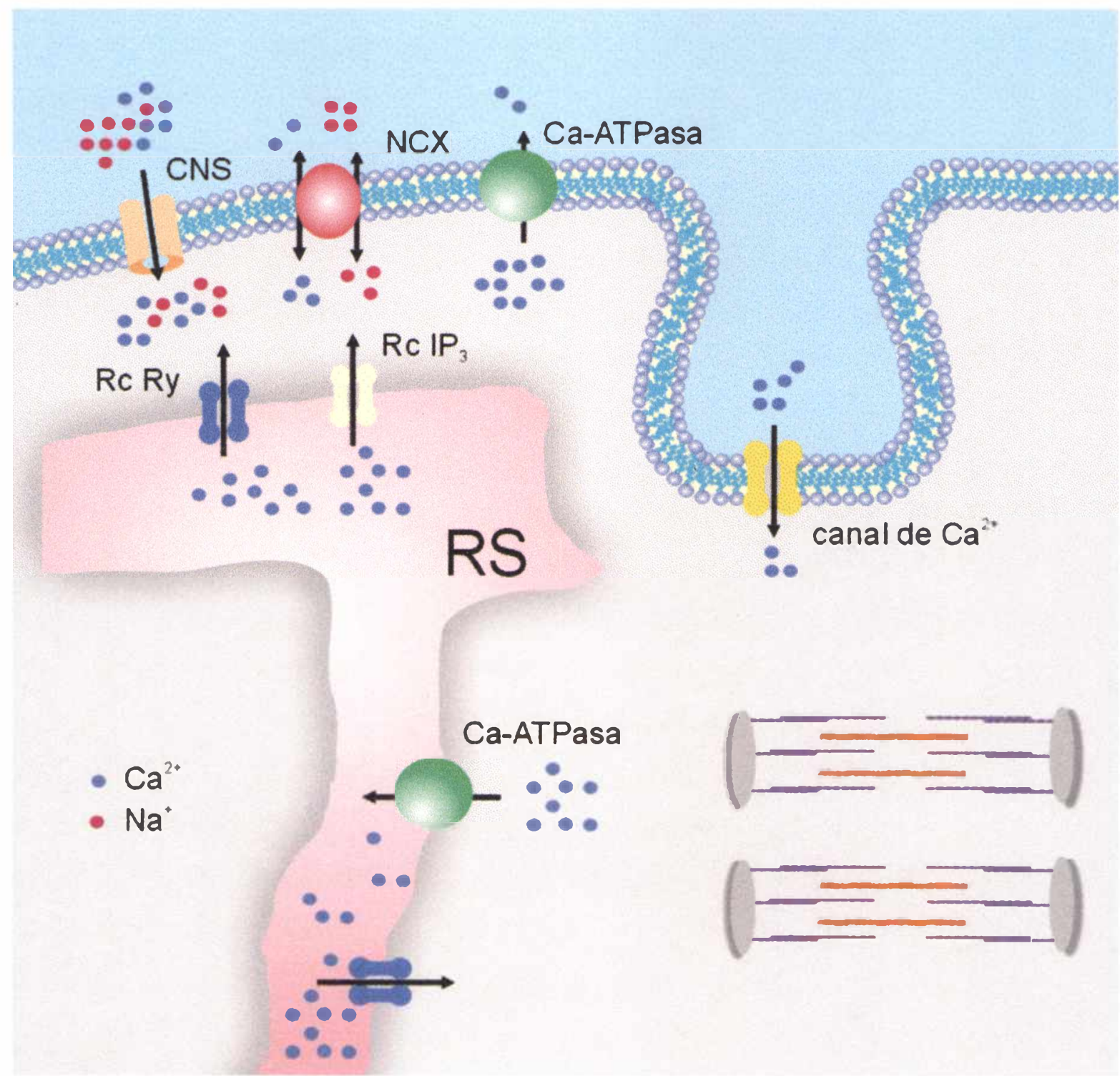

Figura II: esquema de las estructuras involucradas en los flujos de $\mathrm{Ca}^{2+}$ en una célula de músculo liso vascular. CNS, canal catiónico no selectivo, $\mathrm{NCX}$, intercambiador $\mathrm{Na} / \mathrm{Ca}$, RcRy, canal receptor de rianodina, $\mathrm{RcIP}_{3}$, canal receptor de $\mathrm{IP}_{3}, \mathrm{RS}$, reticulo sarcoplásmico. 


\section{Regulación de la función contráctil en el músculo liso vascular}

Las células de músculo liso vascular están sometidas a numerosos estímulos externos que pueden regular y modificar el mecanismo involucrado en su función contráctil. El tipo y origen de los mismos es muy variado. Se han informado regulaciones por deformaciones mecánicas en la membrana celular, por temperatura, por cambios en las concentraciones de agonistas que alcanzan las células de músculo liso a través de la circulación sanguínea, que se liberan desde las terminales nerviosas de la pared del vaso, que se liberan desde las células endoteliales o desde las mismas células musculares. En la bibliografía se pueden encontrar varios trabajos que describen este tipo de regulaciones de la función contráctil de la células de músculo liso de los vasos utilizados en este trabajo de Tesis Doctoral, algunos de los cuales se irán detallando a continuación.

\section{- Regulación por factores endoteliales}

Con respecto a la regulación por factores endoteliales se conoce desde hace tiempo que las células que forman el endotelio vascular sintetizan y liberan mediadores vasoactivos en respuesta a distintos estímulos. Los mismos pueden ser sustancias circulantes como serotonina, angiotensina II, adrenalina, bradikinina, neurotransmisores liberados por las terminales nerviosas autonómicas (noradrenalina, adrenalina y acetilcolina), sustancias liberadas por las plaquetas o por las células del sistema inmune, cambios en la presión de $\mathrm{O}_{2}$ sanguinea, alteraciones ácido-base, asi como cambios en el flujo sanguineo que generen estímulos mecánicos de roce (del inglés "shear-stress") sobre la superficie celular. Los factores liberados pueden difundir y actuar sobre las células de músculo liso produciendo diversos efectos. Entre los más importantes se encuentran la regulación del estado contráctil de las células de músculo liso y por lo tanto del diámetro de la luz de los vasos. Se ha postulado que una modificación de la función endotelial es uno de los determinantes de la baja resistencia vascular materna durante el embarazo; asi se ha demostrado que en las mujeres que desarrollan preeclampsia existe daño endotelial en los vasos fetales y maternos en los cuales se encuentra reducida la producción de factores vasorrelajantes $(67,68,69)$. 
El primer factor vasodilatador derivado del endotelio descripto, fue la prostaglandina $\mathrm{PGl}_{2} \circ$ prostaciclina (70), la cual se sintetiza en las células endoteliales a partir del ácido araquidónico. La $\mathrm{PGI}_{2}$ relaja el músculo liso mediante su unión a receptores específicos acoplados a proteínas $\mathrm{G}$ que activan la enzima adenilato ciclasa de las células musculares, con el consiguiente aumento de los niveles de AMPc y activación de PKA, esta última promueve la relajación muscular por fosforilación de distintas estructuras (71). En la circulación feto-placentaria se sabe que la síntesis de $\mathrm{PGl}_{2}$ está disminuida en la preeclampsia, aunque se desconoce la significación fisiopatológica de este desorden. $(72,73)$.

Otro de los factores relajantes derivados del endotelio es el óxido nítrico o NO (del inglés "nitric oxide"), sintetizado a partir de L-arginina por la enzima NOsintasa $(74,75)$. El mecanismo por el cual el NO produce relajación del músculo liso vascular es complejo. EI NO difunde a través de las membranas plasmáticas y del espacio mioendotelial, ingresa a las células de músculo liso por difusión simple y en el citoplasma de la células musculares desencadena distintos mecanismos, muchos de los cuales involucran la activación de una guanilato ciclasa soluble, la cual aumenta la concentración de GMPc en la células, activando a la proteína quinasa $\mathrm{G}(\mathrm{PKG})$ y ésta fosforila distintas estructuras produciendo relajación (76, 77).

En la arteria umbilical humana se ha estudiado la actividad vasodilatadora de $\mathrm{PGl}_{2}$ y $\mathrm{NO}$ endógenos, encontrándose que ambos factores relajan anillos vasculares de AUH precontraídos con 5-hidroxitriptamina (5-HT) y bradiquinina, sin embargo los autores de este trabajo muestran que los anillos son más sensibles a los inhibidores de la síntesis de $\mathrm{PGl}_{2}$ que a los de la síntesis de $\mathrm{NO}$, sugiriendo que la liberación de $\mathrm{PGl}_{2}$ sería más importante en este vaso (78). Lovren y colaboradores estudiaron el efecto de $\mathrm{NO}$ y nitroprusiato de $\mathrm{Na}^{+}$, una sustancia exógena productora de NO, sobre las contracciones producidas por 5 HT y U46619, un análogo de tromboxano $A_{2}$. Estos autores encontraron que el mecanismo de relajación del $\mathrm{NO}$ en la AUH involucra la activación de canales de $\mathrm{K}^{+}$, ya que en presencia de bloqueantes de los mismos, el efecto fue significativamente menor (79).

El denominado factor hiperpolarizante derivado del endotelio o EDHF ( del inglés "endothelium-derived hyperpolarizing factor") produce relajación del músculo 
liso vascular por hiperpolarización en forma independiente de la actividad de las enzimas NO-sintasa y cicloxigenasa (80). Ha sido informado que agonistas, como acetilcolina y bradikinina, pueden ser estímulos para la liberación de este factor (81).

Existen muchas hipótesis sobre el mecanismo de producción del EDHF y sobre la naturaleza química de este factor. Se sabe que su producción se inicia por aumento de la concentración de $\mathrm{Ca}^{2+}$ en las células endoteliales en respuesta a determinados estímulos, lo que induce por un lado, la apertura de canales de $\mathrm{K}^{+}$ y un flujo de iones $\mathrm{K}^{+}$hacia el espacio mioendotelial, y por otro lado, la activación de la enzima citocromo P450 epoxigenasa presente en las células endoteliales. Con respecto a la naturaleza del EDHF, en numerosos vasos se han identificado a los epoxieicosaatrienoides (EETs), derivados de la acción de la enzima citocromo P450 epoxigenasa del endotelio sobre el ácido araquidónico. Estas sustancias tienen efecto hiperpolarizante sobre el músculo liso, especialmente en el lecho coronario de distintas especies (81-85). En la AMIH se ha identificado al ácido 11,12 epoxieicosatrienoide (11,12-EET) producido por la citocromo $\mathrm{P} 450-2 \mathrm{C}$ epoxigenasa del endotelio vascular como el posible EDHF en este vaso (86). Otra sustancia que actuaría como EDHF en algunos vasos es la anandamida, otro derivado del ácido araquidónico que actuaría como agonista endógeno de los receptores para cannabinoides (CB1) e hiperpolarizaría las células de músculo liso por apertura de canales de $\mathrm{K}^{+}(80)$. Se ha postulado que el aumento leve de la concentración de $\mathrm{K}^{+}$extracelular $(10 \mathrm{mM}$ ) en el espacio mioendotelial producido por las células endoteliales, provocaría una relajación de las células musculares por activación de canales de $\mathrm{K}^{+}$tipo rectificadores anómalos $\left(\mathrm{K}_{\mathrm{R}}\right)$ y/o de la bomba $\mathrm{Na/K}$ ATPasa (87).

Entre los factores contrayentes derivados del endotelio se encuentran péptidos de 21 aminoácidos denominados endotelinas (ET), de las cuales la de tipo ET-1 se sintetiza mayormente en el endotelio vascular, aunque también es sintetizada por otros tipos celulares. Angiotensina II (Angll) es sintetizada en los vasos a partir de angiotensina I por la enzima conversora de angiotensina (ECA) que está ubicada en el lado externo de la membrana de las células endoteliales. La Angll ejerce su efecto contrayente actuando directamente sobre receptores del músculo liso e indirectamente aumentando la liberación de ET-1 en el endotelio (88). Derivados del ácido araquidónico como endoperóxidos, tromboxano $A_{2}$ 
$\left(T X A_{2}\right)$, prostaglandina $H_{2}\left(P G H_{2}\right)$ y el anión superóxido también son factores contrayentes derivados del endotelio y su liberación está relacionada con estados patológicos como hipoxia o isquemia (88). En la arteria umbilical humana, el análogo de $\mathrm{TXA}_{2}, \mathrm{U} 46619$, produce contracción dependiente del influjo de $\mathrm{Ca}^{2+}$ externo y de la liberación de $\mathrm{Ca}^{2+}$ desde depósitos intracelulares (89).

\section{- Regulación por pH}

Tanto la sangre como los líquidos extra e intracelulares poseen valores de $\mathrm{pH}$ que oscilan dentro de rangos estrechos, y cada uno de estos compartimentos cuenta con distintos sistemas reguladores (sistemas amortiguadores) formados por ácidos 0 bases débiles y sus sales conjugadas que ante cambios agudos regulan el pH, llevándolo hacia su valor normal. En la sangre los principales sistemas amortiguadores son el sistema $\mathrm{CO}_{2} / \mathrm{HCO}_{3}{ }^{\circ}$, el sistema $\mathrm{H}_{3} \mathrm{PO}_{4} / \mathrm{H}_{2} \mathrm{PO}_{4}{ }^{\circ}$, además de proteínas como la hemoglobina. En los demás tejidos, los sistemas amortiguadores son variables pero en todos funciona el sistema $\mathrm{CO}_{2} / \mathrm{HCO}_{3}{ }^{-}$debido a la capacidad del $\mathrm{CO}_{2}$ de atravesar las membranas celulares. Además, las membranas celulares cuentan con proteínas transportadoras que, a expensas de gasto de energía metabólica, transportan iones $\mathrm{H}^{+} \circ \mathrm{HCO}_{3}{ }^{-}$a través de ella en condiciones normales manteniendo el pH constante en sus valores normales. Pequeñas variaciones del $\mathrm{pH}$ pueden afectar numerosos componentes celulares, especialmente cambiar el estado de ionización de proteínas del cual depende el estado conformacional y la actividad de las mismas (56).

En el músculo liso vascular se han caracterizado transportadores alcalinizantes como el intercambiador $\mathrm{Na}^{+} / \mathrm{H}^{+}$que transporta un ion $\mathrm{H}^{+}$hacia el exterior celular por cada ion $\mathrm{Na}^{+}$hacia el interior a favor de gradiente electroquímico. Este transportador es comúnmente inhibido por amiloride y otras sustancias relacionadas (90). Otro transportador alcalinizante es el cotransportador $\mathrm{Na}^{+} / \mathrm{HCO}_{3}{ }^{-}$que transporta un ion $\mathrm{HCO}_{3}{ }^{-}$hacia el interior celular por cada ion $\mathrm{Na}^{+}$en el mismo sentido del cual el bloqueante más utilizado es el ácido 4-4'-diisotio-cianatostilbeno-2,2'disulfónico (DIDS) (91).

Entre los transportadores acidificantes en el músculo liso se encuentra el intercambiador $\mathrm{Cl}^{-} / \mathrm{HCO}_{3}{ }^{-}$que transporta $\mathrm{HCO}_{3}{ }^{-}$hacia el exterior celular y $\mathrm{Cl}^{-}$hacia el medio intracelular y es inhibido por el ácido 4-acetamido-4'-isotiocianatostilbeno-2,2'disulfónico (SITS) (92). 
Si bien estos son los más conocidos, en la arteria mamaria humana se ha descripto, además del intercambiador $\mathrm{Na}^{+} / \mathrm{H}^{+}$, un transportador de $\mathrm{H}^{+}$dependiente de $\mathrm{Na}^{+}$y $\mathrm{HCO}^{-}$. Este último mecanismo parece actuar sólo cuando las células se encuentran en acidosis severa (93).

Muchos procesos celulares fisiológicos inducen cambios en el valor de $\mathrm{pH}$ y se ha planteado que en algunos tejidos, entre los que se encuentra el músculo liso vascular, el cambio en la concentración de $\mathrm{H}^{+}$intra o extracelular participa en distintas cascadas de señalización. Agonistas que produzcan variaciones en la tasa de hidrólisis de ATP, o alteraciones en la actividad de los sistemas transportadores pueden inducir cambios en los valores de $\mathrm{pH}$. Con respecto a esto se ha descripto que el intercambiador $\mathrm{Na}^{+} / \mathrm{H}^{+}$puede ser activado por agonistas como angiotensina II y catecolaminas y de esta forma aumentar el pH intracelular. Este mecanismo tendería a contrarrestar el efecto acidificante producido durante el desarrollo de fuerza debido a la hidrólisis aumentada de ATP y a la activación de las Ca-ATPasas (94).

Los estudios realizados en el músculo liso vascular acerca de la dependencia de la liberación de $\mathrm{Ca}^{2+}$ del retículo con el $\mathrm{pH}$ han brindado resultados dispares. Por ejemplo, con respecto al $\mathrm{IP}_{3}$ se informó que en vasos cerebrales (95) su producción y la concentración de $\mathrm{Ca}^{2+}$ intracelular se incrementan por aumento del pHe, pero no del pHi y en vasos umbilicales (96) por disminución del pHe pero no del $\mathrm{pHi}$. Se ha informado también que, en vena porta de conejo, una disminución del pHi aumenta la liberación de $\mathrm{Ca}^{2+}$ inducida por $\mathrm{Ca}^{2+}$ desde los depósitos sensibles a rianodina (97).

En relación a los efectos del pH sobre el desarrollo de fuerza en el músculo liso vascular se ha reportado que cambios en el pHe afectan el tono de reposo en distintos tipos de vasos. Para la mayoría, se ha observado que la acidificación extracelular disminuye el tono de reposo mientras que la alcalinización lo aumenta (98). El efecto del pHe sobre la fuerza puede estar mediado por el cambio que este induce sobre el pHi. Por ejemplo en mesenterio de rata la contracción producida por el aumento de pHe es abolida al neutralizar el cambio producido en el pHi (99). Sin embargo, en arteriolas cerebrales de rata la relajación por acidificación extracelular persiste aún si se neutraliza el cambio en el pHi (100).

Los cambios de pHi producen, en general, el mismo efecto contráctil que los cambios de pHe (la acidificación intracelular relaja el músculo liso vascular y la 
alcalinización lo contrae) aunque esto es variable dependiendo de la especie y del tipo de vaso (56).

$\mathrm{El} \mathrm{pH}$ puede afectar tambien la sensibilidad al $\mathrm{Ca}^{2+}$ de las proteinas contráctiles. Un estudio realizado por Crichton y colaboradores muestra que, en experimentos realizados con vena porta de rata y arteria umbilical humana permeabilizadas con $\alpha$-toxina, sólo en la vena porta la alcalinización produjo disminución de la sensibilidad al $\mathrm{Ca}^{2+}$ de los miofilamentos contráctiles (101).

Numerosos trabajos muestran que el cambio en la fuerza producido por cambios en el pHi es abolido por remoción del $\mathrm{Ca}^{2+}$ externo o por bloqueantes de los canales de $\mathrm{Ca}^{2+}$ de tipo $\mathrm{L}$ (56). Por ejemplo, en arterias coronarias porcinas se encontró que la alcalinización intracelular aumenta la corriente de $\mathrm{Ca}^{2+}$ y la acidificación la disminuye. Este efecto fue atribuido a la protonación de un residuo de histidina ubicado en el lado citoplasmático del canal y la alteración de la corriente parece deberse a la modificación de las propiedades de apertura del canal más que a un cambio en su conductancia iónica (102).

\section{- Regulación por estiramiento mecánico}

Con respecto al mecanismo involucrado en la respuesta del músculo liso al estiramiento denominada tono miogénico, característica de algunos vasos como se describió anteriormente, se sabe que el aumento de la presión intravascular y, por lo tanto el estiramiento de la pared arterial produce despolarización de las células de músculo liso (103), y que esta despolarización activa canales de $\mathrm{Ca}^{2+}$ operados por voltaje, produciendo entrada de $\mathrm{Ca}^{2+}$ y desarrollo de contracción (104). Así, al estudiar este mecanismo en el músculo liso vascular varios autores han informado que el bloqueo de estos canales inhibe la respuesta contráctil pero no la despolarización inicial de la respuesta miogénica (105-107).

Se ha informado que varios canales de la membrana celular estarian involucrados tanto en la despolarización como en la entrada directa de $\mathrm{Ca}^{2+}$ que se observa en esta respuesta. Entre los mecanismos propuestos se plantea que un aumento en la presión de perfusión produce estiramiento de la pared de los vasos, lo cual constituye un estímulo mecánico capaz de activar directamente canales iónicos de la membrana celular. Se ha demostrado que distintos tipos de canales iónicos como canales de $\mathrm{Ca}^{2+}$ operados por voltaje, canales catiónicos no selectivos (que permiten el pasaje de $\mathrm{Na}^{+}, \mathrm{K}^{+}$y $\mathrm{Ca}^{2+}$ en distintas proporciones), 
canales de $\mathrm{K}^{+}$y canales de $\mathrm{Cl}^{-}$son sensibles al estiramiento (108). Con respecto a cómo estos canales censan el estiramiento, se ha postulado que proteínas tipo integrinas presentes en la membrana plasmática pueden ser activadas por la deformación de la misma, participando en el mecanismo de transducción de la señal. Se ha informado que éstas también pueden modular la actividad de canales de $\mathrm{Ca}^{2+}$ operados por voltaje contribuyendo al desarrollo del tono miogénico (109). Del mismo modo es posible que las proteínas que conforman el citoesqueleto como el sistema de los microtúbulos y la actina jueguen un rol importante en la transducción de la señal mecánica (110). Con respecto a este mecanismo, más adelante se detallará la regulación de canales catiónicos no selectivos por el estiramiento.

Los flujos iónicos que se producen durante el desarrollo de la respuesta miogénica, pueden afectar la actividad de proteinas sensibles al $\mathrm{Ca}^{2+}$ y/o al $\mathrm{Na}^{+}$ intracelular, que a su vez regulan el potencial de membrana y/o la concentración de $\mathrm{Ca}^{2+}$ intracelular; como así también el flujo de $\mathrm{Ca}^{2+}$ inducido en esta respuesta puede directamente activar a la MLCK y por lo tanto modificar el estado contráctil del vaso. Algunos de estos mecanismos cobran importancia a partir de los conocimientos recientes sobre localizaciones específicas de las estructuras involucradas en la regulación del estado contráctil del músculo liso vascular (proteínas contráctiles, canales iónicos y transportadores de la membrana plasmática) y de las relaciones espaciales de los mismos con zonas del retículo sarcoplásmico $(33,64)$.

Se han descripto además, otras vías de señalización que pueden ser activadas por los estímulos mecánicos y participar así en la respuesta miogénica de los vasos. Se ha encontrado activación de la vía de la fosfolipasa $C$, de la fosfolipasa $A_{2}$ y de vías dependientes de tirosinas quinasas (110).

En el siguiente esquema se resumen los mecanismos propuestos que pueden contribuir al desarrollo de la respuesta miogénica. 


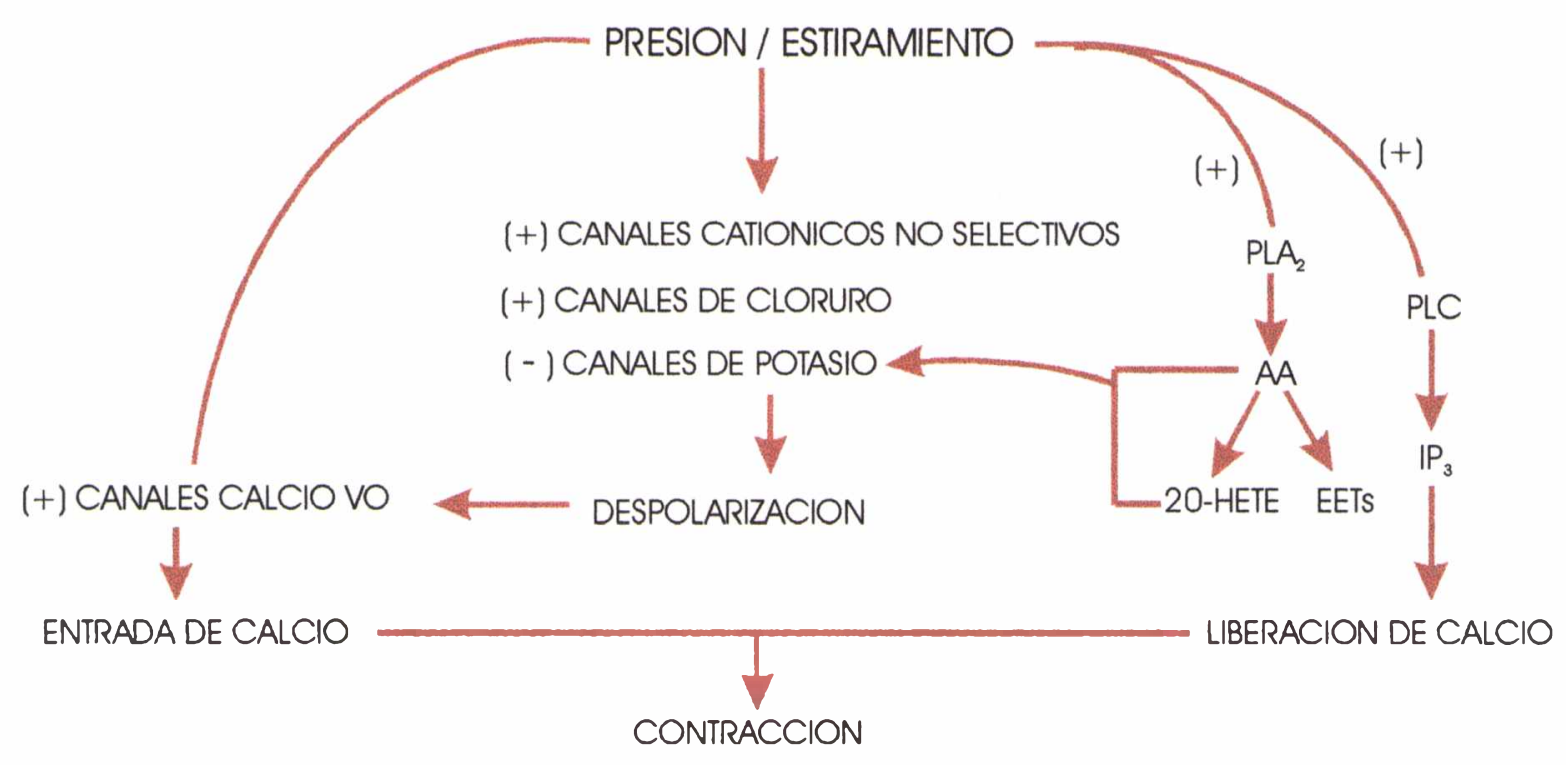

Figura III: esquema de los posibles mecanismos involucrados en el desarrollo de la respuesta miogénica (110).

\section{Canales iónicos v propiedades bioeléctricas de las células de músculo liso vascular}

El potencial de membrana constituye una propiedad bioeléctrica de vital importancia en la fisiología celular. Los valores de potencial de membrana de reposo $(\mathrm{Vm})$ de las células de músculo liso vascular oscilan en el rango de -40 a $-60 \mathrm{mV}$, variando de acuerdo con el tejido y los métodos de medida $(111,112)$. Este valor de potencial es mantenido por flujos iónicos a través de canales iónicos de la membrana plasmática en función del gradiente electroquímico y de la permeabilidad de la membrana plasmática para cada ión (113). Numerosos trabajos, han demostrado la participación de distintos tipos de canales selectivos al $\mathrm{K}^{+}$en la regulación y mantenimiento del $\mathrm{Vm}$ en células de músculo liso vascular $(111,114)$. Si bien en general el flujo de $\mathrm{K}^{+}$es el más importante, no es el único que determina los valores observados ya que el valor de potencial de equilibrio electroquímico para este ión (aproximadamente $-90 \mathrm{mV}$ para el gradiente fisiológico de $\mathrm{K}^{+}$) es más negativo que los valores de $\mathrm{Vm}$ comúnmente informados, esto sugiere que otros flujos iónicos deben contribuir a mantener el potencial de membrana de las células de músculo liso vascular en un valor menos negativo (despolarizado) que el esperado para células que fuesen permeables solo al $\mathrm{K}^{+}$. 
Ya en el año 1977, Casteels informó que la relación de permeabilidades $P_{N a} / P_{K}$ de la arteria pulmonar es 0,22 ; indicando la presencia de conductancia al $\mathrm{Na}^{+}$en este vaso (115). Recientemente, se ha demostrado la participación de canales catiónicos no selectivos y canales selectivos al $\mathrm{Cl}^{-}$en la regulación del potencial de membrana de células de músculo liso vascular $(116,117,118)$.

Los canales iónicos de la membrana plasmática son proteínas con uno o mas segmentos de transmembrana dependiendo del tipo de canal iónico; en genral presentan un poro hidrofílico, selectivo a determinados iones, a través del cuál se verifica el flujo iónico entre el interior y el exterior celular. Las propiedades eléctricas y las características moleculares de estas proteínas de membrana han sido objeto de numerosos estudios en las últimas dos décadas los cuales han aportado, en algunos casos, un detallado conocimiento sobre su composición amionacídica, propiedades bioeléctricas, selectividad, sensibilidad farmacológica, función fisiológica y modificaciones de las mismas asociadas a estados patológicos.

Muchos canales son multiméricos, formados por subunidades iguales 0 distintas y pueden asociarse a subunidades reguladoras que modifican sus propiedades eléctricas o su sensibilidad a diversos factores.

Los canales iónicos pueden cambiar su conformación proteica entre dos o más estados permitiendo o no, el pasaje de iones a través de ellos. Se denomina canal abierto al estado permeable del canal, y canal cerrado y canal inactivado a dos estados diferentes de no permeabilidad del canal. Estas transiciones se verifican en forma estocástica y existen diversos factores (agonistas, voltaje, tiempo, etc.) que pueden modificar el tiempo relativo que el canal pasa en los diferentes estados conformacionales (119). La técnica de "patch-clamp" (120) ha permitido estudiar las propiedades y la modificación de estas transiciones mediante la medición de la corriente iónica que fluye a través de un único canal iónico. La magnitud de esta corriente depende de la conductancia del canal, o sea de la capacidad del canal de dejar pasar iones a través de su poro y de la fuerza impulsora dada por la diferencia entre el $\mathrm{Vm}$ y el potencial de equilibrio electroquímico $(E)$ del ion que transporta la corriente.

Algunos tipos de canales iónicos pueden ser regulados por el potencial de membrana debido a que poseen zonas proteicas de transmembrana con 
aminoácidos altamente cargados, por lo que variaciones del potencial establecido en la membrana pueden modificar la barrera energética para las transiciones conformacionales de la proteína y hacer que el canal varie su estado de permeación en función del $\mathrm{Vm}$.

Por otro lado, la identificación, secuenciación y clonación de distintos tipos de canales iónicos así como la realización de mutaciones puntuales en la cadena polipeptídica del canal y expresión de los mismos en oocitos de rana y en otros tipos celulares, han permitido profundizar el conocimiento de las distintas familias de canales iónicos e identificar las regiones proteicas formadoras del poro, sensoras del campo eléctrico, de unión con iones u otros mensajeros intra o extracelulares (121). También ha cobrado importancia, en los últimos años, el estudio de la interacción entre los canales iónicos y los lípidos de membrana que se encuentran en el entorno del canal. Se ha informado que distintos fosfolípidos poseen no solo una función estructural en la membrana plasmática sino que pueden modificar la actividad de canales iónicos (122).

\section{Canales de $\mathrm{K}^{+}$}

Con los conocimientos actuales, los canales selectivos al $\mathrm{K}^{+}$pueden agruparse según su estructura proteica primaria en tres grandes superfamilias (123).

Canales formados por seis seamentos de transmembrana: este grupo se conoce como superfamilia S4, están formados por cuatro subunidades denominadas $\alpha$ con seis segmentos de transmembrana cada una (S1-S6).

El segmento S4, denominado sensor de voltaje, se caracteriza por poseer varios residuos aminoacídicos cargados positivamente (lisina $o$ arginina) cada tres posiciones de aminoacidos $y$, entre ellos, aminoácidos neutros que le confieren al canal la capacidad de sensar el campo eléctrico a los lados de la membrana. La región proteica de unión de los segmentos de $\alpha$-hélice $S 5$ y $S 6$ de cada subunidad forma la pared del poro, se denomina $H 5$ o región $P$ y contribuye a la determinación de la selectividad iónica del canal. A esta superfamilia pertenecen diferentes tipos de canales de $\mathrm{K}^{+}$como son los canales de $\mathrm{K}^{+}$sensibles al voltaje $\left(\mathrm{K}_{\mathrm{v}}\right)$, sensibles al voltaje y al $\mathrm{Ca}^{2+}$ de alta conductancia $\left(\mathrm{BK}_{\mathrm{Ca}}\right)$ y los sensibles al $\mathrm{Ca}^{2+}$ de media $\left(\mathrm{IK}_{\mathrm{Ca}}\right)$ y baja conductancia $\left(\mathrm{SK}_{\mathrm{Ca}}\right)$. 


\section{canal $\mathrm{BK}_{\mathrm{Ca}}$}

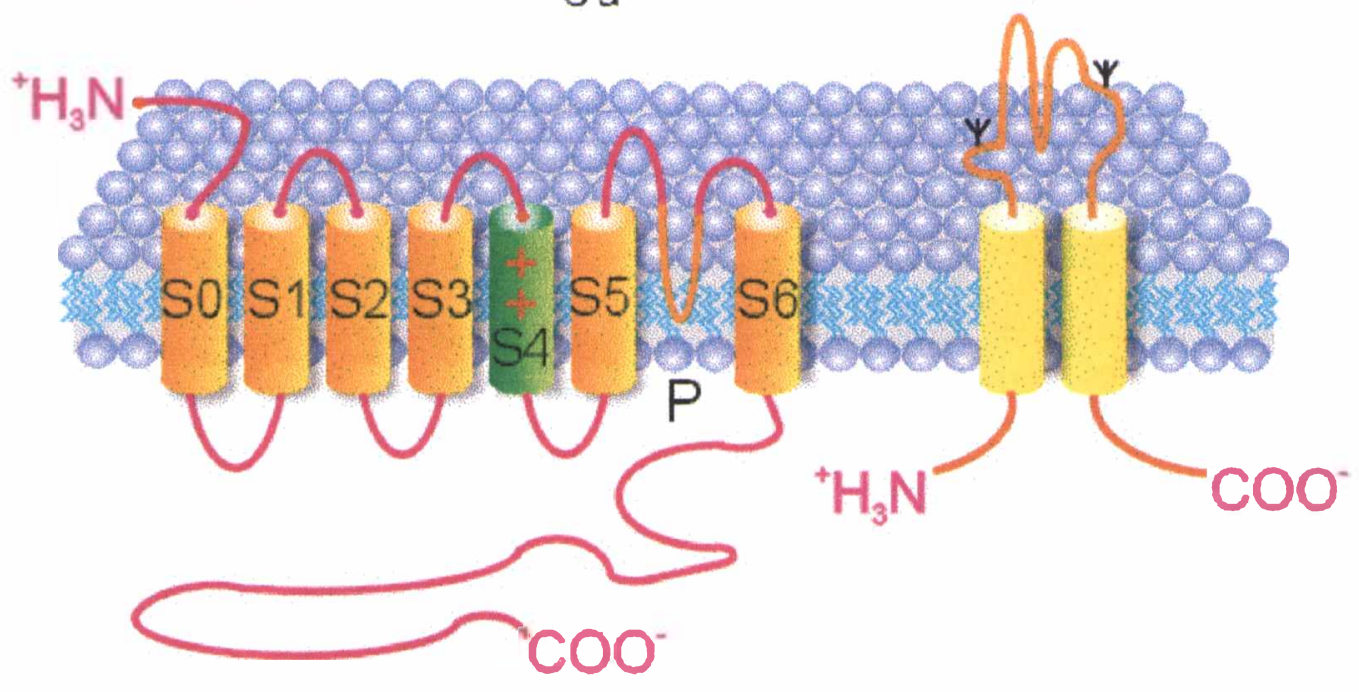

canal $\mathrm{K}_{\checkmark}$

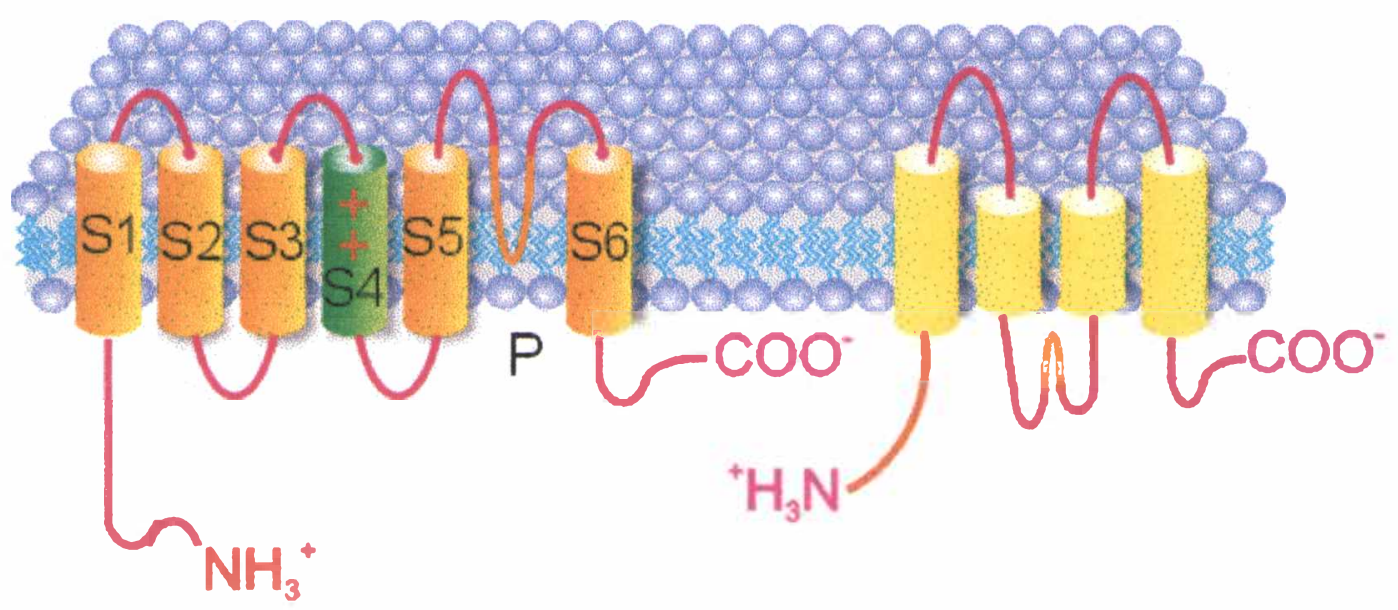

Figura IV: estructura molecular de los canales $B K_{C_{a}}$ y $K_{v}(124)$.

Si bien esta es una clasificación general existen variaciones en la estructura proteica de estos canales cuyo conocimiento ha generado una amplia división en subfamilias. Esta diversidad está relacionada con la presencia de genes múltiples, la capacidad de generar diferentes isoformas a partir de un gen debido al procesamiento diferencial del ARN mensajero heterogéneo nuclear ("alternative splicing") y la formación de canales heteromultiméricos (123). Para algunos de 
estos canales se conoce cuales son las subunidades que los forman, pero dentro de una subfamilia existen distintas combinaciones de monómeros. Sin embargo, las subunidades pertenecientes a distintas subfamilias no se expresan juntas para dar un canal funcional. Tampoco se conocen aún los factores que gobiernan la expresión diferencial de determinados tipos de canales en distintas células y tejidos (123).

Canales formados por dos seamentos de transmembrana: A esta superfamilia pertenecen los canales de $\mathrm{K}^{+}$cuya estructura corresponde a cuatro subunidades formadas por dos segmentos de transmembrana cada una (M1-M2) unidas por un segmento lineal. A este grupo pertenecen dos tipos de canales iónicos hallados en el músculo liso, el canal rectificador anómalo $\left(K_{\mathbb{R}}\right)$ y el canal

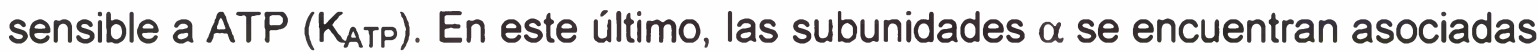
a receptores de sulfonilurea (SUR), y han sido descriptos en diferentes tipos celulares mostrando propiedades heterogéneas, hecho que sugiere la existencia de una familia de proteínas relacionadas con este tipo de canal (125). En general, la actividad de este tipo de canal es independiente del potencial de membrana, es sensible a la concentración intracelular de ATP y depende del estado metabólico celular. Estos canales son inhibidos por concentraciones fisiológicas de ATP, por diazoxido y sulfonilureas y regulados por nucleótidos difosfatos en presencia de $\mathrm{Mg}^{2+}(126)$

Existen menos evidencias acerca de las propiedades y funciones de canales de tipo $K_{\mathbb{R}}$, en el músculo liso vascular, se ha hallado que en arteriolas están involucrados en la regulación del potencial de membrana mediando el efecto hiperpolarizante que producen pequeños aumentos de la concentración extracelular de $\mathrm{K}^{+}$en este tipo de vaso. (127)

Canales formados por un seamento de transmembrana: son canales selectivos al ion $\mathrm{K}^{+}$formados por una sola cadena proteica, que forma un solo segmento $\alpha$-hélice de transmembrana. Se los denomina mínimos $0 \min K$ y poseen su extremo amino terminal en el dominio extracelular del canal $(123,128)$. 


\section{Propiedades de los canales de $\mathrm{K}^{+}$pertenecientes a la familia S4}

Canales de $\mathrm{K}^{+}$sensibles al voltaje $\left(\mathrm{K}_{\mathrm{V}}\right)$ : Estos canales representan una componente importante de la corriente total presente en muchos tipos de músculo liso vascular como el coronario, el renal, el cerebral y el pulmonar entre otros (111). Antes de conocerse en detalle su naturaleza molecular, los canales Kv se subdividian en dos grupos según la cinética de la corriente de $\mathrm{K}^{+}$mediada por estos canales. Hoy se conocen 38 genes humanos que codifican para distintas proteinas de esta familia (129), las cuales pueden ser agrupadas en 6 subfamilias: $K v_{1}, K v_{2}, K v_{3}, K v_{4}$, EAG (ether a go-go) y KCNQ con diferentes subtipos cada una. En el músculo liso vascular se ha encontrado expresado predominantemente el subtipo $\mathrm{KV}_{1}$ (130). Las subunidades $\alpha$ de los canales $\mathrm{Kv}$ se pueden encontrar asociadas a subunidades $\beta$ auxiliares (una subunidad $\beta$ por cada subunidad $\alpha$ ). Estos canales se caracterizan en general, por su sensibilidad al Vm, su insensibilidad a cambios en la concentración interna de $\mathrm{Ca}^{2+}$, su cinética de activación e inactivación y su sensibilidad farmacológica. Un inhibidor relativamente específico y ampliamente utilizado para identificar los canales $\mathrm{Kv}$ es la 4-aminopiridina, si bien actualmente existen toxinas especificas para muchos de los subtipos citados (caribdotoxina, dendrotoxina y noxiustoxina) (131, 132). A continuación se presenta una clasificación de las corrientes mediadas por los canales $\mathrm{Kv}$ que se basa en las propiedades cinéticas de las mismas y es la que se usa en la mayoría de los trabajos que realizan una caracterización electrofisiológica de la corriente de $\mathrm{K}^{+}$en distintos tipos celulares:

Corrientes iónicas tipo IK $\mathrm{K}_{\mathrm{DR}}$ (del inglés "delayed rectifier"): los canales que generan corrientes $\mathrm{IK}_{\mathrm{DR}}$ son aquellos cuya probabilidad de apertura aumenta con la despolarizacion y disminuye con la hiperpolarizacion. Su función, en general, es la repolarización celular. En el músculo liso vascular las corrientes ionicas mediadas por este tipo de canal se activan a valores de potencial cercanos a -50 mV y se inactivan en forma dependiente del voltaje, siendo esta inactivación lenta e incompleta (133). Las conductancias de canal único informadas para canales tipo $K_{D R}$ están en el rango de 5 a 60 pS (134-138). Miembros de las 6 subfamilias citadas anteriormente pueden generar corrientes de este tipo (139). 
Corrientes iónicas tipo $\mathrm{IK}_{\mathrm{A}}$ : Las corrientes a través de este tipo de canal se caracterizan por poseer una cinética de activación e inactivación muy rápida. Generalmente las proteínas de los subgrupos $K_{V_{1}}$ y $K_{V_{4}}$ son las que generan corrientes de este tipo. Se ha descripto que la expresión de subunidades $\beta$ auxiliares es necesaria para el fenómeno de inactivación rápida de esta corriente $(140,141)$.

Requlación $v$ rol funcional de los canales de tipo Kv: Los canales $\mathrm{Kv}$ cumplen funciones importantes en el músculo liso vascular y en muchos tipos de vasos sistémicos se ha informado que regulan el potencial de membrana (142).

Gollash y colaboradores realizaron un exhaustivo estudio de la corriente iónica total presente en células de músculo liso de arterias coronarias humanas, arribando a la conclusión de que la corriente a través de canales $\mathrm{Kv}$ es una componente importante de la corriente total (143). Un resultado similar fue hallado por otro grupo de investigación en cultivos del mismo tipo celular. En este último estudio se encontró que la corriente $\mathrm{Kv}$ es mediada por un canal con una conductancia de 109 pS (144).

Smirnov y colaboradores caracterizaron las corrientes de $\mathrm{K}^{+}$en células de músculo liso vascular de arteria mesentérica humana, encontrando una corriente sensible a 4-aminopiridina con dos componentes, una rápida que inactiva y otra más lenta (145).

Se han reportado numerosas regulaciones de estos canales por fosforilación a través de proteinas quinasas. Con respecto a esto, se ha informado que la activación de PKC por agonistas como angiotensina II o endotelina inhibe los canales $\mathrm{Kv}$ en células de músculo liso de vena porta de conejo (146). Además, la estimulación $\beta$-adrenérgica que activa PKA por aumento de los niveles de AMPC en células de músculo liso de vena porta de conejo estimula la corriente a través de los canales Kv (147). Entre las sustancias derivadas del endotelio, el NO aumenta el GMPc y activa PKG en varios tipos de músculo liso vascular y en algunos, como la arteria pulmonar de rata activa canales $K_{v}(148)$.

Algunos estudios muestran que la corriente a través de canales $K_{v}$ medida en presencia de $\mathrm{Ca}^{2+}$ está disminuida en vasos pertenecientes a animales hipertensos. Sin embargo, cuando la medida se realiza en ausencia de $\mathrm{Ca}^{2+}$ externo o se inhibe el influjo de $\mathrm{Ca}^{2+}$, la corriente $\mathrm{K}_{v}$ es mayor en células de 
músculo liso de vasos de animales crónicamente hipertensos que en células de animales normotensos (130). En relación con esto se ha encontrado que en células de músculo liso vascular de animales hipertensos la expresión del subtipo $\mathrm{K}_{\mathrm{v}} 1.5$ está disminuida mientras que la del $\mathrm{K}_{\mathrm{v}} 1.2$, el cual es inhibido por $\mathrm{Ca}^{2+}$ intracelular, está aumentada con respecto al mismo tejido en animales normotensos (149). Así esto podría tener relación con la mayor corriente encontrada en animales hipertensos en ausencia de $\mathrm{Ca}^{2+}$.

Canales de $\mathrm{K}^{+}$activados por $\mathrm{Ca}^{2+}$ : Los canales de $\mathrm{K}^{+}$activados por $\mathrm{Ca}^{2+}$ pertenecen a la superfamilia S4 y poseen la característica de aumentar su probabilidad de apertura ( $\mathrm{Po}$ ) al unirse a $\mathrm{Ca}^{2+}$ del lado intracelular de la membrana. Estos canales poseen mucha variabilidad en la expresión de las subunidades que los forman, lo que les confiere diferencias en sus propiedades, tal como ha sido observado en distintos tipos celulares. Según los valores de conductancia de canal único se clasifican en:

$\mathrm{SK}_{\mathrm{ca}} \mathrm{O}$ de pequeña conductancia: este canal fue clonado de cerebro de rata y de humano y la expresión del mismo en otros sistemas hizo posible su estudio detallado (150), mientras que su secuenciación fue resuelta más tarde (151). Este tipo de canal posee en general una conductancia muy pequeña (10- 80 $\mathrm{pS}$ ) en condiciones de $\mathrm{K}^{+}$simétrico $(140 \mathrm{mM})$. Son activados por concentraciones submicromolares de $\mathrm{Ca}^{2+}$ y generalmente no presentan sensibilidad al voltaje, si bien estructuralmente poseen el segmento S4, sensor de voltaje (125). Se ha informado en muchos casos (células musculares esqueléticas de rata, células $T$ leucémicas humanas, células cromafines adrenales de rata) que el veneno de abeja apamina (60 pM-1 nM) inhibe a este canal. Los sitios de unión al calcio no se conocen aún y presentan sitios de fosforilación muy distintos de otros tipos de canales pertenecientes a esta familia (152). En las células endoteliales de la arteria hepática y mesentérica de rata ha sido descripta la activación de canales sensibles a apamina involucrados en el mecanismo de liberación de EDHF $(153,154)$.

$\mathrm{IK}_{\mathrm{Ca}} \mathrm{O}$ de conductancia intermedia: estos canales presentan una conductancia entre 30 y $60 \mathrm{pS}$ en $\mathrm{K}^{+}$simétrico $(140 \mathrm{mM})$ y son insensibles al potencial de membrana. Son inhibidos por clotrimazole y caribdotoxina y aunque 
poseen muchas similitudes en su estructura con los canales $\mathrm{SK}_{\mathrm{Ca}}$ no son sensibles a apamina (125).

Se encontró que la proteina calmodulina se une al extremo carboxilo terminal del canal IK $\mathrm{K}_{\mathrm{Ca}}$ modulando la activación dependiente de $\mathrm{Ca}^{2+}(155,156)$.

Otro regulador descripto para este tipo de canal es el 1-etil-2-benzimidazol (EBIO $100 \mu \mathrm{M}$ ), el cual activa el canal clonado de tejido humano (hIK) y expresado en células renales embrionarias humanas (HEK 293). Esta activación puede darse en forma directa sobre las subunidades $\alpha$ que forman el canal o sobre proteínas reguladoras que se encuentran muy cerca del mismo y es dependiente de la concentración de $\mathrm{Ca}^{2+}$ en el lado interno del canal (157).

En músculo liso vascular se ha encontrado que este tipo de canal participa en la vasodilatación independiente de NO producida por acetilcolina en arteria renal de rata (158).

$\mathrm{BK}_{\mathrm{Ca}} \circ$ de alta conductancia: Este canal posee valores de conductancia muy altos entre 240 y 300 pS en $\mathrm{K}^{+}$simétrico ( $140 \mathrm{mM}$ ), su actividad depende de la concentración de $\mathrm{Ca}^{2+}$ intracelular y a diferencia de los otros dos subtipos su probabilidad de apertura depende también del potencial de membrana.

Este canal ha sido ampliamente estudiado y se encuentra expresado en las membranas de numerosos y diferentes tipos celulares. En particular en el músculo liso vascular ha sido identificado en la todos los lechos vasculares estudiados cumpliendo un rol funcional importante en la determinación del estado contráctil de los vasos (111).

En la siguiente sección se describirá detalladamente este último tipo de canal iónico $\left(\mathrm{BK}_{\mathrm{Ca}}\right)$ ya que en este trabajo de Tesis se ha indagado la presencia de este tipo de canal en dos vasos humanos: la arteria mamaria interna y la arteria umbilical.

Estructura molecular: Las subunidades $\alpha$ que forman el poro se encuentran codificadas en un gen simple, esta proteína fue clonada por primera vez a partir de la mosca Drosophila melanogaster (gen dSlo) y luego de distintos tipos celulares humanos (gen hSLo). Actualmente se emplea la denominación KCNM1 para este gen (159).

Este tipo de canal posee, en la estructura de las subunidades $\alpha$, un segmento de transmembrana $\alpha$ hélice adicional (SO) ubicado en el extremo $\mathrm{N}$ 
terminal respecto a los 6 descriptos para la superfamilia S4 $(160,161)$. En el extremo carboxilo terminal de la subunidad $\alpha$ existe una larga cadena citoplasmática formada por los segmentos denominados S7, S8, S9 y S10 (133).

Este canal puede encontrarse expresado con subunidades $\beta$ auxiliares, las cuales se encuentran codificadas en los genes denominados KCNM $\beta$, de los que existen cuatro tipos distintos (KCNM $\beta$ 1-4). En el músculo liso hasta el momento sólo ha sido identificada la isoforma $\beta-1$ (133). Esta subunidad está formada por dos segmentos de transmembrana $\alpha$-hélice unidos por un segmento lineal extracelular de forma que los dos extremos de la cadena se encuentran del lado citoplasmático. La presencia de subunidad $\beta$ modifica las propiedades del canal y se postula que existen interacciones entre la subunidad $\beta$ y el segmento so que permiten las distintas regulaciones que la subunidad $\beta$ ejerce sobre el canal; también se propone que la interacción entre la subunidad $\beta$ y la larga cadena intracelular modifica la sensibilidad del canal al $\mathrm{Ca}^{2+}(161)$.

Dependencia del $\mathrm{Ca}^{2+} v$ del voltaie: Este canal puede ser activado por voltaje aún en ausencia de $\mathrm{Ca}^{2+}$ (132) ya que la sensibilidad al voltaje está dada por la presencia del segmento cargado $\mathrm{S} 4$ en las subunidades $\alpha$ que forman el canal. Sin embargo a mayores concentraciones de $\mathrm{Ca}^{2+}$ intracelular (> que $100 \mathrm{nM}$ ) se produce un corrimiento de la curva de activación del canal hacia valores de potencial de membrana más negativos. Los segmentos S9 y S10 de la cadena lineal intracelular poseen zonas de unión a $\mathrm{Ca}^{2+}$ (162). Sin embargo, se debe considerar la existencia de otros sitios de unión ya que si se expresa el canal en forma separada de estos segmentos el canal conserva aún cierta sensibilidad al $\mathrm{Ca}^{2+}$.

El grado de sensibilidad al $\mathrm{Ca}^{2+}$ de este canal depende de la expresión o no de subunidad $\beta-1$ auxiliar. A concentraciones de $\mathrm{Ca}^{2+}$ mayores que $100 \mathrm{nM}$, la presencia de subunidad $\beta$ hace que el canal sea más sensible al $\mathrm{Ca}^{2+}(163)$, esta propiedad es muy importante para el rol del canal en la fisiología normal de una célula, ya que aumentos rápidos y locales de $\mathrm{Ca}^{2+}$ en determinadas zonas del citoplasma ("sparks" y "puffs" de $\mathrm{Ca}^{2+}$ ) pueden activar o no este canal en forma aguda dependiendo de la presencia o ausencia de subunidad $\beta$ auxiliar $(164,165)$.

Por otro lado, se ha descripto que el ion $\mathrm{Ca}^{2+}$ actuaría además, como estabilizador de la estructura de este canal, ya que en ausencia de $\mathrm{Ca}^{2+}$ 
extracelular el poro del canal pierde su alta selectividad al potasio y permite el pasaje de otros cationes generando de esta forma una corriente de fuga a través de la membrana. Este efecto se debería a que en ausencia del ion existiría una interacción menos rígida entre las 4 subunidades $\alpha$ que forman el poro del canal (166).

Selectividad iónica y sensibilidad farmacológica: Un hecho que puede considerarse paradójico es la gran selectividad al ion $\mathrm{K}^{+}$que presenta este canal y su valor de conductancia muy alto, ya que la alta selectividad implica una fuerte interacción entre los iones y zonas del poro del canal. Estos canales tienen la siguiente secuencia de selectividad iónica determinada por mediciones de potencial bi-iónico: $\mathrm{Tl}^{+}>\mathrm{K}^{+}>\mathrm{Rb}^{+}>\mathrm{NH}_{4}^{+} \gg \mathrm{Cs}^{+}, \mathrm{Na}^{+}, \mathrm{Li}^{+}$. La relación de permeabilidad entre $\mathrm{Na}^{+}$y $\mathrm{K}^{+}$es menor que 0,01 . Este canal es 10 a 50 veces más selectivo al $\mathrm{K}^{+}$que los canales operados por voltaje de tipo rectificador tardio $\left(K_{D R}\right)$.

El canal $\mathrm{BK}_{\mathrm{Ca}}$ se considera del tipo de canales con poro multi-ionicos ya que varios iones pueden permear por el canal al mismo tiempo (139). Este tipo de canal posee, como característica estructural, vestíbulos del poro amplios con varios grupos carboxilo que le confieren carga negativa a estas zonas permitiendo acumular iones $\mathrm{K}^{+}$en la boca del poro. El poro del canal es estrecho, altamente selectivo al $\mathrm{K}^{+}$y posee al menos cuatro sitios de unión para moléculas de agua. $\mathrm{E}$ hecho de que un ion de gran dimensión como el tetraetilamonio (TEA) bloquee este canal apoya la existencia de vestíbulos amplios. EI TEA se puede unir al canal tanto del lado intracelular como del lado externo. Sin embargo el bloqueo presenta características diferentes: el sitio interno de bloqueo sería una zona hidrofóbica, ya que un aumento de la cadena carbonada del bloqueante aumenta el nivel de bloqueo, mientras que el sitio externo es altamente selectivo a TEA. No todos los canales $\mathrm{BK}_{\mathrm{Ca}}$ presentan la misma sensibilidad al TEA; si bien este bloqueante no se considera especifico, en el músculo liso vascular de diferentes vasos se ha demostrado que, en el rango de concentraciones de 0.1-1 mM, bloquea selectivamente los canales $\mathrm{BK}_{\mathrm{Ca}}$ mientras que a concentraciones más altas (5-10 mM) puede inhibir otros tipos de canales iónicos (152).

Se han descubierto toxinas aisladas de veneno de escorpión, las cuales a muy bajas concentraciones $(n M)$ producen un efecto inhibidor altamente específicos para este tipo de canal. Algunas de estas toxinas son: 
Caribdotoxina (ChTX): aislada del veneno de Leiurus quinquestriatus (132) fue la primera de estas toxinas descubierta y utilizada en la caracterización del canal $\mathrm{BK}_{\mathrm{Ca}}$ en distintos tejidos. Actualmente se sabe que no es tan específica para el $B K_{C a}$, ya que también puede inhibir algunos subtipos de los canales de tipo $K_{v} 1$ y al canal de tipo $\mathrm{SK}_{\mathrm{Ca}}(167)$. En general, se ha informado que la presencia de subunidad $\beta$ afecta la unión de ChTX al canal, aunque en células de miométrio humano la dosis efectiva para el $50 \%$ de bloqueo $\left(D_{50}\right)$ para esta toxina no se modifica cuando el canal se expresa en presencia de subunidad $\beta$ (168).

Iberiotoxina (IBTX): esta toxina purificada de Buthus tamulus es un inhibidor altamente específico para este canal en concentraciones muy bajas (en el rango nM) (132). Al igual que ChTX, actúa en forma dependiente de la presencia de la subunidad $\beta$, siendo su $D E_{50} 16$ veces menor cuando el canal se expresó acoplado a subunidad $\beta$ (169). Hanner y colaboradores han identificado los residuos presentes en el segmento extracelular de la subunidad $\beta$ que están involucrados en el aumento de la sensibilidad del canal a IBTX (163).

Slotoxina (SITX): esta toxina también es muy específica y bloquea el canal no solo dependiendo de la presencia de subunidad $\beta$ sino también de la variante de la subunidad $\alpha$ expresada (167).

Existen también varias sustancias que son capaces de activar específicamente estos canales mediante distintos mecanismos. Una de las primeras descriptas fue un flavonoide denominado floretina, que en concentraciones en el rango 10-200 $\mu \mathrm{M}$ activa el canal $\mathrm{BK}_{\mathrm{Ca}}$, modificando la dependencia de la actividad del canal al voltaje, aumentando el tiempo medio de abierto y reduciendo el tiempo medio de cerrado (170). Sustancias del tipo hidrosaponina, cuyo prototipo fue extraído de Desmodium adsendens también activan este tipo de canal. En los últimos años se ha demostrado que dehidrosoyasaponina (DHS-1) y $\beta$-estradiol aumentan la actividad del canal solo cuando este canal se encuentra asociado a la subunidad $\beta$ auxiliar debido a que la interacción droga-canal ocurre en regiones extracelulares de la subunidad $\beta$ (171). Esta propiedad se ha utilizado para probar la expresión de la subunidad $\beta-1$ en distintos vasos (172).

En relación con la propiedad de los estrógenos sobre este canal, recientemente ha sido informado que tamoxifeno, un xenoestrogeno 
quimioterapéutico, activa el canal en células de músculo liso gastrointestinal en dosis clínicamente relevantes $(0,1-10 \mu \mathrm{M})$. Cuando el tamoxifeno se prueba en células que expresan el canal solo con subunidades $\alpha$, éste actúa disminuyendo la conductancia del canal, y en cambio cuando las células expresan además subunidades $\beta-1$, el efecto es un aumento de la probabilidad de apertura del canal (173).

El esteroide natural dehidroepiandrosterona (DHEA), previene la constricción de músculo liso de vasos pulmonares humanos crónicamente hipóxicos por aumento de la corriente a través de canales $\mathrm{BK}_{\mathrm{Ca}}$. Este efecto parece ser directo sobre la estructura del canal e independiente de vías que utilizan AMPc y GMPc (174). También se ha demostrado que los glucocorticoides inhiben la expresión del canal $\mathrm{BK}_{\mathrm{Ca}}$ en células en cultivo de músculo liso vascular. Esta inhibición podría estar asociada con el aumento del tono arterial y de la presión arterial que se observan en la exposición crónica a glucocorticoides (175).

Hasta aqui se han descripto regulaciones del canal $\mathrm{BK}_{\mathrm{Ca}}$ en forma directa por el potencial de membrana, la concentración de $\mathrm{Ca}^{2+}$ y sustancias inhibidoras o activadoras especificas que han permitido la caracterización del canal en distintos tipos de células y la participación de los mismos en diferentes funciones celulares.

Este canal puede ser regulado, además, por segundos mensajeros y proteínas quinasas involucrados en las vías de señalización intracelular de diferentes agonistas endógenos. Las proteinas quinasas son moduladoras directas de la actividad de este canal modificando la sensibilidad del canal al $\mathrm{Ca}^{2+}$ y al voltaje (176). La proteína quinasa $\mathrm{C}$ (PKC) es dependiente de $\mathrm{Ca}^{2+}$ e inhibe este canal en el músculo liso y las proteínas quinasas dependientes de AMPc (PKA) y GMPc (PKG) lo activan. Relacionado con estas últimas propiedades se han identificado en la estructura molecular del canal $\mathrm{BK}_{\mathrm{Ca}}$ clonado de músculo liso, sitios de fosforilación para PKG y PKC en la subunidad $\alpha$, asi como uno para PKG en la subunidad $\beta$, además de sitios posibles de fosforilación por PKA tanto en la subunidad $\alpha$ como en la $\beta$ (177). Algunos ejemplos de vías de señalización que involucran actividad de proteínas quinasas y $\mathrm{BK}_{\mathrm{Ca}}$ se resumen en el siguiente cuadro $(176,133)$. 
INTRODUCCIÓN

\begin{tabular}{|c|c|c|c|}
\hline Agonista & PK & efecto sobre BK Ba & Células de músculo liso \\
\hline CGRP & PKA & aumento de Po & arteria cerebral de cerdo \\
\hline 20-hidroxieicosatrienoico & PKC & disminución de Po & arteria cerebral de gato \\
\hline Angiotensina II & PKC & disminución de Po & arteria coronario de cerdo \\
\hline U46619 $\left(\sim \mathrm{TXA}_{2}\right)$ & PKC & disminución de Po & arteria coronaria de cerdo \\
\hline óxido nítrico & PKG & aumento de Po & arteria pulmonar humana \\
\hline nitroprusiato sódico & PKG & aumento de Po & arteria mesentérica de rata \\
\hline Isoproterenol & PKA & aumento de Po & arteria basilar de cobayo \\
\hline
\end{tabular}

Po: probabilidad de apertura del canal, PK: proteina quinasa.

La subunidad $\alpha$ formadora del poro del canal $\mathrm{BK}_{\mathrm{Ca}}$ presenta distintas isoformas las cuales son reguladas en forma diferencial por las distintas proteínas quinasas. Así la PKC fosforila el canal en un sitio "en tandem" de la cadena intracelular $C$ terminal presente sólo en las isoformas $A$ y $B$ de la subunidad $\alpha$, en esa misma cadena intracelular ejerce su acción la PKG. Korth y colaboradores demostraron en estas isoformas que la fosforilación del canal por PKC es un prerrequisito para que el canal pueda ser activado por PKG. Estos autores encontraron además, que PKA es capaz de fosforilar la isoforma $C$, que carece del sitio "en tandem" en el extremo C terminal y puede fosforilar las isoformas A y B solo si han sido previamente fosforiladas por PKC y desfoforiladas por una enzima fosfatasa. Estos resultados indican que la fosforilación del canal por PKC controla las regulaciones del mismo por PKA y PKG y contribuyen a entender la complejidad de los mecanismos de regulación que pueden actuar sobre los canales $\mathrm{BK}_{\mathrm{Ca}}(178)$.

Rol funcional de los canales $\mathrm{BK}_{\mathrm{Ca}}$ en el músculo liso vascular: En el músculo liso vascular los canales de $\mathrm{K}^{+}$juegan un rol fundamental en diferentes funciones celulares involucradas en la regulación del tono (111) y la proliferación celular (133).

Existen evidencias de variabilidad en la expresión de canales de $\mathrm{K}^{+}$entre diferentes lechos vasculares, entre distintos segmentos del mismo vaso e incluso entre poblaciones celulares dentro del mismo segmento. Con respecto a esto, Michelakis y colaboradores demostraron que en la arteria pulmonar de rata los canales tipo BK $\mathrm{K}_{\mathrm{Ca}}$ están más expresados en segmentos distales (de resistencia) y canales tipo $K_{D R}$ en segmentos proximales (de conducción) (134). Las células de músculo liso de arteria aorta poseen una mayor conductancia al $\mathrm{K}^{+}$en la arteria 
adulta que en la fetal, se ha informado además, que esto se debe a que el canal $\mathrm{BK}_{\mathrm{Ca}}$ posee un tiempo medio de abierto mayor en células de aorta adulta humana que en aorta fetal humana. Estos resultados indicarian que el aumento de la conductancia al $\mathrm{K}^{+}$en estas células durante el desarrollo se debe a una alteración en el tiempo medio de abierto del canal $\mathrm{BK}_{\mathrm{Ca}}$ (179). En numerosos trabajos se demuestra que el canal $\mathrm{BK}_{\mathrm{Ca}}$ regula el potencial de membrana y el tono contráctil de distintos vasos $(114,116)$.

En general, los canales de $\mathrm{K}^{+}$de las células de músculo liso de arterias intactas poseen niveles de actividad muy bajos a valores fisiológicos de $\mathrm{Vm}$ (entre -60 y $-40 \mathrm{mV}$ ) y pequeños cambios en la actividad de los mismos producen importantes variaciones del Vm y consecuentemente, del tono contráctil y del diámetro del vaso. De esta forma, en muchas cascadas de señalización pueden funcionar como mecanismo compensador que limita la vasoconstricción (103).

Un claro ejemplo de este mecanismo es la participación de los canales BK en el desarrollo del tono miogénico, ya que se activan por el aumento de $\mathrm{Ca}^{2+}$ producido por el efecto de la despolarización sobre los canales de $\mathrm{Ca}^{2+}$ sensibles al voltaje, y de esta forma el flujo hiperpolarizante de $\mathrm{K}^{+}$genera vasodilatación y contrarresta el efecto vasoconstrictor generado por del aumento de presión sobre la pared arterial (180). Este efecto ha sido observado en arterias coronarias y cerebrales, especialmente en arterias de pequeño diámetro donde se ha observado que distintos bloqueantes de los canales de $\mathrm{K}^{+}$aumentan el tono miogénico arterial (103).

Si bien el aumento global de la concentración de $\mathrm{Ca}^{2+}$ en el citoplasma induce contracción de las células de músculo liso por activación de la MLCK, como se describió anteriormente, aumentos locales de $\mathrm{Ca}^{2+}$ producen relajación del músculo liso por activación de canales $\mathrm{BK}_{\mathrm{Ca}}$ de la membrana plasmática ubicados en la zona de barrera buffer superficial. Brenner y colaboradores estudiaron la importancia de la subunidad $\beta-1$ asociada al canal $\mathrm{BK}_{\mathrm{Ca}}$ en la vasoregulación, utilizando ratones con deleción del gen que codifica para esta subunidad (" $\beta-1$ knockout mice"). En células aisladas de arteria cerebrales de estos ratones se observó que el acoplamiento de los "sparks" de $\mathrm{Ca}^{2+}$ con la actividad del canal $\mathrm{BK}_{\mathrm{Ca}}$ está significativamente disminuido mientras que la amplitud y frecuencia de los mismos no están alteradas. Este grupo encontró que ese desacoplamiento se debe a una menor sensibilidad al $\mathrm{Ca}^{2+}$ del canal $\mathrm{BK}_{\mathrm{C}_{a}}$, indicando la fuerte 
influencia de la expresión de la subunidad $\beta$-1en las propiedades del canal. Los ratones " $\beta-1$ knockout" presentaron un aumento de la presión arterial in vivo y, en las arterias cerebrales in vitro, un mayor efecto contrayente inducido por aumento de la presión de perfusión. Además, la IBTX, inhibidor específico de los canales $\mathrm{BK}_{\mathrm{Ca}}$ produjo aumento del tono basal en las arterias de los ratones controles, mientras que este efecto no se observó en los ratones "knockout" (172). Los datos de la bibliografía sugieren entonces que los canales $B_{C_{a}}$ son muy importantes en la regulación del tono miogénico y que esta influencia depende de la presencia de subunidad $\beta-1$ asociada a la subunidad $\alpha$ formadora del poro.

Con respecto a la regulación del canal por sustancias liberadas por las células endoteliales, Lovren y colaboradores demostraron que el NO relaja la arteria umbilical humana, en parte debido a activación de canales de $\mathrm{K}^{+}$, ya que este efecto es inhibido por 4-AP (boqueante de canales tipo $K_{D R}$ ) y por TEA (bloqueante de canales $\mathrm{K}_{\mathrm{Ca}}$ ) (79). En las arteriolas coronarias humanas la liberación de NO es producida por aumento del flujo en el vaso, un efecto que se conoce como "shear strees" (181). En diferentes tipos de vasos humanos, se ha descripto que el NO regula canales de tipo $\mathrm{BK}_{\mathrm{Ca}}$-a través de la vía de señalización que involucra activación de la guanilato ciclasa soluble del músculo liso. El consecuente aumento de GMPc activa la PKG, la cual mediante fosforilación de la subunidad $\alpha$ del canal produce la activación de los mismos y vasodilatación del vaso. Otro dato interesante que surgió del estudio del efecto de GMPc sobre el canal $\mathrm{BK}_{\mathrm{Ca}}$ en células de miometrio grávido humano, es que algunas proteínas quinasas tipo $G$ están localizadas ancladas en la membrana plasmática en zonas muy próximas a los canales $\mathrm{BK}_{\mathrm{Ca}}$ (168). Además, experimentos realizados modificando grupos sulfidrilos de la proteina que los hace insensibles a reacciones de nitrosilación demostraron que el NO interacciona con estos grupos para ejercer su efecto (182).

Como se mencionó antes, se ha encontrado que el efecto hiperpolarizante de EDHF sobre las células de músculo liso se debe a la apertura de canales de $\mathrm{K}^{+}$ sensibles al $\mathrm{Ca}^{2+}$, de conductancia baja $\left(\mathrm{SK}_{\mathrm{Ca}}\right)$, aunque también se ha informado que podrian estar involucrados canales de conductancia intermedia $\left(\mathrm{I}_{\mathrm{Ca}}\right)$ y los de tipo BK $\mathrm{Ba}$ (82). 
En la AMIH se ha identificado al ácido 11,12 epoxieicosatrienoide $(11,12-$ EET) producido por la enzima citocromo P450-2c epoxigenasa del endotelio vascular como el posible EDHF en este vaso. Se encontró que este factor causa una relajación inducida por la activación de canales de tipo $\mathrm{BK}_{\mathrm{Ca}}$ en forma independiente de la liberación de NO y prostaciclinas. En este mismo trabajo se ha identificado por RT-PCR (del inglés "reverse-transcriptase, polimerase chain reaction"), al canal BK $\mathrm{Ca}_{\mathrm{a}}$ en el músculo liso y a la enzima citocromo P450-2c tanto en el músculo liso como en las células endoteliales (86).

Varios trabajos han informado modificaciones en las caracteristicas de la corriente a través de los canales $\mathrm{BK}_{\mathrm{Ca}}$ del músculo liso vascular en el desarrollo de procesos patológicos como aterosclerosis $(183,184)$ e hipertensión (185). Con respecto a esto, recientemente ha sido descripto que la presencia de la subunidad $\alpha$ del canal $\mathrm{BK}_{\mathrm{Ca}}$ en arteria coronarias humanas es menor cuando aumenta la edad del individuo, lo que podría estar relacionado con la mayor incidencia de patologías de este lecho (186).

Por otro lado, ha sido descripto que en la hipertensión arterial la expresión de los canales $\mathrm{BK}_{\mathrm{Ca}}$ se encuentra aumentada, tanto en la arteria aorta proveniente de ratas espontáneamente hipertensas (185) como en vasos humanos obtenidos de pacientes hipertensos (185). Rusch y colaboradores observaron que la expresión aumentada del canal $\mathrm{BK}_{\mathrm{Ca}}$ puede producirse en forma local en un sector de la aorta de rata sometido a altas presiones por disminución de la luz del vaso. Este aumento de la expresión en este caso seria independiente de factores humorales o regionales y se debería exclusivamente a la acción directa de la presión sobre la pared del vaso (187). Se ha observado también, que el efecto contráctil de inhibidores de canales $\mathrm{BK}_{\mathrm{Ca}}$, como el TEA e IBTX, es mayor en segmentos vasculares provenientes de animales hipertensos, obtenidos por la aplicación de distintos modelos, y en algunos casos incluso el efecto es significativo sólo en los animales hipertensos y no se observa respuesta en los normotensos $(15,188)$. Otra información relevante relacionada es el hecho de que el tono miogénico de pequeñas arterias y la vasoconstricción inducida por aumento de presión en la microcirculación parecen estar aumentadas en la hipertensión (189). Así, la sobreexpresión de los canales $\mathrm{BK}_{\mathrm{Ca}}$ asociada a este estado patológico podría ser un mecanismo que proteje al organismo del aumento progresivo de la PA 
amortiguando la vasoconstricción local inducida por el aumento de la presión global.

La hipertensión arterial pulmonar (HAP) es una anormalidad hemodinámica que involucra remodelación de la pared arterial, vasoconstricción, trombosis y en última instancia, un aumento de la resistencia vascular pulmonar causada por la disminución del lumen de las arterias de pequeño calibre (133). Los mecanismos celulares que contribuyen a este proceso son muy complejos y parecen estar muy relacionados con defectos de la actividad de canales de $\mathrm{K}^{+}$y su rol en la homeostasis del $\mathrm{Ca}^{2+}$ intracelular (133). Una disminución de la actividad de canales de $\mathrm{K}^{+}$ha sido informada en células provenientes de pacientes con HAP. EI menor eflujo de $\mathrm{K}^{+}$produce despolarizacion, mayor influjo de $\mathrm{Ca}^{2+}$ (por canales de $\mathrm{Ca}^{2+}$ ), que lleva a vasoconstricción y activación del ciclo celular (proliferación celular) (133).

\section{Canales catiónicos no selectivos}

Los canales catiónicos no selectivos (canales CNS) están formados por proteínas de membrana permeables a cationes cuyas propiedades biofísicas, farmacológicas y estructurales son muy variables entre los diferentes tejidos. En general se ha encontrado que son inhibidos por lantánidos como $\mathrm{La}^{3+} \mathrm{y} \mathrm{Gd}^{3+}$, en rangos de concentraciones variables (190).

En los últimos años, en varios trabajos, se ha encontrado que proteínas codificadas en los genes denominados trp serían las estructuras moleculares de los canales catiónicos no selectivos presentes en algunos tipos celulares $(191,192)$. Estas proteinas de membrana pertenecen a la misma línea evolutiva que otros tipos de canales bien caracterizados como, por ejemplo, los Kv. Poseen seis segmentos de transmembrana y ambos extremos de la cadena polipeptídica son intracelulares; por analogía con los canales de $\mathrm{K}^{+}$se cree que la zona entre los segmentos 5 y 6 sería la zona formadora del poro, aunque con menor selectividad y que estas proteínas formarian tetrámeros que podrían ser homo o heterométricos. También se sabe que poseen en su extremo amino intracelular sitios de unión a ankirinas, las cuales son proteínas adaptadoras que se pueden acoplar a proteínas del citoesqueleto (espectrinas); esto podria permitir que deformaciones celulares por estiramiento puedan ser censadas por el canal. 
Como puede observarse en la figura $\mathrm{V}$, estos canales poseen una larga cadena intracelular en su extremo carboxilo terminal con un dominio característico denominado sitio TRP. Se han descripto también en varios subtipos de estos canales sitios de unión a calmodulina (CaM). En este extremo poseen un sitio hidrofilico característico, denominado $8 \times 9$, formado por nueve secuencias aminoacidicas especificas repetidas varias veces. También poseen una secuencia PEST, la cual es una secuencia señal para la degradación de proteínas por proteasas dependientes de $\mathrm{Ca}^{2+}$, característica de los sitios de unión a CaM. Además se encuentra otro sitio característico rico en prolina con el dipéptido KP repetido 27 veces el cual es importante para la interacción con proteinas, asi como también un sitio de unión a proteínas INAD (proteínas de anclaje al citoesqueleto) en la zona terminal de esta cadena (191).

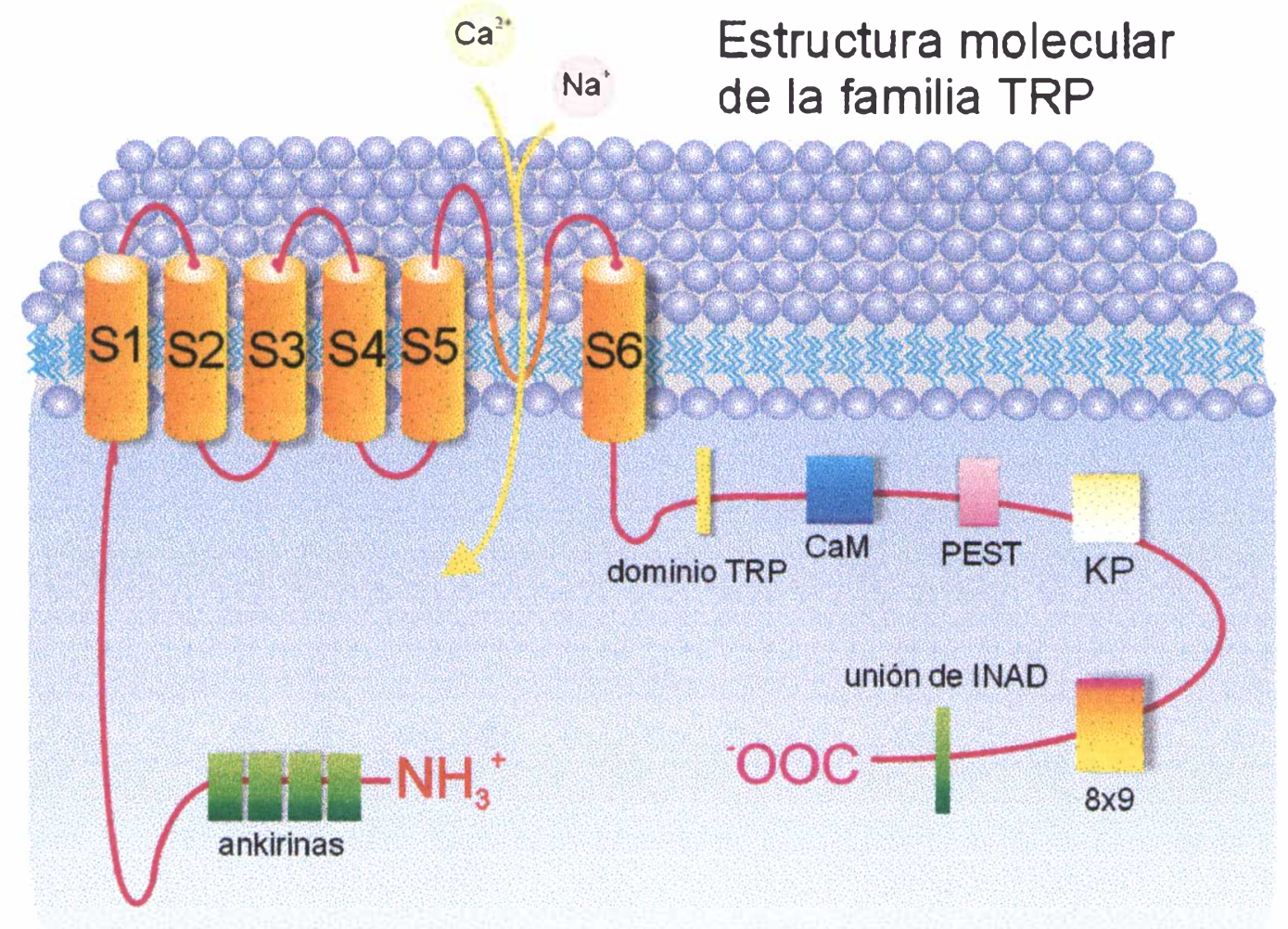

Figura V: estructura molecular de las proteinas pertenecientes a la familia TRP (191).

Minke y Cook han realizado recientemente una extensa revisión acerca de la clasificación y nomenclatura de los diferentes grupos de proteínas y sus 
subfamilias, en la cual se especifica el grado de identidad entre ellas (191). Entre los diferentes subtipos de proteinas caracterizadas las denominadas TRP3, TRP6 y TRP7 son muy similares estructuralmente y forman canales catiónicos no selectivos, expresados en músculo liso, cardíaco y en placenta (192). Estos presentan una baja permeabilidad al $\mathrm{Ca}^{2+}$ respecto del $\mathrm{Na}^{+}$, son inhibidos por la concentración de $\mathrm{Ca}^{2+}$ intracelular y activados por el diacilglicerol (DAG). Además, en la placenta humana, también se ha encontrado que las proteínas autosómicas de tipo policistina-2 constituyen canales catiónicos no selectivos de membrana (193). La estructura de esta proteína, que constituye una subfamilia de las proteinas relacionadas con la expresión de genes trp y comparte un $25 \%$ de identidad aminoacídica con las proteínas de tipo TRPC3 y TRPC6, es anómala en muchos individuos que presentan enfermedad del riñón poliquístico.

En el músculo liso vascular se ha informado la presencia de canales catiónicos no selectivos involucrados en diferentes funciones celulares. Así se ha informado la presencia de canales CNS involucrados en la señalización de diversos agonistas, activados por depleción de $\mathrm{Ca}^{2+}$ de los depósitos intracelulares y activados por deformaciones mecánica de la membrana celular. Por lo tanto, funcionalmente se los puede clasificar en:

Canales catiónicos no selectivos activados por agonistas extracelulares: En la revisión realizada por Barritt se detallan evidencias experimentales y características de este tipo de canal en diferentes tejidos (39). En dicha revisión el autor define como canales de $\mathrm{Ca}^{2+}$ activados por receptor a canales catiónicos no selectivos, permeables al $\mathrm{Ca}^{2+}$ cuya actividad depende de la unión de un agonista con un receptor, separado estructuralmente del canal iónico y se relacionada con el mismo mediante algún mecanismo de acoplamiento.

La activación de canales CNS secundaria a la acción de un agonista puede desencadenar distintos mecanismos tendientes a aumentar el $\mathrm{Ca}^{2+}$ intracelular, la mayor actividad de estos canales puede aumentar la concentración de $\mathrm{Ca}^{2+}$ per se y/o producir despolarización celular debido al influjo de cationes $\left(\mathrm{Na}^{+}, \mathrm{Ca}^{2+}\right)$ y, esta despolarización producir la apertura de canales de $\mathrm{Ca}^{2+}$ operados por voltaje aumentando el influjo de $\mathrm{Ca}^{2+}$. La contribución de cada uno de estos mecanismos dependerá de las propiedades de estos canales en cada tipo de tejido (selectividad iónica, valor de conductancia, densidad de canales, probabilidad de 
apertura, etc). El flujo de $\mathrm{Ca}^{2+}$ y $\mathrm{Na}^{+}$a través de canales $\mathrm{CNS}$ puede modificar la activación del intercambiador $\mathrm{Na} / \mathrm{Ca}$, de la bomba $\mathrm{Na} / \mathrm{K}$ y de canales de $\mathrm{K}^{+}$ activados por $\mathrm{Ca}^{2+}$ que se encuentren colocalizados estructural o funcionalmente con dichos canales $(194,195)$.

En el músculo liso vascular se han identificado canales catiónicos no selectivos activados por sustancias vasoactivas como histamina (196), neuroquinina A, sustancia P (197) y endotelina (198). Recientemente Inoue y colaboradores demostraron que la proteina de tipo TRPC6 es parte esencial del canal catiónico activado por el receptor $\alpha 1$-adrenérgico en miocitos de vena porta de conejo (199).

A este grupo pertenecen también los receptores purinérgicos de tipo P2X de los cuales existen varios subtipos. En la arteria umbilical, vena umbilical y arterias coriónicas humanas de la zona cercana a la placenta se ha descripto recientemente la expresión de los subtipos P2X 1,4,5,y 6 mientras que en la zona de la arteria y la vena umbilical más cercana al feto se encontraron los subtipos P2X 1,2,4 y 6 . Los autores de este trabajo sugieren que el ATP podría participar del desarrollo de la contracción de estos vasos durante el parto, debido posiblemente a la activación de estos canales (200). Restan determinar las propiedades electrofisiológicas de estos canales para conocer sus propiedades bioleléctricas y comprender si contribuyen al desarrollo de fuerza en forma directa (por ingreso de $\mathrm{Ca}^{2+}$ a través del poro) y/o indirecta (por despolarización y activación de los canales de $\mathrm{Ca}^{2+}$ ). También en las células de músculo liso de vena safena humana se encuentran presentes receptores purinergicos del subtipo P2X7, los cuales median una corriente catiónica no selectiva activada por ATP produciendo contracción en las células de músculo liso de este vaso $(201,202)$.

Canales catiónicos no selectivos activados por depleción de depósitos intracelulares de $\mathrm{Ca}^{2+}$ : Existen canales $\mathrm{CNS}$, que presentan alta permeabilidad al $\mathrm{Ca}^{2+}$ y son activados por la depleción del retículo sarcoplásmico, se los denomina canales operados por depósitos de $\mathrm{Ca}^{2+}$ denominados $\mathrm{SOC}$ (del ingles "storeoperated channels") y la corriente iónica a través de este tipo de canal se denomina corriente capacitativa de $\mathrm{Ca}^{2+}$. El mecanismo de activación de estos canales aún es desconocido. Se han propuesto mecanismos de activación 
directos, como el acoplamiento estructural del retículo sarcoplásmico con los canales de membrana e indirectos, mediados por señales intracelulares (203).

Los canales CNS de este tipo pueden ser afectados por cambios de pH. Iwasawa y colaboradores demostraron que, en células de aorta de rata cultivadas (A7r5), dos tipos de canales permeables a $\mathrm{Ca}^{2+}$, identificados como catiónico no selectivo (I $I_{C A T}$ ) y como canal activado por depleción del retículo sacoplásmico responsable de la corriente capacitativa (I IRAC), fueron modificados por el pH externo, de modo tal que la acidificación disminuyó y la alcalinización aumentó la actividad de estos canales (204). En relación con este hallazgo, recientemente se ha encontrado que canales CNS sensibles a 2-aminoetoxidifenilborato regulan el influjo de $\mathrm{Ca}^{2+}$ producido por la alcalosis intracelular y mediado por canales de $\mathrm{Ca}^{2+}$ operados por voltaje en células de músculo liso vascular en cultivo (A7r5) (205). En cuanto a la estructura molecular, algunos estudios han sugerido que las proteinas TRP4 y TRP5 forman canales de tipo SOC (206).

Canales CNS activados por estímulos mecánicos: Estos canales se denominan canales mecano-activados O MGC (del inglés "mechanogated channels") y su activación es modulada directa o indirectamente por un estímulo mecánico (207). La deformación mecánica de la membrana celular debida a estiramiento, cambios de volumen y presión, entre otros factores, constituye un estímulo para canales de tipo CNS que permiten un influjo de $\mathrm{Ca}^{2+}$ con el consecuente aumento en la contractilidad. Como se describió anteriormente, el desarrollo del tono miogénico implica en su primera fase una despolarización de la membrana plasmática en las células de músculo liso de la pared arterial, producto del estiramiento de la misma. Sin embargo no se conocen con exactitud las estructuras involucradas en dicha despolarización. Se ha postulado que los canales CNS mecano-activados son los responsables de esta primer fase en algunos lechos vasculares (207). Recientemente, Brayden y colaboradores demostraron que la corriente catiónica no selectiva a través de canales tipo TRP6 es responsable de la despolarización en la respuesta miogénica de arterias cerebrales presurizadas de rata (207).

Al igual que en los otros tipos de canales CNS el flujo iónico a través de canales mecano-activados puede desencadenar mecanismos regulados por la 
despolarización y/o acoplados al aumento de $\mathrm{Ca}^{2+}$ intracelular como por ejemplo la activación de canales BK $\mathrm{Ca}_{\mathrm{a}}$ (195).

El aumento del calcio a través de canales CNS en células de músculo liso vascular influye no sólo en el tono contráctil de las células de músculo liso del vaso sino también en procesos de proliferación celular como fue demostrado por Golovina y colaboradores (208). 


\section{OBJETIVOS}

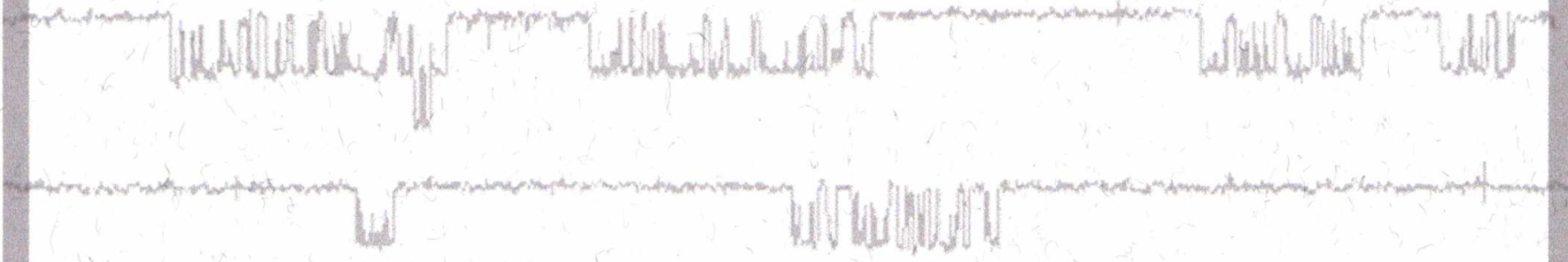

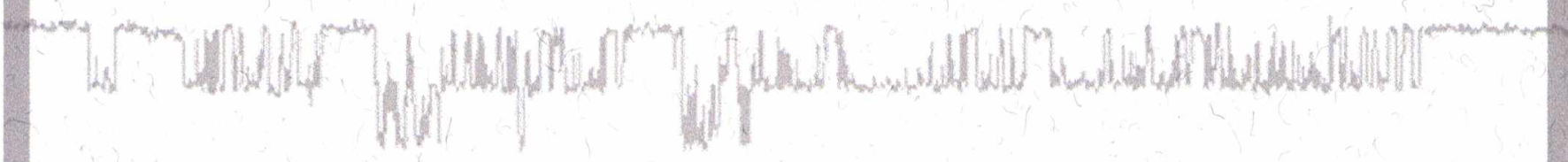




\section{OBJETIVOS}

La investigación en fisiología vascular tiene como objetivo relevante la identificación de los mecanismos que median las respuestas contráctiles del músculo liso en condiciones fisiológicas, patológicas 0 ante la administración de fármacos. Distintos tipos de canales iónicos, permitiendo y modulando el pasaje de iones a través de la membrana celular, participan en la regulación de la función contráctil de las células de músculo liso que forman parte de la pared de los vasos sanguíneos. En particular, el mantenimiento del potencial de membrana celular, la regulación del grado de polarización del mismo y la modulación del influjo de $\mathrm{Ca}^{2+}$ y $\mathrm{Na}^{+}$, constituyen algunos de los mecanismos donde dichos canales cumplen un rol fundamental.

Este trabajo de Tesis Doctoral tuvo como objetivo central identificar y caracterizar las propiedades electrofisiológicas de distintos tipos de canales iónicos en células aisladas de músculo liso humano e indagar su participación en el mecanismo de contracción y relajación del tejido intacto, con la finalidad de producir conocimiento acerca de los mecanismos fisiológicos que sustentan la función contráctil del músculo liso vascular humano. En particular, contribuir a la caracterización de las propiedades de los canales iónicos de $\mathrm{K}^{+}$y de los mecanismos reguladores de los mismos, en un tipo celular muy poco estudiado en este campo, ya sea aportando datos obtenidos en células frescas aisladas como a partir de segmentos intactos donde se pueden poner en juego mecanismos reguladores intrínsecos de la pared vascular (endotelio, subendotelio, uniones "gap", etc.). De la correlación de los mismos pueden surgir indicaciones sobre distintos roles fisiológicos de dichos canales en estos vasos humanos. Las arterias umbilicales tienen gran relevancia fisiológica ya que estos vasos son responsables de mantener una resistencia al flujo baja para lograr recibir alrededor del $40 \%$ del volumen minuto cardíaco fetal que se oxigenará circulando por la placenta. Con respecto a la arteria mamaria interna humana, el objetivo central fue indagar las propiedades del canal de $\mathrm{K}^{+}$activado por $\mathrm{Ca}^{2+}$ de alta conductancia, su regulación por cambios de $\mathrm{pH}$ y la influencia sobre el estado contráctil de este vaso que pueda tener este factor. Estos resultados permitirán conocer mejor la fisiología de este vaso humano ampliamente utilizado en cirugías de revascularización miocárdica. 


\section{MATERIALES Y MÉTODOS}

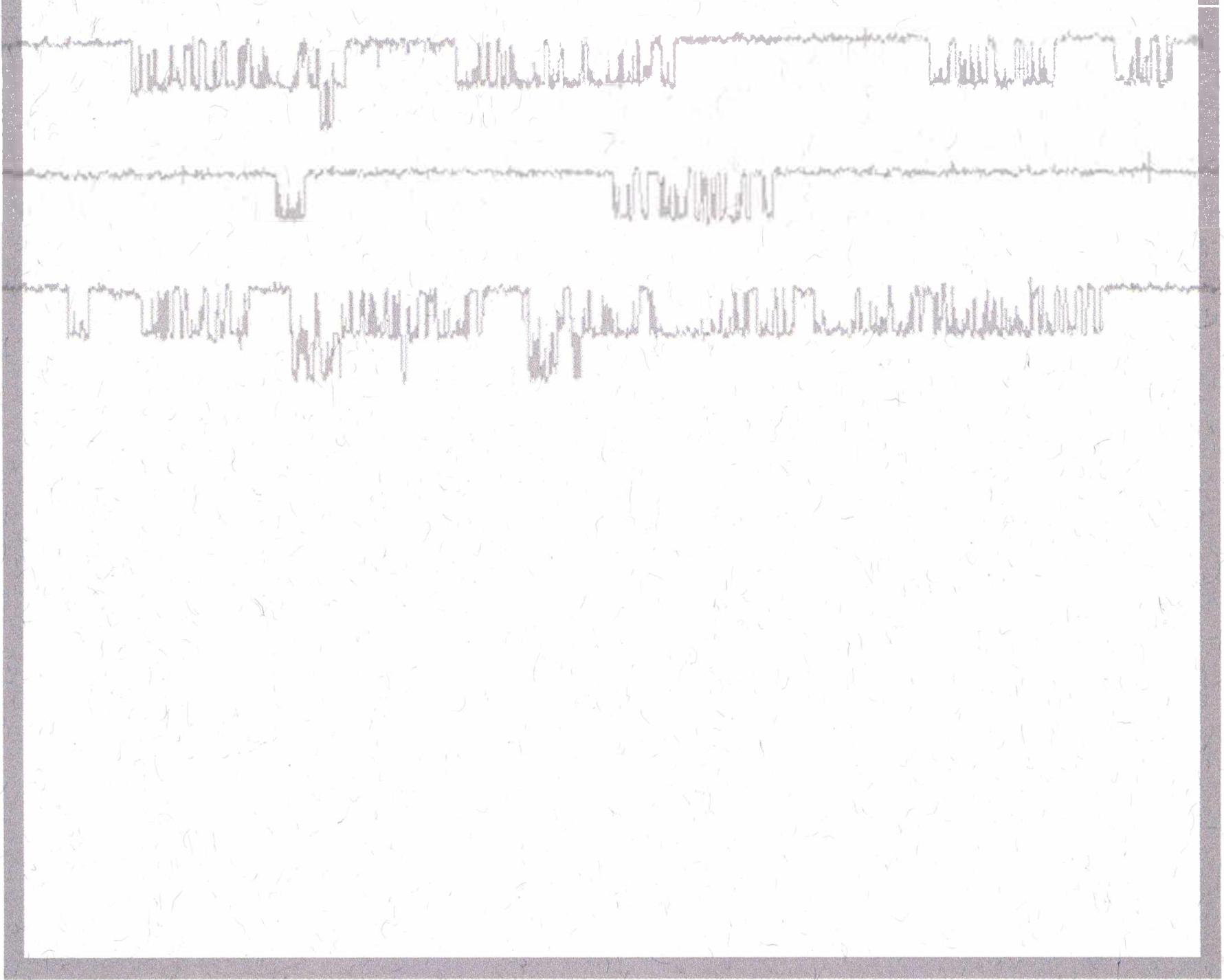




\section{MATERIALES Y METODOS}

\section{1- Determinaciones electrofisiológicas mediante la técnica de patch-} clamp

\section{1- Disociación celular}

1.1.1- Disociación enzimática de células de músculo liso de arteria mamaria interna humana

Se utilizaron segmentos de arteria mamaria interna humana obtenidos de remanentes de cirugía de revascularización miocárdica provistos por el equipo de Cirugía Cardiovascular del Hospital San Juan de Dios de La Plata. Los vasos fueron mantenidos a $0-4{ }^{\circ} \mathrm{C}$ en solución salina fisiológica $(\mathrm{NaCl} 0,9 \%)$ desde su extracción en el acto quirúrgico hasta su traslado a nuestro laboratorio (dentro de las 2 horas posteriores). La obtención de miocitos lisos vasculares humanos aislados se realizó mediante el siguiente protocolo de disociación celular descrito por Klockner para arteria mesentérica humana (209) y utilizado anteriormente en nuestro laboratorio para la disociación de vena safena humana (114). En primer lugar, se coloca la muestra en un recipiente con solución salina físiológica para separar cuidadosamente el segmento vascular del tejido muscular esquelético y conjuntivo adherido. Una vez obtenido el segmento limpio (20-40 mg), se corta en porciones de $2 \times 2 \mathrm{~mm}$ aproximadamente y se coloca el tejido en una solución de disociación (SD) de la siguiente composición (en $\mathrm{mM}$ ): $\mathrm{NaCl} 140 ; \mathrm{KH}_{2} \mathrm{PO}_{4}$ 1,2; $\mathrm{MgCl}_{2}$ 5; Hepes 5; glucosa 20; y pH 7,4. Luego de 15 minutos se transfiere el tejido a un tubo conteniendo $1 \mathrm{ml}$ del mismo medio al cual se le adicionan $2 \mathrm{mg}$ de colagenasa, $0,5 \mathrm{mg}$ de proteasa tipo I y $2 \mathrm{mg}$ de papaína. El tubo con el tejido permanece en un baño termostatizado a $30^{\circ} \mathrm{C}$ durante 30 minutos con agitación suave. Luego cada 15 minutos se separa el tejido del medio de disociación que contiene las células que se van aislando y se centrifuga; se obtiene así un precipitado que se resuspende en el mismo medio SD sin enzimas. Esta suspensión se coloca en una cámara donde se realizarán los registros electrofisiológicos y se seleccionan las células por su aspecto relajado para intentar el logro de sellos con microelectrodos. 


\subsection{2 - Disociación enzimática de células de músculo liso de arteria}

\section{umbilical humana}

Se utilizaron segmentos vasculares de arteria umbilical humana obtenidos de muestras de cordones umbilicales provistos por los servicios de Obstetricia del Sanatorio Argentino de La Plata, del Instituto Médico Platense y del Instituto Central de Medicina de La Plata. Se seleccionaron cordones provenientes de nacimientos normales a término por partos vaginales o cesáreas. Los cordones umbilicales fueron mantenidos a $0-4^{\circ} \mathrm{C}$ en una solución conteniendo (en $\mathrm{mM}$ ): $\mathrm{NaCl} 130 ; \mathrm{KCl} 4,7 ; \mathrm{CO}_{3} \mathrm{HNa} 24 ; \mathrm{NaH}_{2} \mathrm{PO}_{4}$ 1,17; $\mathrm{MgSO}_{4} 1,16 ;$ glucosa 6, y pH 7,4; desde su obtención hasta su traslado a nuestro laboratorio y fueron utilizados dentro de las 24 horas posteriores. Las arterias umbilicales son en primer lugar cuidadosamente aisladas del tejido conectivo que las recubre (jalea de Warthon del cordón umbilical). La obtención de los miocitos lisos aislados se realiza a partir de segmentos de esta arteria mediante un protocolo de disociación celular similar al utilizado para la arteria mamaria interna humana. Se coloca un segmento del vaso (20-40 mg) cortado en porciones de aproximadamente $2 \times 2 \mathrm{~mm}$ en la solución de disociación (SD). Pasados 15 minutos se transfiere el tejido a un tubo conteniendo $1 \mathrm{ml}$ del mismo medio al cual se le adicionan $2 \mathrm{mg}$ de colagenasa y $0,5 \mathrm{mg}$ de proteasa tipo I. El tubo con el tejido permanece en un baño termostatizado a $30^{\circ} \mathrm{C}$ durante 25 minutos con agitación suave. Cada 15 minutos se separa el tejido del medio de disociación que contiene las células que se van aislando, se centrifuga y se obtiene así un precipitado que se resuspende en medio SD. Esta suspensión de células se coloca en una cámara donde se realizarán los registros electrofisiológicos y seleccionan las células por su aspecto relajado para intentar el logro de sellos con microelectrodos adecuados.

\section{2- Registro de corrientes iónicas en células aisladas}

\subsection{1- Consideraciones generales}

Mediante la aplicación de la técnica de "patch-clamp" se registraron corrientes iónicas totales en configuración de célula entera o W-C (del inglés "whole-cell") y corrientes de canal único en segmentos de membrana en distintas configuraciones.

La unidad de "patch-clamp" y, en particular, el tipo de amplificador eléctrico que se utiliza en esta técnica permiten registrar corriente o cambios de potencial a 
través del circuito eléctrico que se establece entre un electrodo de $\mathrm{Ag} / \mathrm{AgCl}$ sumergido en una micropipeta de vidrio conteniendo una solución salina, la totalidad de la membrana celular o un segmento de membrana según la configuración y el electrodo de referencia compuesto por una placa de $\mathrm{Ag}$ clorurada $(\mathrm{Ag} / \mathrm{AgCl})$ sumergida en el líquido que baña las células.

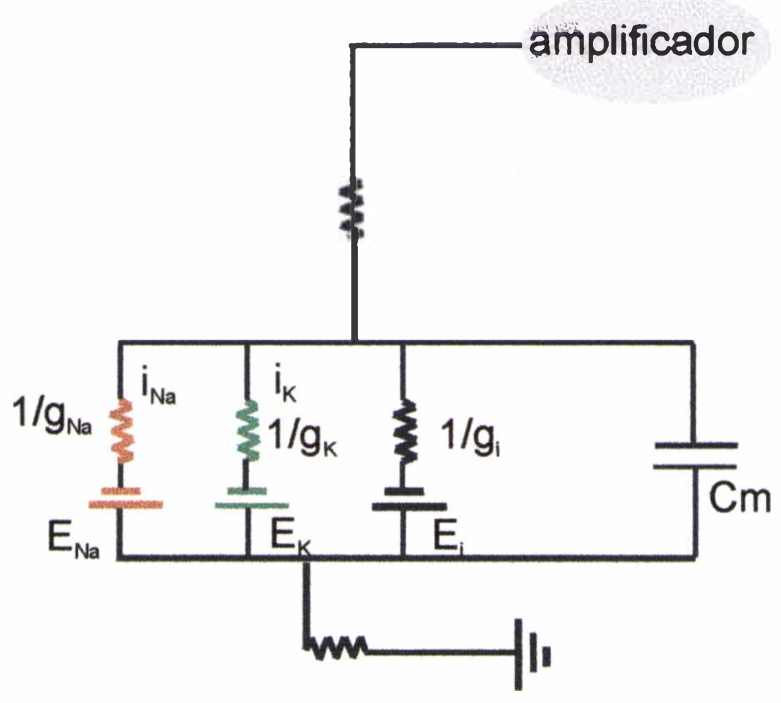

Circuito equivalente de la membrana plasmática de una célula. Donde g es la conductancia de la membrana a los distintos iones, Cm es la capacitancia de la membrana y E es el valor del potencial de equilibrio electroquímico para los distintos iones.

El condensador eléctrico presente de este circuito representa a la bicapa lipídica de la membrana mientras que las resistencias o conductancias ( $g$ ) representan las proteínas de membrana que constituyen canales iónicos. Por lo tanto una diferencia de potencial aplicada a los lados de este circuito evoca una corriente con dos componentes, una capacitiva relacionada con la capacitancia de la membrana (condensador) y una resistiva proporcional a las características de permeabilidad de los canales iónicos presentes y a la fuerza impulsora de la corriente (diferencia entre el potencial de membrana celular y el potencial electroquímico del ion transportado). La capacitancia de la membrana $\left(\mathrm{C}_{\mathrm{m}}\right)$ está relacionada con el área de la membrana según la siguiente ecuación y es uno de los parámetros que se utilizan comúnmente en electrofisiología para estimar el área de membrana celular. 


\section{$C_{m}=\varepsilon A / d$}

donde
$A=$ área de la membrana
$\varepsilon=$ constánte dielétrica
$d$ = espesor de la membrana

Cuando el protocolo experimental exigió reducir la concentración del ión $\mathrm{Cl}^{-}$ en las soluciones salinas de llenado de la micropipeta y/o de perfusión se utilizó un puente de agar salino para evitar la sumación de potenciales de junta líquida en las medidas experimentales (210). Este puente se coloca en forma tal que un extremo se encuentre en contacto con el líquido de la cámara experimental que contiene las células y el otro extremo con un recipiente con solución salina normal donde se coloca el electrodo de referencia ( $\mathrm{Ag} / \mathrm{AgCl})$. El puente de agar salino se realizó llenando un capilar de vidrio con agar preparado al 1,8\% PN en una solución $3 \mathrm{M}$ de $\mathrm{KCl}$.

La técnica de "patch-clamp", desarrollada por los investigadores Hamill, Martin, Neher, Sakmann y Sigworth del Instituto Max-Planck de Alemania (120), consiste brevemente en la aproximación de una micropipeta de "patch" a la superficie de la membrana de la célula aislada elegida y en el establecimiento de un sello de alta resistencia eléctrica (aproximadamente $10 \mathrm{G} \Omega$ ) entre el vidrio de la punta de la pipeta y la membrana celular. Esto se logra cuando la superficie de la membrana y el vidrio de la micropipeta se ponen en contacto y se aplica una leve presión negativa (por tracción del embolo de una jeringa o succión suave) a través de una cánula conectada con el interior de la micropipeta. Cuando se trabaja en esta configuración denominada C-A (del inglés "cell-attached") no hay acceso al interior celular por lo que este se conserva intacto, mientras que la solución de la micropipeta se encuentra en contacto con el lado extracelular del segmento de membrana celular y por lo tanto del canal presente en dicho segmento. A partir de la configuración C-A se pueden obtener el resto de las configuraciones posibles. 
configuración C-A

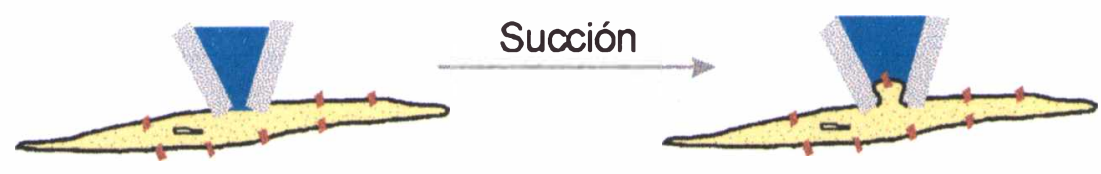

Para obtener la configuración W-C (del inglés "whole-cell"), se aplica mayor presión negativa a través de la micropipeta lo cual rompe el sector de membrana por debajo de la misma y permite la conexión eléctrica entre el electrodo y el interior celular como se muestra en el siguiente esquema.

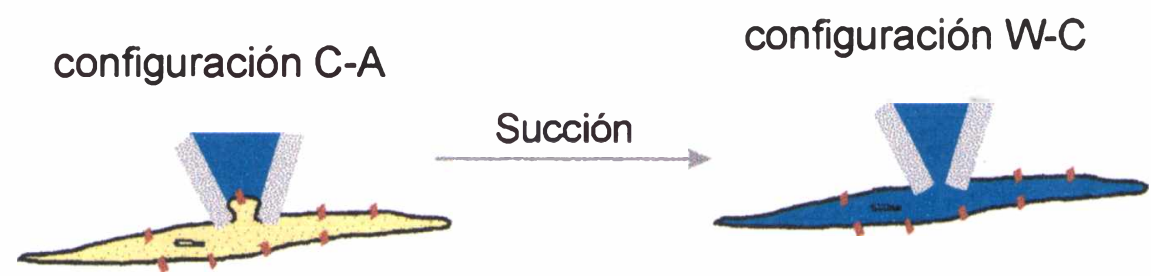

A partir de la configuración W-C y mediante un movimiento de tracción es posible obtener un segmento de membrana aislado en la configuración O-O (del inglés "outside-out"), donde el lado externo de la membrana está en contacto con la solución de perfusión y la cara interna con la solución de la mocropipeta.

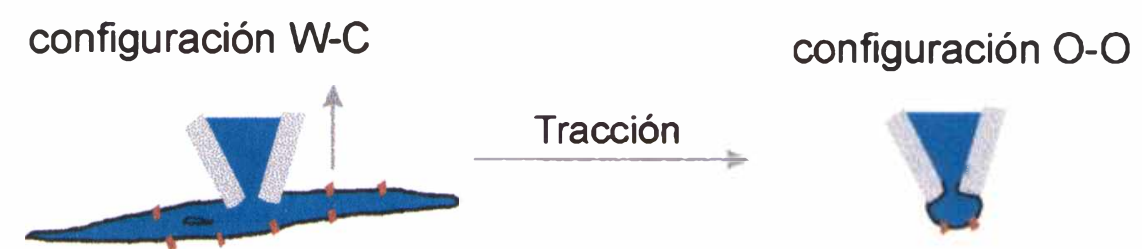

A partir de la configuración C-A y mediante un movimiento de tracción es posible obtener un segmento de membrana aislado en la configuración I-O (del inglés "inside-out"), donde el lado interno de la membrana está en contacto con la solución de perfusión y la cara externa con la solución de la mocropipeta.

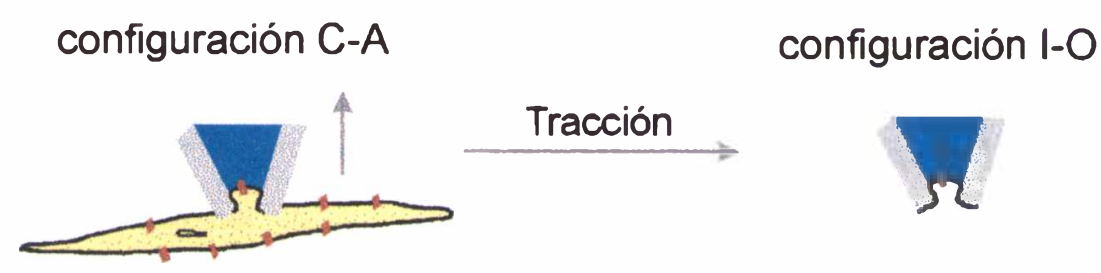


Para la preparación de las muestras de células aisladas, luego de la disociación enzimática, la solución SD conteniendo las células de músculo liso aisladas de $\mathrm{AUH}$ o $\mathrm{AMIH}$ fue colocada en cámaras experimentales de $0,5 \mathrm{ml}$ de capacidad con una superficie central de vidrio, la cual facilita la adhesión de las células al fondo de la cámara.

Se observaron las células con un microscopio invertido equipado con una lente objetivo de 40X (Telaval 3; Zeiss, Jena, Alemania) estabilizado mecánicamente sobre una mesa antivibratoria (Newport) recubierto con una caja de Faraday para filtrar ruidos eléctricos del ambiente. La cámara experimental que contiene las células es perfundida con solución extracelular normal a una velocidad constante $0.5 \mathrm{ml} / \mathrm{min}$ mediante un sistema multivía de perfusión continua. En este sistema las soluciones alcanzan la cámara por gravedad desde varios reservorios conectados mediante cánulas flexibles a una pipeta multivía que se moviliza mediante un micromanipulador (Leitz). El líquido es retirado de la cámara mediante succión por una bomba de vacio. La pipeta de perfusión se posicionó muy cerca de la célula a ensayar y la cámara fue perfundida durante 15 minutos con la solución control de cada experimento antes de comenzar con los registros eléctricos. Luego de cada experimento la cámara conteniendo la célula ensayada se reemplazó por otra con células nuevas. Para realizar los registros eléctricos se seleccionaron las células que estuvieran relajadas (aspecto liso) con forma ahusada y adheridas al vidrio de la cámara. Los datos se obtuvieron entre 4 y 6 horas luego de la disociación celular. Todos los experimentos fueron realizados a temperatura ambiente $\left(\sim 20^{\circ} \mathrm{C}\right)$.

Las micropipetas fueron realizadas con capilares de vidrio WPI PG52165-4 en un sistema de estirado ("puller") vertical a dos fases (PP-83, Narishige Scientific Instrument Laboratories, Tokio, Japón). La resistencia de las mismas estuvo en el rango de 2 a $4 \mathrm{M} \Omega$ medida en solución extracelular normal (ver composición más adelante). La micropipeta se movilizó mediante un micromanipulador de precisión (Huxley-Style precisión MX310R, Newport). El electrodo de referencia adecuadamente clorurado se colocó dentro de la solución del baño.

La señal de corriente eléctrica o de potencial en función del tiempo, se filtró adecuadamente con un filtro tipo Bessel de 8 polos y se registró con un amplificador Axopatch 200A (Axon Instruments, Foster City, CA). Los datos fueron 
convertidos mediante una placa conversora AVD - D/A (DIGIDATA 1200 - Axon Instruments) y almacenados en el disco duro de una computadora para su análisis posterior con un programa apropiado. Todos los componentes del equipo se conectaron a tierra adecuadamente con el fin de disminuir el ruido eléctrico durante los experimentos. En la siguiente figura se esquematizan las conexiones entre los componentes de la unidad de "patch-clamp".

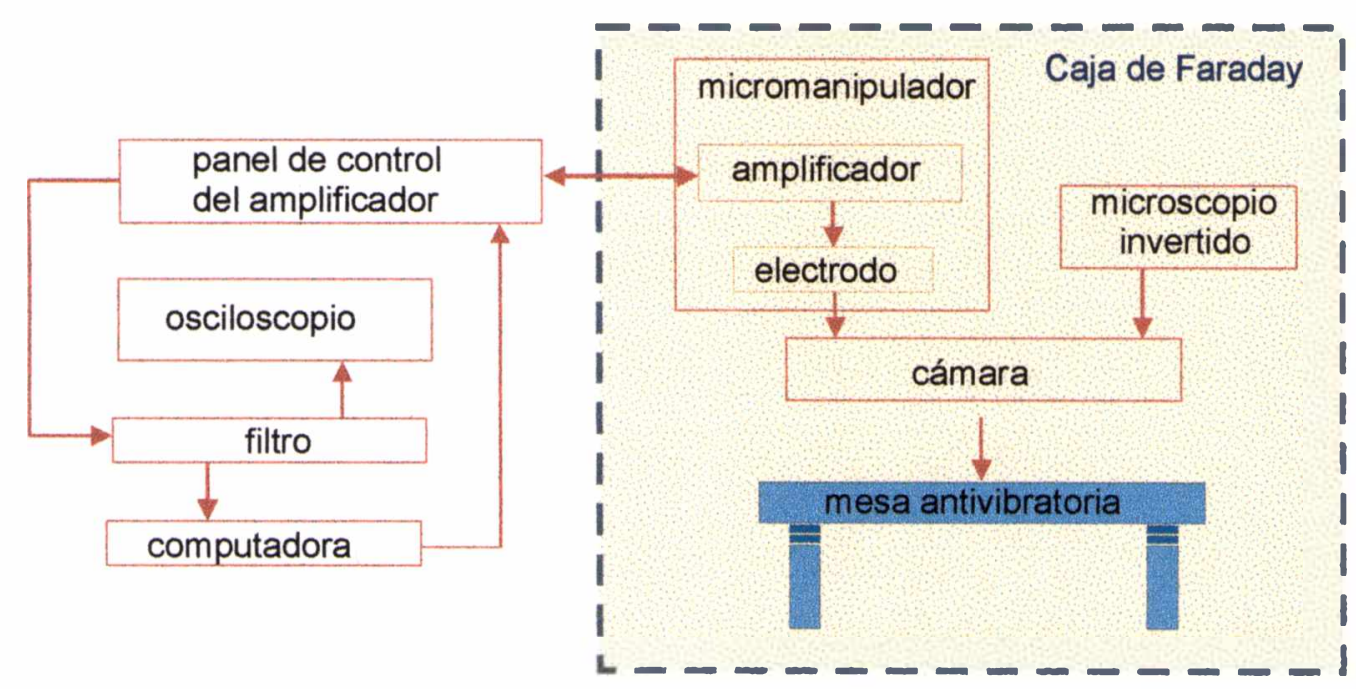

Esquema de la unidad de "patch-clamp"

\subsection{2- Registros de corrientes totales en configuración W-C}

Como se puede observar en el esquema de la figura 3 en la sección anterior, en configuración W-C, la solución salina de la micropipeta difunde hacia el interior celular y mediante la aplicación de un protocolo de fijación de voltaje es posible registrar la corriente macroscópica total que fluye a través de la sumatoria de canales presentes en toda la superficie de la membrana celular (modo "voltageclamp" o fijación de voltaje). En esta configuración es también posible registrar el valor de potencial de membrana de reposo o en respuesta a un estímulo fijo de corriente (modo "current-clamp" o fijación de corriente).

En este trabajo se realizaron registros de corriente y de potencial en configuración W-C en células musculares lisas de AUH.

Para registrar corrientes iónicas totales se aplicaron protocolos de voltaje de dos tipos: 
Protocolos de voltaje en pulso: cambio discreto instantáneo del valor de potencial desde un valor determinado (potencial de mantenimiento) que se mantiene durante un cierto tiempo y luego retorna también en forma instantánea al valor inicial:

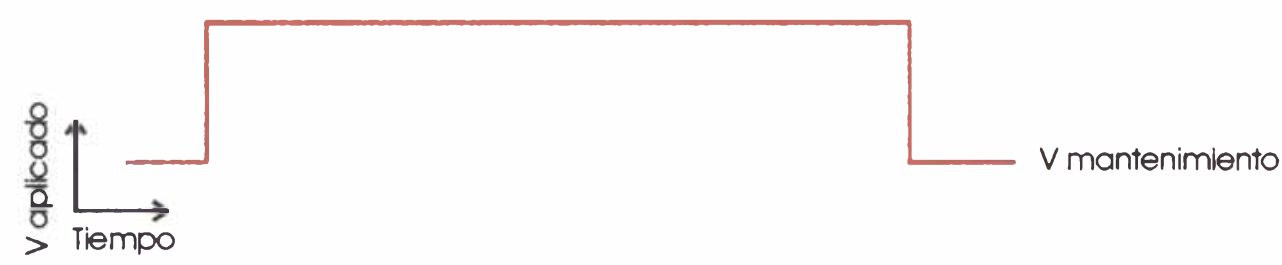

Protocolo de voltaje en rampa: cambio continuo del valor de potencial aplicado a una cierta velocidad durante un determinado período de tiempo desde el valor de potencial de mantenimiento:

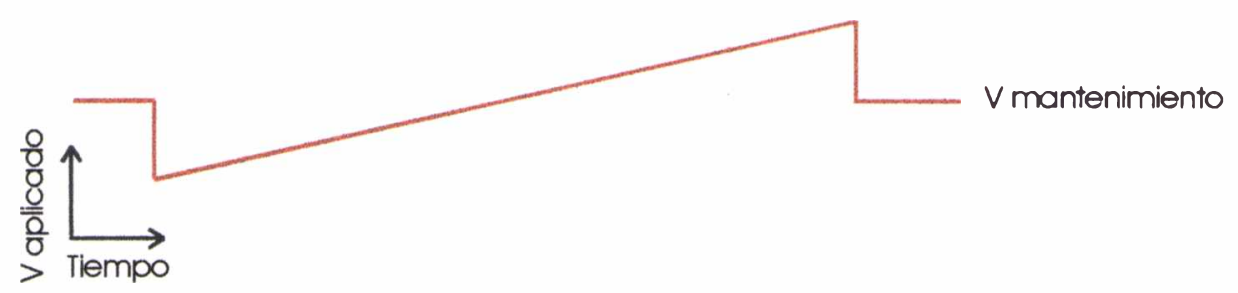

Estos protocolos se generan con el programa Clampex (pClamp6) y se aplican en forma automática según las necesidades experimentales.

Las corrientes obtenidas en esta configuración fueron filtradas a $2 \mathrm{kHz}$ y digitalizadas a una frecuencia de muestreo de $40 \mathrm{kHz}$ (en los experimentos con protocolos de pulsos de voltaje) y a $5 \mathrm{kHz}$ (en los experimentos con protocolos de rampas de voltaje). Los valores de la resistencia en serie estuvieron en el rango de 10 a $15 \mathrm{M} \Omega$ y fue compensada electrónicamente al $70 \%$ en la mayoría de los experimentos.

La componente capacitiva de la corriente evocada por un pulso de potencial fue compensada electrónicamente antes de realizar los registros en cada experimento y a partir de esta compensación el programa realiza el cálculo del valor de $\mathrm{Cm}$. 
El análisis de los datos obtenidos fue realizado empleando el programa Clampfit ( $p$ Clamp6) que permite en primer lugar visualizar, luego del experimento, el archivo de corriente correspondiente en función del tiempo, obtener el valor de $\mathrm{Cm}$ en unidades de $\mathrm{pF}$ y realizar el tratamiento de los datos que se considere necesario. En este trabajo, utilizando este programa, se realizaron curvas que relacionan los valores de corriente en función del valor de voltaje aplicados en diferentes pulsos (curvas I-V) y ajustes de las corrientes evocadas en función del tiempo a diferentes tipos de curvas (exponencial, sigmoidea, etc.) con el fin de cuantificar las características cinéticas de la corriente estudiada.

\subsection{3- Registros de canal único}

Se utilizaron las configuraciones $\mathrm{C}-\mathrm{A}, \mathrm{I}, \mathrm{O}$ y $\mathrm{O}-\mathrm{O}$ previamente descritas para obtener registros de corriente de canal único con el fin de estudiar las propiedades de canales selectivos al ión $\mathrm{K}^{+}$en células de músculo liso de AMIH y AUH. La elección de la configuración utilizada se realizó en base a las características particulares de cada experimento considerando la necesidad de

mantener el medio intracelular intacto (C-A)

modificar la composición del medio intracelular (I-O)

modificar la composición del medio extracelular (O-O)

En la sección de resultados se especifican la configuración y las soluciones utilizadas en cada experimento.

Se realizaron registros de la actividad de canal único con una duración de 30 a 60 segundos a distintos potenciales constantes. Los diferentes valores de potencial fueron aplicados directamente desde el amplificador del equipo. La señal proveniente del amplificador fue filtrada a $2 \mathrm{kHz}$ y digitalizada a $16 \mathrm{kHz}$.

El análisis de los datos se realizó con los programas Fetchan y Pstat (pClamp 6). Se detalla a continuación la metodología de análisis utilizado para la obtención de los parámetros que describen las características de canal único que luego son presentados en los resultados.

Cálculo de la conductancia iónica del canal: La conductancia de un canal es un valor empírico que se obtiene a partir de la amplitud de la corriente de canal único dividida por la fuerza impulsora de la corriente, la cual corresponde a la diferencia entre el potencial aplicado a la membrana menos el potencial electroquímico para el ion permeante (121). Entonces, a partir de los registros de 
corriente obtenidos, se miden los valores de amplitud de la corriente (i) para cada valor de potencial aplicado $(\mathrm{V})$ y se construye un gráfico i versus $\mathrm{V}$ que relaciona estos parámetros según la siguiente expresión:

$$
\mathrm{i}_{\mathrm{i}}=\gamma_{\mathrm{i}}\left(\mathbf{V}-\mathrm{E}_{\mathrm{i}}\right)
$$

Donde

$\mathrm{i}_{\mathrm{i}}=$ corriente de canal único

$V=$ potencial aplicado

$\gamma_{i}=$ conductancia iónica de canal único

$E_{i}=$ potencial de equilibrio electroquímico para el ion $i$, obtenido mediante la aplicación de la ecuación de Nernst considerando las concentraciones iónicas utilizadas en el experimento.

De esta forma, si es posible ajustar por cuadrados mínimos los valores del gráfico a una recta, se realiza el cálculo de la pendiente de la misma, obteniéndose el valor de conductancia del canal $(\gamma)$ en unidades de pS (pApV). En los casos donde la relación I-V no se ajusta completamente a una relación lineal a todos los potenciales ensayados, $\gamma$ se calcula entre los potenciales que muestran una relación $\mathrm{I}-\mathrm{V}$ lineal y se informa el rango de potenciales empleados. Además, como el valor $\gamma$ puede variar según las concentraciones iónicas a los lados de la membrana, éstas también debe informarse en cada caso.

Cálculo de la probabilidad de apertura (Po): La actividad de un canal iónico es un fenómeno estocástico por lo que la misma se cuantifica en términos de probabilidad de apertura del canal.

La probabilidad de apertura (Po) de un canal puede ser modificada por numerosos factores como el potencial de membrana, sustancias químicas y deformaciones mecánicas de la membrana, entre tantos otros.

La Po se define como la relación del tiempo que un canal iónico pasa en estado abierto dividido por el tiempo total (tiempo en estado abierto más tiempo en estado cerrado). En la mayoría de los experimentos la probabilidad de apertura se estima con el parámetro NPo, donde $\mathrm{N}$ es el número total de canales presentes en el segmento de membrana (ya que en general se observan entre 2 y 5 niveles de corriente por segmento de membrana) y Po es la probabilidad de apertura individual del canal. Para calcular este parámetro se tomaron siempre registros de 
corriente de canal único de una duración de 30 segundos (tiempo total) y a partir de estos registros se realizaron histogramas de amplitud de corriente mediante el empleo del programa Fetchan. Utilizando el programa Pstat se ajustaron los histogramas de amplitud de corriente con curvas de Gauss mediante la aplicación del método de cuadrados mínimos en forma gráfica. Para esto se seleccionó el centro y el ancho del histograma en forma manual realizando pruebas hasta obtener un ajuste aceptable. A partir de los valores de las áreas de los picos del histograma correspondientes al estado cerrado (pico en el valor más cercano a 0 pA de amplitud) y a los distintos estados abiertos se calculó el valor de NPo mediante la siguiente expresión (211):

$$
N P o=\left(A_{1}+2 A_{2}+\ldots+n A_{n}\right) /\left(A_{0}+A_{1}+A_{2}+\ldots A_{n}\right)
$$

Donde $A_{0}$ es el área bajo la curva de amplitud del histograma que corresponde al estado cerrado del canal y $A_{1}, A_{2} \ldots A_{n}$ son las áreas a los $n$ niveles abiertos de los canales.

1.3- Composición de las soluciones utilizadas en los experimentos de "patch-clamp"

1.3.1- Soluciones extracelulares utilizadas como solución de perfusión en los experimentos realizados en configuración W-C

$\checkmark \quad$ Solución extracelular normal (SEN): Composición en mM: $150 \mathrm{NaCl}$; $5,4 \mathrm{KCl} ; 1,2 \mathrm{MgCl}_{2} ; 1 \mathrm{CaCl}_{2} ; 20$ glucosa y 5 HEPES; el pH fue ajustado a 7,4 con una solución concentrada de $\mathrm{NaOH}$.

Solución extracelular con $5 \mathrm{mM}$ de 4-aminopiridina (SE-5mM 4-AP): solución SEN en la cual $5 \mathrm{mM}$ de $\mathrm{NaCl}$ fueron reemplazados por 4-AP. Composición en mM: $145 \mathrm{NaCl} ; 5,4 \mathrm{KCl} ; 5 \mathrm{MgCl}_{2} ; 1 \mathrm{CaCl}_{2} ; 20$ glucosa; 5 HEPES y 5 4-aminopiridina; el pH fue ajustado a 7,4 con una solución concentrada de $\mathrm{HCl}$.

$\checkmark \quad$ Solución extracelular con $20 \mathrm{mM}$ de tetraetilamonio (SE-20mM TEA): solución SEN en la cual $20 \mathrm{mM}$ de $\mathrm{NaCl}$ fueron reemplazados por cloruro de 
tetraetilamonio. Composición en mM: $130 \mathrm{NaCl} ; 5,4 \mathrm{KCl} ; 5 \mathrm{MgCl}_{2} ; 1 \mathrm{CaCl}_{2} ; 20$ glucosa; 5 HEPES y 20 cloruro de tetraetilamonio; el pH fue ajustado a 7,4 con una solución concentrada de $\mathrm{NaOH}$.

$\checkmark \quad$ Solución extracelular con baio $\mathrm{Cl}^{-}$(SE-baio $\mathrm{Cl}^{-}$): Solución SEN en la cual se redujo la concentración del ion $\mathrm{Cl}^{-}$reemplazando una proporción del $\mathrm{NaCl}$ por gluconato de sodio. Composición en mM: $30 \mathrm{NaCl} ; 5,4 \mathrm{KCl} ; 1,2 \mathrm{MgCl}_{2} ; 1$ $\mathrm{CaCl}_{2} ; 20$ glucosa; 5 HEPES y $120 \mathrm{mM}$ gluconato de sodio; el pH fue ajustado a 7,4 con una solución concentrada de $\mathrm{NaOH}$

$\checkmark \quad$ Solución extracelular con $142 \mathrm{mM} \mathrm{de} \mathrm{Cs}^{+}\left(\mathrm{SE}-142 \mathrm{mM} \mathrm{Cs}^{+}\right)$: solución en la cual el único catión extracelular presente es el $\mathrm{Cs}^{+}$. Composición en mM: 142 CsCl; 5 HEPES; $0,5 \mathrm{MgCl}_{2}$ y 10 glucosa; el pH fue ajustado a 7,4 con una solución concentrada de $\mathrm{CsOH}$.

$\checkmark \quad$ Solución extracelular con $142 \mathrm{mM}$ de Li ${ }^{+}\left(\mathrm{SE}-142 \mathrm{mM} \mathrm{Li}{ }^{+}\right.$: solución en la cual el único catión extracelular presente es el $\mathrm{Li}^{+}$. Composición en mM: 142 LiCl; 5 HEPES; $0,5 \mathrm{MgCl}_{2}$ y 10 glucosa; el pH fue ajustado a 7,4 con una solución concentrada de $\mathrm{LiOH}$.

$\checkmark \quad$ Solución extracelular con $142 \mathrm{mM} \mathrm{de} \mathrm{Na}^{+}\left(\mathrm{SE}-142 \mathrm{mM} \mathrm{Na}^{+}\right.$): solución en la cual el único catión extracelular presente es el $\mathrm{Cs}^{+}$. Composición en mM: $142 \mathrm{NaCl} ; 5$ HEPES; $0,5 \mathrm{MgCl}_{2}$ y 10 glucosa; el pH fue ajustado a 7,4 con una solución concentrada de $\mathrm{NaOH}$.

Solución extracelular con $142 \mathrm{mM}$ de $\operatorname{Tris}^{+}\left(\mathrm{SE}-142 \mathrm{mM}\right.$ Tris $\left.^{+}\right)$: solución en la cual el único catión extracelular presente es el Tris ${ }^{+}$. Composición en mM: 142 trizma base; 5 HEPES y $0,5 \mathrm{MgCl}_{2} ; 10$ glucosa; el pH fue ajustado a 7,4 con una solución concentrada de $\mathrm{HCl}$. 
Solución extracelular con $60 \mathrm{mM}$ de $\mathrm{Ca}^{2+}$ (SE- $60 \mathrm{mM} \mathrm{Ca}^{2+}$ ): solución

SE- $142 \mathrm{mM} \mathrm{Cs}^{+}$en la cual 60 milimoles de $\mathrm{CsCl}$ por litro de solución se reemplazaron por $\mathrm{CaCl}_{2}$. Composición en mM: $82 \mathrm{CsCl} ; 5$ HEPES; $0,5 \mathrm{MgCl}_{2} ; 10$ glucosa y $60 \mathrm{CaCl}_{2}$; el pH fue ajustado a 7,4 con una solución concentrada de $\mathrm{CsOH}$.

$\checkmark \quad$ Solución extracelular con $60 \mathrm{mM}$ de $\mathrm{Ba}^{2+}\left(\mathrm{SE}-60 \mathrm{mM} \mathrm{Ba}^{2+}\right)$ : solución SE- $142 \mathrm{mM} \mathrm{Cs}^{+}$en la cual 60 milimoles de $\mathrm{CsCl}$ por litro se reemplazaron por $\mathrm{BaCl}_{2}$. Composición en mM: $82 \mathrm{CsCl} ; 5$ HEPES; $0,5 \mathrm{MgCl}_{2} ; 10$ glucosa y $60 \mathrm{BaCl}_{2}$; el pH fue ajustado a 7,4 con una solución concentrada de $\mathrm{CsOH}$.

Solución extracelular con TrisCl (SE-Tris): solución SEN donde todo el $\mathrm{NaCl}$ fue reemplazado isosmóticamente por TrisCl. Composición en mM: 150 Trizma base, $5,4 \mathrm{KCl} ; 1,2 \mathrm{MgCl}_{2} ; 1 \mathrm{CaCl}_{2} ; 20$ glucosa y 5 HEPES; el pH fue ajustado a 7,4 con una solución de $\mathrm{HCl}$ al $37 \%$ PN.

$\checkmark \quad$ Solución extracelular conTrisCl sin calcio (SE-Tris $0 \mathrm{Ca}^{2+}$ ): solución $\mathrm{SEN}$ en la cual todo el $\mathrm{NaCl}$ fue reempazado isosmóticamente por $\mathrm{Tris} \mathrm{Cl}$ y se omitió el agregado de $\mathrm{CaCl}_{2}$. Composición en mM: 150 Trizma base; $5,4 \mathrm{KCl} ; 1,2$ $\mathrm{MgCl}_{2} ; 20$ glucosa y $5 \mathrm{HEPES}$; el pH fue ajustado a 7,4 con una solución de $\mathrm{HCl}$ al $37 \%$ PN.

$\checkmark \quad$ Solución extracelular con alto magnesio (SE-alto $\mathrm{Mg}^{2+}$ ): solución SEN en la cual el $\mathrm{MgCl}_{2}$ fue aumentado a $5 \mathrm{mM}$. Composición en mM: $142,5 \mathrm{NaCl} ; 5,4$ $\mathrm{KCl} ; 5 \mathrm{MgCl}_{2} ; 1 \mathrm{CaCl}_{2} ; 20$ glucosa y $5 \mathrm{HEPES}$; el pH fue ajustado a 7,4 con una solución concentrada de $\mathrm{NaOH}$. 
1.3.2- Soluciones intracelulares utilizadas como solución de llenado de la micropiteta en configuración W-C

$\checkmark \quad$ Solución intracelular normal (SIN): Composición en mM: $130 \mathrm{KCl} ; 5$ $\mathrm{Na}_{2} \mathrm{ATP} ; 1 \mathrm{MgCl}_{2} ; 10$ glucosa; 0,1 EGTA y $20 \mathrm{HEPES}$; pH fue ajustado a 7,3 con una solución concentrada de $\mathrm{NaOH}$.

Solución intracelular con $\mathrm{CsCl}$ (SICs): Composición en mM: 130 CsCl; $5 \mathrm{Na}_{2} \mathrm{ATP} ; 1 \mathrm{MgCl}_{2} ; 10$ glucosa; 0,1 EGTA y 20 HEPES; $\mathrm{pH}$ fue ajustado a 7,3 con una solución concentrada de $\mathrm{NaOH}$.

$\checkmark \quad$ Solución intracelular con $\mathrm{Cs}^{+}$como único catión (SI-142 mM $\mathrm{Cs}^{+}$):Composición en mM: $142 \mathrm{CsCl} ; 5$ HEPES; 10 EGTA y $0,5 \mathrm{MgCl}_{2}$; $\mathrm{pH}$ fue ajustado a 7.3 con una solución concentrada de $\mathrm{CsOH}$.

\subsection{3- Soluciones utilizadas en los experimentos de canal único}

Solución extracelular normal (SEN): ver composición en 1.3.1

Solución intracelular normal (SIN): ver composición en 1.3.2

$\checkmark \quad$ Solución de perfusión (B1): Composición en mM: $140 \mathrm{KCl} ; 0,5 \mathrm{MgCl}_{2}$; 1 EGTA; 10 HEPES y 10 glucosa; el pH fue ajustado a 7,4 con una solución concentrada de $\mathrm{NaOH}$. En algunos experimentos se modificó la concentración del ion $\mathrm{Ca}^{2+}$ libre presente en la solución $\mathrm{B} 1(\mathrm{a} \mathrm{pH} 7,4)$ y en otros experimentos se varió el $\mathrm{pH}$ manteniendo la concentración de $\mathrm{Ca}^{2+}$ libre constante. Para calcular la cantidad de $\mathrm{CaCl}_{2}$ agregada a cada $\mathrm{pH}$ para lograr las distintas concentraciones del ion $\mathrm{Ca}^{2+}$ libre se utilizó un programa de cálculo personal.

$\checkmark \quad$ Solución de la pipeta (B2): Composición en mM: $140 \mathrm{KCl} ; 0,5 \mathrm{MgCl}_{2}$; $1 \mathrm{CaCl}_{2} ; 10$ HEPES y 10 glucosa; el pH fue ajustado a 7,4 con una solución concentrada de $\mathrm{NaOH}$.

$\checkmark \quad$ Solución alto potasio (SAK): Composición en mM: $130 \mathrm{KCl} ; 0.5$ $\mathrm{MgCl}_{2} ; 1 \mathrm{CaCl}_{2} ; 10$ HEPES y 10 glucosa; el pH fue ajustado a 7,4 con una solución concentrada de $\mathrm{NaOH}$. 


\section{2- Determinación de fuerza isométrica en anillos vasculares intactos}

\section{1- Consideraciones generales}

A partir de segmentos vasculares aislados de AUH y AMIH se obtuvieron anillos de aproximadamente $30 \mathrm{~mm}$ de largo. En el caso de la AMIH se obtuvieron entre 1 y 3 anillos por muestra y en el caso de la AUH 40 más por muestra. Los anillos vasculares son colocados en cámaras termostatizadas a $37^{\circ} \mathrm{C}$ sujetos mediante alambres rígidos en forma isométrica con uno de los extremos fijo y el otro conectado a un transductor de fuerza (Letica TRI 201; Letica Scientific Instruments, Barcelona, España).

Los anillos fueron sumergidos en las cámaras de aproximadamente $20 \mathrm{ml}$ de capacidad conteniendo la solución control de cada experimento y se estabilizaron durante 60 minutos, con o sin estiramiento según cada experimento, con cambios sucesivos de la solución control cada 20 minutos. En la mayoría de los experimentos los anillos se estiraron inicialmente hasta una señal de fuerza de 2 gF y en esas condiciones se estabilizaron durante 60 minutos. En otros experimentos se modificó la longitud inicial de estiramiento de los anillos con los micrómetros del equipo que permiten modificar cuantitativamente la longitud de estiramiento (mínima variación: $10 \mu \mathrm{m}$ ).

Las cámaras se termostatizaron en todos los experimentos a $37^{\circ} \mathrm{C}$ mediante un baño calefaccionado impulsado por una bomba y la solución fue burbujeada con una mezcla de $95 \%$ de $\mathrm{CO}_{2}$ y $5 \%$ de $\mathrm{O}_{2}$ (carbógeno) o con $\mathrm{O}_{2}$ según la solución utilizada en cada experimento (ver más adelante).

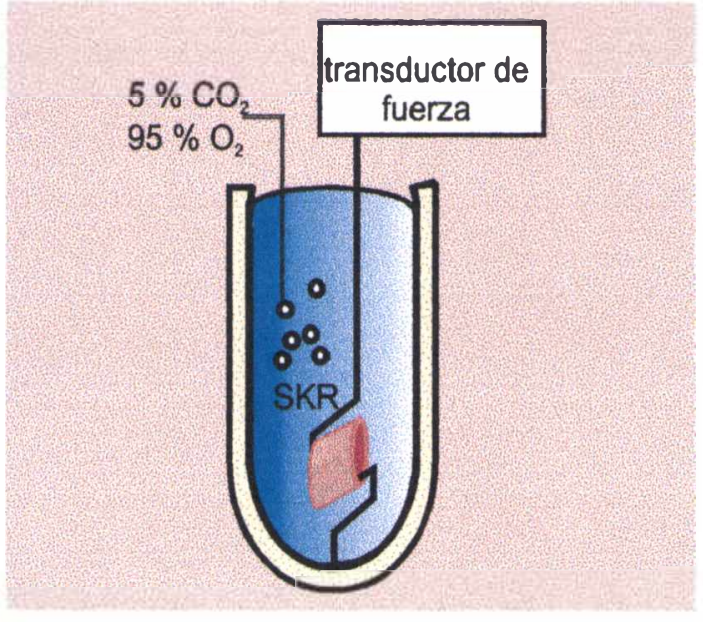

Esquema de la cámara experimental utilizada en los experimentos de determinación de fuerza en anillos vasculares aislados. 
En el laboratorio se cuenta con 4 cámaras experimentales y un amplificador de 4 canales (WPI). La fuerza desarrollada en las distintas intervenciones fue digitalizada con una placa adquisidora (DT16EZ o DT302, Data Translation Inc., Marlboro,MA) mediante el programa Labtech Notebook Pro (Laboratory Technology Corp., Wilmington, MA) y convertida por una placa conversora AVD (DT2801 Data Translation, Inc. Marlboro, MA) con visualización a tiempo real en la pantalla de una computadora. Los datos fueron grabados en el disco duro de la computadora para la posterior lectura de los registros. La recuperación de los registros y las determinaciones de fuerza de contracción y relajación se realizaron con un programa de cálculo adecuado (Origin 7.0). La fuerza desarrollada se expresó en $\mathrm{gF}$ en algunos experimentos, mientras que en la mayoría de las series experimentales se normalizó con el peso del anillo y se expresó como la fuerza desarrollada en gramos fuerza por gramo de tejido (gF/gT).

\section{2- Composición de las soluciones utilizadas}

\subsection{1-Experimentos en anillos vasculares de $\mathrm{AMIH}$}

Solución extracelular normal (SEN): Composición en mM: $150 \mathrm{NaCl}$; $5,4 \mathrm{KCl} ; 1,2 \mathrm{MgCl}_{2} ; 1 \mathrm{CaCl}_{2} ; 20$ glucosa y $5 \mathrm{HEPES}$; el pH fue ajustado a 7,4 con una solución concentrada de $\mathrm{NaOH}$. Esta solución se burbujea con $\mathrm{O}_{2}$.

En algunos experimentos se utilizó esta solución a distintos valores de $\mathrm{pH}$, el cual fue ajustado a 6,8 o 7,8 modificando las alícuotas de solución concentrada de $\mathrm{NaOH}$ utilizadas para llevar a pH la solución.

En otros experimentos se reemplazaron $20 \mathrm{mM}$ de $\mathrm{NaCl}$ por $\mathrm{NH}_{4} \mathrm{Cl}$ o por propionato de sodio en forma isosmótica.

\subsection{2- Experimentos en anillos vasculares de $\mathrm{AUH}$}

Solución Krebs-Ringer bicarbonato (KRB): Composición en mM: $130 \mathrm{NaCl}$; $4,7 \mathrm{KCl} ; 24 \mathrm{NaCO}_{3} \mathrm{H} ; 1,17 \mathrm{Na}_{2} \mathrm{PO}_{4} \mathrm{H} ; 1,16 \mathrm{MgSO}_{4} ; 1,6 \mathrm{CaCl}_{2}$ y 11 glucosa. Esta solución se burbujea con carbógeno obteniéndose a $37^{\circ} \mathrm{C}$ un valor de pH de 7,4.

Solución $\mathrm{KRB}$ con baio $\mathrm{Na}^{+}\left(\mathrm{KRB}\right.$ bajo $\left.\mathrm{Na}^{+}\right)$: solución $\mathrm{SKR}$ en la cual el $\mathrm{NaCl}$ fue isosmóticamente reemplazado por $\mathrm{D}(+)$-sacarosa. Composición en $\mathrm{mM}: 260$ $\mathrm{D}(+)$-sacarosa; $4,7 \mathrm{KCl} ; 24 \mathrm{NaCO}_{3} \mathrm{H} ; 1,17 \mathrm{Na}_{2} \mathrm{PO}_{4} \mathrm{H} ; 1,16 \mathrm{MgSO}_{4} ; 1,6 \mathrm{CaCl}_{2}$ y 11 glucosa. Burbujeada con carbógeno $\left(37^{\circ} \mathrm{C}, \mathrm{pH}: 7,4\right)$. 
Solución KRB con alto maanesio (KRB-alto $\mathrm{Mq}^{2+}$ ): solución SKR en la cual el $\mathrm{MgSO}_{4}$ fue aumentado a $5 \mathrm{mM}$. Composición en mM: $126 \mathrm{NaCl} ; 4,7 \mathrm{KCl} ; 24$ $\mathrm{NaCO}_{3} \mathrm{H} ; 1,17 \mathrm{Na}_{2} \mathrm{PO}_{4} \mathrm{H} ; 5 \mathrm{MgSO}_{4} ; 1,6 \mathrm{CaCl}_{2}$ y 11 glucosa. Burbujeada con carbógeno $\left(37^{\circ} \mathrm{C}, \mathrm{pH}: 7,4\right)$.

Solución KRB sin $\mathrm{CaCl}_{2}\left(\right.$ KRB $\left.\sin \mathrm{Ca}^{2+}\right)$ : solución SKR sin el agregado de $\mathrm{CaCl}_{2}$. Composición en mM: $130 \mathrm{NaCl} ; 4,7 \mathrm{KCl} ; 24 \mathrm{NaCO}_{3} \mathrm{H} ; 1,17 \mathrm{Na}_{2} \mathrm{PO}_{4} \mathrm{H} ; 5$ $\mathrm{MgSO}_{4}$; y 11 glucosa. Burbujeada con carbógeno $\left(37^{\circ} \mathrm{C}, \mathrm{pH}: 7,4\right)$.

Solución KRB con distintas concentraciones de KCl: solución SKR en la cual se reemplaza el $\mathrm{NaCl}$ isosmóticamente por distintas concentraciones de $\mathrm{KCl}(20$, 40, 60 y $80 \mathrm{mM}$ ). Estas soluciones se denominaron SKR-20 mM K', SKR-40 mM $\mathrm{K}^{+}, \mathrm{SKR}-60 \mathrm{mM} \mathrm{K}^{+}$y SKR-80 $\mathrm{mM} \mathrm{K}^{+}$respectivamente y fueron burbujeada con carbógeno $\left(37^{\circ} \mathrm{C}, \mathrm{pH}: 7,4\right)$.

\section{3- Determinación de presión de perfusión en seqmentos vasculares} intactos

\section{1- Consideraciones generales}

Este tipo de determinaciones se realizaron mediante el siguiente método experimental: un segmento de cordón umbilical de $3-4 \mathrm{~cm}$ se coloca en una cápsula de Petri con solución KRB. Se diseca cuidadosamente una longitud de aproximadamente $1 \mathrm{~cm}$ de una de las arterias umbilicales y se la canula con un cateter de Tygon (0,06 pulgadas de diámetro). Se coloca el cordón canulado en una platina termostatizada y se lo perfunde con una bomba peristaltica tipo Masterflex $\mathrm{C} / \mathrm{L}$, mientras se mide continuamente la presión de perfusión con un transductor de presión (Gould-Statham P23Gb) conectado a la línea de perfusión justo antes del punto de canulación. La solución efluente del extremo no canulado de la arteria se recoge en un reservorio de $15 \mathrm{ml}$ de capacidad suspendido de un transductor de fuerza. Las señales de presión y fuerza se amplifican y adquieren mediante una plaqueta analógico-digital conectada a una computadora, donde se almacenan para posterior análisis. Se obtiene la derivada de la señal del transductor de fuerza (peso del líquido del reservorio), lo que provee una estimación muy precisa del flujo de perfusión en forma continua. El cociente entre la presión de perfusión y el flujo permite calcular continuamente la resistencia al flujo ejercida por la arteria umbilical. Un experimento típico consiste en estabilizar 
el preparado durante 60 minutos al menor flujo de perfusión posible $(\approx 0,7 \mathrm{ml} / \mathrm{min})$, y luego modificar la solución de perfusión o la velocidad de perfusión para observar posibles cambios en la resistencia de la arteria.

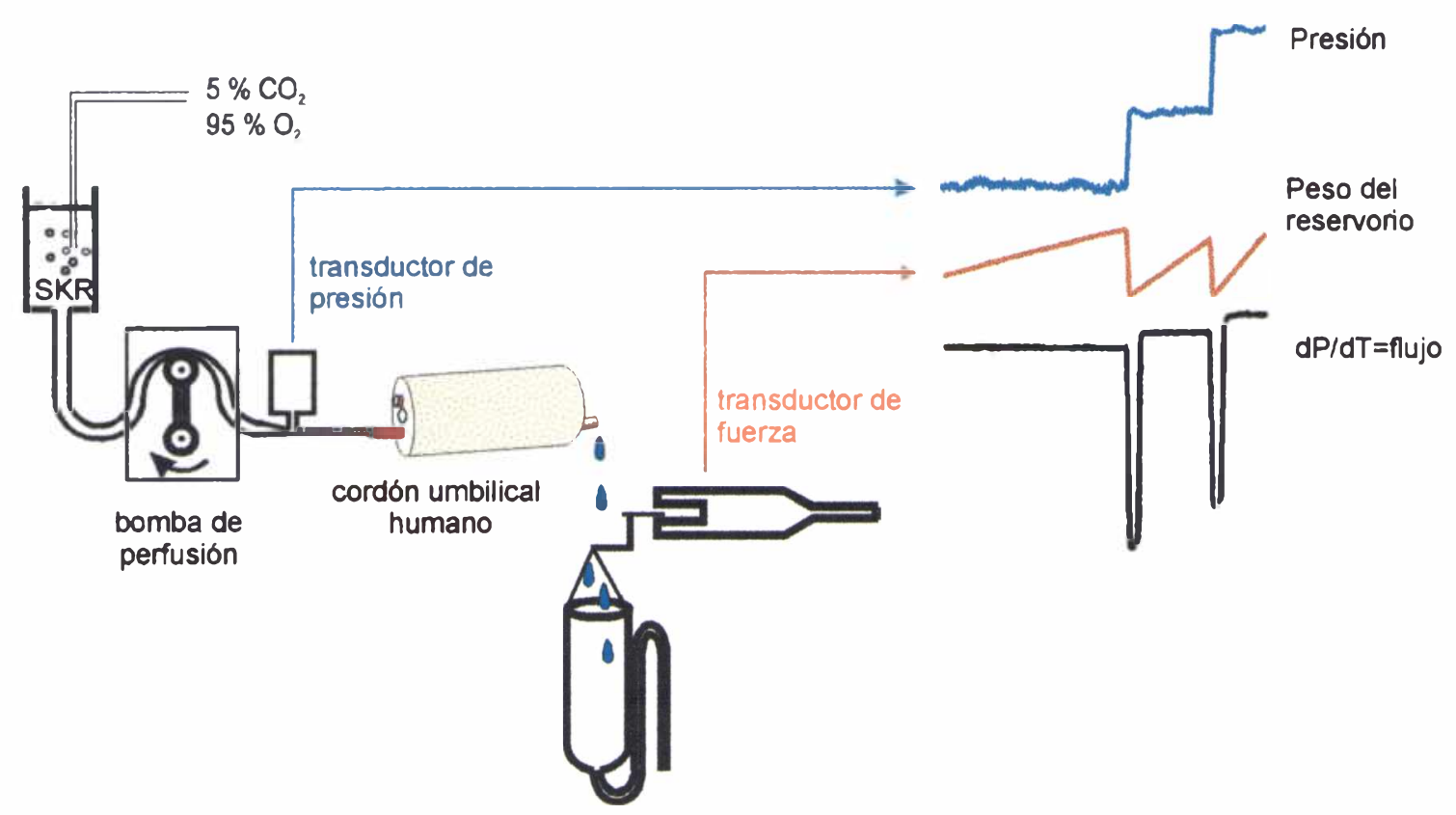

Esquema del equipo utilizado para la determinación de presión de perfusión en segmentos vasculares intactos.

\section{2- Soluciones utilizadas}

Solución Krebs-Ringer bicarbonato (KRB): Ver composición en 2.4.2. Burbujeada con carbógeno $\left(37^{\circ} \mathrm{C}, \mathrm{pH}: 7,4\right)$. En algunos experimentos se varió la concentración de $\mathrm{CaCl}_{2}$ de 1,6 a 0,$4 ; 0,8$ o $1,2 \mathrm{mM}$.

Solución KRB sin $\mathrm{CaCl}_{2}$ (KRB sin $\mathrm{Ca}^{2+}$ ): Ver composición en 2.4.2. Burbujeada con carbógeno $\left(37^{\circ} \mathrm{C}, \mathrm{pH}: 7,4\right)$.

Solución KRB con $80 \mathrm{mM}$ de $\mathrm{K}^{+}\left(\mathrm{KRB}-80 \mathrm{mM} \mathrm{K}{ }^{+}\right.$): Ver composición en 2.4.2. Burbujeada con carbógeno $\left(37^{\circ} \mathrm{C}, \mathrm{pH}: 7,4\right)$.

\section{4- Droaas v reactivos utilizados}

Las siguientes drogas fueron adquiridas en Sigma Chemical Co.:

Cloruro de tetraetilamonio (TEA), 4-aminopiridina (4-AP), iberiotoxina (IBTX), floretina, ácido etilenglicol-bis( $\beta$-aminoetil eter) $N, N, N^{\prime}, N^{\prime}$,-tetraacetico (EGTA), apamina, Tris(hydroxymethyl)aminoethane (Trizma base), $\mathrm{Na}_{2} \mathrm{ATP}$, nitroprusiato de sodio (SNP), Br-GMPc, GMPc, nifedipina, $\mathrm{CsCl}, \mathrm{BaCl}_{2}, \mathrm{NiCl}_{2}, \mathrm{GdCl}_{3}, \mathrm{LaCl}_{3}$, $\mathrm{MgCl}_{2}$, y todas las enzimas utilizadas en las disociaciones celulares. La sustancia 
mesilato de KB-R7943 fue de marca Tocris Inc. Todas las demás drogas utilizadas fueron de grado analítico.

Alícuotas de soluciones acuosas concentradas de TEA, IBTX, apamina, $\mathrm{KBR}$, floretina, SNP, Br-GMPc, BaCl $2, \mathrm{GdCl}_{3}, \mathrm{LaCl}_{3}$ y $\mathrm{MgCl}_{2}$ fueron adicionadas a las soluciones correspondientes en el momento del experimento. En los experimentos donde se utilizó nifedipina y nitrendipina se procedió igual pero la solución concentrada fue preparada en dimetil-sulfóxido (DMSO).

\section{5- Análisis estadístico}

Los resultados son expresados como valor medio \pm ESM en todos los gráficos de este trabajo. El análisis estadístico utilizado dependió del protocolo experimental. Si los grupos comparados eran solo dos se usó un Test de Student no paramétrico $(t)$ : apareado, cuando los valores a comparar son de la misma célula o el mismo anillo (antes y después de una intervención experimental) y no apareado cuando los valores comparados corresponden a distintas muestras.

Se utilizó análisis ANOVA de una vía (no paramétrico) seguido por un Test de Tukey para comparar medias de más de dos grupos experimentales. En el caso de comparar varios grupos contra un mismo grupo control se utilizó un Test de Dunnett.

Se utilizaron los programas Prism 3.0 y Sigma-stat para realizar estas pruebas estadisticas.

Para estudiar la independencia entre grupos de células de AMIH tratadas y no tratadas con IBTX se utilizó un test paramétrico de Chi-cuadrado.

Se utilizó siempre un nivel de significancia con $p<0.05$. 


\section{RESULTADOS}

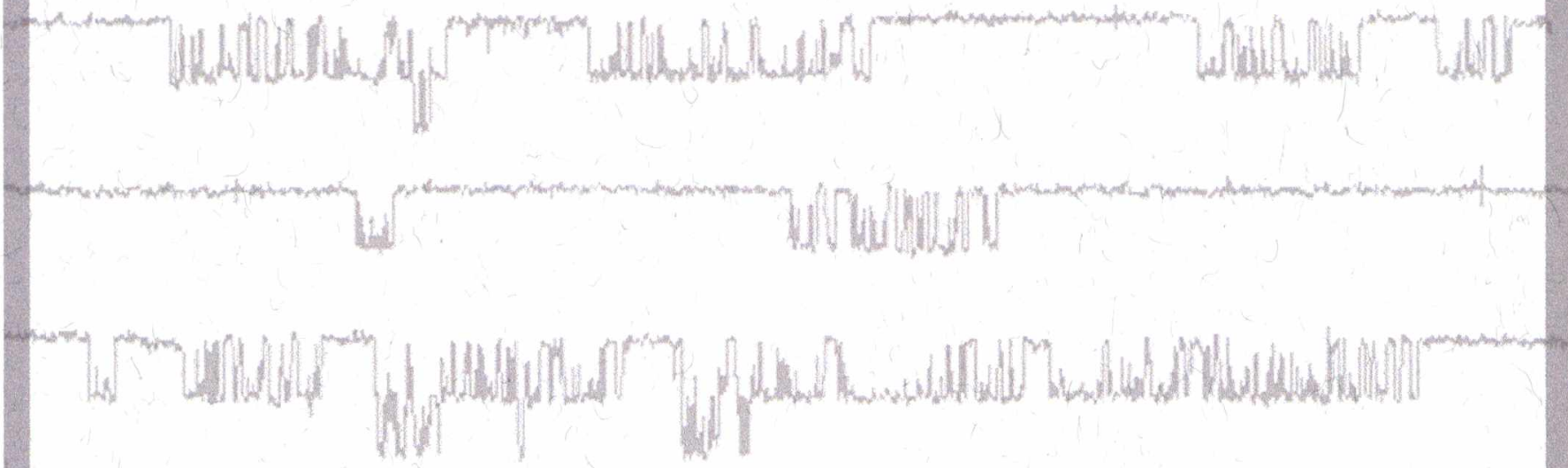




\section{Caracterización electrofisiológica de células de músculo liso aisladas de arteria umbilical humana (AUH)}

\section{Registros de corrientes iónicas macroscópicas}

La caracterización electrofisiológica de las células de músculo liso de AUH comenzó con una primera etapa donde se realizó el estudio de las corrientes iónicas macroscópicas evocadas por cambios en el potencial de membrana. Se aislaron las células mediante disociación enzimática, y se perfundieron con una solución extracelular normal (SEN). En estas condiciones se registraron las corrientes iónicas totales mediante la aplicación de protocolos de fijación de voltaje en configuración de célula entera o W-C (del inglés "whole-cell") utilizando una solución intracelular normal con un contenido de $\mathrm{Ca}^{2+}$ libre de $100 \mathrm{nM}$ (SIN). Estas soluciones permiten trabajar en condiciones iónicas similares a las fisiológicas y, la composición iónica de las mismas, ha sido detallada en la sección "materiales y métodos".

En los protocolos de fijación de voltaje utilizados en la primera serie de experimentos se mantuvieron las células en un valor de potencial de $-60 \mathrm{mV}$ (denominado potencial de mantenimiento) a partir del cual se aplicaron estímulos de voltaje en el rango de valores entre -140 y $+120 \mathrm{mV}$ en incrementos de $10 \mathrm{mV}$. En respuesta a este protocolo, a partir de valores de estímulo de $-50 \mathrm{mV}$, las células de músculo liso de AUH evocaron una familia de corrientes iónicas positivas (salientes) cuya amplitud y cinética fueron dependientes del voltaje y del tiempo. En un alto porcentaje de células se observó también a potenciales negativos entre -50 y $-140 \mathrm{mV}$, la presencia de corrientes negativas (entrantes) independientes del tiempo y del voltaje. La figura $1 \mathrm{~A}$ muestra un ejemplo típico de todas las corrientes salientes y entrantes evocadas por el protocolo de voltaje La dependencia de la amplitud de la corriente con el voltaje se muestra en la figura $1 \mathrm{~B}$, este gráfico se denomina curva corriente-voltaje o $\mathrm{I}-\mathrm{V}$ y muestra, para los valores de potencial entre -50 y $+80 \mathrm{mV}$, una relación de tipo exponencial creciente, típica de corrientes iónicas a través de canales sensibles al voltaje, activados por la despolarización. A valores mayores que $+80 \mathrm{mV}$, se observa una 
disminución en la amplitud de la corriente, característica de corrientes sensibles al $\mathrm{Ca}^{2+}$ intracelular. Sin embargo, en la región de valores de potencial más negativos que $-50 \mathrm{mV}$, la curva presenta una relación lineal característica de corrientes cuya activación es independiente del voltaje. Esta curva nos permite además obtener un valor estimado del valor de potencial de membrana de reposo $(\mathrm{Vm})$, ya que el mismo se corresponde con el punto de corriente total igual a cero de la curva. En estas células el valor obtenido por interpolación de esta curva fue de $-51 \mathrm{mV}$.

A

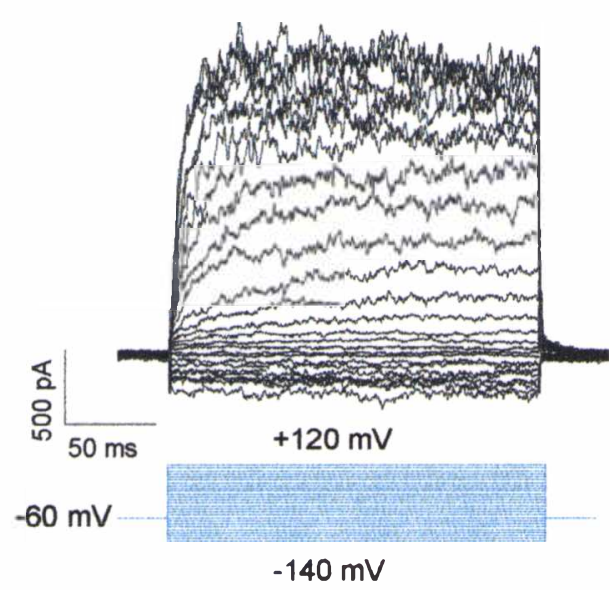

B

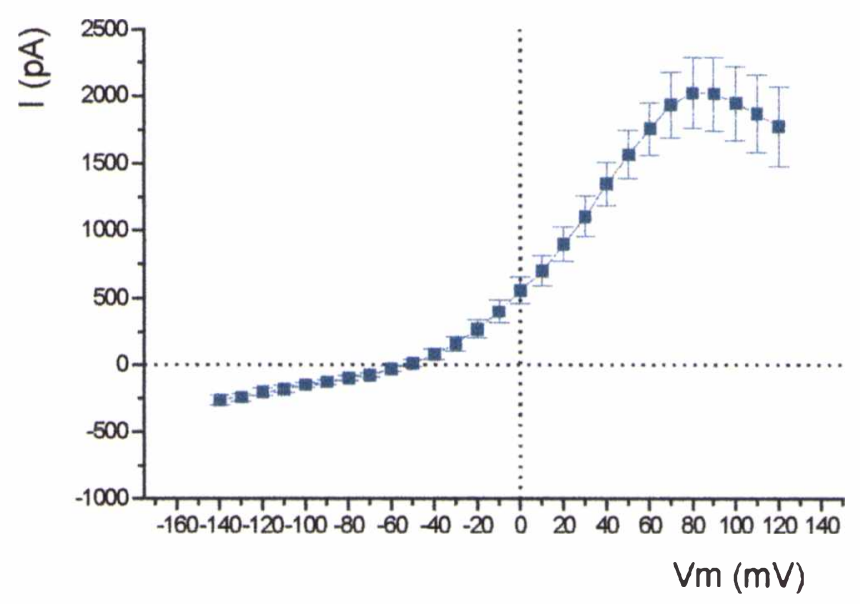

Figura 1: A- Ejemplo tipico de registro de corriente total, evocada por pulsos de voltaje en el rango de valores entre $-140 \mathrm{y}+120 \mathrm{mV}$ en incrementos de $10 \mathrm{mV}$ desde un potencial de mantenimiento de $-60 \mathrm{mV}$. B- Curva I-V promedio en las mismas condiciones que en $\mathrm{A}$, corriente medida al final del pulso ( $n=61$ células de 26 cordones umbilicales).

La dependencia del tiempo de las corrientes salientes se cuantificó determinando la cinética de activación de la corriente evocada por el pulso de voltaje de $+60 \mathrm{mV}$ durante los primeros $130 \mathrm{~ms}$. Se eligió dicho tiempo ya que se observó que el estímulo de voltaje instantáneo genera una corriente que tiene una primer fase de crecimiento que dura aproximadamente $150 \mathrm{~ms}$ para luego alcanzar un valor estable durante el resto del pulso. Se ajustaron los valores de corriente en función del tiempo con una curva exponencial de primer orden y se obtuvo así la constante de tiempo $\left(\tau_{60}\right)$ como parámetro cuantitativo de la cinética de activación de la corriente total (figura $2 \mathrm{~A}$ ). Los valores de $\tau_{60}$ hallados resultaron variables entre las distintas células ensayadas, obteniéndose valores en el rango de 1 a 57,6 ms. La dispersión en los valores de $\tau_{60}$ se observó aún en células pertenecientes a una misma muestra de $\mathrm{AUH}$. En la figura $2 \mathrm{~B}$ se puede observar 
la frecuencia de distribución de este parámetro hallado en las distintas células estudiadas.

\section{A}

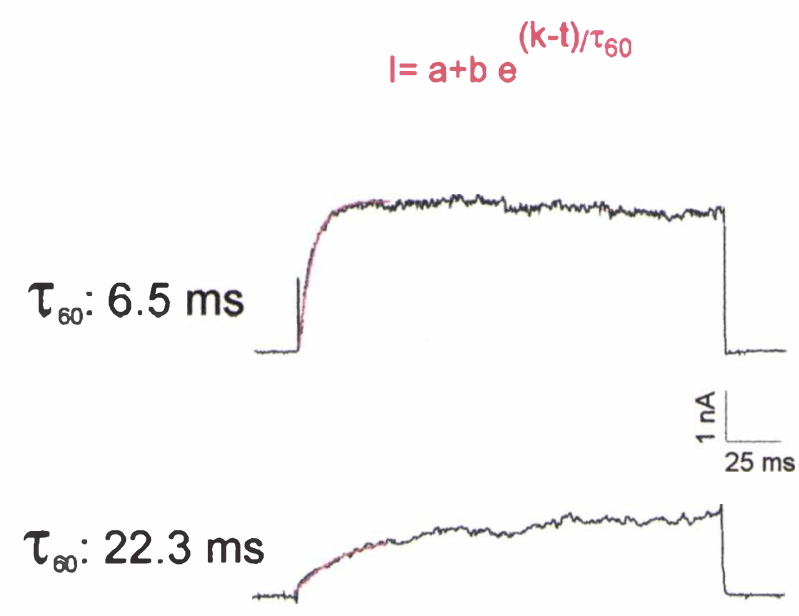

B

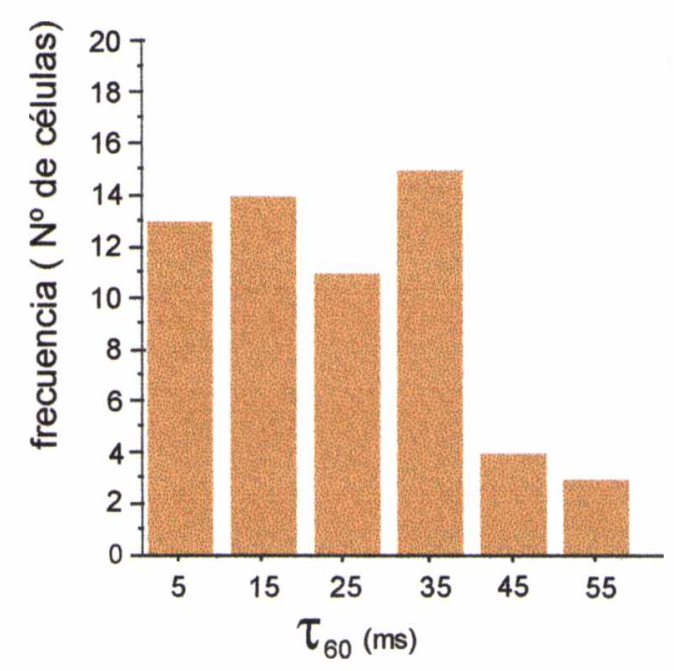

Figura 2: A- Ajuste exponencial de primer orden de los primeros $130 \mathrm{~ms}$ de registros típicos de corriente total a $+60 \mathrm{mV}$. B. Frecuencia de distribución de la constante de tiempo $\left(\tau_{60}\right)$ de las distintas células ensayadas ( $n=61$ células de 26 cordones umbilicales).

En todas las células se obtuvo el valor de la capacitancia de la membrana celular utilizando el circuito que ofrece para este fin el amplificador de señales. Esta herramienta permite compensar eléctricamente la componente capacitiva de la corriente evocada por un pulso de potencial y a partir de ese valor obtener la capacitancia de la célula $\left(\mathrm{C}_{\mathrm{m}}\right)$. Este es un parámetro importante ya que depende del área de la membrana celular (según se detalló en la sección de materiales y métodos) y permite obtener una estimación del tamaño celular, así como calcular las propiedades bioeléctricas celulares referidas al área total de membrana (densidad de corriente, densidad de canales etc.). En nuestros experimentos los valores de capacitancia obtenidos en las células ensayadas fueron homogéneos $(32,7 \pm 1,2 \mathrm{pF}, \mathrm{n}=61)$, indicando que no existiría diferencia en el valor del área total de la membrana entre las células. 
Caracterización farmacológica: La corriente total evocada por el protocolo de voltaje anteriormente descripto fue sensible a los bloqueantes inespecificos de canales de potasio $20 \mathrm{mM}$ de tetraetilamonio (TEA) y $1 \mathrm{mM}$ de BaCl . La presencia de TEA (SE-20 mM TEA) o de $\mathrm{BaCl}_{2}$ en la solución de perfusión produjo, sobre la corriente total evocada por un pulso a $+60 \mathrm{mV}$, un efecto inhibitorio de $82,1 \pm 6,8$ $\%(n=6, p<0.05)$ y $86,0 \pm 5,0 \%(n=5, p<0.05)$, respectivamente. Este resultado indica que la mayor parte de la corriente saliente en estas células es llevada por el ion $\mathrm{K}^{+}$. Para confirmar esto, y conociendo que el ión $\mathrm{Cs}^{+}$es incapaz de permear a través de los canales selectivos para el $\mathrm{K}^{+}$, se realizaron experimentos utilizando $\mathrm{Cs}^{+}$como principal ión en la solución intracelular (SICs). En estas condiciones se obtuvieron corrientes de menor amplitud, independientes del tiempo y del voltaje en respuesta al mismo protocolo de voltaje. (Corriente evocada en $\mathrm{Cs}^{+}$vs $\mathrm{K}^{+}: 176$ \pm 38 vs $2101 \pm 615 \mathrm{pA}, a+60 \mathrm{mV}, n=11$ células, $p<0.05$ ). En la figura 3 se muestran corrientes típicas evocadas por el mismo protocolo de voltaje utilizando $\mathrm{K}^{+} \circ \mathrm{Cs}^{+}$como principal ion intracelular; en la misma se pueden observar las características (amplitud, dependencia del voltaje y del tiempo) de las corrientes evocadas.
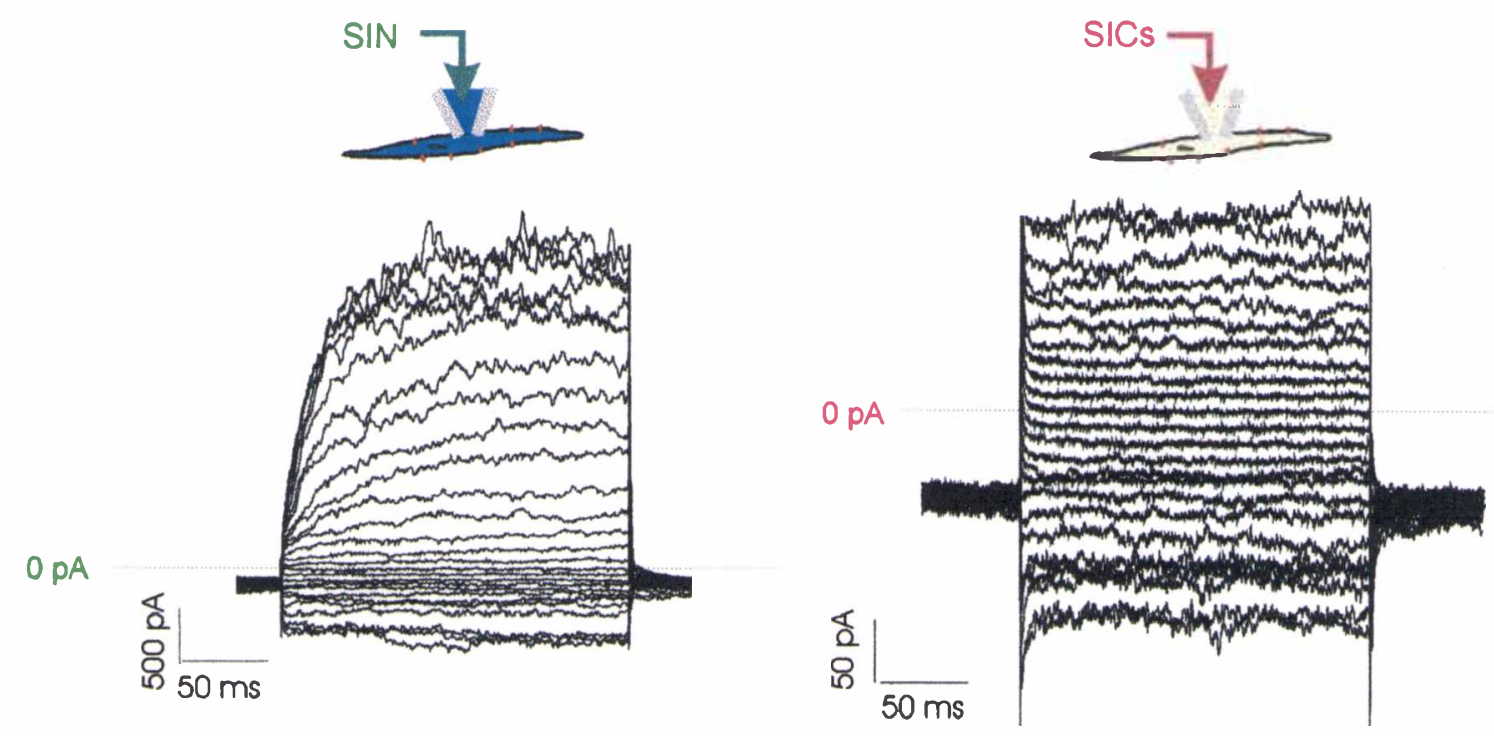

Figura 3: Ejemplos típicos de corriente total, utilizando $\mathrm{K}^{+} \circ \mathrm{Cs}^{+}$como principal catión intracelular, evocada por pulsos de voltaje en el rango de valores entre -140 y $+100 \mathrm{mV}$ en incrementos de $10 \mathrm{mV}$ desde un potencial de mantenimiento de $-40 \mathrm{mV}$. 
En base a las características de las corrientes totales encontradas se decidió estudiar en primera instancia los canales de $\mathrm{K}^{+}$responsables de la corriente total y en una segunda etapa estudiar las propiedades de la corriente que se observa cuando el ión $\mathrm{K}^{+}$ha sido reemplazado por el ión $\mathrm{Cs}^{+}$. Por lo tanto, utilizando las condiciones iónicas cercanas a las fisiológicas descritas anteriormente (soluciones SIN y SEN) se investigó la presencia de corrientes de $\mathrm{K}^{+}$transitorias, denominadas con las siglas $I_{T O} O I_{A}$ en el músculo cardíaco y liso y también $I_{A}$ en las neuronas. Estas corrientes presentan como características generales una cinética de activación rápida que lleva a un máximo de corriente y luego decae en el tiempo debido a la inactivación rápida de los canales iónicos responsables de la misma. Utilizando protocolos de fijación de voltaje adecuados se pueden poner en evidencia este tipo de corrientes. El protocolo que se aplicó en este caso despolarizaba a la célula mediante pulsos de voltaje de $+60 \mathrm{mV}$, precedidos por un pulso de potencial de condicionamiento de 1 segundo a valores entre -100 y -20 $\mathrm{mV}$ con incrementos de $20 \mathrm{mV}$; los prepulsos de condicionamiento permiten la remoción de la inactivación de canales iónicos que presenten la propiedad de inactivarse con la despolarización, como es el caso de los canales que median la corriente $I_{\text {TO }}$. Los resultados obtenidos en células de músculo liso de AUH no mostraron evidencias electrofisiológicas de corrientes de este tipo y un ejemplo típico de este experimento se muestra en la figura 4 , este comportamiento se repitió en todas las células donde se aplicó dicho protocolo ( $n=15)$.

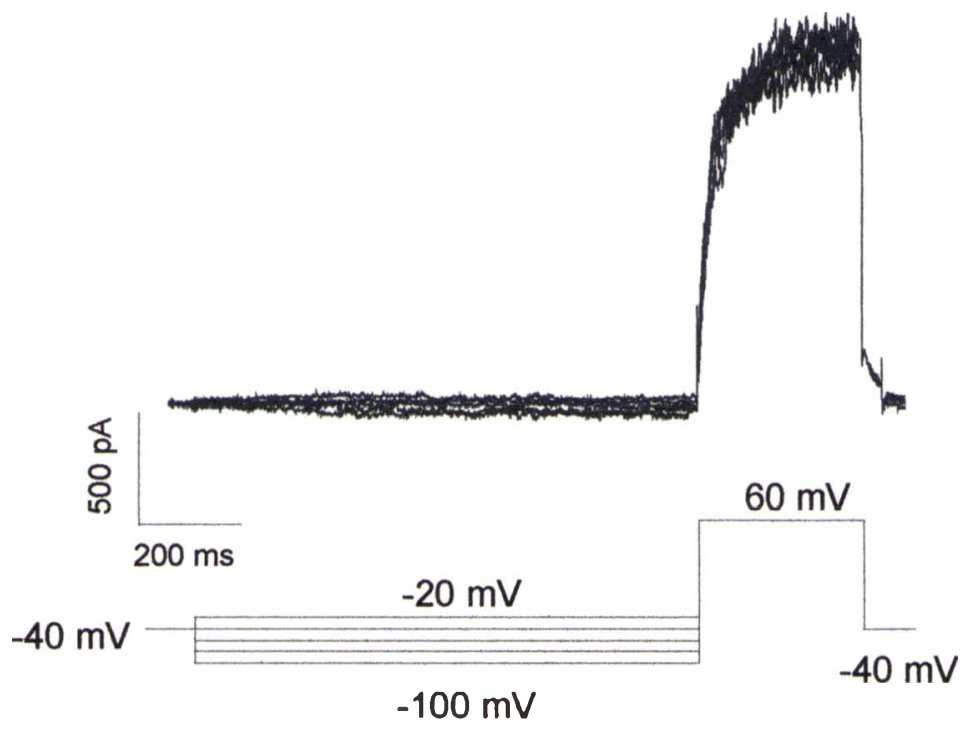

Figura 4: Ejemplo típico del protocolo para corrientes tipo ITO 
La presencia de canales de $\mathrm{K}^{+}$de tipo $\mathrm{K}_{\mathrm{v}}$ y $\mathrm{BK}_{\mathrm{Ca}}$ se estudió mediante el uso de diferentes drogas comúnmente utilizadas como bloqueantes de los distintos tipos de canales de $\mathrm{K}^{+}$en células de músculo liso vascular (111).

La sustancia 4- aminopiridina (4-AP) a una concentración de $5 \mathrm{mM}$ es una base débil utilizada en numerosos trabajos para bloquear la corriente de $\mathrm{K}^{+}$de tipo $K_{D R}\left(K_{D R}\right)$ en células de músculo liso vascular. Se estudió el efecto de este bloqueante sobre las corrientes totales evocadas por pulsos de voltaje desde -80 hasta $+60 \mathrm{mV}$ aplicados en incrementos de $10 \mathrm{mV}$ desde un potencial de mantenimiento de $-60 \mathrm{mV}$ en condiciones control (soluciones SIN y SEN) y luego de la perfusión de la células con una solución que contiene $5 \mathrm{mM}$ de 4-AP (SE- 5 mM 4-AP). Los resultados obtenidos fueron los siguientes:

* En 7 células que presentaban una corriente total con cinética de activación rápida con un valor promedio de $\tau_{60}$ de $12,8 \pm 3,2 \mathrm{~ms}$, la 4-AP $(5 \mathrm{mM})$ inhibió significativamente la corriente evocada por pulsos de voltaje en el rango de -30 a $+60 \mathrm{mV}(92 \pm 4 \%$ de bloqueo a $0 \mathrm{mV}, \mathrm{p}<0.05)$. La figura $5 \mathrm{~A}$ muestra un ejemplo típico del efecto inhibitorio de la 4-AP sobre un registro de corriente total y la curva $\mathrm{I}-\mathrm{V}$ promedio en condiciones control y en presencia de la droga.

* En 9 células que presentaban una corriente total con cinética de activación lenta ( $\tau_{60}$ media: $27,2 \pm 5,2 \mathrm{~ms}, p<0.05$ comparada con el primer grupo) la 4-AP 5 $\mathrm{mM}$ no produjo bloqueo y aumentó significativamente la amplitud de la corriente evocada por potenciales en el rango de $+10 \mathrm{a}+60 \mathrm{mV}(108 \pm 40 \%$ de aumento de la corriente a $+60 \mathrm{mV}, \mathrm{p}<0.05$ ).

Cuando se ensayó la 4-AP a concentraciones menores $(0.3$ y $1 \mathrm{mM})$ no se observó ningún efecto significativo sobre las corrientes.

En segundo lugar se estudió el efecto del TEA, el cual a bajas concentraciones (hasta $1 \mathrm{mM}$ ) es utilizado como bloqueante de canales de tipo $\mathrm{BK}_{\mathrm{Ca}}$ en células de músculo liso vascular $(111,212)$. En la $\mathrm{AUH}, \mathrm{TEA} 1 \mathrm{mM}$ redujo la corriente total en $71 \pm 4 \%$ medida a $+60 \mathrm{mV}(n=4$ células, $p<0.05)$, mientras que una concentración menor $(0.1 \mathrm{mM})$ no logró inhibirla significativamente. La figura 5B muestra un ejemplo típico del efecto inhibitorio del TEA $1 \mathrm{mM}$ sobre un registro de corriente total y la curva I-V promedio en condiciones control y en presencia de la droga. 


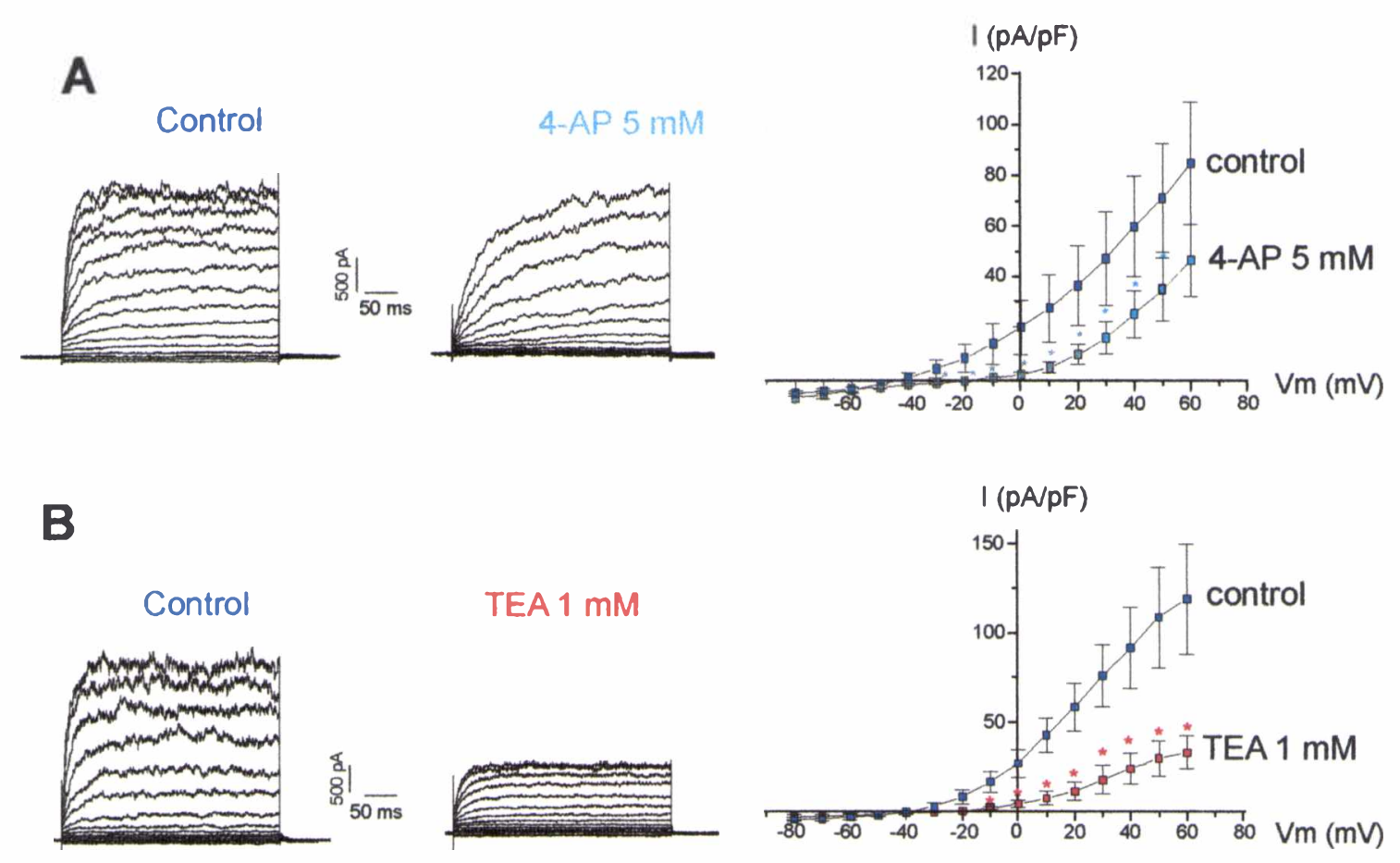

Figura 5: A- Ejemplo típico del efecto inhibitorio de la 4-AP (5 mM) sobre un registro de corriente total y curva I-V en condiciones control y en presencia de la droga, Corriente medida al final del pulso y normalizada por la capacitancia de la célula. (" indica diferencia significativa del valor en condición control, $n=7$ células). B- Ejemplo típico del efecto inhibitorio de TEA (1 mM) sobre un registro de corriente total y curva I-V promedio (iguales condiciones que en $5 \mathrm{~A}$ ) en condiciones control y en presencia de la droga. (" indica diferencia significativa del valor en condición control, $\mathrm{n}=4$ células).

La IBTX es una toxina que posee alta especificidad para inhibir el canal de tipo $\mathrm{BK}_{\mathrm{ca}}$. Utilizada en una concentración de $100 \mathrm{nM}$ redujo significativamente la corriente total en un $32 \pm 9 \%$ en 4 de 7 células ensayadas, mientras que en las otras 3 células no tuvo efecto. Se realizaron experimentos adicionales aumentando la dosis de IBTX a $200 \mathrm{nM}$ y exponiendo primero las células a 4-AP 5 $\mathrm{mM}$, observándose que en estas condiciones IBTX inhibió la corriente en todas las células ensayadas $(64 \pm 7 \%$ de inhibición medido a $+60 \mathrm{mV}, \mathrm{p}<0.05, n=4$ células, figura $6 \mathrm{~A}$ ). En estos experimentos, y a partir del cálculo de la pendiente de la curva I-V para la corriente sensible a IBTX, se obtuvo la conductancia total de la célula (a valores de potencial despolarizados de $+30 \mathrm{a}+60 \mathrm{mV}$ ) para el canal de tipo BK $\mathrm{BK}_{\text {ca. }}$ El valor obtenido fue de 1207,5 $\pm 58,2$ pS/pF (figura 6B). 
B

control

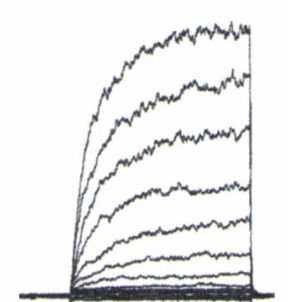

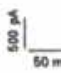

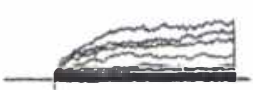

IBTX $200 \mathrm{nM}$
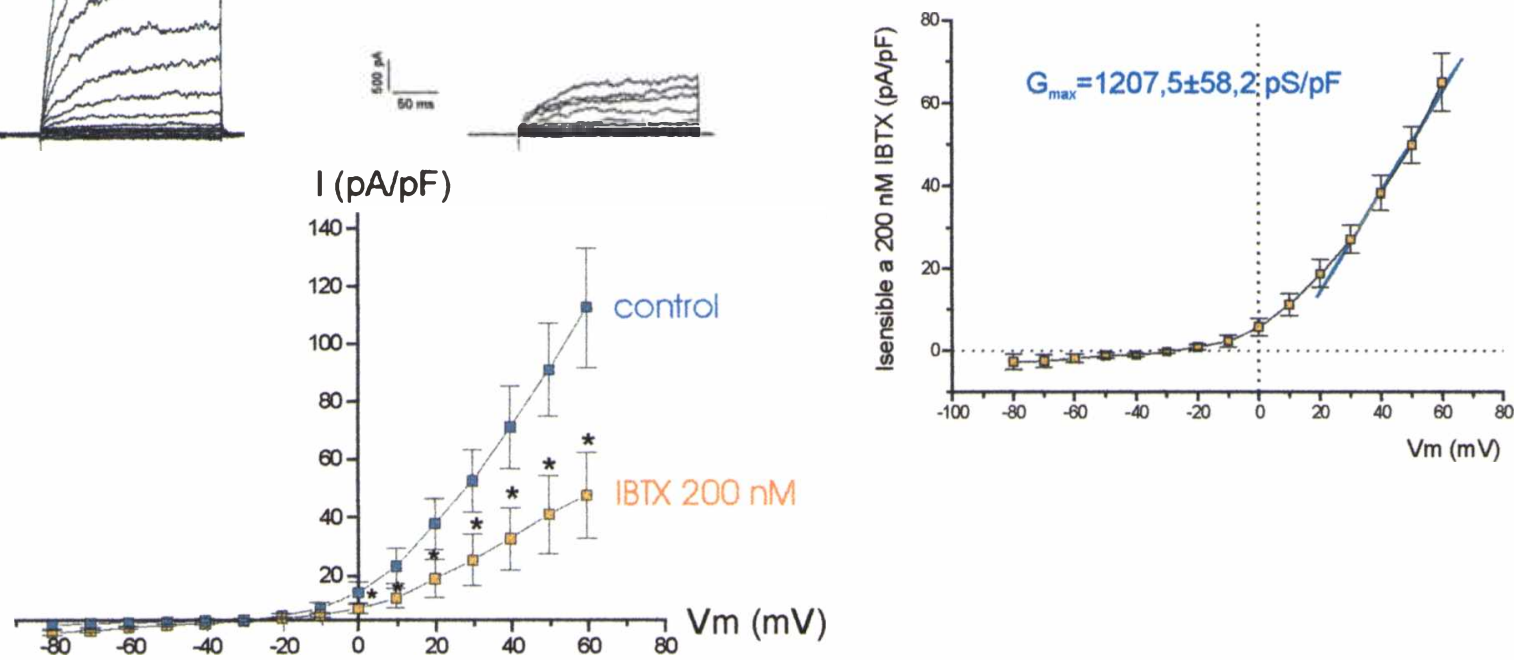

Figura 6: A- Ejemplo típico del efecto inhibitorio de IBTX (200 nM) sobre un registro de corriente total y la curva I-V promedio en condiciones control y en presencia de la droga. Corriente medida al final del pulso y normalizada por la capacitancia de la célula. ( ${ }^{*}$ indica diferencia significativa del valor en condición control, $n=4$ células). B- Curva I-V promedio para la corriente sensible a IBTX ( $n=4$ células). Ajuste lineal entre los potenciales de +30 a $+60 \mathrm{mV}$ para obtener la conductancia total de la célula para el canal de tipo BK

Se evaluó también la presencia de canales de $\mathrm{K}^{+}$de tipo $\mathrm{SK}_{\mathrm{Ca}}$ estudiando sobre la corriente total el efecto de apamina $100 \mathrm{nM}$, una toxina que bloquea específicamente este tipo de canal. Los resultados muestran que dicha toxina no tiene efecto en estas células ( $I_{\text {apamina }}=108 \pm 20 \mathrm{pA} / \mathrm{pF}, I_{\text {control }}=110 \pm 24 \mathrm{pApF}, a$ $+60 \mathrm{mV}, \mathrm{n}=7, \mathrm{~N} . \mathrm{S}$.).

Tal como se mostró en la figura 3 cuando en configuración W-C se inhiben por completo las corrientes de $\mathrm{K}^{+}$(mediante la utilización de $\mathrm{Cs}^{+}$como catión intracelular principal) las células de músculo liso de AUH presentan una corriente independiente del tiempo y del voltaje cuyas características se presentan a continuación:

La aplicación de una serie de pulsos de voltaje desde -140 hasta $+100 \mathrm{mV}$ a partir de un potencial de mantenimiento de $-40 \mathrm{mV}$ evocó una familia de corrientes cuya amplitud y cinética de activación son independientes del tiempo y del voltaje aplicado, si bien se puede observar que la amplitud posee una pequeña dependencia del potencial a valores muy negativos. La relación I-V promedio 
obtenida en estas condiciones es lineal y presenta un valor promedio de potencial de reversión cercano a $0 \mathrm{mV}(-2,1 \pm 1,2 \mathrm{mV}, \mathrm{n}=15$ células). El potencial de reversión indica el valor de potencial al cual la corriente neta a través de la membrana es igual a cero.

En la figura 7 se muestra la curva I-V promedio correspondiente a las células ensayadas en presencia de $\mathrm{Cs}^{+}$.

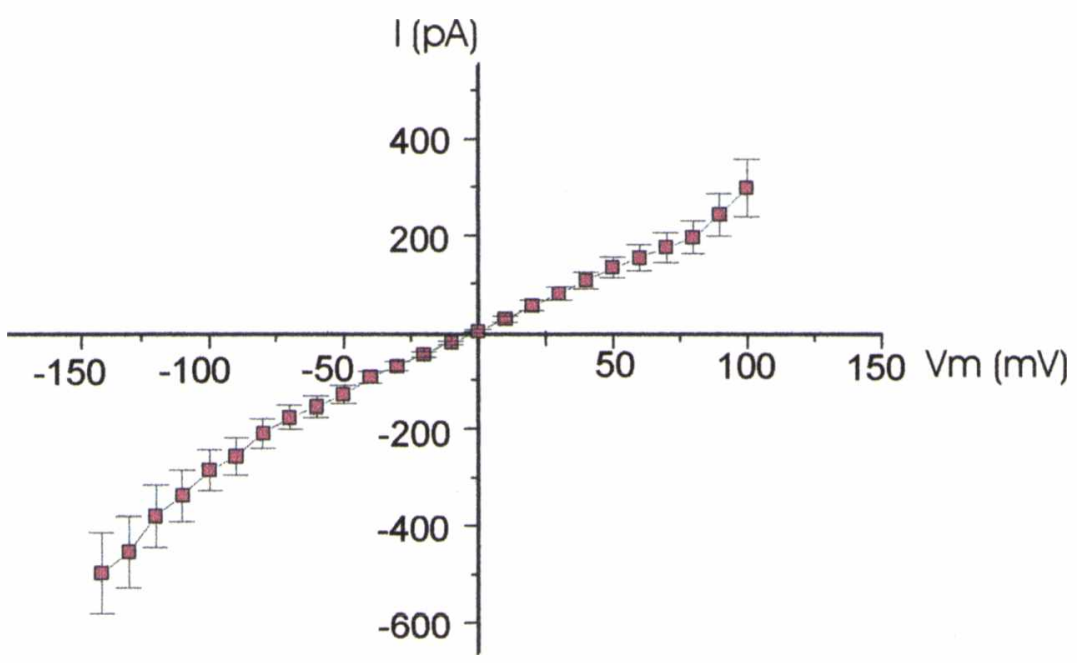

Figura 7: Curva I-V promedio en presencia de $\mathrm{Cs}^{+}$como principal ion intracelular ( $n=11$ células).

Estas características se corresponden con las de una corriente mediada por canales catiónicos no selectivos o mediada por iones simétricamente distribuidos a los lados de la membrana.

Considerando que en presencia de $\mathrm{Cs}^{+}$en la solución intracelular la corriente evocada es independiente del tiempo y del voltaje, se estudiaron sus propiedades mediante la realización de protocolos de fijación de voltaje a incremento continuo, denominadas rampas de voltaje, durante 1,6 segundos desde -140 hasta $+100 \mathrm{mV}$ partiendo de un potencial de mantenimiento de $-40 \mathrm{mV}$.

En primer lugar se ensayó la sensibilidad de esta corriente a $\mathrm{Gd}^{3+}$ y $\mathrm{La}^{3+}$, ambas sustancias con probados efectos inhibitorios sobre los canales catiónicos no selectivos en diferentes tipos celulares (190).

El efecto de $\mathrm{GdCl}_{3}$ se evaluó en el rango de concentraciones de 0,001 a 200 $\mu \mathrm{M}$, en células perfundidas con SEN (control) y luego de la perfusión con diferentes concentraciones de $\mathrm{Gd}^{3+}$. Se encontró que esta sustancia inhibe la corriente, en forma independiente del voltaje, a todas las concentraciones 
ensayadas. En la figura 8 se observa el efecto de $\mathrm{Gd}^{3+}$ expresado como porcentaje de inhibición de la corriente obtenido a distintos potenciales a todas las concentraciones ensayadas.

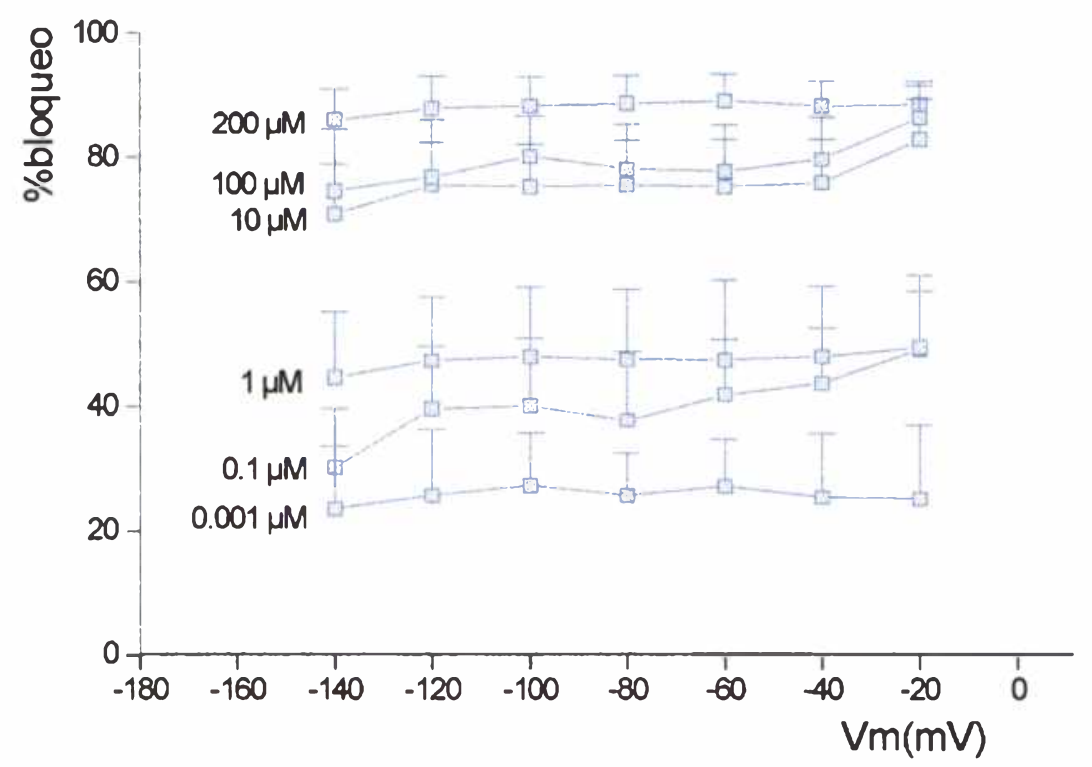

Figura 8: Porcentajes de bloqueo por $\mathrm{Gd}^{3+}$ obtenidos a distintos potenciales a todas las concentraciones ensayadas.

Se realizó entonces una curva dosis-respuesta a $\mathrm{Gd}^{3+}$ a un valor de potencial fijo (-40 mV), como se puede observar en la figura 9A. Esta relación se ajustó utilizando una ecuación de tipo sigmoidea obteniendo una curva que muestra que el efecto inhibitorio de $\mathrm{Gd}^{3+}$ depende de la concentración. El valor de concentración inhibitoria correspondiente al $50 \%$ de bloqueo $\left(\mathrm{DI}_{50}\right)$ fue de 1,05 $\mu \mathrm{M}$. En la figura $9 B$ se muestra un ejemplo representativo del efecto inhibitorio que produce una concentración saturante de $\mathrm{Gd}^{3+}(100 \mu \mathrm{M})$ sobre la corriente evocada por la rampa de voltaje. El efecto de $\mathrm{Gd}^{3+}$ no fue reversible luego de 15-20 minutos de lavado, siendo ésta una característica del bloqueo por $\mathrm{Gd}^{3+}$ descripta en otros estudios $(116,203)$. 
A

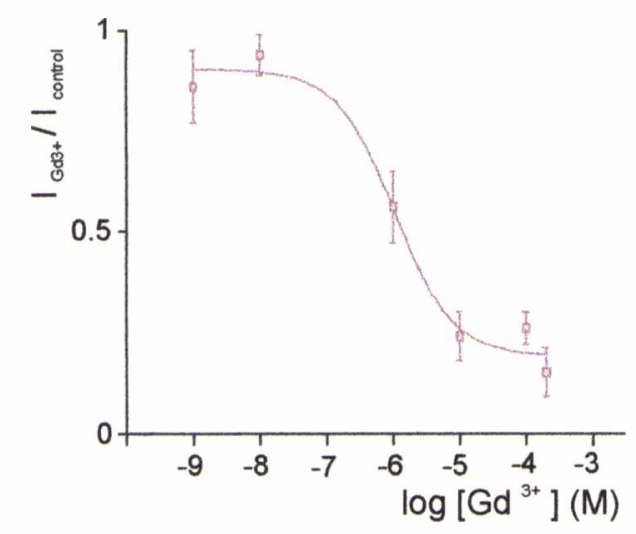

B

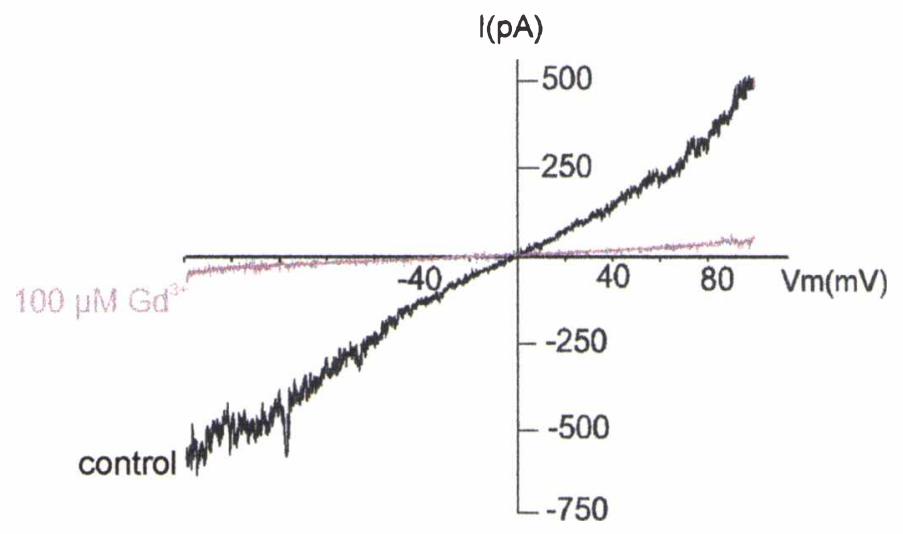

Figura 9: A-curva dosis-respuesta para el efecto bloqueante de $\mathrm{Gd}^{3+}$ sobre la corriente total ( $\mathrm{Cs}^{+}$como principal catión intracelular), expresado como corriente relativa en presencia de

$\mathrm{Gd}^{3+}\left(\mathrm{I}_{\mathrm{Gd} 3+} / I_{\text {control }}\right)$ ( $\mathrm{n}=6$ en cada punto). B- Ejemplo representativo del efecto inhibitorio que produce una concentración saturante de $\mathrm{Gd}^{3+}(100 \mu \mathrm{M})$ sobre la corriente.

También se ensayó el efecto de una concentración saturante de $\mathrm{Gd}^{3+}$ sobre la corriente registrada en células de músculo liso de AUH dializadas con solución SIN ( $\mathrm{K}^{+}$como ion principal en el medio intracelular) y con el potencial fijo a -40 $\mathrm{mV}$. Esta situación experimental nos permitió evaluar los efectos del $\mathrm{Gd}^{3+}$ en una condición iónica más fisiológica (en comparación con los registros en presencia del ion $\mathrm{Cs}^{+}$) y a un valor de potencial que simula la condición de potencial de membrana de reposo en una célula de músculo liso vascular. La corriente fue inhibida significativamente con $100 \mu \mathrm{M}$ de $\mathrm{Gd}^{3+}$ y este efecto resultó no reversible luego de 15 minutos de lavado con solución normal. El valor promedio de este efecto y un ejemplo se muestran en la figura 10.
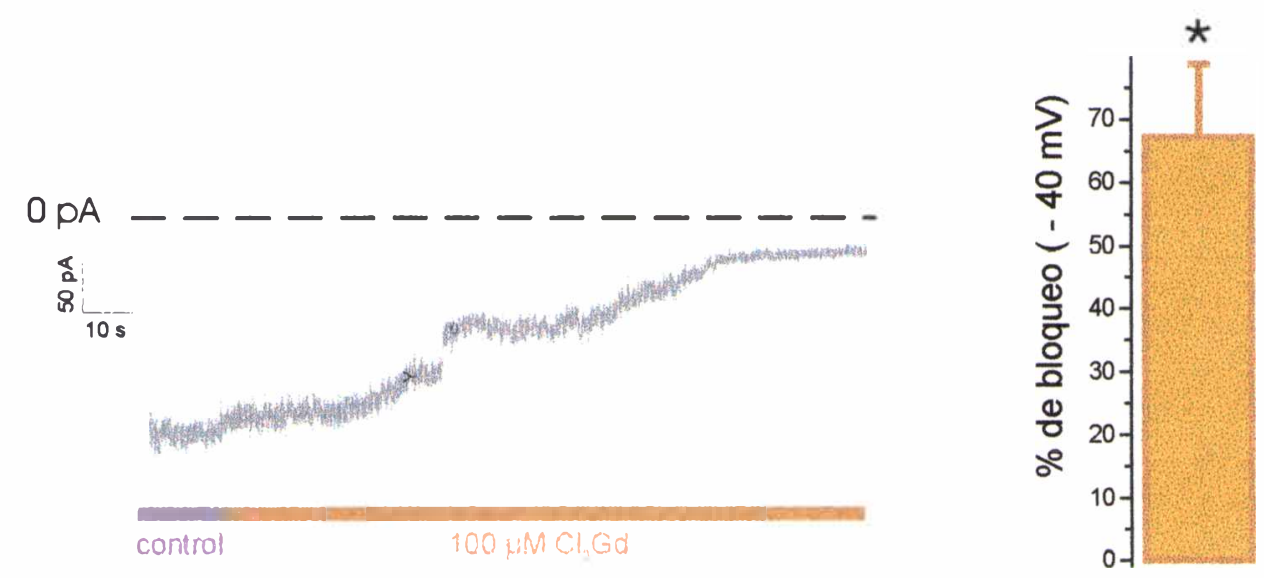

Figura 10: ejemplo típico del efecto de $\mathrm{Gd}^{3+}(100 \mu \mathrm{M})$ sobre la corriente de W-C registrada en células dializadas con solución SIN y con el potencial fijo a $-40 \mathrm{mV}$. La barra representa el valor promedio de este efecto expresado como porcentaje de bloqueo, " indica diferencia significativa de cero $(n=8, p<0,05)$. 
Antes y durante la perfusión con SEN y con $\mathrm{Gd}^{3+}$ se anuló momentáneamente el modo de fijación de voltaje y se midió el potencial de membrana de las células observándose un efecto hiperpolarizante de $\mathrm{Gd}^{3+}$ sobre el potencial de membrana. En presencia de $\mathrm{Gd}^{3+}$ el potencial de membrana se hiperpolariza 12,5 $\pm 4,7 \mathrm{mV}$ respecto del valor en situación control (SEN) ( $n=6$ células, $p<0.05)$.

El ion $\mathrm{La}^{3+}$, ensayado a una concentración de $100 \mu \mathrm{M}$, induce un bloqueo significativo sobre la corriente evocada por las rampas de voltaje. Esta corriente es también sensible al $\mathrm{Mg}^{2+}$, ya que cuando la concentración de $\mathrm{MgCl}_{2}$ se aumentó en la solución extracelular desde $1 \mathrm{mM}$ (condiciones control) a $5 \mathrm{mM}$ (SE-alto $\mathrm{Mg}^{2+}$ ), la corriente se redujo significativamente. La figura 11 muestra un ejemplo típico y los valores medios de bloqueo inducidos por $100 \mu \mathrm{M}$ de $\mathrm{La}^{3+}$ y $5 \mathrm{mM}$ de $\mathrm{Mg}^{2+}$ medidos a $-40 \mathrm{y}+40 \mathrm{mV}$.

A
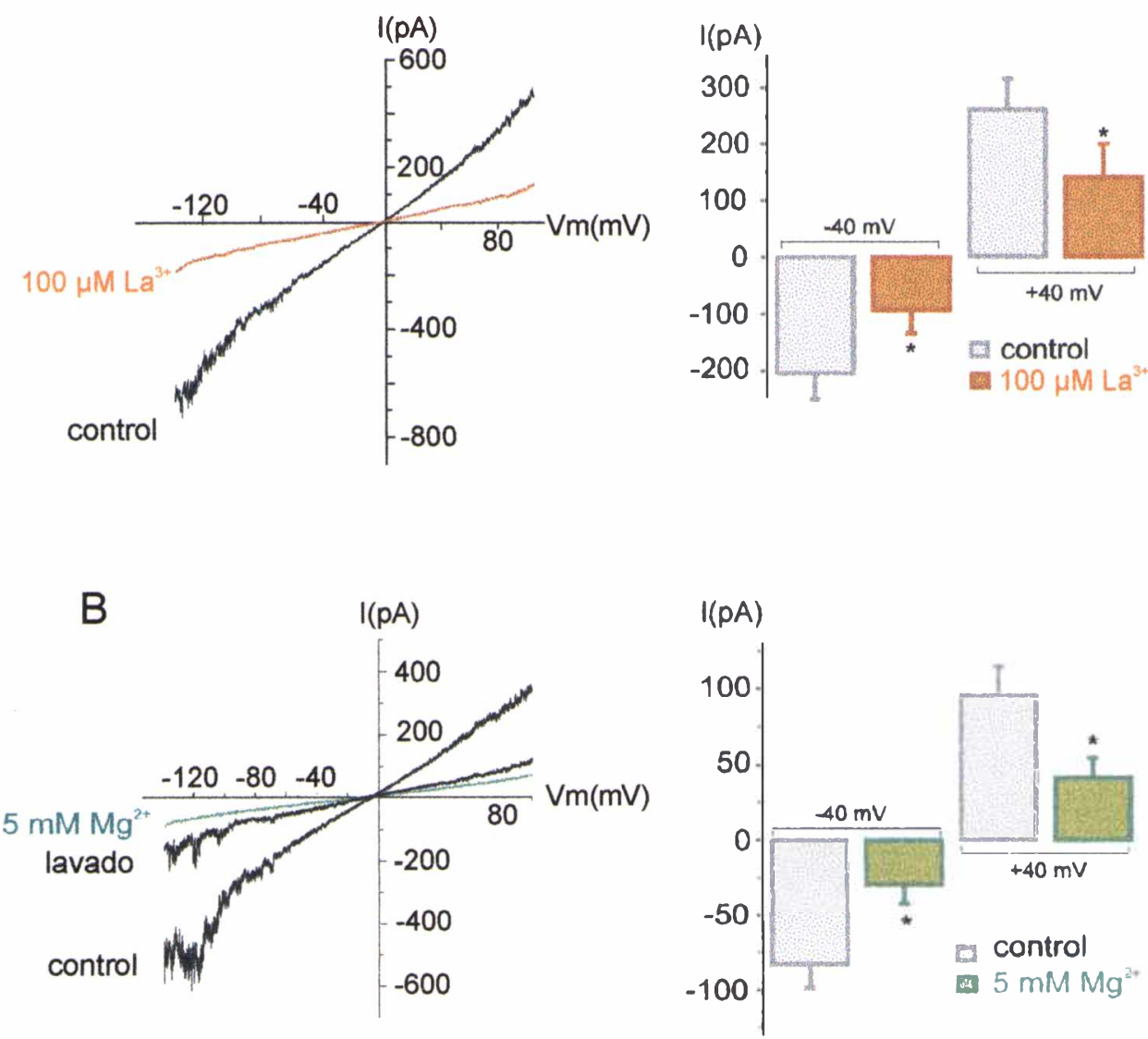

Figura 11: A- Ejemplo típico y valores medios de bloqueo inducidos por $\mathrm{La}^{3+}$ medidos a -40 $y+40 \mathrm{mV}$. ( ${ }^{*}$ indica diferencia significativa del control, $n=4, p<0,05$ ). B- Ejemplo típico y valores medios de bloqueo inducidos por el aumento de la concentración de $\mathrm{MgCl}_{2}$ medidos a -40 y +40 $\mathrm{mV}$. (" indica diferencia significativa del control, $n=6, p<0,05)$. 
A continuación, basados en las características electrofisiológicas y en la sensibilidad farmacológica de esta corriente, se decidió indagar sobre la selectividad de esta corriente en las células de músculo liso de $\mathrm{AUH}$.

En nuestras condiciones experimentales las soluciones intra y extracelular poseen concentraciones similares de ión $\mathrm{Cl}^{-} y$, por lo tanto el potencial teórico de equilibrio electroquímico de este ión $\left(E_{\mathrm{Cl}}=-4,8 \mathrm{mV}\right.$ ) es cercano al potencial de reversión $\left(E_{\text {rev }}\right)$ observado para esta corriente $(-2,1 \mathrm{mV})$. Se indagó entonces, en primer lugar la posible contribución del ión $\mathrm{Cl}^{-}$a la corriente observada. Para esto se realizaron experimentos donde se modificó el gradiente para este ion, utilizando la solución SEN-bajo $\mathrm{Cl}^{-}$. En esta solución el $\mathrm{Cl}^{-}$extracelular se redujo a una concentración de $39,8 \mathrm{mM}$ con el objeto de producir un corrimiento del $\mathrm{E}_{\mathrm{Cl}}$ a valores más positivos (de $-4,8 \mathrm{mV}$ a $+30,2 \mathrm{mV}$ ). En estas condiciones se obtuvo un valor de $E_{\text {rev }}$ de la corriente total de $-5,4 \pm 0,9 m V(n=4)$ en condiciones control y de $-3,1 \pm 0,3 \mathrm{mV}(n=4)$ en condiciones de gradiente de $\mathrm{Cl}^{-}$modificado. Basados en que el resultado encontrado fue un pequeño corrimiento del $E_{\text {rev }}$ en dirección opuesta a la esperada, asumimos que el $\mathrm{Cl}^{-}$no contribuye a esta corriente.

Habiendo excluido la posibilidad de que se trate de una corriente de $\mathrm{Cl}^{-}, \mathrm{y}$ sabiendo que la sensibilidad farmacológica se corresponde con una corriente catiónica no selectiva (CNS) se estudió en profundidad la relación de permeabilidades para cationes mono y divalentes. Se realizaron experimentos en condiciones tales que siempre hubiesen sólo dos cationes presentes (condiciones bi-ionicas) con el objeto de poder aplicar la ecuación de Goldman Hodgkin Katz (GHK) de la Teoría del Campo Constante (213) para el cálculo de las permeabilidades relativas.

En el caso de los cationes monovalentes se utilizó la solución intracelular SI$142 \mathrm{mM} \mathrm{Cs}^{+}$conteniendo como único catión monovalente $\mathrm{Cs}^{+}$y se midió el $\mathrm{E}_{\mathrm{rev}}$ de la corriente en presencia de soluciones extracelulares conteniendo $\mathrm{Cs}^{+}, \mathrm{Li}^{+}, \mathrm{Na}^{+} \mathrm{O}$ Tris $^{+}$como únicos cationes extracelulares (soluciones SE-142 $\mathrm{mM} \mathrm{Cs}^{+}, \mathrm{SE}-142$ $\mathrm{mM} \mathrm{Na}^{+}, \mathrm{SE}-142 \mathrm{mM} \mathrm{Li}{ }^{+}$o SE-142 $\mathrm{mM} \mathrm{Tris}^{+}$, ver métodos). Los valores de $\mathrm{E}_{\mathrm{rev}}$, en cada caso, se obtuvieron de la corriente evocada por las rampas de potencial aplicadas sobre distintas células en las diferentes condiciones bi-iónicas descriptas. A partir de los valores de $E_{\text {rev }}$ promedios obtenidos, es posible calcular 
la permeabilidad relativa al $\mathrm{Cs}^{+}$para los distintos iones $\left(\mathrm{P}_{\mathrm{x}} / \mathrm{P}_{\mathrm{Cs}}\right)$ utilizando la ecuación de GHK, que para esta situación se simplifica a la siguiente expresión:

$$
P_{X} / P_{C s}=\left(C s_{\text {int }} / X_{\text {ext }}\right) \exp \left(E_{\text {rev }} F / R T\right)
$$

Donde

$X_{\text {ext }}=$ concentración de $\mathrm{Cs}^{+}, \mathrm{Na}^{+}, \mathrm{Li}^{+}$o Tris ${ }^{+}$presentes en la solución externa

$\mathrm{Cs}_{\text {int }}=$ concentración de $\mathrm{Cs}^{+}$en la solución intracelular

$E_{\text {rev }}=$ valor de potencial de reversión promedio expresado en volts $(V)$

$\mathrm{F}=$ constante de Faraday $\left(9,648 \times 10^{4} \mathrm{C} \mathrm{mol}^{-1}\right)$

$\mathrm{R}=$ constante de los gases $\left(8,315 \mathrm{~J}^{\circ} \mathrm{K}^{-1} \mathrm{~mol}^{-1}\right)$

$\mathrm{T}=$ temperatura absoluta $\left(298,16^{\circ} \mathrm{K}\right)$

En la siguiente tabla se muestran los valores medios de $E_{\text {rev }}$ obtenidos y la permeabilidad relativa respecto al ion $\mathrm{Cs}^{+}$calculada aplicando la ecuación anteriormente descripta para los distintos iones ensayados.

\begin{tabular}{|c|c|c|}
\hline$X$ & Erev & PX/P \\
\hline $\mathrm{Cs}^{+}$ & $-0,20 \pm 0,56 \mathrm{mV}(n=23)$ & 1 \\
\hline $\mathrm{Na}^{+}$ & $-18,66 \pm 1,45 \mathrm{mV}(n=6)$ & 0,9 \\
\hline $\mathrm{Tris}^{+}$ & $-4,10 \pm 0,76 \mathrm{mV}(\mathrm{n}=10)$ & 0,5 \\
\hline $\mathrm{Li}^{+}$ & $-10,16 \pm 1,48 \mathrm{mV}(\mathrm{n}=6)$ & 0,7 \\
\hline
\end{tabular}

Para obtener la relación de permeabilidad de los cationes divalentes se utilizó la ecuación de GHK para la situación de una mezcla de un ión monovalente (en nuestro caso $\left.\mathrm{Cs}^{+}\right)$y uno divalente $\left(\mathrm{Ca}^{2+} \circ \mathrm{Ba}^{2+}\right)$

$$
P_{x} / P_{c s}=\frac{\left(1+\exp \left(-F E_{r e v} / R T\right)\left\{C s_{\text {int }}-C s_{\text {exx }}\left[\exp \left(-F E_{r e v} / R T\right)\right]\right\}\right)}{\left.\left(4\left\{X_{\text {ext }} \exp \left(-2 F E_{\text {rev }} / R T\right)\right]-X_{\text {in }}\right\}\right)}
$$

Donde

$X_{\text {ext }}=$ concentración de $\mathrm{Ca}^{2+} \circ \mathrm{Ba}^{2+}$ presentes en la solución extracelular

$X_{\text {int }}=$ concentración de $\mathrm{Ca}^{2+} \circ \mathrm{Ba}^{2+}$ en la solución intracelular

$C s_{\text {int }}=$ concentración de $\mathrm{Cs}^{+}$en la solución intracelular

$C s_{\text {ext }}=$ concentración de $\mathrm{Cs}^{*}$ en la solución extracelular

$E_{\text {rev }}=$ valor de potencial de reversión promedio expresado en volts $(V)$

$\mathrm{F}=$ constante de Faraday $\left(9,648 \times 10^{4} \mathrm{C} \mathrm{mol}^{-1}\right)$ 


$$
\begin{aligned}
& \mathrm{R}=\text { constante de los gases }\left(8,315 \mathrm{~J}^{\circ} \mathrm{K}^{-1} \mathrm{~mol}^{-1}\right) \\
& T=\text { temperatura absoluta }\left(298,16^{\circ} \mathrm{K}\right)
\end{aligned}
$$

Los valores de $E_{\text {rev }}$ se obtuvieron utilizando la misma solución intracelular, que en el caso de los iones monovalentes, con $\mathrm{Cs}^{+}$como único catión intracelular (SI-142 $\mathrm{mM} \mathrm{Cs}^{+}$), y considerando un valor aproximado de la concentración del ión divalente intracelular de $1 \mathrm{nM}$. La elección de las concentraciones extracelulares del catión monovalente y divalente se hizo mediante la realización de curvas teóricas obtenidas de la aplicación de la ecuación para diferentes mezclas de iones (figura 12).

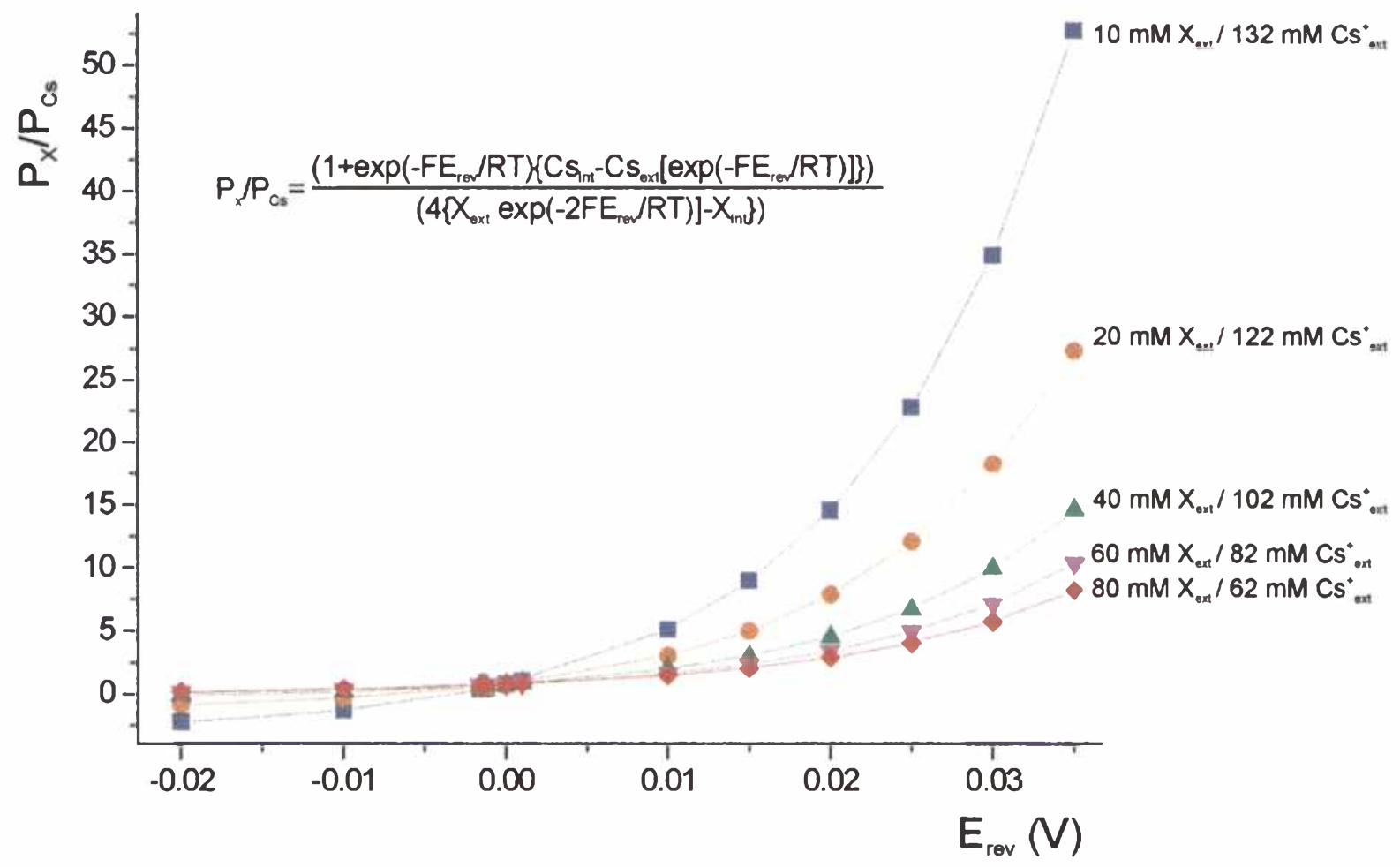

Figura 12: Curvas teóricas obtenidas de la aplicación de la ecuación de Goldman Hodgkin Katz de la Teoría del Campo Constante para diferentes mezclas de iones.

(abreviaturas: ver del texto)

En base a las curvas teóricas obtenidas se seleccionó la concentración de 60 $\mathrm{mM}$ para el catión divalente y de $82 \mathrm{mM}$ para el monovalente como una mezcla adecuada, ya que en este caso pequeñas variaciones de la medida experimental del $E_{r e v}$ no influyen significativamente en el calculo del valor de $P_{X} / P_{C s}$. Trabajando con estas soluciones extracelulares, que se denominaron SE- $60 \mathrm{mM} \mathrm{Ca}^{2+}$ y SE$60 \mathrm{mM} \mathrm{Ba}^{2+}$, se obtuvieron los siguientes valores de $E_{\mathrm{rev}} \mathrm{y}$ de $\mathrm{P}_{\mathrm{X}} / \mathrm{P}_{\mathrm{Cs}}$ : 


\begin{tabular}{|c|c|c|}
\hline$x$ & $\mathrm{E}_{\mathrm{rev}}$ & $\mathrm{P}_{X} / \mathrm{P}_{\mathrm{Cs}}$ \\
\hline $\mathrm{Ca}^{2+}$ & $-1,57 \pm 0,76 \mathrm{mV} \quad(n=5)$ & 0,7 \\
\hline $\mathrm{Ba}^{2+}$ & $-1,37 \pm 0,64 m V \quad(n=6)$ & 0,7 \\
\hline
\end{tabular}

Los resultados obtenidos para cationes mono y divalentes indican la siguiente relación de permeabilidad para la corriente CNS en las células de AUH:

$$
P_{x} / P_{C_{s}}: 1: 0,9: 0,7: 0,7: 0,7: 0,5
$$

donde $\mathrm{X}=\mathrm{Cs}^{+}, \mathrm{Na}^{+}, \mathrm{Li}^{+}, \mathrm{Ca}^{2+}, \mathrm{Ba}^{2+}$ y $\mathrm{Tris}^{+}$respectivamente.

Además, a partir de estos valores se puede calcular la permeabilidad relativa entre el $\mathrm{Na}^{+}$y el Ca ${ }^{2+}$ obteniéndose un valor de $\mathrm{P}_{\mathrm{Na}+} / \mathrm{P}_{\mathrm{Ca} 2+}=1,3$.

Las concentraciones de $\mathrm{Na}^{+}$y de $\mathrm{Ca}^{2+}$ en la SEN son 150 y $1 \mathrm{mM}$ respectivamente, en esta condición similar a la fisiológica se trató de poner en evidencia si la corriente entrante evocada por una rampa de voltaje, puede ser llevada por estos dos cationes. Se registró la corriente en presencia de SEN (control) y luego de la perfusión con una solución sin $\mathrm{Na}^{+}$(SE-Tris). Se observó que la sustitución completa del $\mathrm{Na}^{+}$por $\mathrm{Tris}^{+}$redujo significativamente la corriente entrante $(-67,3 \pm 11,4 \%$, medida a $-40 \mathrm{mV}, \mathrm{n}=7$ células, $p<0.05)$ mientras que la corriente saliente permaneció inalterada $(-5,1 \pm 14,0 \%$, medida a $+40 \mathrm{mV}, \mathrm{n}=7$ células, N.S., figura 13A). En concordancia con este resultado, se observó un corrimiento del $E_{\text {rev }}$ de la corriente hacia valores hiperpolarizados de potencial, ( $E_{\text {rev }}$ control $=-1,7 \pm 0,8 m V, E_{r e v}$ Tris $^{+}=-18,9 \pm 4,8 m V, n=7$ células, $\left.p<0,05\right)$. Se aplicaron luego rampas de voltaje en células perfundidas con solución $\sin \mathrm{Na}^{+}$con $1 \mathrm{mM}$ de $\mathrm{Ca}^{2+}$ (SE-Tris) o sin adición de $\mathrm{CaCl}_{2}$ a la solución extracelular (SE-Tris-0 $\left(\mathrm{Ca}^{2+}\right)$. La figura 13B muestra un registro típico de la corriente medida en estas condiciones donde puede observarse que la solución SE-Tris-0 $\mathrm{Ca}^{2+}$ produce una disminución de la corriente entrante de 69,8 \pm 8,8 \% respecto de la corriente en presencia de SE-Tris (medida a $-40 \mathrm{mV}, \mathrm{n}=9$ células, $\mathrm{p}<0,05$ ) mientras que la corriente saliente no fue modificada $(-2,1 \pm 9,2 \%$, medida a $+40 \mathrm{mV}, \mathrm{n}=9$ células, N.S.). El E $E_{\text {rev }}$ medido en SE-Tris-0 $\mathrm{Ca}^{2+}$ también fue significativamente modificado 
hacia valores más hiperpolarizados de potencial comparado con el valor alcanzado por el reemplazo sólo del $\mathrm{Na}^{+}\left(E_{\text {rev }}\right.$ en SE-Tris $=-22,1 \pm 3,0 \mathrm{mV}$, $E_{\text {rev }}$ en SE-Tris-0 $\mathrm{Ca}^{2+}=-32,9 \pm 1,9 \mathrm{mV}, \mathrm{n}=9$ células, $\left.\mathrm{p}<0,05\right)$. Estos datos indican que tanto el $\mathrm{Na}^{+}$ como el $\mathrm{Ca}^{2+}$ son capaces de llevar la corriente entrante a concentraciones similares a las fisiológicas.

A

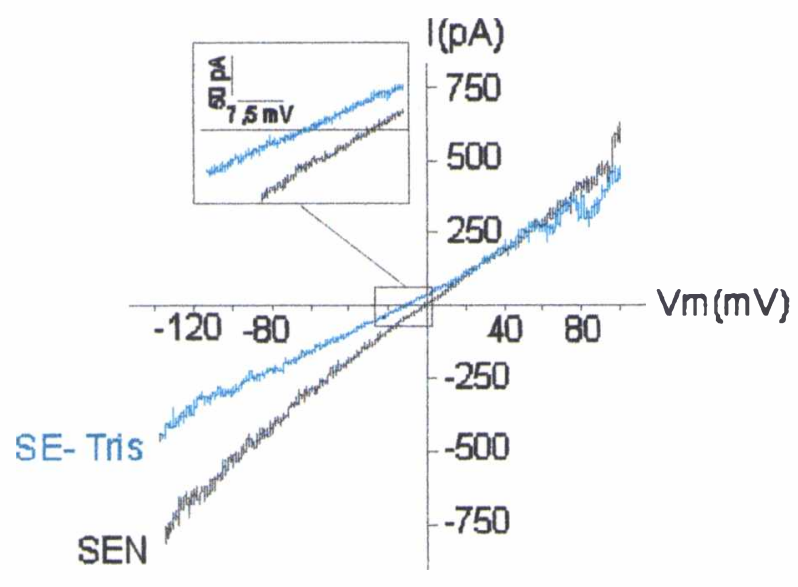

B

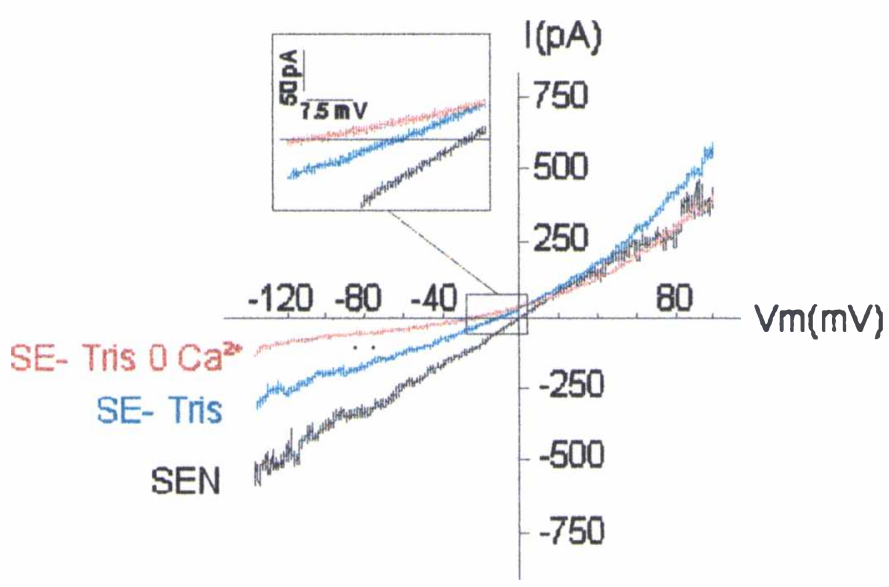

Figura 13: A- Ejemplo típico de corriente total evocada por rampas de potencial en presencia de SEN (control) y luego de la perfusión con una solución sin $\mathrm{Na}^{+}$(SE-Tris). En el recuadro se observa el corrimiento del $E_{r e v}$ en presencia de SE-Tris con respecto a SEN. BEjemplo típico de corriente total evocada por rampas de potencial en presencia de solución sin $\mathrm{Na}^{+}$, con $1 \mathrm{mM}$ de Ca ${ }^{2+}$ (SE-Tris) o sin adición de $\mathrm{CaCl}_{2}$ a la solución extracelular (SE-Tris-0 $\mathrm{Ca}^{2+}$ ). En el recuadro se observa el corrimiento del $\mathrm{E}_{\mathrm{rev}}$ en presencia de $\mathrm{SE}-\mathrm{Tris}-\mathrm{O} \mathrm{Ca}^{2+}$ con respecto a SE-Tris. 


\section{Registros de canal único}

Los resultados presentados en la sección anterior obtenidos en configuración de célula entera o W-C mostraron que una gran parte de la corriente total en estas células es sensible a la IBTX, lo cual indica que la componente de corriente sensible a IBTX es mediada por canales de $\mathrm{K}^{+}$de tipo $\mathrm{BK}_{\mathrm{Ca}}$. Se presenta a continuación el estudio realizado para caracterizar las propiedades de canal único del canal de $\mathrm{K}^{+}$de tipo $\mathrm{BK}_{\mathrm{Ca}}$ en las células de músculo liso de $\mathrm{AUH}$.

En primer lugar se trabajó en configuración O-O (del ingles "outside-out") con un gradiente de concentración de $\mathrm{K}^{+}$asimétrico similar al utilizado para los registros de corriente macroscópica ( $130 \mathrm{mM}$ y $5 \mathrm{mM}$ en contacto con la región intracelular y extracelular del segmento de membrana, respectivamente). Se utilizó la solución SIN en la micropipeta y SEN en el baño. En estas condiciones se aplicaron protocolos de fijación de voltaje durante 30 segundos que permiten mantener constante el potencial a los lados de la membrana durante el tiempo determinado. Se observaron corrientes de canal único de diferente amplitud a valores de potencial de membrana entre -30 y $+50 \mathrm{mV}$, destacándose que a cero $\mathrm{mV}$ existía actividad de canales iónicos como se espera para corrientes llevadas por el ion $\mathrm{K}^{+}$en condiciones de gradiente asimétrico. Debido a que el canal $\mathrm{BK}_{\mathrm{Ca}}$ es de alta conductancia, se esperaría que las corrientes de canal único de mayor amplitud correspondiesen a este canal. Asumiendo esto se seleccionaron, en un grupo de células, los niveles de corriente de mayor amplitud para cada valor de potencial aplicado y se construyó la curva I-V promedio. La figura 14 muestra registros representativos obtenidos en esta configuración a distintos potenciales y la curva I-V promedio para este canal. Mediante el ajuste de la misma con la ecuación de una recta, se obtuvo el valor de la pendiente, el cuál estima la conductancia del canal único $(\gamma)$. El valor obtenido fue de $124 \pm 4$ pS $(n=111,24$ células). 

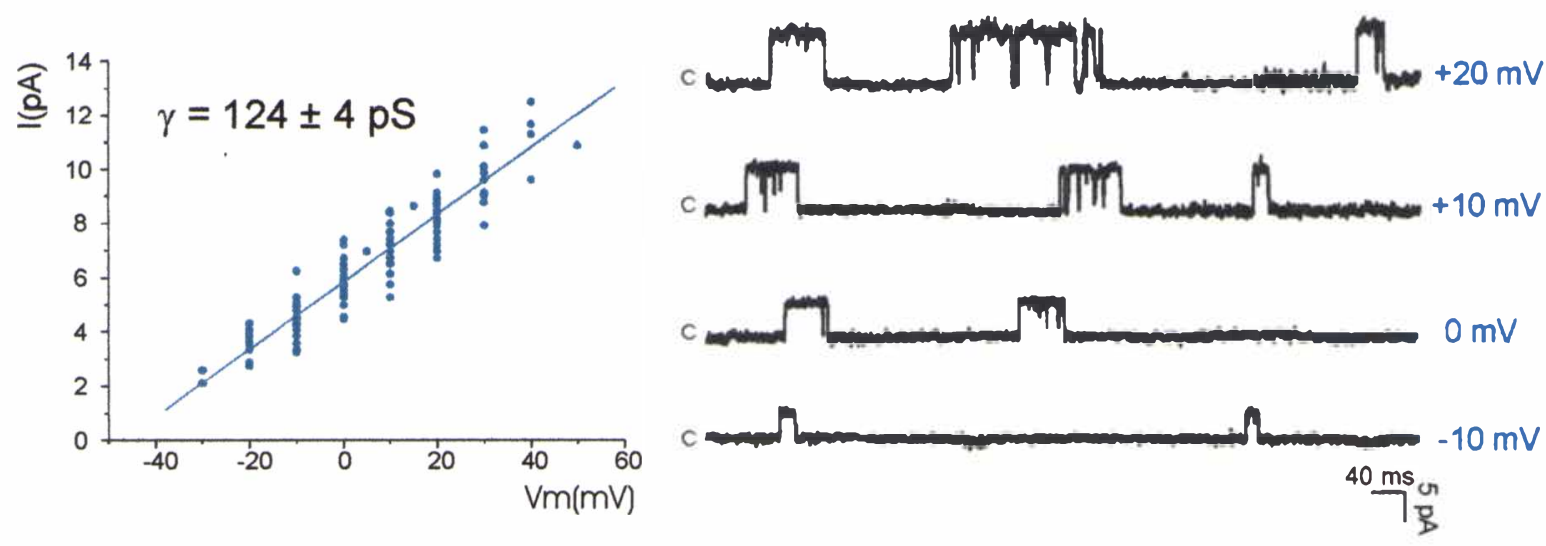

Figura 14: Registros representativos obtenidos en configuración $0-0$ a distintos potenciales y curva I-V promedio para este canal. ( $C$ indica el nivel de corriente para el estado cerrado del canal)

Varios trabajos muestran que, en condiciones de $\mathrm{K}^{+}$el valor de conductancia que presenta el canal $\mathrm{BK}_{\mathrm{Ca}}$ es mayor, un valor típico es de aproximadamente 250 pS (214). Teniendo en cuenta esta propiedad se estudió la conductancia del canal en los dos tipos de gradiente de $\mathrm{K}^{+}$(asimétrico y simétrico). Para esto, una vez registrada la actividad del canal en gradiente asimétrico de $\mathrm{K}^{+}$, se cambió la concentración extracelular de dicho ion perfundiendo con una solución que contenía $130 \mathrm{mM}$ de $\mathrm{K}^{+}$(solucion SAK), y se registró así la actividad del mismo canal en condiciones de gradiente simétrico de $\mathrm{K}^{+}$. Este procedimiento permitió medir la amplitud de la corriente de canal único en ambas condiciones de gradiente de $\mathrm{K}^{+}$para diferentes valores de potencial. La figura 15 muestra la evidencia directa del cambio en el nivel de corriente en ambas condiciones experimentales y la curva I-V obtenida para una célula. El valor de conductancia obtenido a partir de la curva I-V promedio en $\mathrm{K}^{+}$simétrico fue de $216 \pm 4 \mathrm{pS}$ ( $n=16$, 4 células). 
A

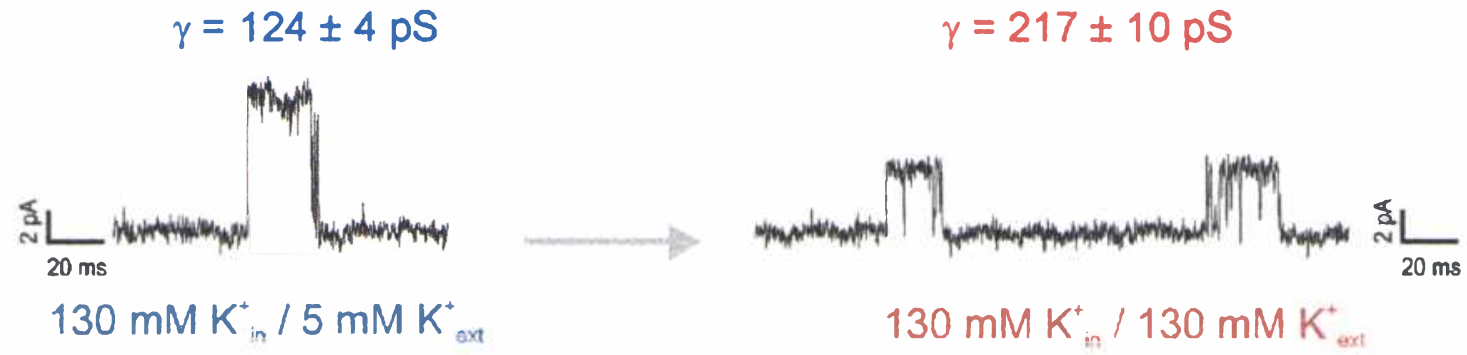

B

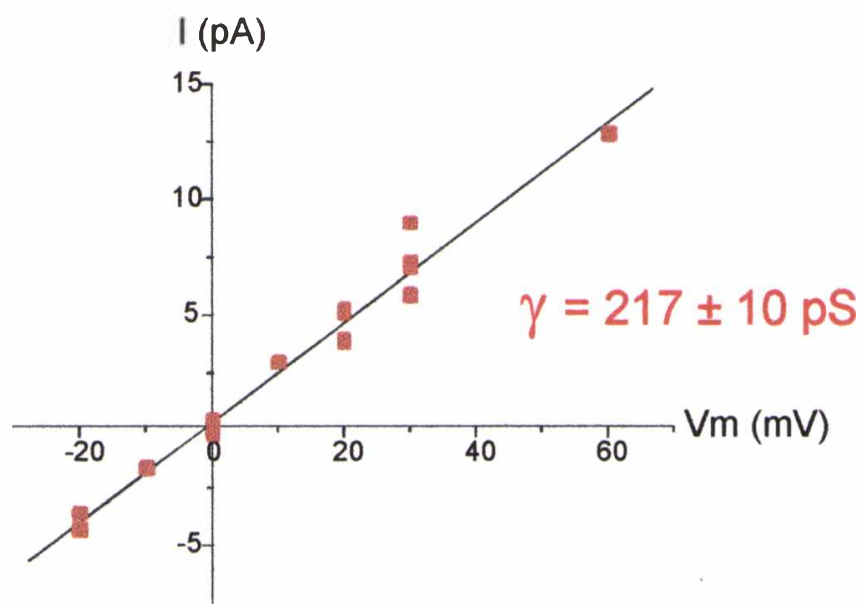

Figura 15: A- Registro típico en O-O mostrando la evidencia directa en una célula del cambio en el nivel de corriente cuando se modifica el gradiente para el ion $\mathrm{K}^{+}$( $\mathrm{K}_{\text {ext }}=$ concentración externa de $\mathrm{K}^{+}, \mathrm{K}_{\mathrm{int}}=$ concentración interna de $\mathrm{K}^{+}$). B- Curva $\mathrm{I}-\mathrm{V}$ obtenida para esta célula en la condición de $\mathrm{K}_{\mathrm{ext}}=\mathrm{K}_{\mathrm{int}}=130 \mathrm{mM}$.

Sensibilidad al $\mathrm{Ca}^{2+}$ y al voltaje: Otras dos propiedades características de este tipo de canal son la sensibilidad al voltaje y al $\mathrm{Ca}^{2+}$. Para estudiar estas propiedades se trabajó en configuración I-O (del inglés "inside-out") con gradiente simétrico para el ion $\mathrm{K}^{+}$(solución B1 para la perfusión y solución B2 en la micropipeta). En estas condiciones el valor promedio de conductancia para el canal $\mathrm{BK}_{\mathrm{Ca}}$ fue de $274 \pm 7$ pS ( $n=47,8$ células). Los registros de la actividad de canal único en configuración $1-O$ realizados a diferentes valores de potencial aplicado permitieron observar que la actividad de este canal aumenta con el valor de potencial. La figura 16 muestra esta propiedad del canal. 

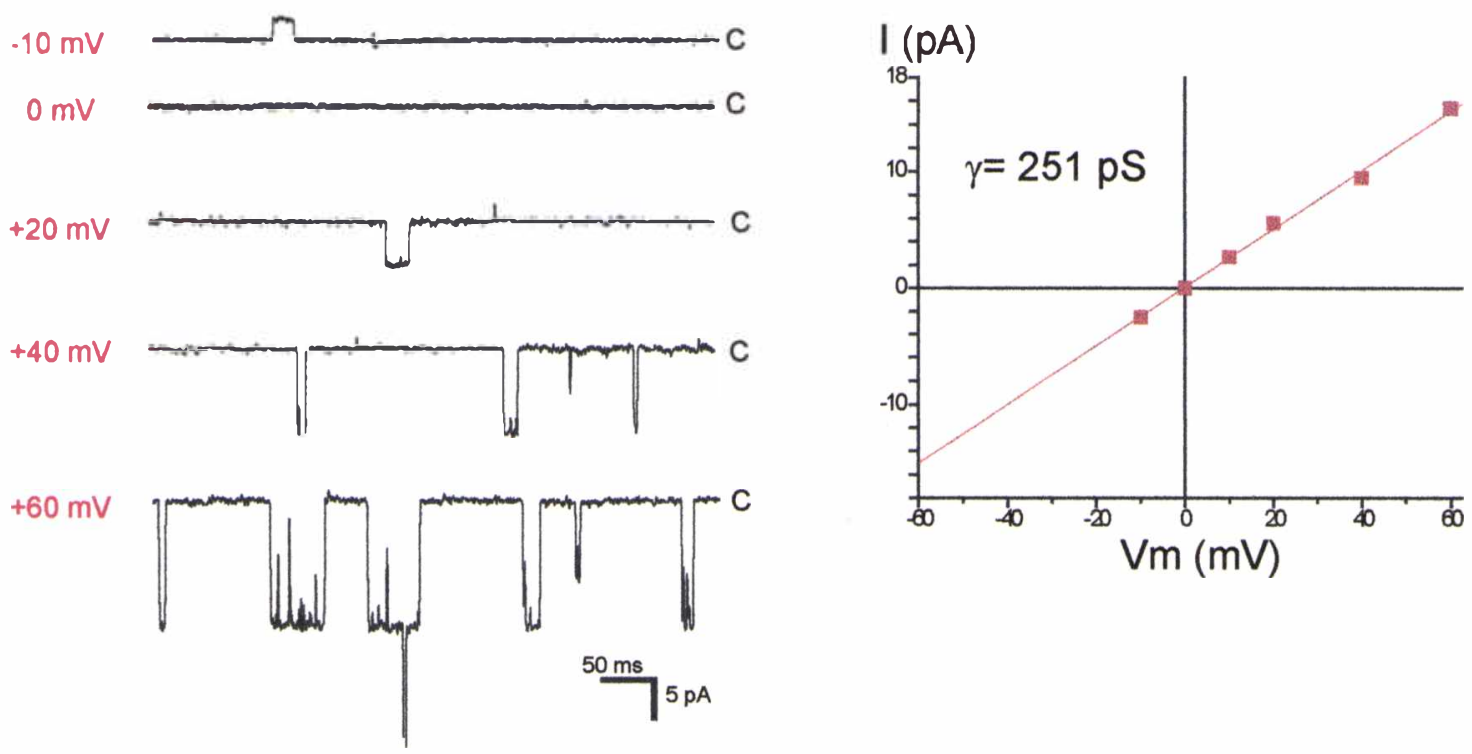

Figura 16: Registros de la actividad de canal único en configuración I-O, en presencia de solución B1 en el baño y solución B2 en la micropipeta, realizados a diferentes valores de potencial aplicado y curva I-V promedio para esta condición. C indica el nivel de corriente para el estado cerrado del canal)

En relación a la sensibilidad al $\mathrm{Ca}^{2+}$ de este canal, en primer lugar se observó que, utilizando solución B1 para la perfusión (la cual contiene una concentración estimada de $\mathrm{Ca}^{2+}$ libre de $10 \mathrm{nM}$ ) y solución $\mathrm{B} 2$ en la micropipeta, el pasaje de la configuración de C-A (del inglés "cell-attached") a I-O muestra una disminución de la actividad del canal. Esta disminución puede deberse a la diferente concentración de $\mathrm{Ca}^{2+}$ a la que se encuentra expuesta la cara interna del segmento de membrana en las dos configuraciones $\left(\mathrm{Ca}^{2+}\right.$ intracelular en $\mathrm{C}-\mathrm{A}$ y aproximadamente $10 \mathrm{nM}$ en I-O). La figura 17 muestra un registro del pasaje de CA a I-O.

$$
\text { C-A }
$$

$1-0$

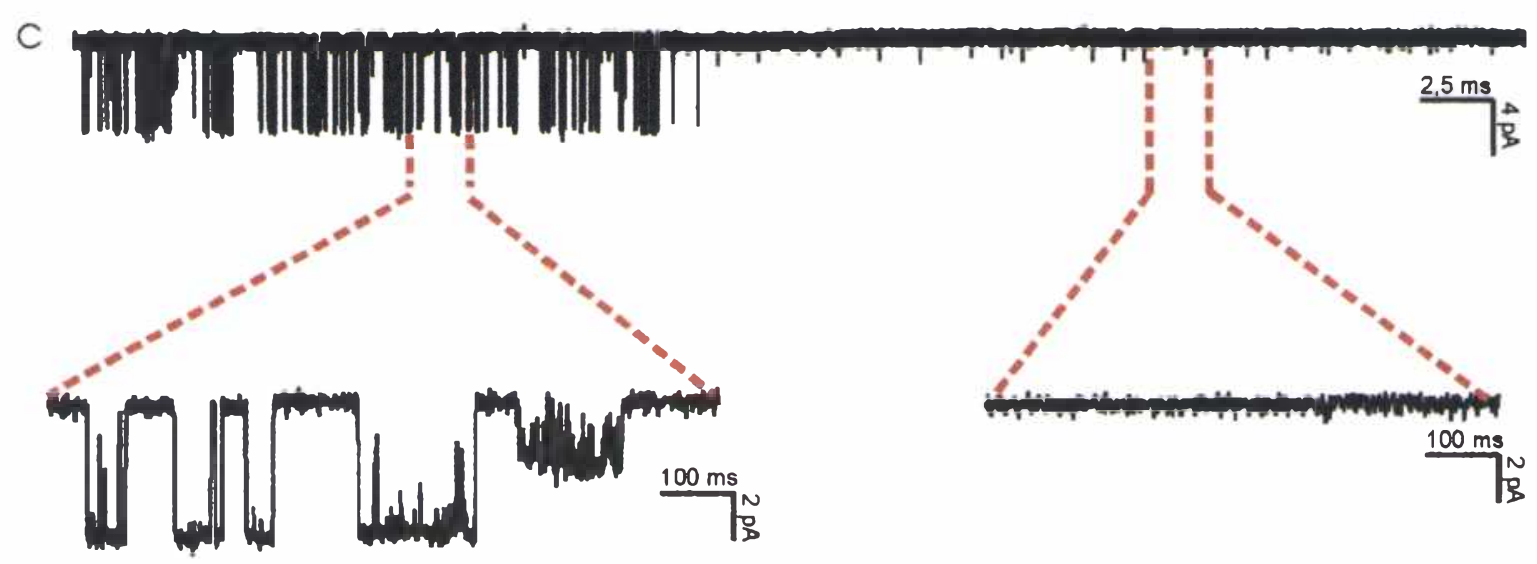

Figura 17: Registro continuo en una célula durante el pasaje de la configuración de C-A a I-O. 
Se estudió entonces, la sensibilidad al $\mathrm{Ca}^{2+}$ en configuración 1-O manteniendo constante el valor de potencial aplicado y variando la concentración de $\mathrm{Ca}^{2+}$ en contacto con el lado interno de la membrana. Se encontró que la probabilidad de apertura del canal medida como NPo a $+20 \mathrm{mV}$ aumentó significativamente de un valor de 0,000625 $\pm 0,000498$ ( $n=8$ células) en condiciones control (solución B1 conteniendo una concentración libre de calcio estimada en $10 \mathrm{nM}$ ) a 0,424 $\pm 0,137$ ( $n=7$ células) cuando se perfundió con una solución B1 cuya concentración de $\mathrm{Ca}^{2+}$ libre fue aumentada a $1 \mu \mathrm{M}$. La figura 18 muestra un registro típico de la activación del canal por $\mathrm{Ca}^{2+}$ y los histogramas de amplitud de la corriente a partir de los cuales se obtienen los valores de NPo (ver métodos).

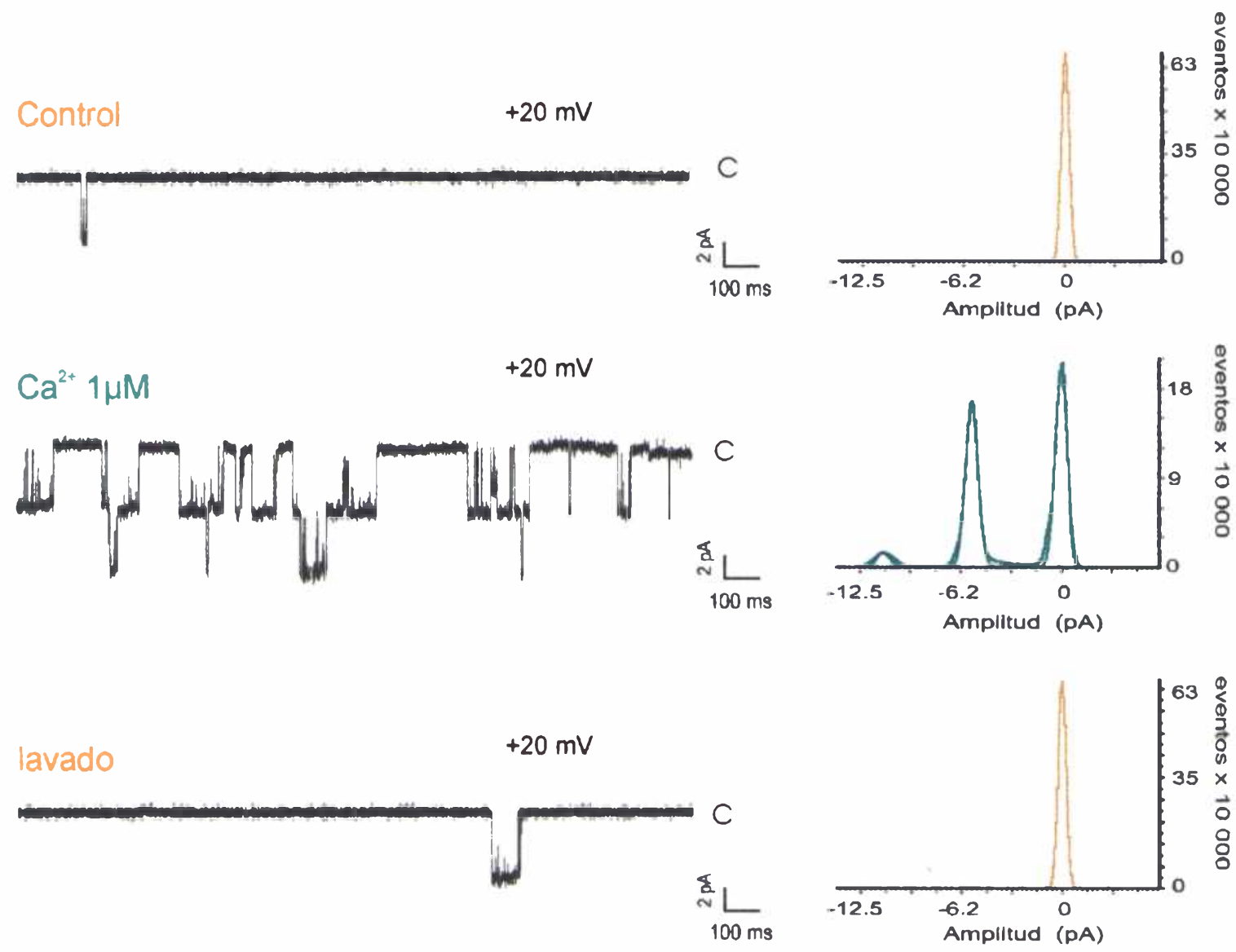

Figura 18: Registros típicos en condición control, luego de la activación del canal por $\mathrm{Ca}^{2+}$ y luego del lavado; también se muestran los histogramas de amplitud de la corriente a partir de los cuales se obtienen los valores de NPo. 
La sensibilidad farmacológica se estudió evaluando el efecto de los bloqueantes de la corriente macroscópica (TEA e IBTX) sobre los registros de canal único.

En configuración $\mathrm{O}-\mathrm{O}$ y en las mismas condiciones de gradiente de $\mathrm{K}^{+}$ asimétrico o simétrico descritas anteriormente, la aplicación de TEA $1 \mathrm{mM}$ extracelular redujo la amplitud de la corriente aumentando el nivel de ruido del estado abierto, observándose luego un bloqueo total de la corriente ( $n=4$ células en ambos casos). Este tipo de bloqueo es completamente reversible y característico del TEA que actúa como un bloqueante de alta velocidad. La figura 19 muestra uno de estos experimentos de bloqueo en configuración de O-O.

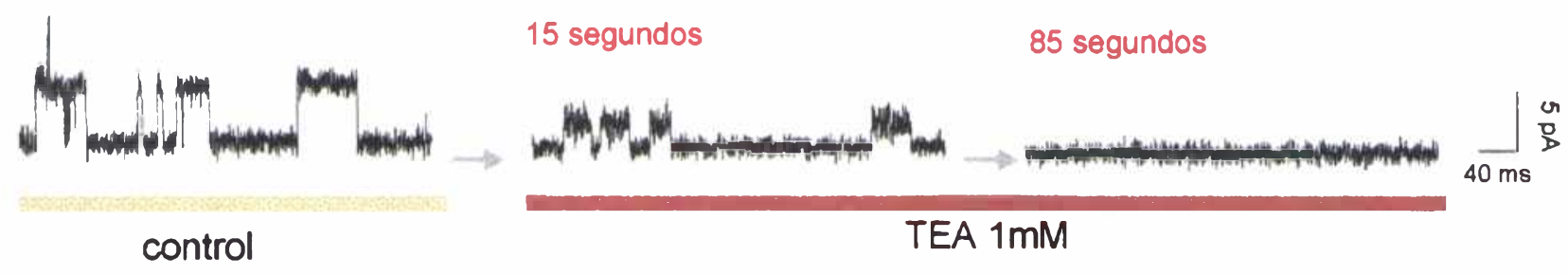

Figura 19: Experimento típico del bloqueo de la corriente en configuración de O-O por TEA $1 \mathrm{mM}$ en el tiempo.

En configuración C-A utilizando SEN como solución de perfusión y SAK en la micropipeta el canal presentó una conductancia de $106 \pm 3$ pS ( $n=72,30$ células). En estas condiciones, la IBTX en concentración 100 nM se utilizó para confirmar la identidad del canal. Para realizar estos experimentos la micropipeta se llenó con solución SAK en el sector más cercano a la punta y con la misma solución conteniendo IBTX 100 nM en la zona posterior, esperando que por difusión hacia la punta entraran en contacto la toxina y la proteína del canal presente en la membrana celular. El resultado fue el bloqueo del canal en el total de las células ensayadas, las cuales mostraron actividad inicial, que luego disminuyó en un tiempo aproximado de 5-25 minutos (NPo 2 min $=0,197 \pm 0,031, p<$ 0,05 y NPo $15 \min =0, n=6$ células). La figura 20 muestra la curva I-V promedio para el canal BK $\mathrm{Ca}_{\mathrm{a}}$ en estas condiciones y un ejemplo típico del bloqueo por 100 nM de IBTX. 
A

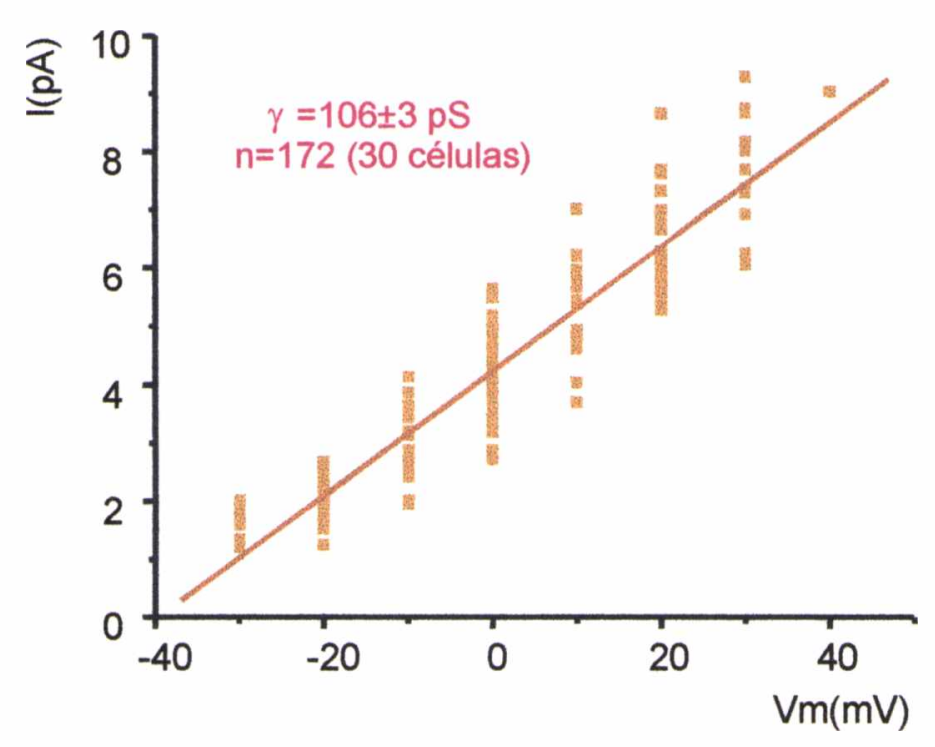

B
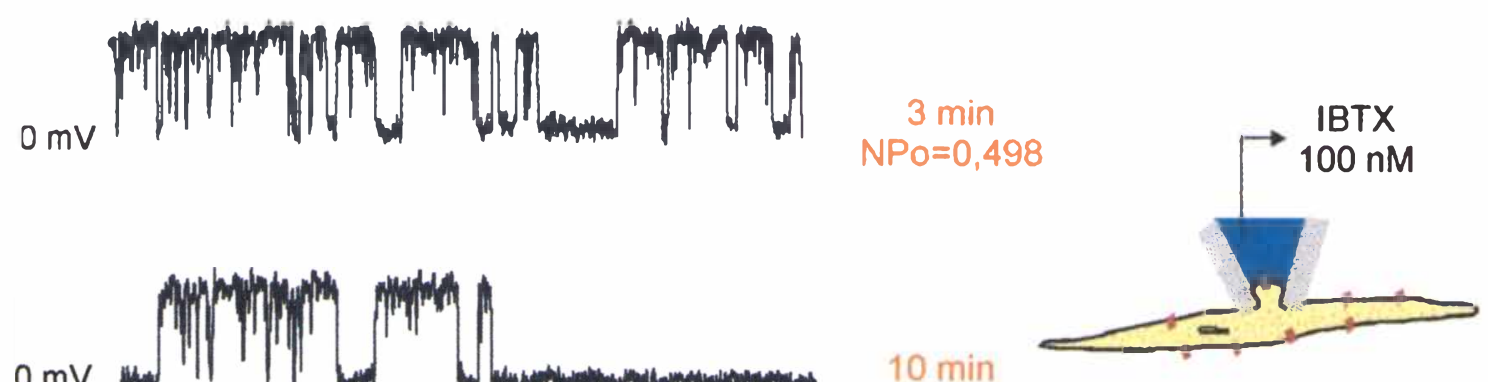

$0 \mathrm{mV}$

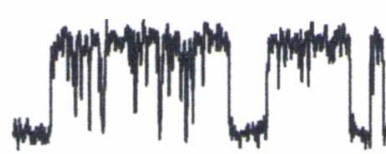

$\sqrt{4}$

$10 \mathrm{~min}$

$N P O=0,397$

$20 \mathrm{~ms}$

$0 \mathrm{mV}$

$25 \mathrm{~min}$

NPo $=0$

Figura 20: Curva I-V promedio para el canal $\mathrm{BK}_{\mathrm{Ca}}$ en configuración $\mathrm{C}-\mathrm{A}$ y un ejemplo típico del bloqueo por $100 \mathrm{nM}$ de IBTX en el tiempo.

Estudio del efecto del oxido nítrico sobre el canal BK $\mathrm{ca}_{\mathrm{a}}$ en AUH: Lovren y colaboradores demostraron que el óxido nítrico o NO (del inglés "nitric oxide") relaja la arteria umbilical humana, en parte debido a la activación de canales de $\mathrm{K}^{+}$, ya que este efecto es inhibido por 4-AP (boqueante de corrientes de tipo $K_{D R}$ ) y por TEA (bloqueante de canales de tipo $\mathrm{BK}_{\mathrm{C}_{\mathrm{a}}}$ ) (79). En base a estos resultados se 
decidió estudiar el efecto del nitroprusiato de sodio o SNP (del inglés "sodium nitroprusiate"), una sustancia dadora de NO, sobre la actividad del canal BK previamente caracterizado en las células aisladas de AUH.

Se trabajó en configuración C-A con solución SEN en el baño para permitir que las células pudieran establecer su potencial de membrana y se utilizó solución SAK en la micropipeta.

Cuando las células fueron perfundidas con solución SEN con $10 \mu \mathrm{M}$ de SNP se observó un aumento significativo de la probabilidad de apertura del canal $\mathrm{BK}_{\mathrm{Ca}}$ luego de 15 minutos de acción de la droga (figura 21).
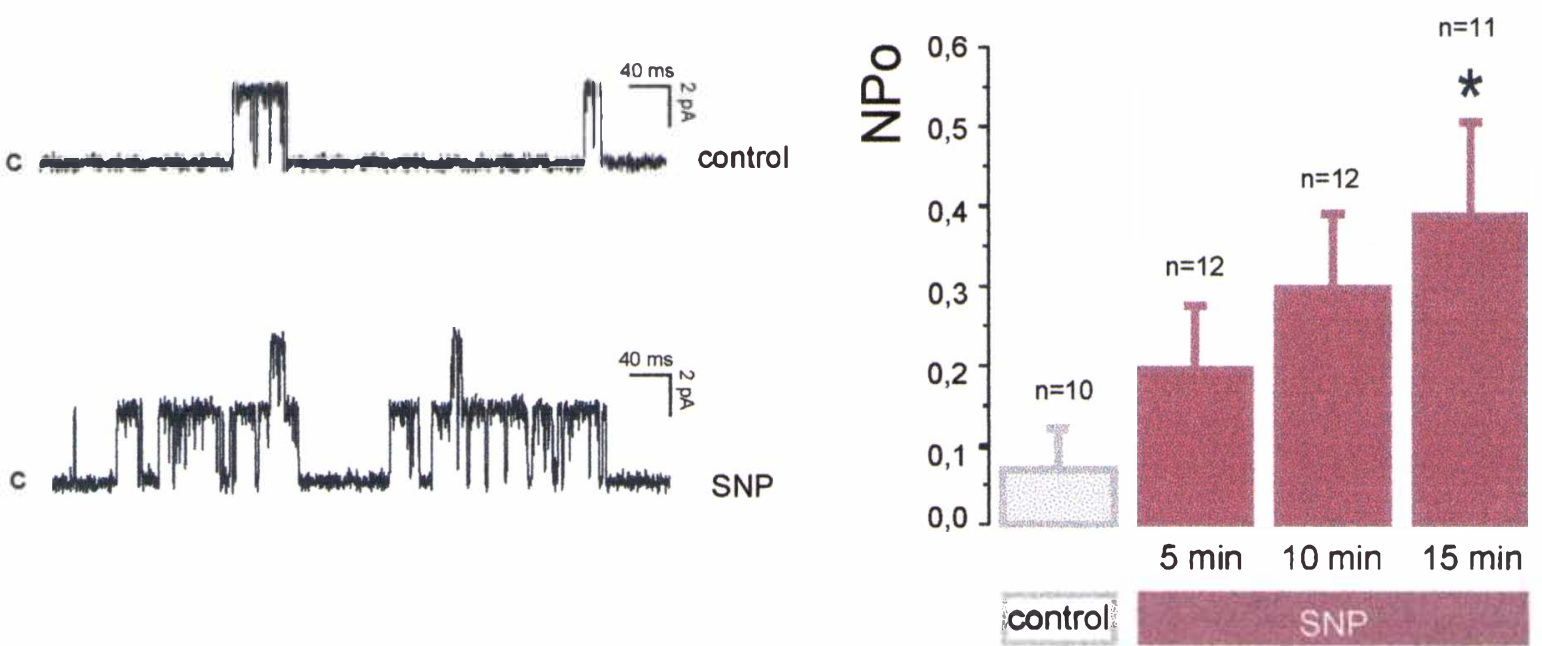

Figura 21: registros típicos de corriente en condición control y luego de la perfusión con 10 $\mu \mathrm{M}$ de SNP en configuración C-A (a $0 \mathrm{mV}$ ). Las barras representan los valores medios de la NPo \pm EMS para la condición control y a distintos tiempos de perfusión con SNP.

Se ensayó también en C-A el efecto del Br-GMPc, un análogo del GMPc capaz de permear las membranas celulares, observándose que la perfusión con 1 $\mathrm{mM}$ de Br-GMPc produjo un aumento significativo en la NPo del canal BK $\mathrm{C}_{\mathrm{Ca}}$ a los 5 minutos de acción (figura 22). 

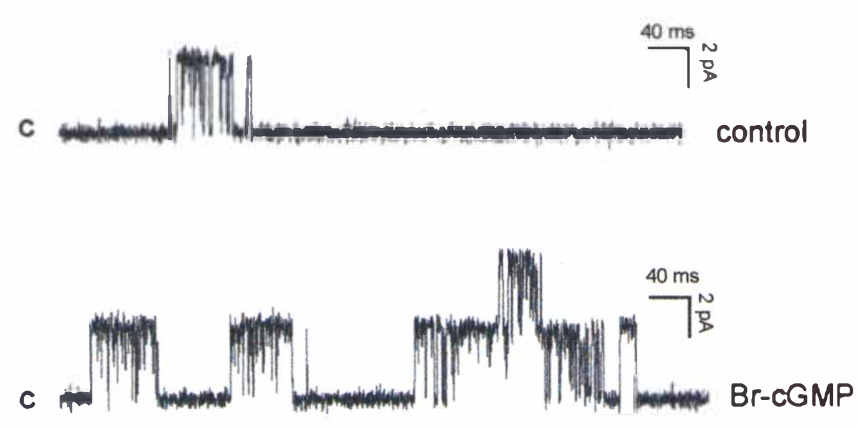

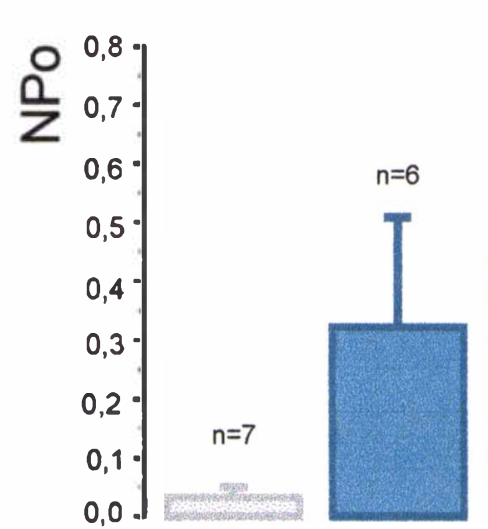

$2,5 \mathrm{~min}$

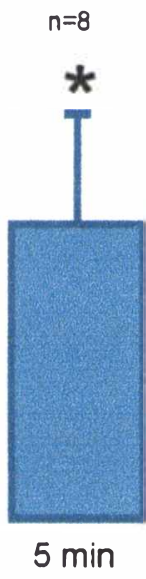

Br-GMPC

Figura 22: Se muestran registros de corriente típicos (a $0 \mathrm{mV}$ ) en condición control y luego de la perfusión con $1 \mathrm{mM}$ de Br-GMPc Las barras representan los valores medios de la NPo \pm ESM para la condición control y a distintos tiempos de perfusión con $\mathrm{Br}-\mathrm{GMPc}$. (" indica diferencia significativa del control, $p<0,05$ )

Para explorar si el SNP o el GMPc tienen algún efecto directo sobre la proteína de canal o estructuras muy próximas en la membrana plasmática, se utilizó la configuración $\mathrm{I}-\mathrm{O}$ en condiciones de $\mathrm{K}^{+}$simétrico. En estas condiciones no se observó ningún efecto directo de $10 \mu \mathrm{M}$ de SNP (NPo SNP $=0,014 \pm 0,007$ vs NPo control $=0,015 \pm 0,007 ; n=5$ células, N.S.) ni de $1 \mathrm{mM}$ de cGMP (NPo GMPc $=0,030 \pm 0,013$ vs NPo control $=0,026 \pm 0,01 ; n=5$ células, N.S.) sobre la actividad del canal. 


\section{Estudio de la función contráctil de la arteria umbilical humana}

Las células de músculo liso y del endotelio que forman la pared vascular tienen un rol fundamental en los múltiples mecanismos que se ponen en juego en la regulación del diámetro de los vasos sanguíneos. En esta sección se describirán los resultados obtenidos mediante experimentos de mecánica vascular "in vitro" utilizando segmentos aislados de arteria umbilical humana (AUH).

La primer serie de experimentos se realizó con el objetivo de estudiar el desarrollo de fuerza isométrica en anillos vasculares de AUH. Una vez conectados los anillos vasculares al transductor de fuerza, fueron sometidos a un estiramiento de 2 gramos fuerza $(\mathrm{gF})$, lo que constituye un procedimiento estándar ampliamente utilizado en este tipo de experimentos con segmentos vasculares $(215,79,216)$. Este protocolo produjo una respuesta al estiramiento caracterizada por una relajación rápida y transitoria seguida de una contracción de desarrollo lento que se estabilizó en el término de 30 minutos y luego se mantuvo constante por tiempos prolongados. La respuesta promedio para un total de 15 anillos se muestra en la figura 23. 


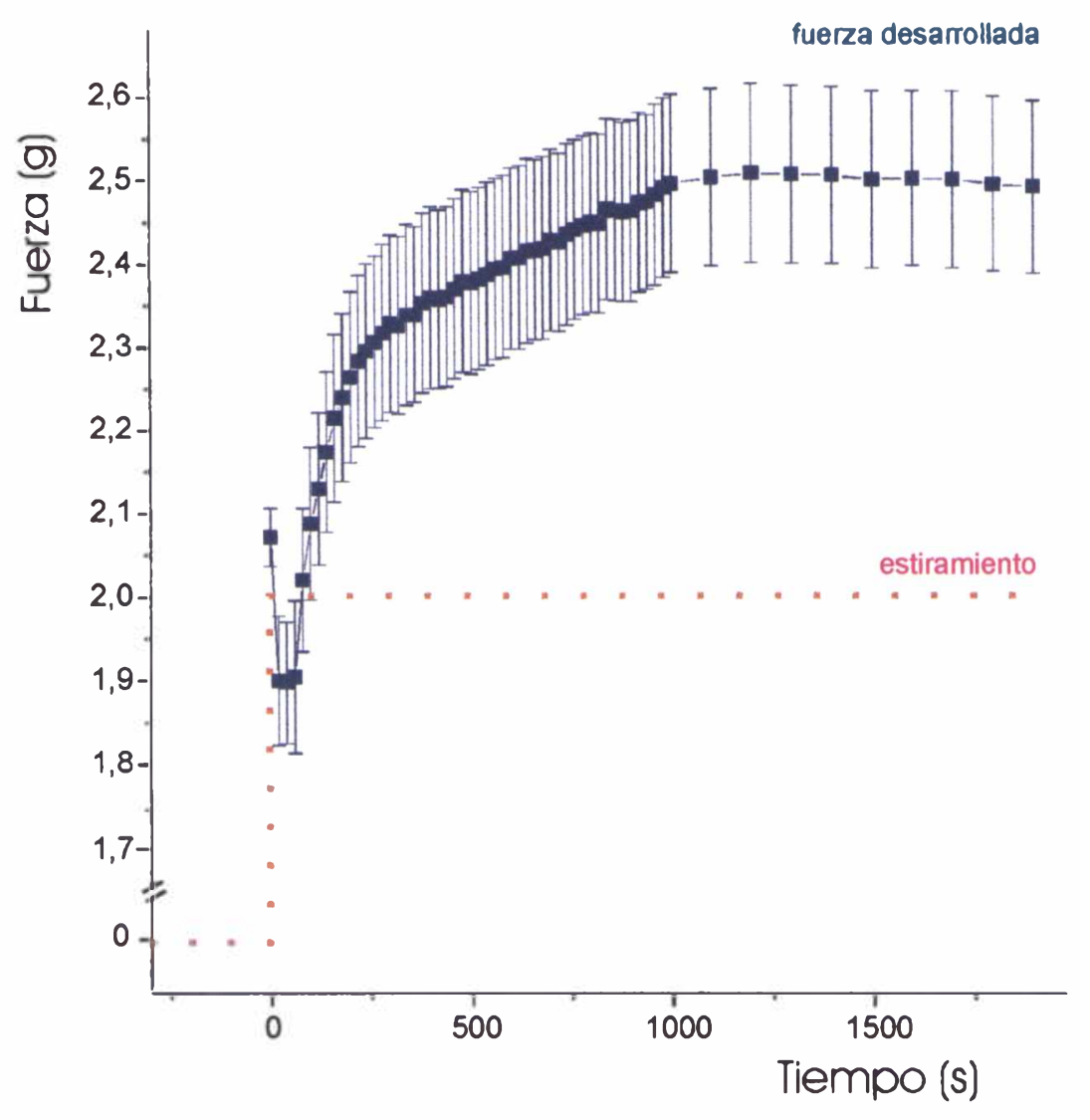

Figura 23: fuerza media desarrollada por los anillos de AUH en respuesta a un estiramiento de 2 gF en función del tiempo ( $n=15$ anillos para todos los tiempos estudiados).

En estas condiciones y luego de 1 hora de estabilización de la respuesta al estiramiento, se reemplazó la solución Krebs Ringer Bicarbonato (KRB) normal presente en la cámara de experimentación por una solución sin $\mathrm{CaCl}_{2}(\mathrm{KRB} \sin$ $\mathrm{Ca}^{2+}$ ) observándose que la remoción del $\mathrm{Ca}^{2+}$ del medio extracelular relaja los anillos vasculares en forma significativa, indicando que la contracción observada se trata de una respuesta activa sensible al $\mathrm{Ca}^{2+}$ externo (Figura 24). 

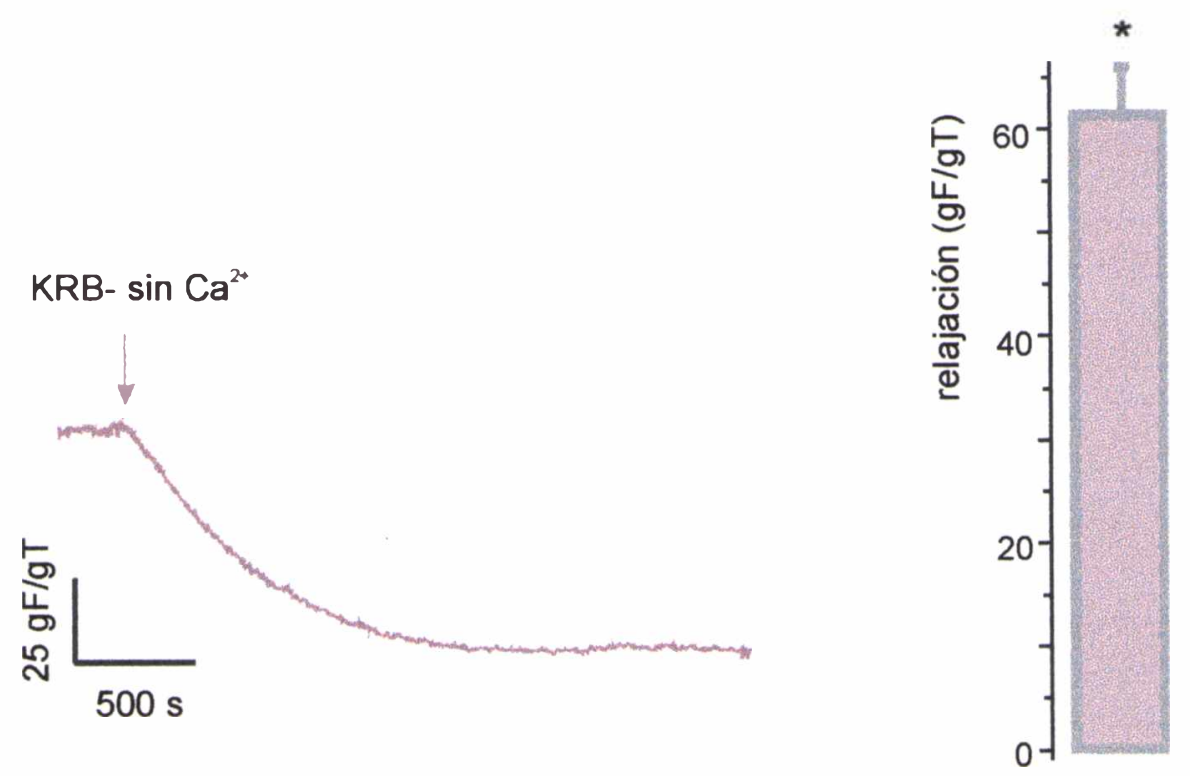

Figura 24: Registro típico mostrando la relajación inducida por la remoción del $\mathrm{Ca}^{2+}$ de la solución del baño en anillos de AUH estirados a $2 \mathrm{gF}$. La barra representa el valor medio de la relajación normalizada por el peso del anillo (gF/gT) \pm ESM para esta respuesta, " indica diferencia significativa de cero ( $n=21$ anillos, $p<0,05$ ).

A partir de esta primera evidencia de respuesta activa de la pared vascular al estiramiento, se realizó una segunda serie de experimentos con el objetivo de estudiar la sensibilidad de dicha respuesta al $\mathrm{Ca}^{2+}$ y a distintos grados de estiramiento. Se utilizaron anillos vasculares en condiciones isométricas estabilizados durante 1 hora sin estiramiento inicial en las siguientes condiciones:

- solución KRB sin $\mathrm{Ca}^{2+}$

- solución KRB con $0.4 \mathrm{mM}$ de $\mathrm{CaCl}_{2}$

- solución KRB con $0.8 \mathrm{mM}$ de $\mathrm{CaCl}_{2}$

- solución KRB con $1.2 \mathrm{mM}$ de $\mathrm{CaCl}_{2}$

- solución KRB con $1.6 \mathrm{mM}$ de $\mathrm{CaCl}_{2}$

Luego del periodo de estabilización se estiraron los anillos, mediante el uso del micrómetro del equipo, hasta la mínima longitud que evoca una señal de fuerza (Lo) y a partir de ese punto se realizaron estiramientos sucesivos incrementando la longitud del estiramiento $\left(L_{x}\right)$ y registrando la fuerza en forma continua. De todos los experimentos se calculó la fuerza en unidades de $\mathrm{g}$ fuerza $(\mathrm{gF})$ por $\mathrm{g}$ de peso de tejido (gT) para valores de $L_{x} / L_{0}$ entre 1,00 y 2,25 . Con los datos promedio obtenidos mediante este protocolo se realizaron las curvas fuerza-longitud para cada una de las diferentes concentraciones de $\mathrm{Ca}^{2+}$ externo descriptas. 


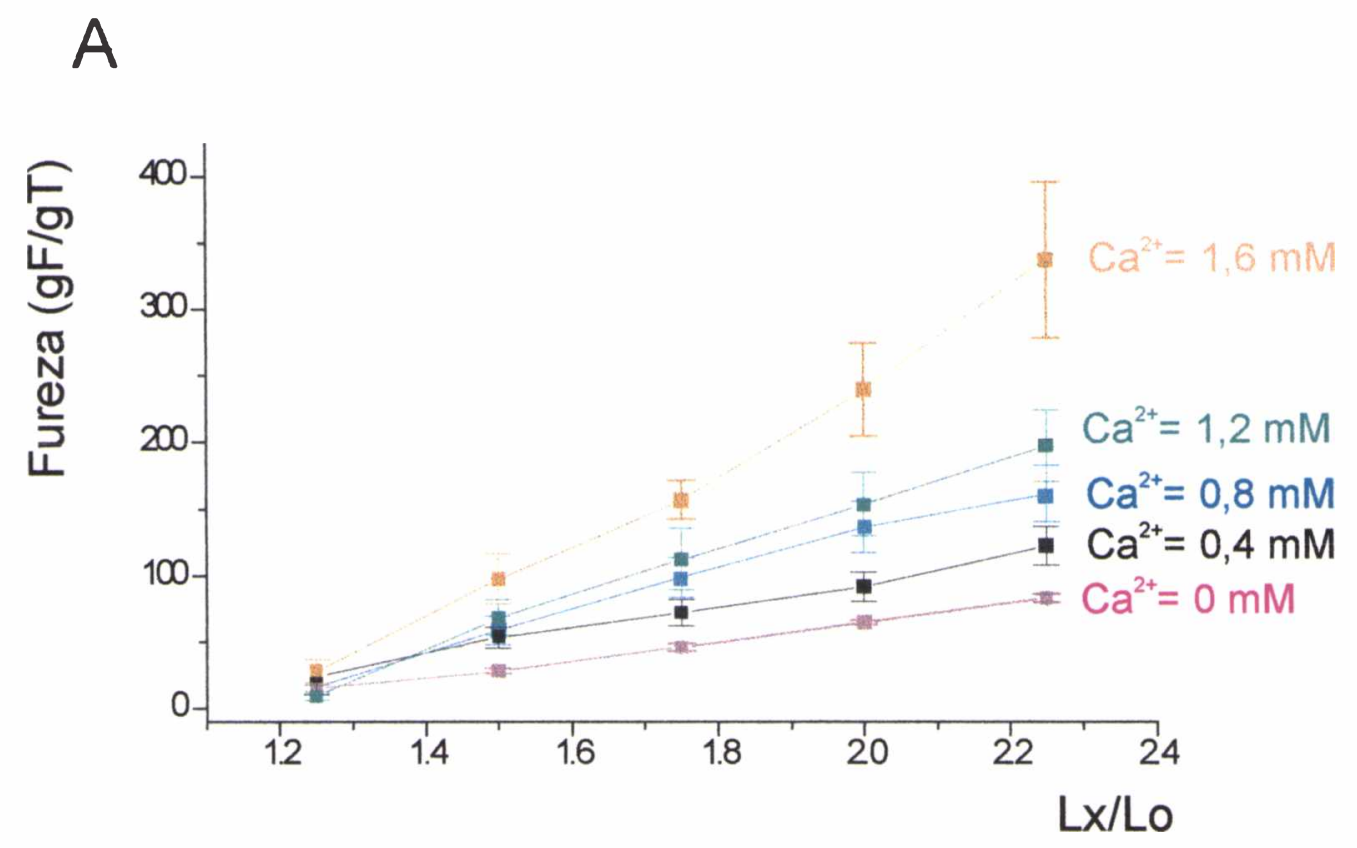

B

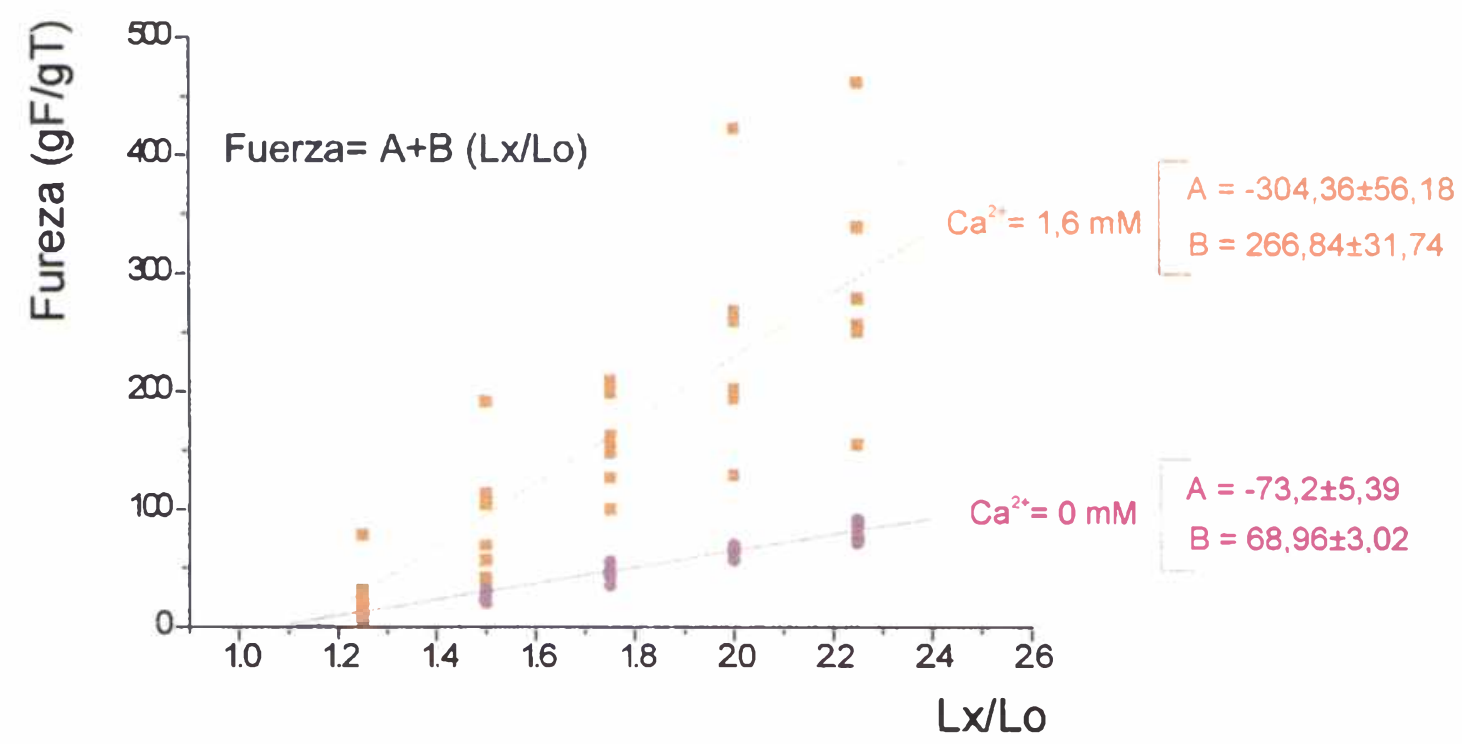

Figura 25: A- Fuerza media desarrollada en función del estiramiento $\left(L_{x} / L_{0}\right)$ para las distintas concentraciones de ion $\mathrm{Ca}^{2+}$ (ver texto) ( $n=9$ para cada punto). B-Ajuste lineal de las curvas realizadas en ausencia y en presencia de $1,6 \mathrm{mM}_{\mathrm{de}} \mathrm{Ca}^{2+}$. Los parámetros de ambos ajustes son estadísticamente significativos $(p<0,05)$ y los parámetros de ambas rectas son estadisticamente diferentes entre si $(p<0,05)$.

En la figura 25A se observa que, en todas las condiciones experimentales, la fuerza crece con el estiramiento $\left(L_{x} / L_{0}\right)$ y que este crecimiento es más pronunciado a concentraciones mayores de $\mathrm{Ca}^{2+}$ externo. Para realizar un análisis cuantitativo se seleccionaron las curvas en ausencia de $\mathrm{Ca}^{2+}$ y en presencia de $1,6 \mathrm{mM}$ de $\mathrm{CaCl}_{2}$ (concentración de $\mathrm{Ca}^{2+}$ cercana a la concentración normal extracelular). Primero se ajustaron estas curvas con una ecuación lineal, encontrándose por un 
test de hipótesis para regresión lineal que ambos ajustes son significativos. Este resultado indica que en ambos casos la fuerza desarrollada depende del estiramiento aplicado a los anillos. Por otro lado, se realizó un test estadístico para comparar los parámetros de dichas rectas entre sí, encontrándose una diferencia significativa entre ambas, lo que indica que el estiramiento produce un desarrollo de fuerza mayor en presencia de $\mathrm{Ca}^{2+}$ que en ausencia de este ión. Los valores de estos datos se muestran en la figura 25B.

La función contráctil de la pared vascular puede también estudiarse con la metodología experimental detallada en la sección 3 de "materiales y métodos". La misma permite evaluar la respuesta de la $\mathrm{AUH}$ en términos de presión de perfusión o de resistencia vascular al valor del flujo de perfusión, utilizando para esto segmentos arteriales intactos de AUH perfundidos con distintas soluciones y a diferentes velocidades. En una serie de experimentos, se estudió la respuesta de segmentos vasculares estabilizados inicialmente durante 60 minutos en solución KRB a una velocidad mínima de perfusión que genera un flujo constante de $0,77 \pm 0,03 \mathrm{ml} / \mathrm{min}$ y luego a distintas velocidades de perfusión aumentadas en cuatro pasos sucesivos las cuales producen un flujo de 2,96 $\pm 0,09 ; 5,27 \pm 0,15$; $7,46 \pm 0,21$ y $8,70 \pm 0,20 \mathrm{ml} / \mathrm{min}$. En cada experimento se midió en forma continua el flujo (constante para cada velocidad de perfusión) y la presión desarrollada para cada cambio de velocidad. Se calcularon los valores de resistencia vascular como el cociente entre la presión desarrollada y el flujo en cada caso. Los resultados obtenidos, que se muestran en la figura 26 , indican que la resistencia del vaso intacto disminuye cuando aumenta la velocidad de perfusión. Cuando este mismo protocolo se realizó en ausencia de $\mathrm{Ca}^{2+}$ externo (en solución $\mathrm{KRB}$ sin $\mathrm{Ca}^{2+}$ ) se encontró que la disminución de la resistencia es mayor a todas las velocidades ensayadas. 


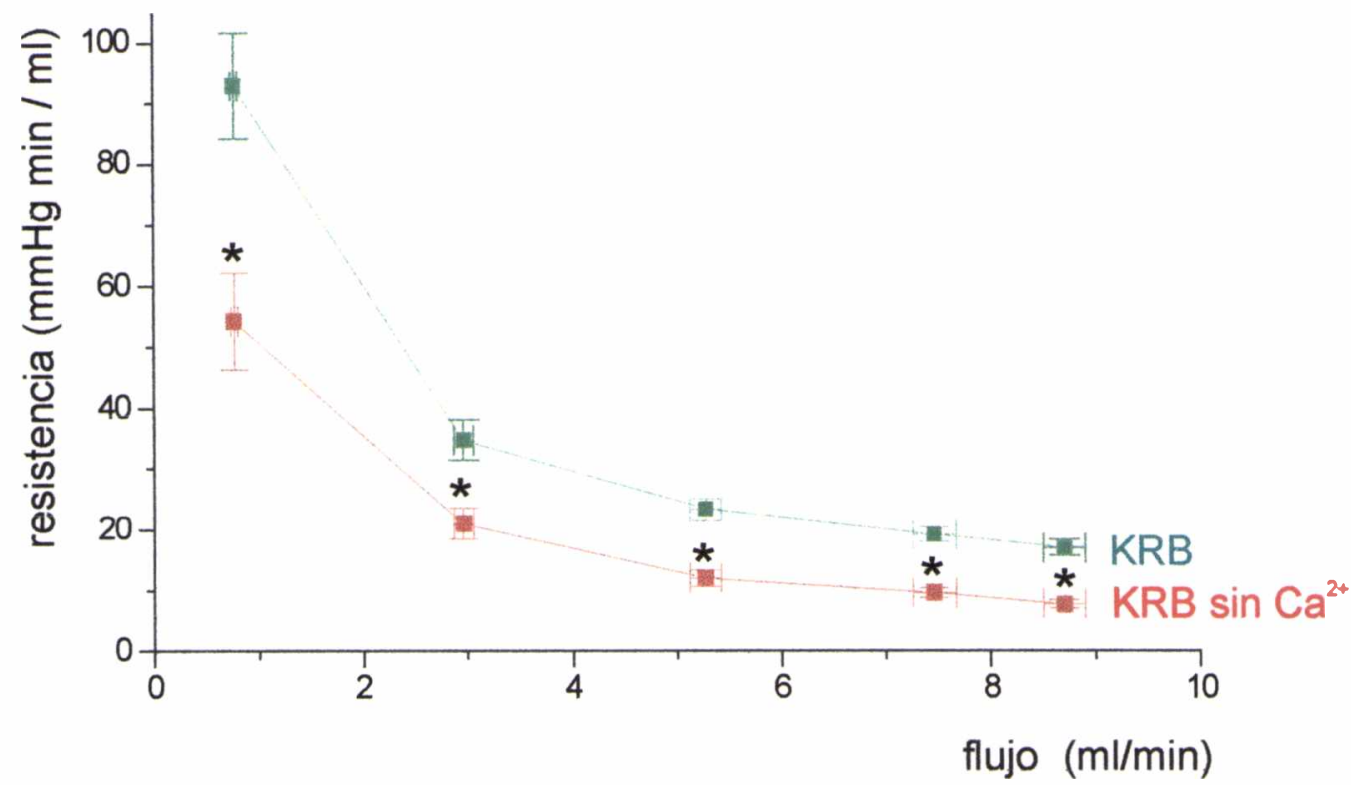

Figura 26: curvas de resistencia vascular $(\mathrm{mmHg} \mathrm{min} / \mathrm{ml})$ de segmentos de AUH perfundidos en presencia (KRB) y en ausencia de $\mathrm{Ca}^{2+}\left(\mathrm{KBR} \sin \mathrm{Ca}^{2+}\right)$, en función del flujo correspondiente a las distintas velocidades de perfusión. " indica diferencia significativa entre los valores de resistencia en presencia y en ausencia de $\mathrm{Ca}^{2+}$ a la misma velocidad $(n=8$ para todos los puntos, $p<0,05$ ).

En otro grupo de experimentos, manteniendo la mínima velocidad de la bomba de perfusión constante durante todo el experimento (la cual en este caso arrojó un promedio de 1,21 $\pm 0,10 \mathrm{ml} / \mathrm{min}, \mathrm{n}=13$ ), los segmentos arteriales de $A U H$ fueron estabilizados en presencia de una solución KRB sin $\mathrm{Ca}^{2+}$ durante 60 minutos, observándose al final de este periodo un valor estable de presión de $13 \pm$

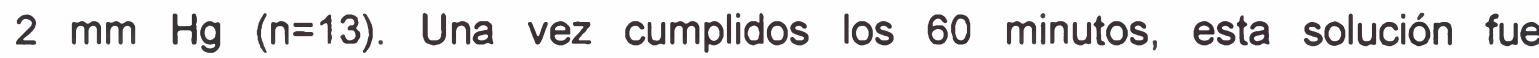
reemplazada por una solución KRB con distintas concentraciones de $\mathrm{Ca}^{2+}$ observándose que esta intervención genera un aumento de la presión de perfusión y que el mismo es dependiente de la concentración de $\mathrm{Ca}^{2+}$ que contenía la solución. Esta respuesta muestra dos fases, un aumento inicial de presión (pico) que luego se estabiliza en un valor menor (meseta). Al final de cada experimento se reemplazó la solución de perfusión por una solución KRB despolarizante con alto $\mathrm{K}^{+}$la cuál indujo un aumento ulterior de la presión de perfusión. El valor de la presión alcanzado en los segmentos de $\mathrm{AUH}$ cuando se agrega 1,6 $\mathrm{mM}$ de $\mathrm{Ca}^{2+}$ luego de un período de perfusión en solución KRB sin $\mathrm{Ca}^{2+}$ fue de 151,02 $\pm 32,42$ $\mathrm{mmHg}$. Este valor es mayor que el obtenido cuando este tipo de experimento se realiza en presencia de 1,6 $\mathrm{mM}$ de $\mathrm{Ca}^{2+}$ durante el período de estabilización $(77,26$ $\pm 7,95 \mathrm{mmHg}$ ) y el aumento de la presión inducido por el agregado de $\mathrm{Ca}^{2+}$ no fue 
observado en otros vasos ensayados como la arteria aorta o el lecho mesentérico de rata. En la figura 27 pueden observarse ejemplos típicos de estas respuestas y los valores medios de presión de perfusión, expresados como porcentaje de la respuesta al alto $\mathrm{K}^{+}$, en función de la concentración de $\mathrm{Ca}^{2+}$ ensayada en la $\mathrm{AUH}$.

A
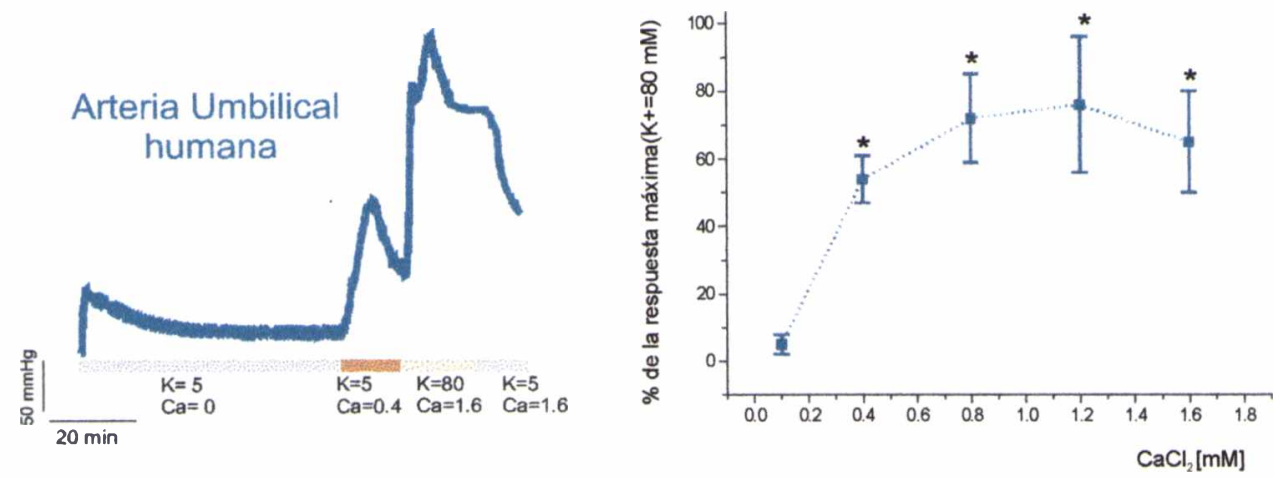

B
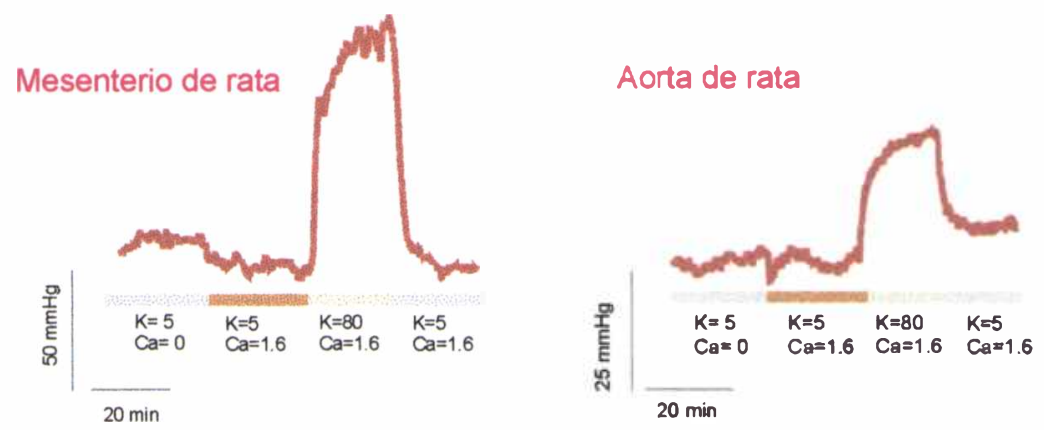

Figura 27: A -panel izquierdo - ejemplo típico de un registro de presión de perfusión en un segmento de $A U H$ realizado a velocidad minima de perfusión. Los segmentos arteriales fueron estabilizados en solución KRB sin $\mathrm{Ca}^{2+}$ (60 minutos), la cual luego se reemplazó por una solución $\mathrm{KRB}$ con distintas concentraciones de $\mathrm{Ca}^{2+}$ (en este caso 0,4 $\mathrm{mM}$ ). Al final de cada experimento se reemplazó la solución de perfusión por una solución KRB- $80 \mathrm{mM} \mathrm{K}^{+}$. -Panel derecho-valores medios de presión de perfusión obtenidos para las distintas concentraciones de $\mathrm{Ca}^{2+}$ utilizando el protocolo ejemplificado en el panel izquierdo (" significa diferencia significativa de cero, $n=9$ en cada punto, $p<0,05)$. B- Ejemplos típicos de este mismo protocolo aorta y arterias mesentéricas de rata.

Los resultados de registros de fuerza isométrica presentados hasta aqui y la comparación de las respuesta de presión de perfusión a velocidad variable o constante en presencia de diferentes concentraciones de $\mathrm{Ca}^{2+}$ externo sugieren que esta arteria responde al estiramiento de la pared vascular evocando una respuesta contráctil activa dependiente del $\mathrm{Ca}^{2+}$ extracelular que podría asimilarse a la respuesta miogénica descripta en otros vasos.

Tomando como base estos resultados y utilizando la misma metodología experimental se decidió profundizar en el estudio de las estructuras de membrana que podrian estar implicadas en este fenómeno. Tal como se describió en la 
"introducción" de este trabajo canales de $\mathrm{Ca}^{2+}$ operados por voltaje y canales CNS son las estructuras de membrana más comúnmente halladas como mediadoras del influjo de $\mathrm{Ca}^{2+}$ en esta respuesta. El intercambiador $\mathrm{Na} / \mathrm{Ca}$ actuando en su modo reverso también podría mediar un influjo de $\mathrm{Ca}^{2+}$ que contribuya al desarrollo de tono miogénico de estas arterias.

La corriente catiónica no selectiva caracterizada en los experimentos electrofisiológico podría ser responsable de un influjo de $\mathrm{Ca}^{2+}$ contribuyendo a dicha respuesta contráctil, por to tanto se evaluó el efecto de los distintos inhibidores de la corriente CNS sobre el desarrollo de fuerza producido por el estiramiento de anillos de $\mathrm{AUH}$ a $2 \mathrm{gF}$, lo que corresponde a un valor aproximado

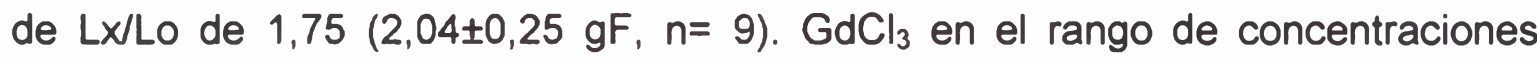
entre 100 y $250 \mu \mathrm{M}, \mathrm{LaCl}_{3} 100 \mu \mathrm{M}$ y $\mathrm{MgSO}_{4} 5 \mathrm{mM}$ (SKR-alto $\mathrm{Mg}^{2+}$ ) relajaron significativamente los anillos vasculares en estas condiciones. Las concentraciones de $\mathrm{GdCl}_{3}$ que resultaron efectivas para relajar la $\mathrm{AUH}$ fueron mayores que las utilizadas en la solución SEN para inhibir la corriente iónica. Esto último probablemente se deba a la presencia de $\mathrm{CO}_{3} \mathrm{H}^{-}$y $\mathrm{PO}_{4}{ }^{3-}$ en la solución $K R B$, ya que se ha informado que estas sustancias pueden disminuir la concentración libre de $\mathrm{Gd}^{3+}(217)$. Los valores medios obtenidos para el efecto de estos bloqueantes sobre los anillos de AUH se resumen en la figura 28.
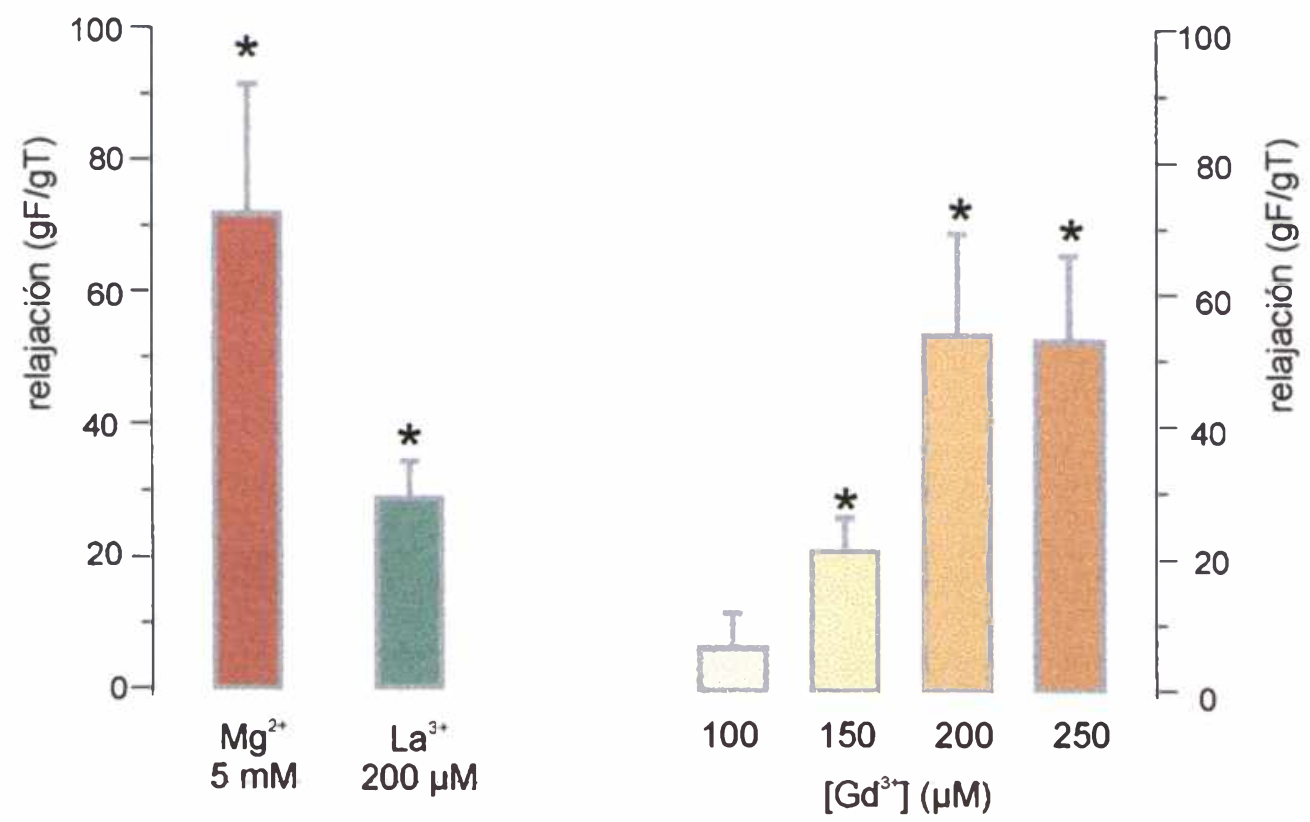

Figura 28: barras representando los valores medios \pm ESM para el efecto relajante sobre anillos de AUH de los distintos bloqueantes de los canales catiónicos no selectivos $(n=13$ para cada concentración de $\mathrm{Gd}^{3+}$ ensayada, $\mathrm{n}=18$ para $\mathrm{Mg}^{2+}$ y $\mathrm{n}=9$ para $\mathrm{La}^{3+}$,

* indica diferencia significativa de cero, $p<0,05$ ). 
Existen referencias bibliográficas donde se informa que el $\mathrm{Gd}^{3+}$ tiene la capacidad de inhibir en forma directa canales de $\mathrm{Ca}^{2+}$ operados por voltaje en algunos tipos celulares (218); por lo tanto se indagó en la AUH la posibilidad de que el $\mathrm{Gd}^{3+}$ produjera vasorrelajación por bloqueo de canales de $\mathrm{Ca}^{2+}$. Para esto se indujo contracción de los anillos vasculares con una solución despolarizante conteniendo $80 \mathrm{mM}$ de $\mathrm{K}^{+}$, la cual produce activación de canales de $\mathrm{Ca}^{2+}$ operados por voltaje, influjo de $\mathrm{Ca}^{2+}$ y contracción. Este protocolo se aplicó en anillos con y sin preincubación con una dosis saturante de $\mathrm{Gd}^{3+}(250 \mu \mathrm{M})$ y se encontró que la contracción evocada no fue afectada por este bloqueante (en presencia de $\mathrm{Gd}^{3+}=$ $137,6 \pm 18,1 \mathrm{gF} / \mathrm{gT}, \mathrm{n}=10$; vs control $=176,7 \pm 36,5 \mathrm{gF} / \mathrm{gT} n=15$; N.S.), mientras que $10 \mu \mathrm{M}$ de nifedipina, un bloqueante específico de canales de $\mathrm{Ca}^{2+}$ operados por voltaje, la relajó completamente (Figura 29). Este resultado descarta la posibilidad de que el efecto relajante de $\mathrm{Gd}^{3+}$ se deba a un bloqueo de canales de $\mathrm{Ca}^{2+}$ voltaje operados y refuerza la hipótesis de que canales $\mathrm{CNS}$ estén mediando un influjo de $\mathrm{Ca}^{2+}$ que contribuya a la respuesta miogénica de esta arteria.
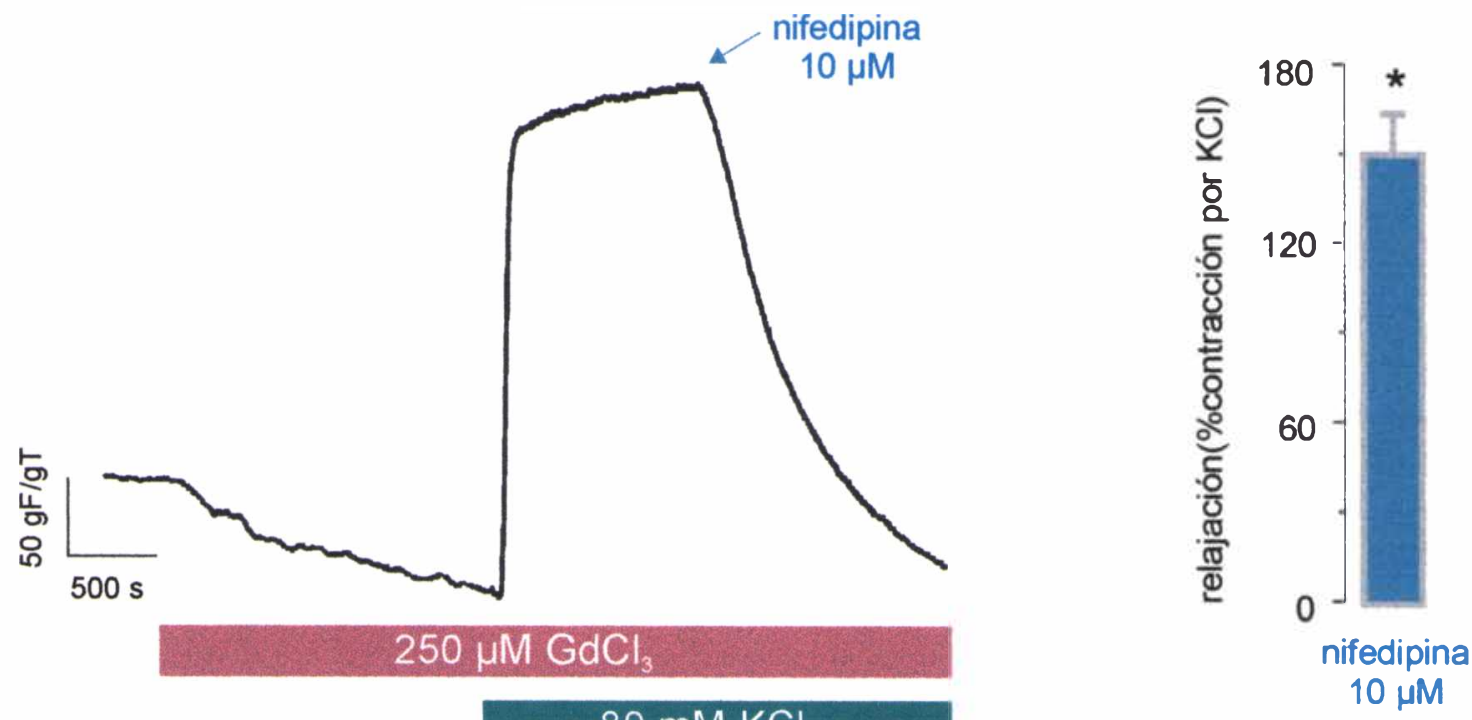

$80 \mathrm{mM} \mathrm{KCl}$

Figura 29: panel izquierdo- ejemplo típico mostrando la contracción por KRB - $80 \mathrm{mM} \mathrm{K}$ en presencia de $250 \mu \mathrm{M}$ de $\mathrm{Gd}^{3+}$ y la relajación posterior que produce $10 \mu \mathrm{M}$ de nifedipina y panel derecho- barra representando el valor medio \pm ESM de la relajación por $10 \mu \mathrm{M}$ de nifedipina expresada como porcentaje de la contracción por KRB $-80 \mathrm{mM} \mathrm{K}^{+}(n=7$ anillos, * indica diferencia significativa de cero, $p<0,05$ ).

Por otro lado. cuando se ensayó nifedipina, sobre el desarrollo de fuerza isométrico en respuesta al estiramiento inicial se observó que la misma a una 
concentración de $10 \mu \mathrm{M}$ produce relajación del segmento vascular $(-19,0 \pm 7,5$ $g F / g T, n=31, p<0,05)$ y no se observó ningún efecto a dosis menores.

En otra serie de experimentos se indagó el efecto de $\mathrm{GdCl}_{3}(200 \mu \mathrm{M})$ y $\mathrm{MgCl}_{2}$ (5 mM) sobre anillos sometidos a distintas tensiones de estiramiento y se realizaron las curvas fuerza-longitud respectivas. En las mismas se observó que los valores de fuerza obtenidos en presencia de dichos bloqueantes fueron significativamente menores respecto de la curva control y no se diferenciaron de aquellos obtenidos en ausencia de $\mathrm{Ca}^{2+}$ externo (figura 30 ).

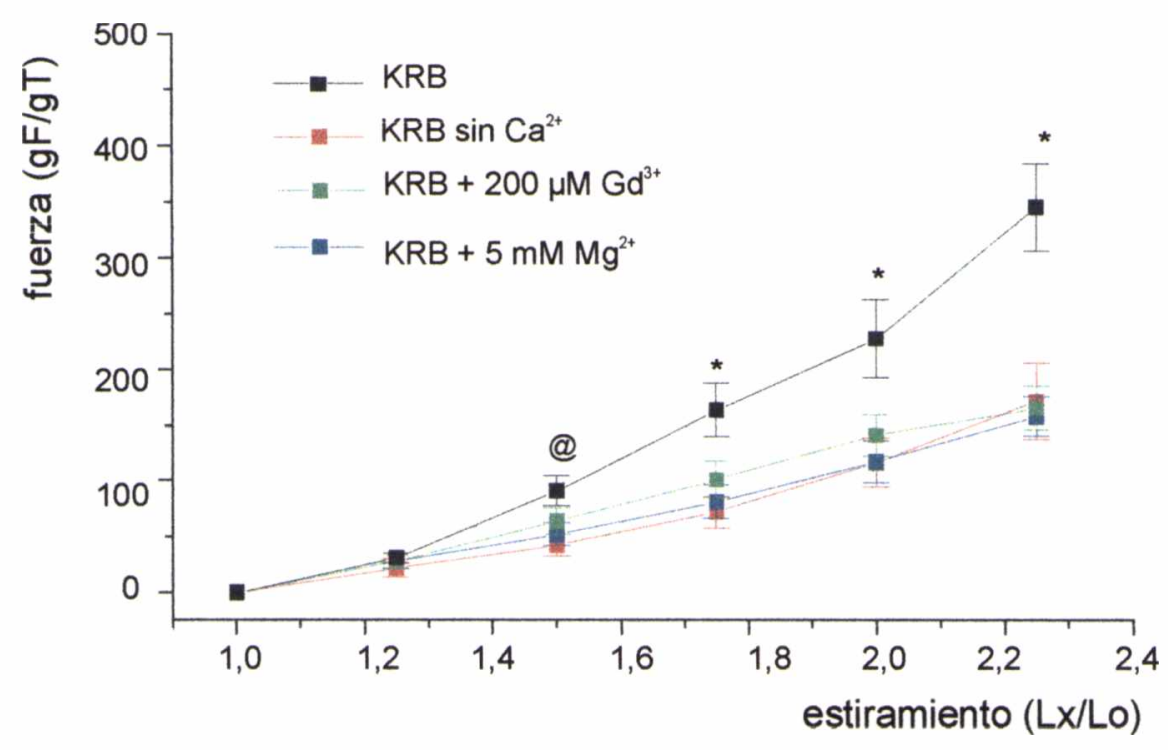

Figura 30: curvas de fuerza normalizada ( $\mathrm{gF} / \mathrm{gT}$ ) desarrollada en función del estiramiento ( $L$ X Lo) realizadas en distintas condiciones (ver texto). * indica diferencia significativa entre los valores en presencia de $\mathrm{Mg}^{2+}$, en presencia de $\mathrm{Gd}^{3+}$, en ausencia de $\mathrm{Ca}^{2+}$ y el valor en KRB en ausencia de estos bloqueantes y @ indica diferencia entre KRB y KRB- $\sin \mathrm{Ca}^{2+}$ (analizado por ANOVA con un test posterior de Dunnett, considerando los valores en KRB como controles, $n=9$, $p<0,05$.)

Se evaluó también si los canales CNS participaban en la respuesta contráctil evocada por el agregado de $\mathrm{Ca}^{2+}$ a la solución de perfusión en segmentos arteriales perfundidos con solución sin $\mathrm{Ca}^{2+}$ a velocidad mínima constante. El protocolo se realizó en condiciones control (anteriormente descriptas) y en presencia de $200 \mu \mathrm{M}$ de $\mathrm{GdCl}_{3}$ durante los últimos 20 minutos del período de perfusión con solución KRB sin $\mathrm{Ca}^{2+}$. La preincubación con $\mathrm{Gd}^{3+}$ provocó una disminución significativa en el valor de presión de perfusión (pico y meseta) desarrollado en respuesta al agregado de $\mathrm{Ca}^{2+}$ a la solución de perfusión. Además, y al igual que lo observado en los experimentos de fuerza isométrica, la 
presencia de $\mathrm{Gd}^{3+}$ no disminuyó la respuesta contráctil del vaso evocada por la solución despolarizante con alto $\mathrm{K}^{+}$. La figura 31 muestra los valores medios de presión de perfusión obtenidos en esta serie de experimentos y su comparación con los valores control.

A

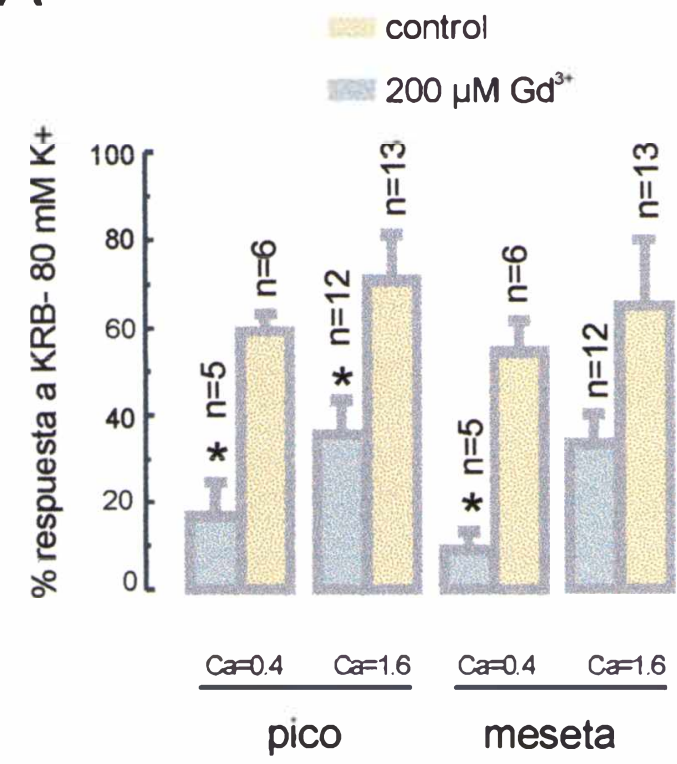

B

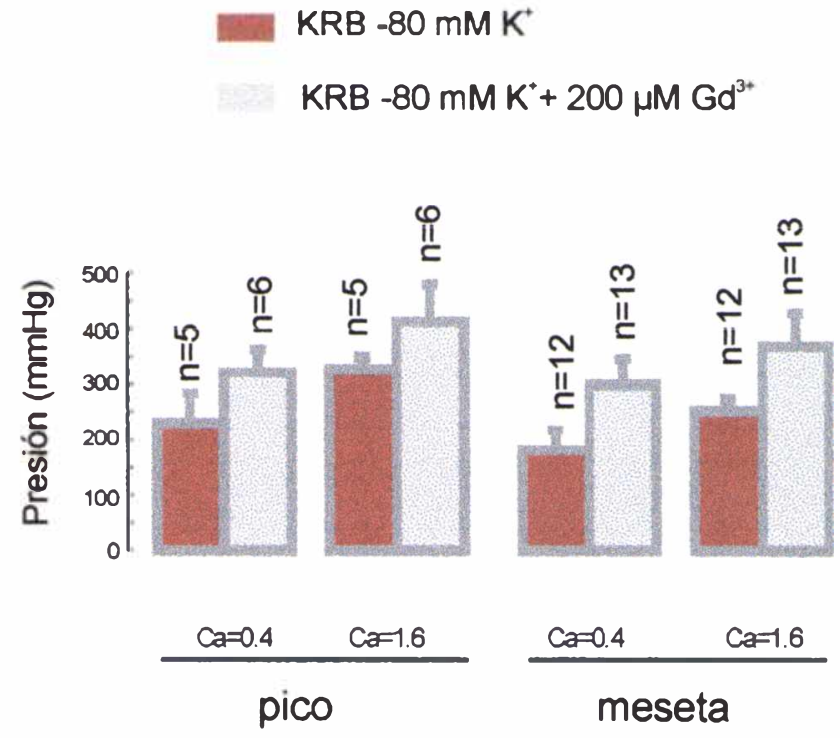

Figura 31: A- Las barras representan los valores medios \pm ESM de la respuesta contráctil evocada por el agregado de $\mathrm{Ca}^{2+}(0.4$ y $1.6 \mathrm{mM})$ a la solución de perfusión (pico y meseta) en ausencia o presencia de $200 \mu \mathrm{M}$ de $\mathrm{Gd}^{3+}$ (* indica diferencia significativa del valor medio en ausencia de $\left.\mathrm{Gd}^{3+}, p<0,05\right)$. B- Respuesta contráctil del vaso evocada por la solución despolarizante con alto $\mathrm{K}^{+}$en ausencia o presencia de $200 \mu \mathrm{M}$ de $\mathrm{Gd}^{3+}$.

El intercambiador $\mathrm{Na} / \mathrm{Ca}$ (NCX) funcionando en modo reverso constituye otra posible vía de entrada de $\mathrm{Ca}^{2+}$, por lo tanto se evaluaron los efectos de los siguientes bloqueantes del intercambiador sobre la fuerza isométrica desarrollada en respuesta al estiramiento inicial de $2 \mathrm{gF}$ sobre anillos vasculares de AUH:

$\checkmark \mathrm{NiCl}_{2}(2 \mathrm{mM})$ : bloqueante inespecífico de los dos modos del intercambiador.

$\checkmark \quad$ KB-R7943 $(5 \mu \mathrm{M})$ : bloqueante especifico del modo reverso del intercambiador. 
Ambos bloqueantes producen relajación significativa de la respuesta miogénica de la AUH. La figura 32 muestra ejemplos típicos y los valores promedio de estas relajaciones.
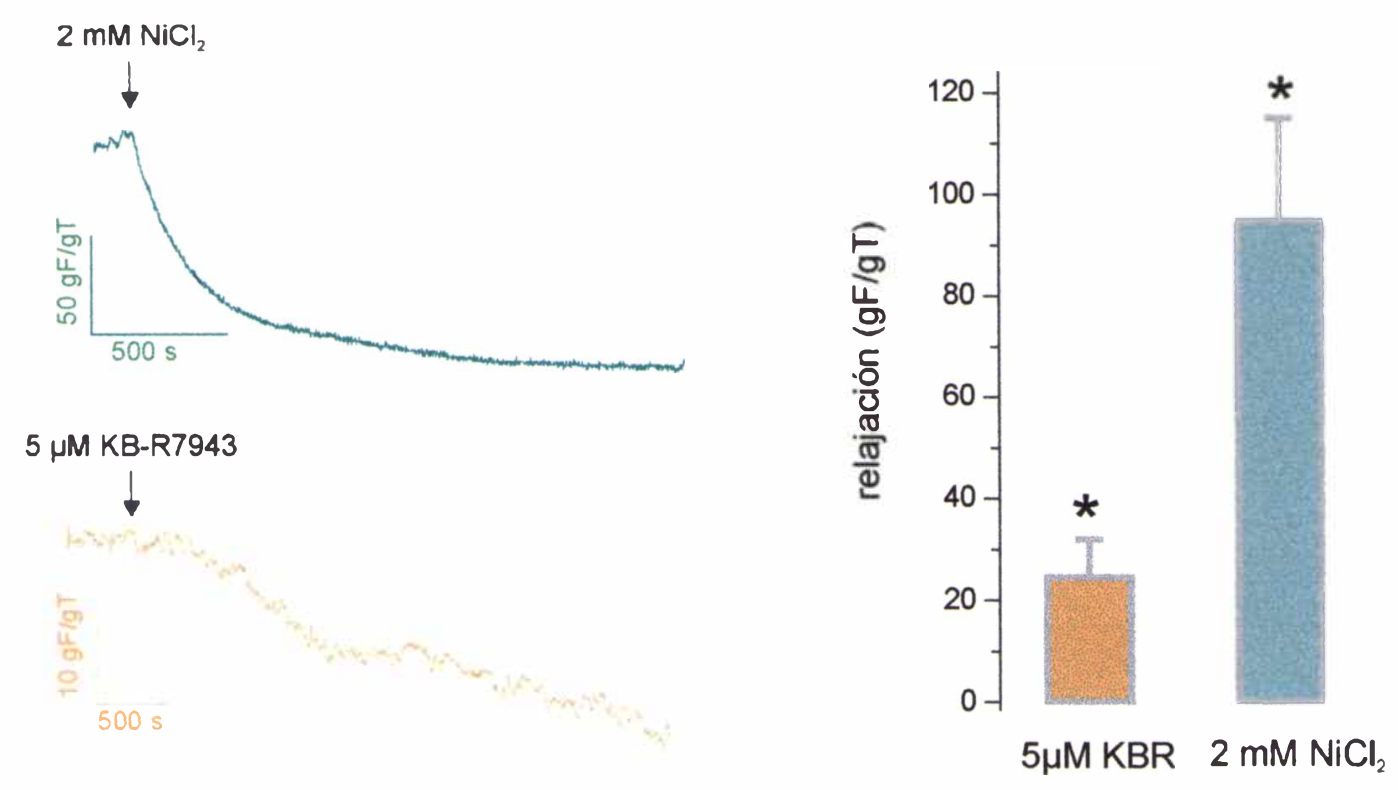

Figura 32: ejemplos típicos de las relajaciones producidas sobre el tono miogénico de anillos de AUH por los bloqueantes del NCX: $\mathrm{NiCl}_{2}(2 \mathrm{mM})$ y KB-R7943 $(5 \mu \mathrm{M})$ y barras representando los valores promedio \pm ESM de estas relajaciones $(n=8$ para KB-R7943 y $n=18$ para $\mathrm{NiCl}_{2}$, indica diferencia significativa de cero, $\mathrm{p}<0,05$ ).

Estos resultados sugieren que en estas condiciones experimentales al menos una proporción de los NCX presentes en la membrana plasmática de las células de músculo liso de la $\mathrm{AUH}$ funciona en modo reverso manteniendo el tono miogénico.

Ha sido descripto en numerosos trabajos (15) que la reducción del $\mathrm{Na}^{+}$ extracelular puede modificar la actividad del NCX disminuyendo la salida de $\mathrm{Ca}^{2+}$ de la célula (menor actividad en el modo directo) o incluso activando la entrada de $\mathrm{Ca}^{2+}$ (en el modo reverso). Se investigó entonces si era posible estimular el modo reverso del NCX disminuyendo el $\mathrm{Na}^{+}$extracelular. Para esto se ensayó el efecto de una solución $\mathrm{KRB}$ donde todo el $\mathrm{NaCl}$ fue reemplazado isosmóticamente por $\mathrm{D}(+)$-sacarosa (KRB-bajo $\mathrm{Na}^{+}$). La solución KRB-bajo $\mathrm{Na}^{+}$produjo una contracción que muestra dos fases: un pico transitorio que alcanza un valor de fuerza de 157,2 $\pm 54,8 \mathrm{gF} / \mathrm{gT}$ que luego se estabiliza en un valor de fuerza menor de $86,8 \pm 31,7$ $\mathrm{gF} / \mathrm{gT}$ ( $n=8$ anillos, $\mathrm{p}<0,05)$. En presencia de los bloqueantes del $\mathrm{NCX}\left(\mathrm{Ni}^{2+}\right.$ y KB$\mathrm{R} 7943$ ) esta contracción disminuye significativamente en ambas fases. En la figura 33 se presentan los valores medios de fuerza en cada condición y un ejemplo 
típico de este experimento en condiciones control y en presencia de KB-R7943. Sin embargo no se logró inhibir totalmente esta contracción ni aún utilizando 10 $\mu \mathrm{M}$ de KB-R7943 (datos no mostrados).

A

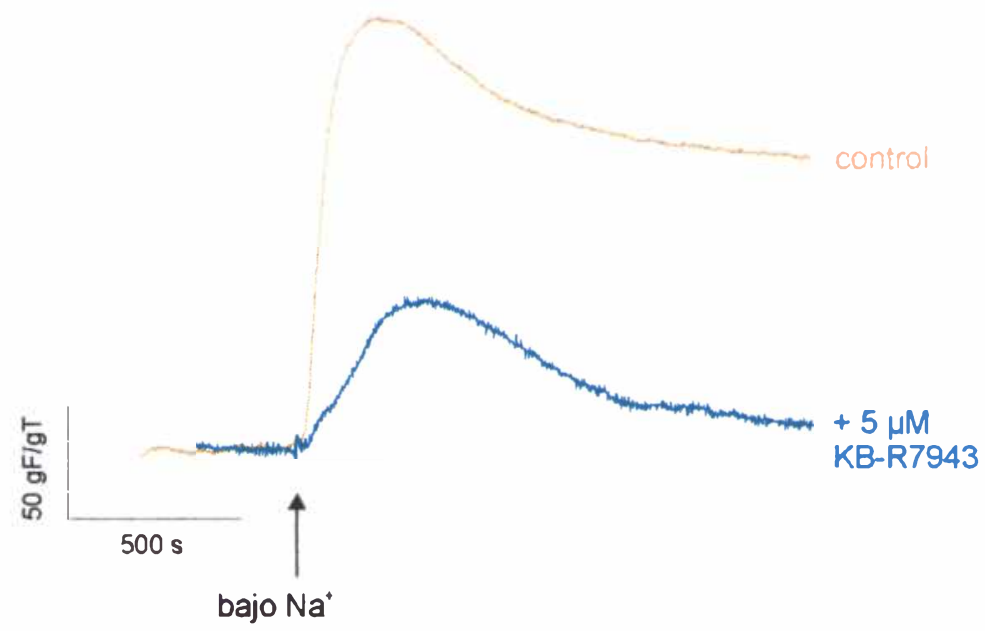

B
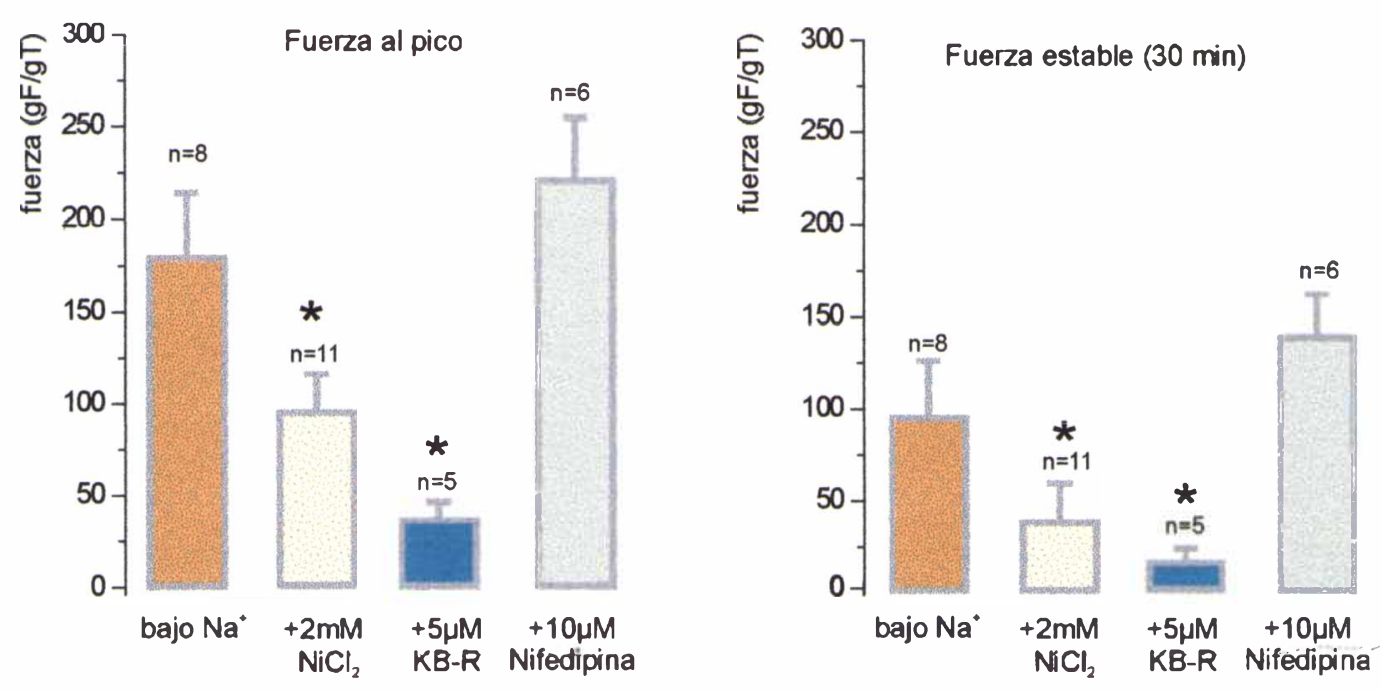

Figura 33: Efecto contráctil sobre anillos vaculares de AUH de la solución KRB-bajo $\mathrm{Na}^{+} \mathrm{A}^{-}$ ejemplo típico de esta contracción en ausencia y en presencia de $5 \mu \mathrm{M}$ de KB-R7943. B- Gráfico de barras representando los valores medios de fuerza al pico y estable \pm ESM para la contracción por bajo $\mathrm{Na}^{+}$en condición control y en presencia de $5 \mu \mathrm{M}$ de KB-R7943, $2 \mathrm{mM}$ de $\mathrm{NiCl}_{2} \circ 10 \mu \mathrm{M}$ de nifedipina. (" indica diferencia respecto de la condición control, analizado por test de ANOVA con posterior test de Dunnett, $p<0,05$ )

Con el objetivo de poner en evidencia si existe un influjo de $\mathrm{Ca}^{2+}$ a través del NCX funcionando en modo reverso, se estudió en otra serie de experimentos la dependencia del $\mathrm{Ca}^{2+}$ externo de la contracción inducida por la solución de bajo 
$\mathrm{Na}^{+}$. Cuando los anillos vasculares son estimulados con una solución de bajo $\mathrm{Na}^{+}$ sin el agregado de $\mathrm{CaCl}_{2}$ (KRB-bajo $\mathrm{Na}^{+} \sin \mathrm{Ca}^{2+}$ ) la respuesta fue significativamente inhibida observándose sólo una pequeña contracción transitoria (fuerza al pico $=12,5 \pm 0,9 \mathrm{gF} / \mathrm{gT}, \mathrm{p}<0,05$; fuerza sostenida $=23,5 \pm 11,0 \mathrm{n}=4$ anillos, N.S.). Además, se observo que $10 \mu \mathrm{M}$ de nifedipina no modificó esta respuesta, indicando que los canales de $\mathrm{Ca}^{2+}$ operados por voltaje no estarian involucrados en el efecto contráctil producido por la reducción del $\mathrm{Na}^{+}$externo (figura 33).

En base al hecho de que la reducción de la concentración de $\mathrm{Na}^{+}$ extracelular, en nuestros experimentos, implica también la sustitución del anión $\mathrm{Cl}^{-}$ por $\mathrm{D}(+)$-sacarosa, se realizaron experimentos control donde solo se disminuyó la concentración de $\mathrm{Cl}^{-}$y se mantuvo la concentración de $\mathrm{Na}^{+}$(el $\mathrm{NaCl}$ de la solución extracelular fue reemplazado por gluconato de sodio en forma isosmótica). Este cambio no produjo ningún efecto contráctil en la $\mathrm{AUH}(14,2 \pm 6,6 \mathrm{gF} / \mathrm{gT}, \mathrm{n}=6$ anillos, N.S.).

Potencial de membrana $v$ tono miogénico: Como se mencionó en la "introducción", la modificación del potencial de membrana y de la actividad de los canales de $\mathrm{K}^{+}$participan en la regulación del tono miogénico $(16,17)$. La actividad basal de los canales de $\mathrm{K}^{+}$regula el potencial de membrana de las células de músculo liso y así, el grado de polarización de estas células podría influenciar la respuesta miogénica en la $\mathrm{AUH}$. Por lo tanto, se investigó en primer lugar la respuesta de esta arteria a diferentes soluciones despolarizantes y luego mediante el uso de inhibidores, la participación de los distintos tipos de canales de $\mathrm{K}^{+}$ previamente estudiados y caracterizados electrofisiologicamente en las células aisladas de $\mathrm{AUH}$.

Al investigar el efecto producido por la modificación del gradiente de $\mathrm{K}^{+}$, se observó que el aumento de la concentración extracelular de $\mathrm{K}^{+}$a $20,40,60$ y 80 $\mathrm{mM}$ contrae este vaso en forma dependiente de la concentración. Cuando la contracción producida por una solución $\mathrm{KRB}$ que contiene $80 \mathrm{mM}$ de $\mathrm{KCl}$ se realiza luego de la preincubación con $10 \mu \mathrm{M}$ de nifedipina se encuentra que esta contracción es significativamente menor. La figura 34 resume estos resultados. 


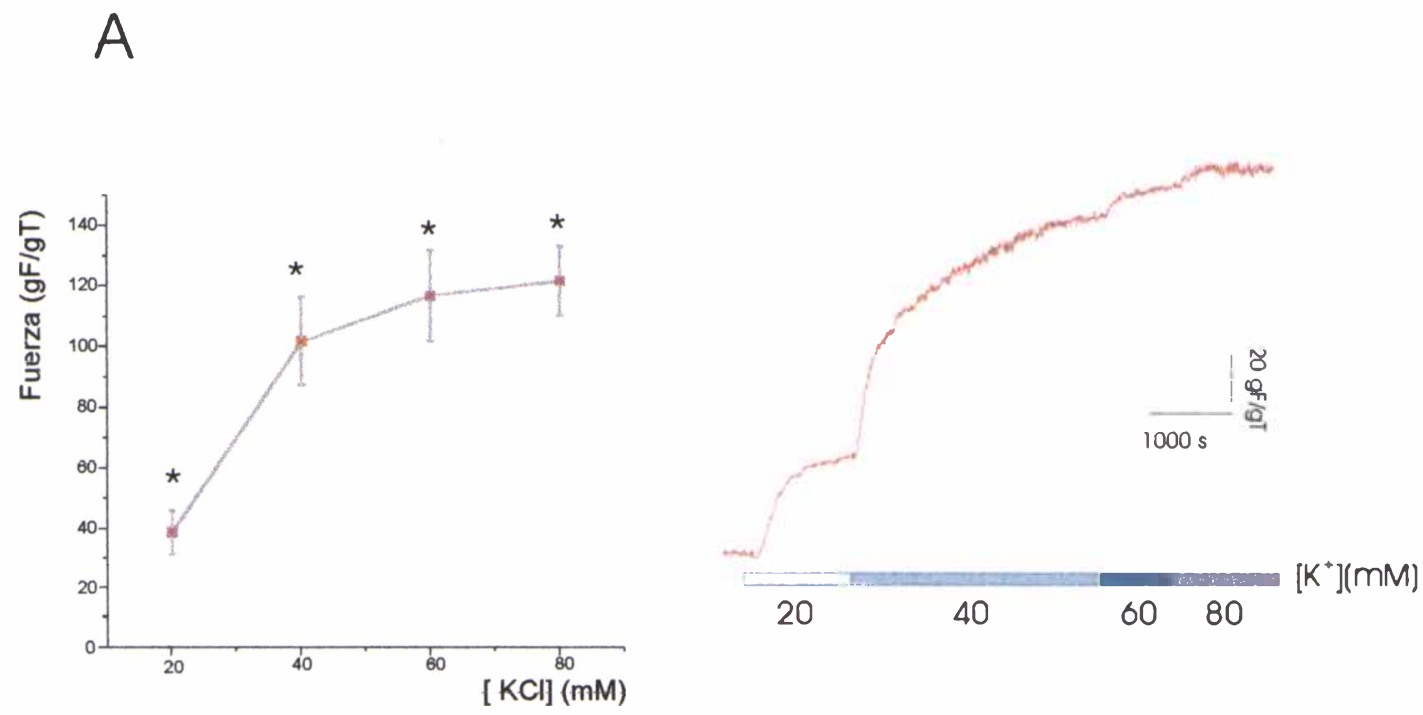

B

Contracción por $80 \mathrm{mM} \mathrm{KCl}$

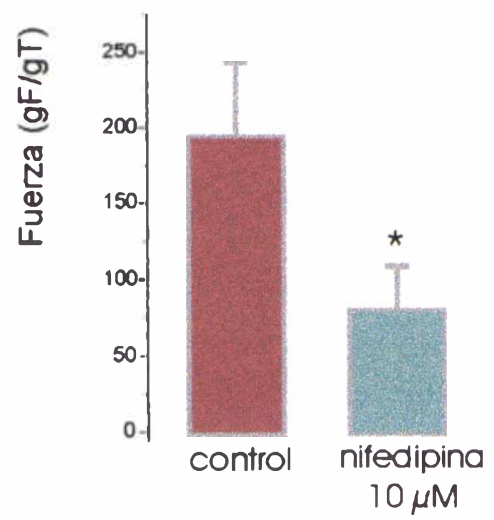

Figura 34: A- Ejemplo tipico y valores medios \pm ESM del efecto contráctil producido por distintas concentraciones de $\mathrm{KCl}$ en la solución KRB (" indica diferencia significativa de cero, $p<0,05, n=7$ en todos los puntos) B- Las barras representan el valor medio \pm ESM de la contracción inducida por KRB $-80 \mathrm{mM}$ de $\mathrm{KCl}$ en ausencia y en presencia de $10 \mu \mathrm{M}$ de nifedipina.

( * indica diferencia significativa del valor control, $p<0,05, n=8$ para cada situación)

Utilizando TEA (1-5 mM) como inhibidor y floretina $50 \mu \mathrm{M}$ como activador de canales de $\mathrm{K}^{+}$de tipo $\mathrm{BK}_{\mathrm{Ca}}$ se evaluó en diferentes series de experimentos el efecto que producen sobre el desarrollo isométrico de fuerza. 2 y $5 \mathrm{mM}$ de TEA produjeron contracción del anillo en forma dependiente de la dosis $(8,5 \pm 3,1$ y $22,3 \pm 5,2 \mathrm{gF} / \mathrm{gT}$, respectivamente $\mathrm{n}=9$ anillos, $p<0,05$ ) mientras que TEA $1 \mathrm{mM}$ no modificó el tono miogénico $(0,5 \pm 1,2 \mathrm{gF} / \mathrm{gT}, n=14$ anillos, N.S.). Floretina (50 $\mu M)$, produjo un efecto relajante significativo sobre el tono miogénico de anillos de esta arteria $(-21,8 \pm 5,6 \mathrm{gF} / \mathrm{gT}, n=7 \mathrm{p}<0,05)$. Estos resultados sugieren que la inhibición de canales $\mathrm{BK}_{\mathrm{Ca}}$ despolariza y aumenta el tono miogénico mientras que la activación de los mismos mediante hiperpolarización lo disminuye (Figura 35). 
A

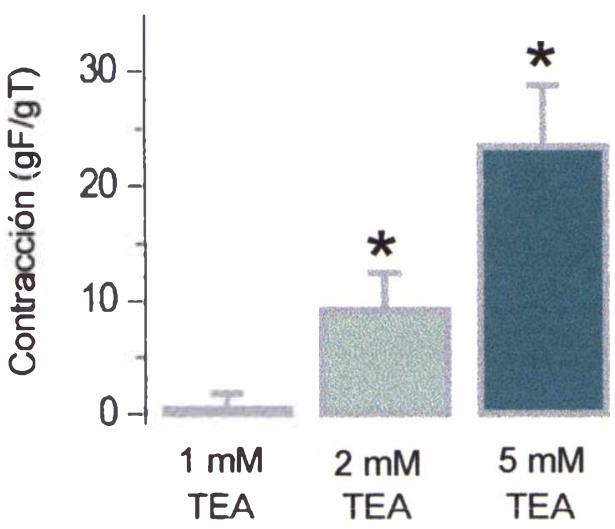

B

$50 \mu \mathrm{M}$ floretina
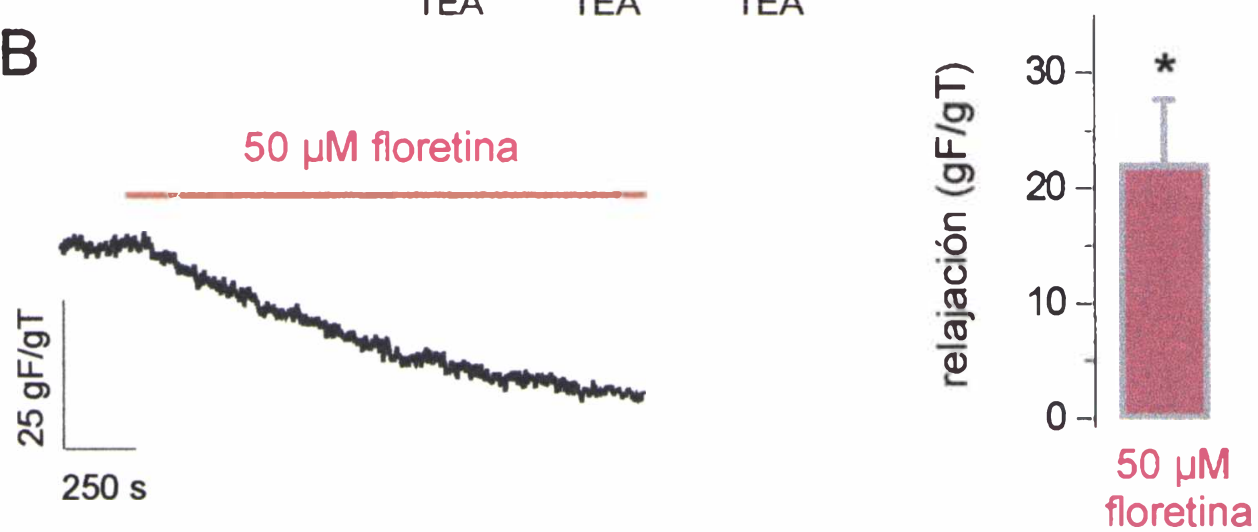

Figura 35: A- Gráfico de barras representando los valores medios \pm ESM para la contracción producida por TEA a distintas concentraciones ("indica diferencia respecto de cero, $n$ $=14,9$ y 9 , respectivamente, $p<0,05$ ) B-Relajación típica producida por $50 \mu \mathrm{M}$ de floretina sobre un anillo vascular de AUH sometido a un estiramiento inicial de $2 \mathrm{gF}$ y gráfico de barras representando el valor medio \pm ESM para este efecto ("indica diferencia respecto de cero, $n=7$, $p<0,05)$

Por otro lado, el bloqueante de canales $\mathrm{K}_{\mathrm{DR}}$ 4-AP $(5 \mathrm{mM})$, que en las células aisladas mostraba un efecto variable sobre la corriente total, no produjo efecto significativo sobre la respuesta miogénica en anillos de AUH $(-5,3 \pm 6,6 \mathrm{gF} / \mathrm{gT}, \mathrm{n}$ $=12$ ).

Finalmente, tomando en cuenta los datos electrofisiológicos que mostraron un aumento en la actividad de canales $\mathrm{BK}_{\mathrm{Ca}}$, en presencia de una sustancia dadora de NO (SNP) se evaluó el rol de los mismos en mecanismos de relajación del vaso que puedan involucrar al NO. En primer lugar, y a partir de los resultados presentados en la figura 26 donde se muestra que la resistencia de la arteria disminuye con el aumento de la velocidad de perfusión, se intento poner en evidencia si este efecto podría deberse al efecto de esfuerzo de corte producido por el cambio de flujo sobre las células endoteliales del vaso el cual induce liberación de NO como factor relajante (denominado vasorrelajación por "shear stress"). Para estudiar esta posibilidad se llevaron a cabo experimentos en 
segmentos arteriales perfundidos y sometidos a diferentes velocidades de perfusión en ausencia (condición control) y en presencia de $0.1 \mathrm{mM}$ de L-NAME, una sustancia que inhibe la producción de NO por la enzima NO-sintasa, o de SNP que adicionaria NO exógeno a la preparación. Los resultados obtenidos en estas dos condiciones mostraron que en presencia de L-NAME la disminución de la resistencia con el flujo es significativamente menor que en la condición control y que en presencia de $10 \mu \mathrm{M}$ de SNP esta caída es significativamente mayor. Si a la presencia de SNP se adiciona $1 \mathrm{mM}$ de TEA el efecto relajante que habia sido observado por acción de SNP se reduce significativamente. Estos resultados, resumidos en la figura 36 sugieren que el NO estaria contribuyendo al efecto relajante mediado por el aumento en la velocidad de perfusión y que los canales BK $K_{\text {a }}$ podrian participar de este mecanismo.

A

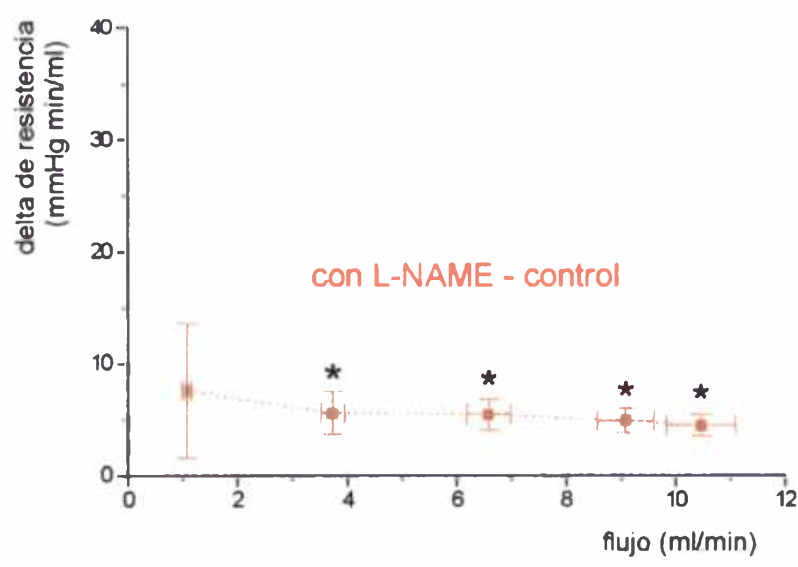

B

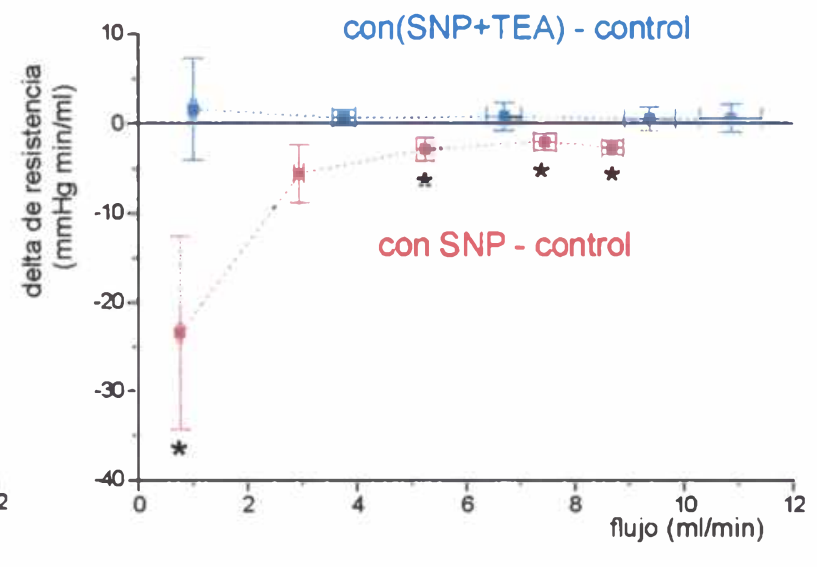

Figura 36:A- Valores medios \pm ESM de la diferencia entre la resistencia en ausencia (condición control) y en presencia de $0.1 \mathrm{mM}$ de L-NAME en los experimentos en segmentos arteriales perfundidos en función del flujo ( $n=10$ para cada valor de flujo). B-Valores medios \pm ESM de diferencias entre las resistencias en ausencia (condición control) y en presencia de 10 $\mu M$ de SNP ( $n=14$ a15 para cada velocidad), y diferencias entre las resistencias en presencia de $10 \mu \mathrm{M}$ de SNP y en presencia de $10 \mu \mathrm{M}$ de SNP y $1 \mathrm{mM}$ de TEA ( $n=9$ para cada velocidad). (en todos los casos * indica diferencia significativa de cero, $p<0,05$ ). 


\section{Caracterización del canal $\mathrm{BK}_{\mathrm{Ca}}$ en células de músculo liso aisladas de arteria mamaria interna humana (AMIH)}

Se realizaron registros de canal único en células de músculo liso aisladas de AMIH en configuración C-A utilizando solución B2 en la pipeta de patch y solución B1 en el baño extracelular.

Aplicando diferentes valores de voltaje se observó la presencia de un canal de alta conductancia. La corriente fue nula a valores de potencial cercanos a cero, como se espera para un canal de $\mathrm{K}^{+}$, trabajando en condiciones simétricas de este ion, y la relación entre el valor de amplitud de la corriente y el potencial aplicado (curva I-V) fue lineal. De la pendiente del ajuste lineal de la curva I-V se obtuvo un valor de conductancia de $228 \pm 4$ pS ( $n=44,8$ células, figura 37). Este valor de conductancia fue observado en el $60,6 \%$ del total de las células ensayadas.

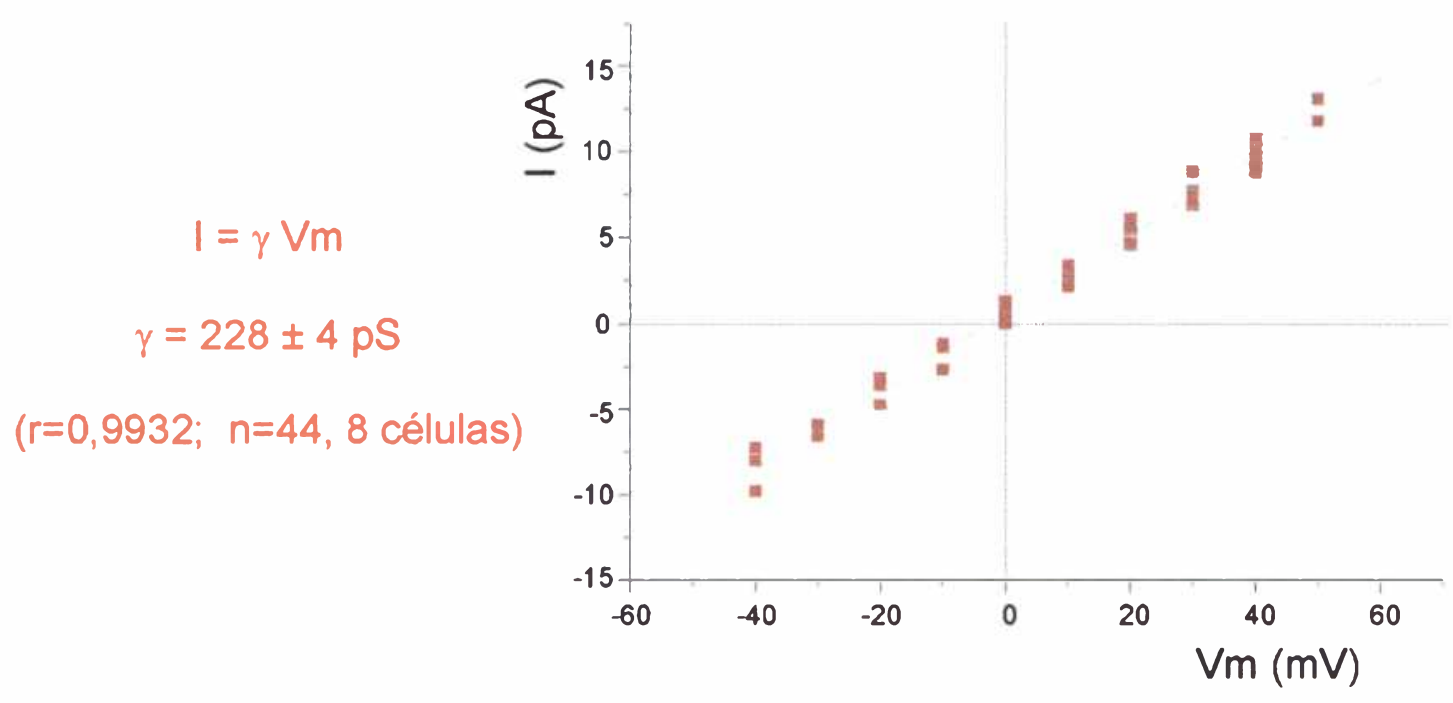

Figura 37: Relación entre el valor de amplitud de la corriente y el potencial aplicado (curva I-V) y parámetros estadisticos del ajuste lineal.

La probabilidad de apertura de este canal (NPo) fue constante en el tiempo y dependiente del potencial aplicado. Así, en las células ensayadas en configuración C-A se observó una relación exponencial de primer orden entre la NPo y el potencial aplicado. En la figura 38 se muestran los parámetros promedios para esta curva y un ejemplo típico de la relación entre la NPo y el potencial aplicado para en una célula. 


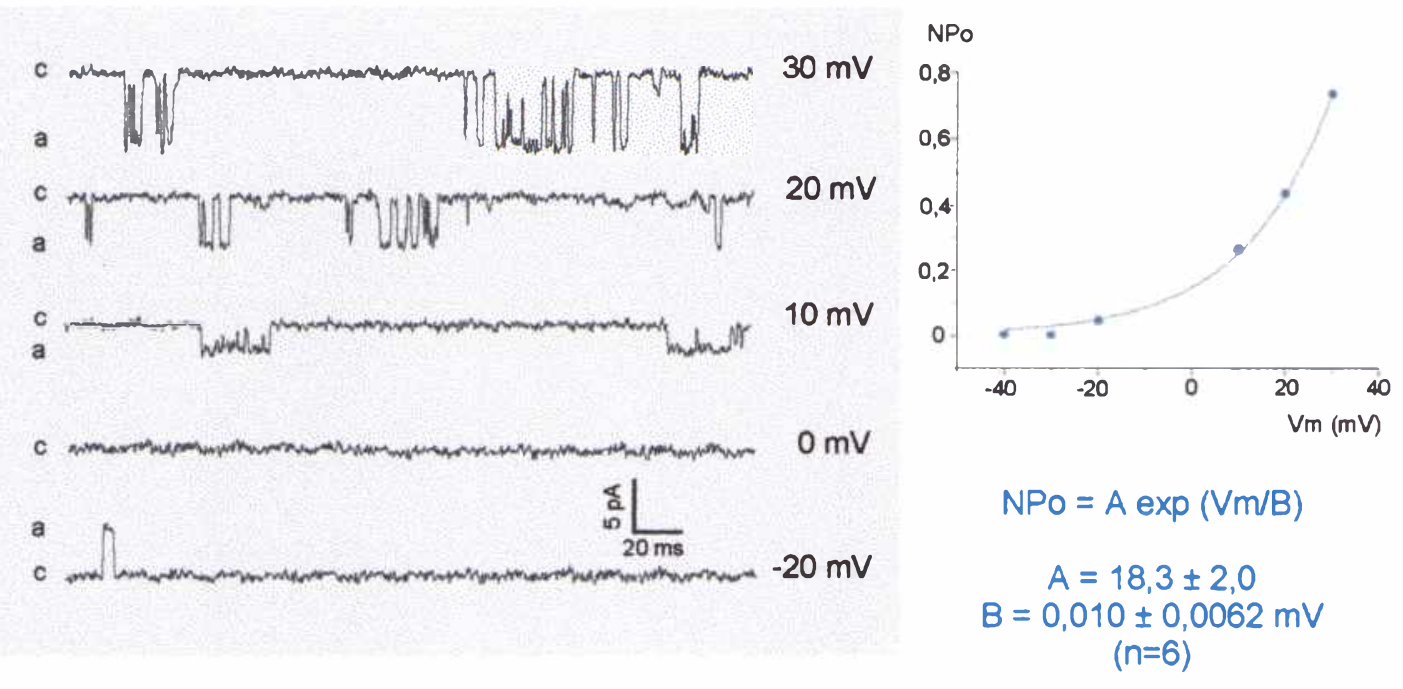

Figura 38: Registros típicos de corriente de canal único a distintos valores de potencial en configuración C-A, relación entre la NPo y el potencial aplicado para una célula y valores medios para los parámetros de la relación exponencial de primer orden entre la NPo y el potencial aplicado.

En base al valor de conductancia obtenido, muy similar al descrito en la literatura para el canal $\mathrm{BK}_{\mathrm{Ca}}$, se realizaron experimentos en $\mathrm{C}-\mathrm{A}$ en presencia de IBTX (100 nM) en el lado extracelular, encontrándose que esta toxina, altamente específica para este tipo de canal, produce un efecto inhibitorio sobre la probabilidad de apertura del canal, confirmando así la presencia del canal $\mathrm{BK}_{\mathrm{Ca}}$ en estas células. Para realizar estos experimentos se utilizaron micropipetas con solución B2 en el sector más cercano a la punta y solución B2 con IBTX (100 nM) en la zona posterior. Esta solución con el tiempo difunde hacia la punta de la pipeta y así la toxina entra en contacto con el canal si éste se encuentra presente en el segmento de membrana. De 22 células estudiadas en estas condiciones 15 no mostraron actividad del canal $\mathrm{BK}_{\mathrm{Ca}}$ en ningún momento del registro y 7 presentaron actividad en los primeros minutos, la cual fue declinando con el tiempo (figura 39). Mediante la realización de un test de Chi-cuadrado se encontró que las variables clasificativas: presencia o ausencia de IBTX en el electrodo y actividad $\mathrm{O}$ no del canal $\mathrm{BK}_{\mathrm{Ca}}$ en la célula no son independientes, permitiendo concluir que la actividad del canal fue realmente sensible a la toxina ( Test de chicuadrado, $p<0.001, n=73$ células). 


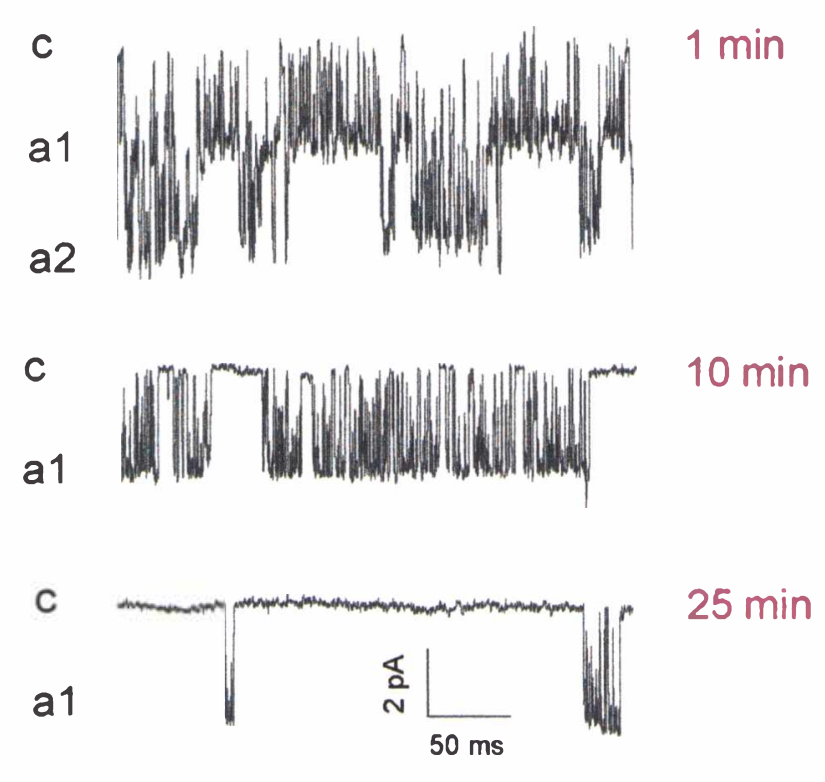

Figura 39: Registro típico de corriente de canal único en función del tiempo en configuración C-A en presencia de IBTX (100 nM).

Cuando se registró a valores fijos de potencial la actividad del canal en C-A en condiciones control y luego se pasó, mediante tracción, a la configuración 1-O, se observó una disminución de la misma, debido posiblemente a la diferencia de concentración del ion $\mathrm{Ca}^{2+}$ entre el medio citoplasmático (en configuración $\mathrm{C}-\mathrm{A}$ ) y la solución del baño (en configuración 1-O). Un ejemplo típico de este comportamiento se puede observar en la figura 40.

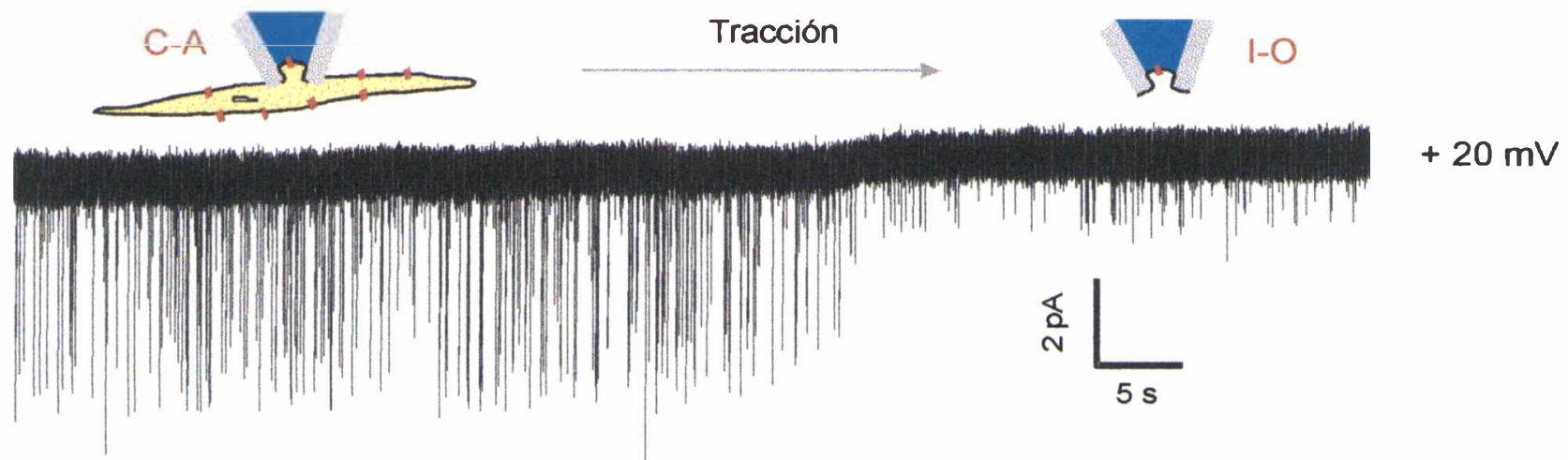

Figura 40: Registro la actividad del canal en condiciones control en C-A y pasaje, mediante tracción, a la configuración I-O, manteniendo fijo el valor de potencial aplicado.

Se estudió la dependencia de la actividad del canal con la concentración de $\mathrm{Ca}^{2+}$ interno en configuración $\mathrm{I}-\mathrm{O}$ registrando la actividad del canal a un potencial fijo de $+20 \mathrm{mV}$ a diferentes concentraciones de $\mathrm{Ca}^{2+}$ libre en la solución de 
perfusión. El valor de NPo aumentó de 0,015 $\pm 0,003$ en solución B1 control ( $\left[\mathrm{Ca}^{2+}\right]_{\text {libre: }} 10^{-8} \mathrm{M}$ ) a $0,097 \pm 0,033$ en solución $\mathrm{B} 1$ con Ca ${ }^{2+}$ libre $10^{-7} \mathrm{M}$ y a 0,265 \pm 0,075 en solución $\mathrm{B} 1$ con $10^{-6} \mathrm{M}$ de $\mathrm{Ca}^{2+}$ libre (ANOVA Test de Tukey, $\mathrm{p}<0,05$, $\mathrm{n}=12$ a 18 células en cada condición). La figura 41 muestra ejemplos de este comportamiento y los valores medios para este experimento.
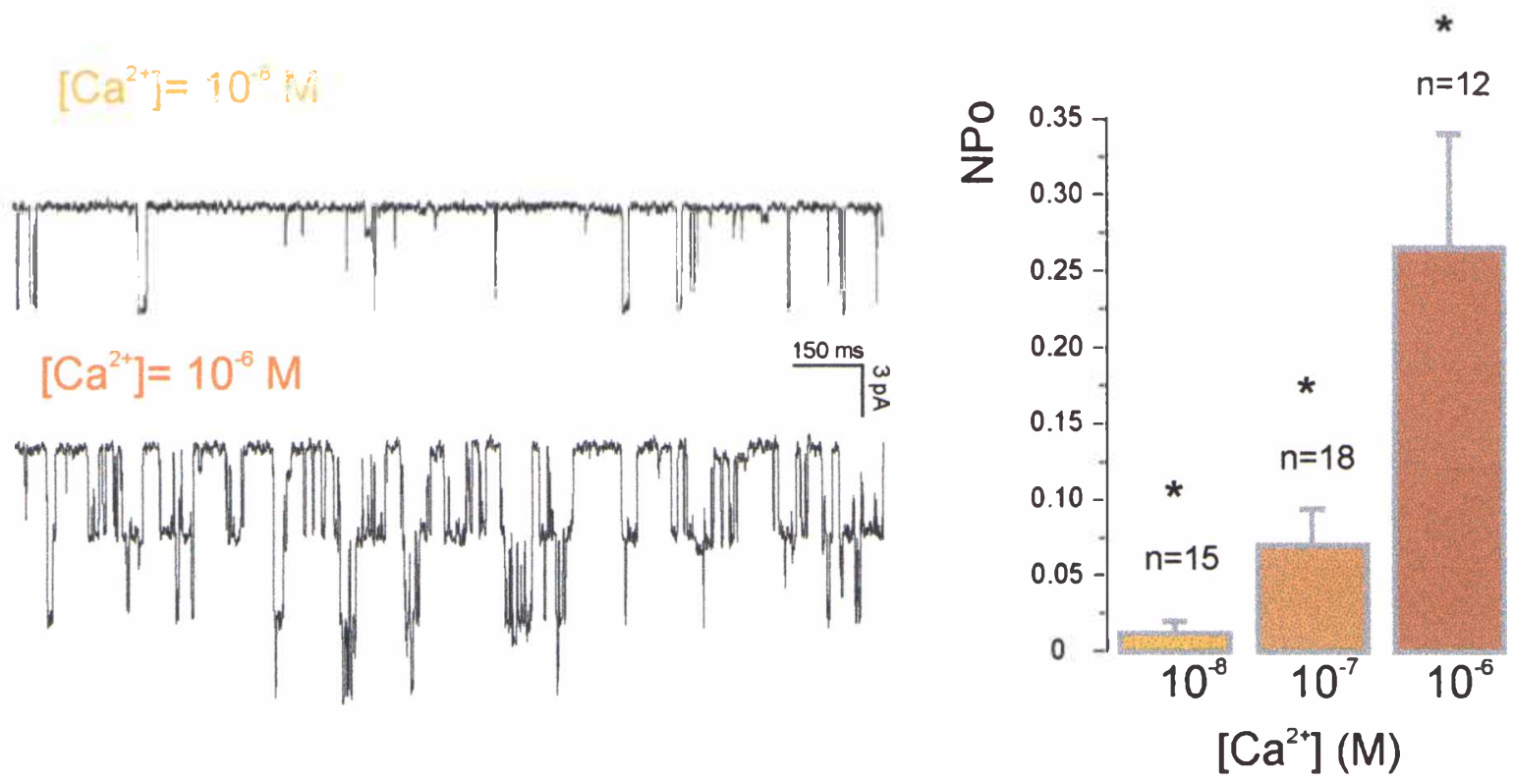

Figura 41: Dependencia de la probabilidad de apertura del canal de la concentración de $\mathrm{Ca}^{2+}$ interno. Registro de corriente de canal único donde se puede observar la activación inducida por aumento de la concentración de $\mathrm{Ca}^{2+} \mathrm{a}+20 \mathrm{mV}$ y en el gráfico de barras los valores medios de NPo \pm ESM . (" indica diferencia entre los grupos por ANOVA y test de Tukey, $p<0,05$ )

\section{Efecto del cambio de $\mathrm{pH}$ sobre la actividad del canal $\mathrm{BK}_{\mathrm{ca}}$}

Con el objetivo de estudiar si la alcalinización $(\mathrm{pH}=7,6)$ y/o la acidificación $(\mathrm{pH}=6,8)$ del medio intracelular modifican la actividad del canal $\mathrm{BK}_{\mathrm{Ca}}$ en la $\mathrm{AMIH}$ se realizaron experimentos en configuración I-O en los cuales se midió la probabilidad de apertura del canal $\mathrm{BK}_{\mathrm{Ca}}$ manteniendo constantes la concentración de $\mathrm{Ca}^{2+}$ libre en un valor de $10^{-7} \mathrm{M}$ y el potencial aplicado en $+30 \mathrm{mV}$, modificando el $\mathrm{pH}$ de la solución en contacto con la región intracelular del canal. Como se muestra en la figura 42, la alcalinización ( $\mathrm{pH}$ 7.6) aumenta la NPo del canal y la acidificación produce una disminución de la misma. El valor de conductancia del canal no se vio afectado por las alteraciones del pH del medio. 


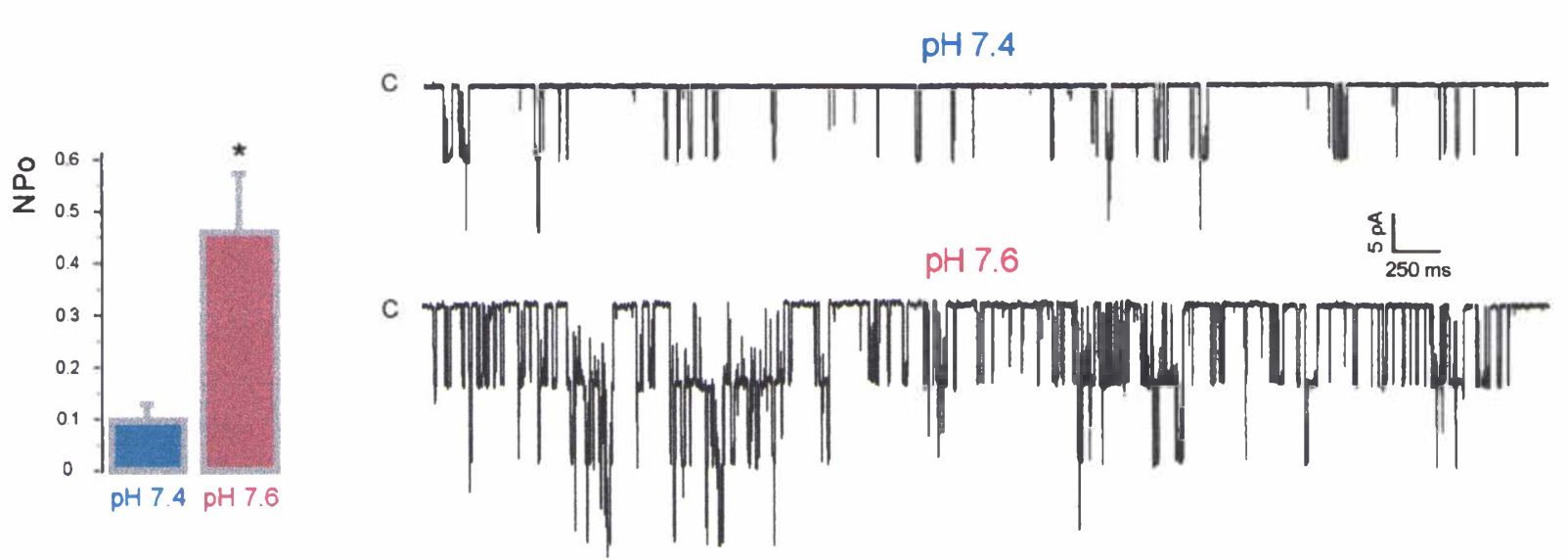

B
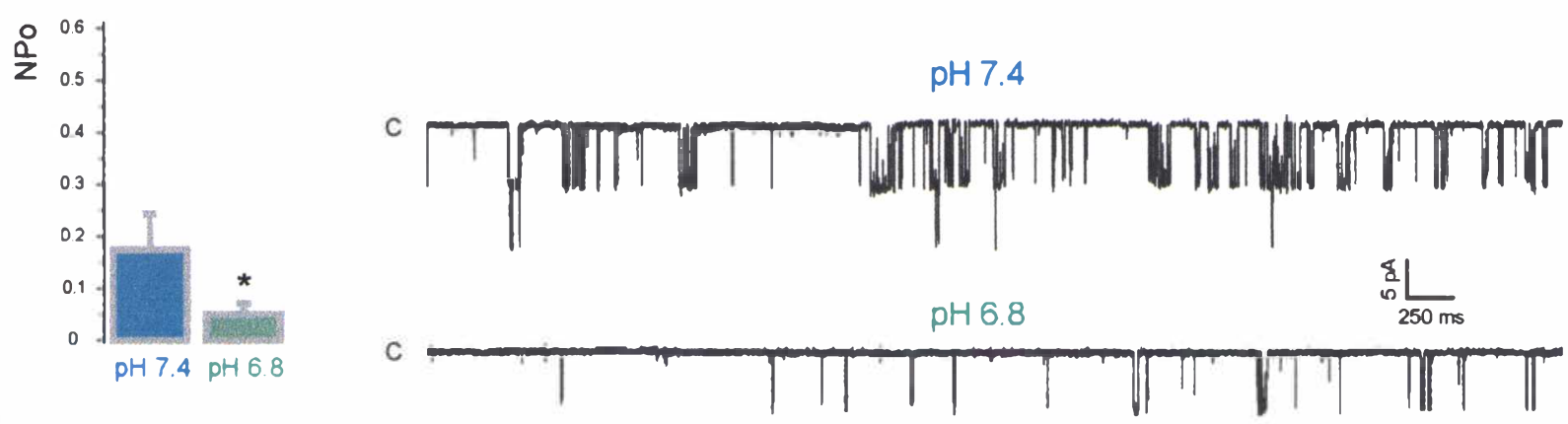

Figura 43: A- Efecto de la alcalinización del medio intracelular $(\mathrm{pH}=7,6)$ sobre la actividad del canal BKCa. Ejemplo típico de los experimentos realizados en configuración $1-O$ manteniendo constantes la concentración de calcio libre en un valor de $10^{-7} \mathrm{M}$ y el potencial aplicado en +30 $\mathrm{mV}$. El gráfico de barras representa los valores medios \pm ESM para la NPo a pH: 7,4 y 7,6. BEfecto de la acidificación del medio intracelular $(\mathrm{pH}=6,8)$ sobre la actividad del canal BK ca. Ejemplo típico de los experimentos realizados en configuración $1-O$ manteniendo constantes la concentración de $\mathrm{Ca}^{2+}$ libre en un valor de $10^{-7} \mathrm{M}$ y el potencial aplicado en $+30 \mathrm{mV}$. El gráfico

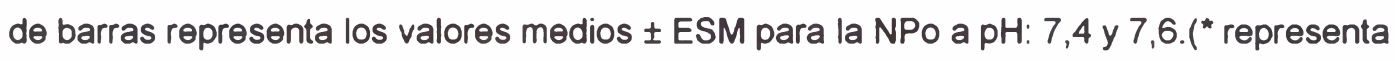
diferencia significativa del control, $p<0,05)$. 


\section{Participación del canal BK ${ }_{\text {ca }}$ en la respuesta contráctil inducida por cambios} de $\mathrm{pH}$ en la AMIH

En anillos intactos aislados de $\mathrm{AMIH}$ se registró la respuesta mecánica inducida por aumento del pH de la solución extracelular (reemplazo de la solución del baño SEN a pH 7,4 por una SEN a pH 7,8); y aumento del pH intracelular, utilizando $\mathrm{NH}_{4} \mathrm{Cl}$ en una concentración de $20 \mathrm{mM}(\mathrm{pH}: 7,4)$ como herramienta para inducir alcalinización intracelular (220).
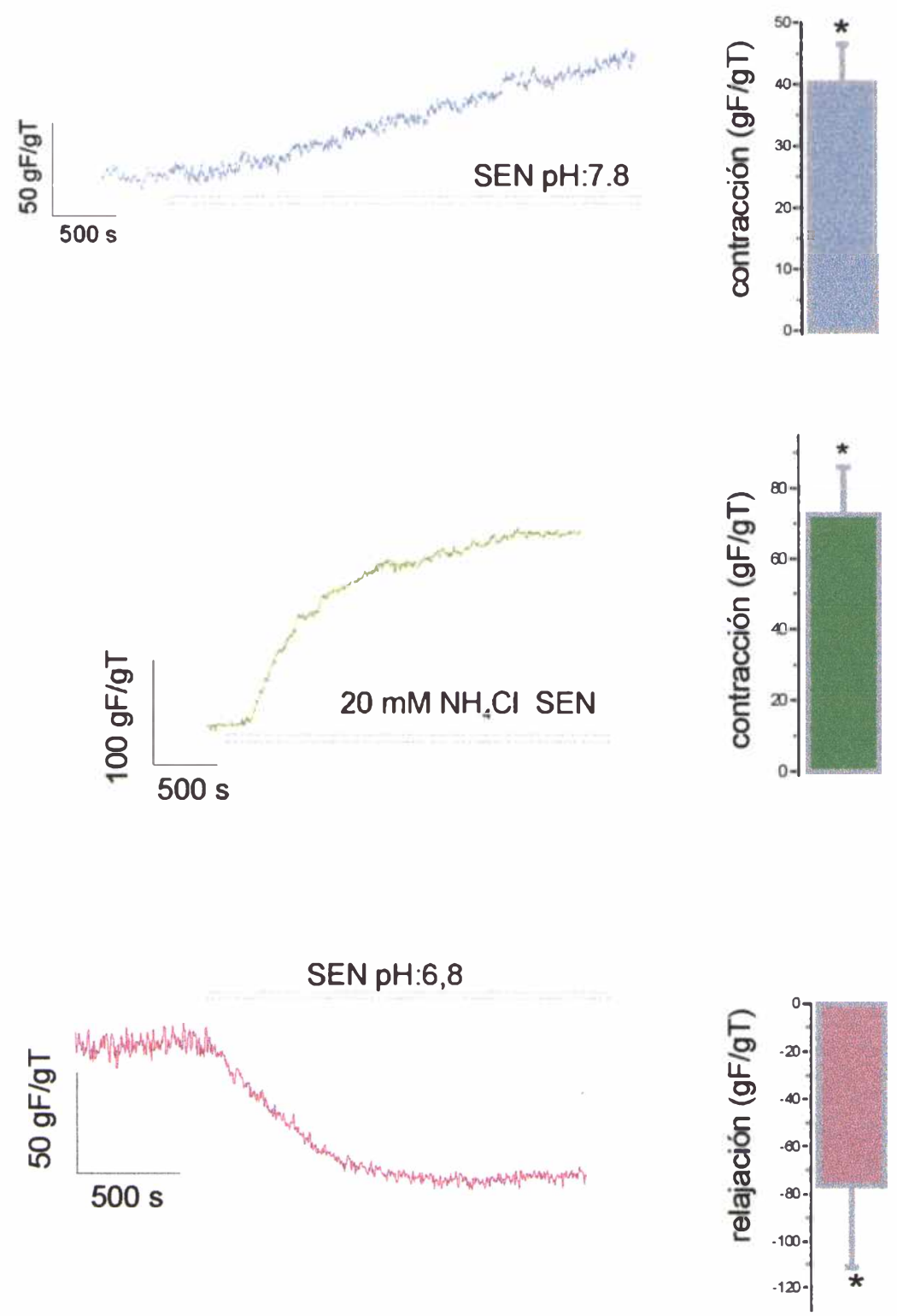

Figura 43: Ejemplos típicos y valores medios \pm ESM del efecto contráctil de la modificación del $\mathrm{pH}$ extracelular $\Theta$ intracelular. 
Como puede observarse en la figura 43 , ambas intervenciones producen una contracción de 40,3 $\pm 6,2 \mathrm{gF} / \mathrm{gT},(n=6, p<0,05)$ y $72,7 \pm 13,4 \mathrm{gF} / \mathrm{gT},(n=10$, $p<0,05)$ respectivamente.

En el desarrollo de fuerza inducido por la alcalinización intracelular los canales $\mathrm{BK}_{\mathrm{Ca}}$, que en base a los resultados obtenidos en células aisladas se activan cuando el medio interno se alcaliniza, podrían estar regulando el nivel de contracción que alcanza el anillo vascular. La acidificación extracelular obtenida por modificación del pH de la solución SEN de 7,4 a 6,8 produce una relajación significativa de los anillos de AMIH $(-76,6 \pm 34,7 \mathrm{gF} / \mathrm{gT}, n=12, p<0,05)$.

Sin embargo cuando se quiso indagar el efecto de la acidificación intracelular sin modificación del pH extracelular utilizando propionato de sodio $20 \mathrm{mM}$ no se observó un efecto significativo sobre el tono de reposo de los anillos de AMIH $(2,5$ $\pm 3,2 \mathrm{gF} / \mathrm{gT} n=8$, N.S.). 


\section{DISCUSIÓN Y CONCLUSIONES}

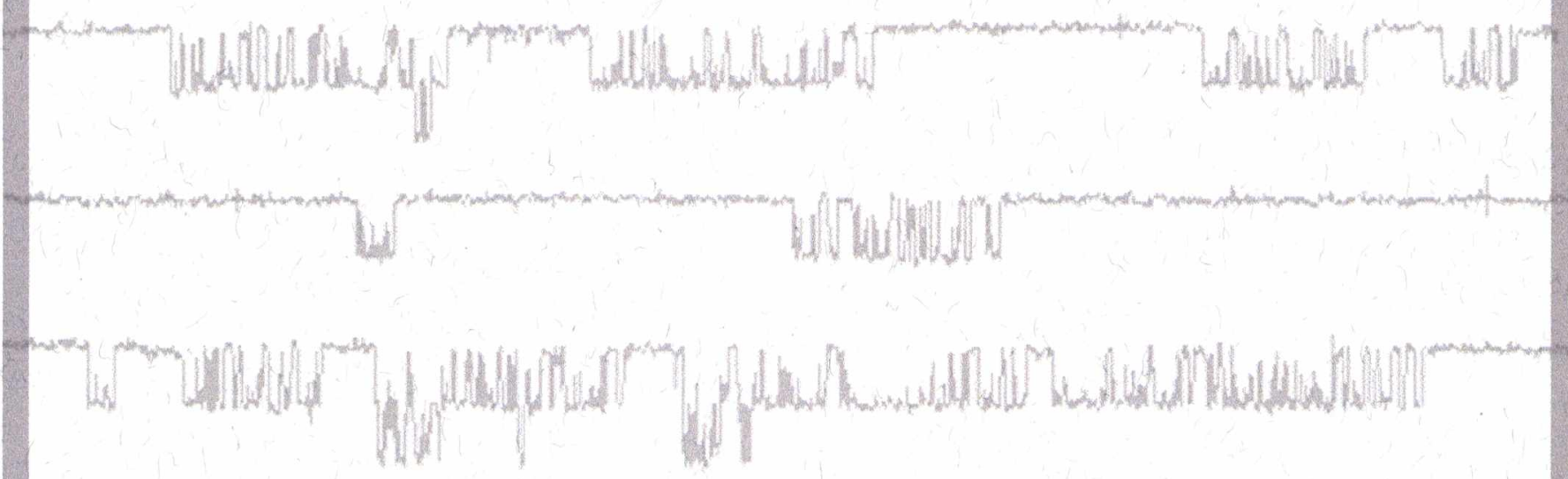




\section{DISCUSIÓN Y CONCLUSIONES}

\section{Canales iónicos en la AUH}

En este trabajo de Tesis Doctoral se presentan las primeras evidencias electrofisiológicas directas que describen diferentes tipos de canales iónicos presentes en células de músculo liso de arteria umbilical humana (AUH) así como también sus propiedades y participación en mecanismos celulares que regulan la función contráctil del músculo liso vascular (MLV).

Como se muestra en la sección "resultados" la mayor parte de la corriente macroscópica en las células de músculo liso de AUH fue inhibida por bloqueantes inespecíficos de canales de $\mathrm{K}^{+}$, sugiriendo que la mayoria de la corriente es mediada por estos canales. Con el fin de investigar las posibles componentes de esta corriente se utilizaron bloqueantes especificos para algunos subtipos de canales de $\mathrm{K}^{+}$. De esta forma se puso en evidencia la presencia de al menos dos corrientes denominadas IK $\mathrm{K}_{D R}$ y $\mathrm{IBK}_{\mathrm{Ca}}$ responsables de la corriente total sensible al voltaje registrada en nuestras condiciones experimentales (gradiente fisiológico de $\mathrm{K}^{+}$).

La corriente $\mathrm{IK}_{\mathrm{DR}}$ es sensible a 4-AP, muestra una cinética de activación rápida y se activa a potenciales de membrana más positivos que $-40 \mathrm{mV}$, mientras que la corriente $\mathrm{IBK}_{\mathrm{Ca}}$ se activa a potenciales más positivos que $-10 \mathrm{mV}$, es una corriente de activación más lenta, sensible a IBTX y a bajas concentraciones de TEA. Al ensayar los efectos de la apamina, bloqueante específico de canales tipo $\mathrm{SK}_{\mathrm{Ca}}$, no se encontró efecto inhibitorio de la corriente macroscópica a la concentración utilizada; ello indica que estos canales no presentan actividad registrable en las células de $\mathrm{AUH}$ en las condiciones experimentales utilizadas.

Los resultados obtenidos mediante protocolos de voltaje que permiten poner en evidencia la presencia de una corriente de activación e inactivación rápida de tipo $I_{A} \circ I_{T O}$, sugieren que tampoco este tipo de corriente iónica está presente en este tipo celular.

Estos datos obtenidos en la AUH concuerdan con numerosos estudios realizados en células de MLV de diferentes vasos y especies donde se describen corrientes de tipo IK $\mathrm{K}_{\mathrm{DR}}$ y IKB $\mathrm{IKa}_{\mathrm{Ca}}$ como contribuyentes principales de la corriente de 
$\mathrm{K}^{+}(111)$. La presencia de corrientes de tipo $\mathrm{I}_{\mathrm{A}}$ ha sido observada en muy pocos vasos.

El efecto de 4-AP sugiere que la componente IK $K_{D R}$ no se encuentra presente en todas las células de músculo liso de $\mathrm{AUH}$. Mientras que la IBK $\mathrm{Ia}_{\mathrm{Ca}}$ está presente en todas las células evaluadas correspondiendo esta componente a, aproximadamente, el $65 \%$ de la corriente total. En concordancia con estos resultados, Gollasch y colaboradores, en arterias coronarias humanas, encontraron que la componente IK $K_{D R}$ de la corriente total se encuentra presente sólo en el $46 \%$ del total de células ensayadas, mientras que el total de las células posee una componente IBK $\mathrm{Ca}_{\mathrm{C}}$ (143). Normalmente, las células presentes en la pared arterial son heterogéneas, asi se pueden encontrar variaciones en su tamaño, forma, contenido de organelas y diferentes niveles de expresión de proteinas contráctiles, del citoesqueleto, o de la membrana (221). Algunos investigadores han planteado el concepto de "diversidad de las células en la pared vascular" para intentar explicar las variaciones encontradas en la respuesta de los vasos de diferentes lechos vasculares a distintas sustancias vasoactivas; estas diferencias pueden aparecer incluso entre distintos segmentos del mismo vaso o entre células de un mismo segmento (134). En relación con este concepto, es importante señalar que las células de MLV pueden presentar una gran variación del tipo, densidad y propiedades de los canales de $\mathrm{K}^{+}$presentes en la membrana plasmática. Se ha descripto que un mismo canal puede estar formado por diferentes isoformas de las subunidades proteicas que lo conforman. Esta particularidad de generar diferentes isoformas a partir de un gen, surge del procesamiento diferencial que sufre el ARN mensajero heterogéneo nuclear de estos canales (o en inglés "alternative splicing") (222). Otra causa importante de dicha diversidad es la presencia de subunidades reguladoras asociadas en forma permanente $\circ$ no al canal, las cuales pueden modificar significativamente las propiedades de un determinado canal iónico y por lo tanto su rol funcional. Como se mencionó en la "introducción", un ejemplo relevante de este hecho es la presencia de subunidad $\beta$ en los canales de tipo $\mathrm{BK}_{\mathrm{Ca}}$.

Dado que en nuestros experimentos los valores de capacitancia de la membrana celular obtenidos de las distintas células son homogéneos, se descarta que la diferencia en la sensibilidad a 4-AP se deba a la presencia de poblaciones celulares que puedan diferenciarse por su tamaño o área de membrana. Sin 
embargo, este bloqueante inhibe una componente de la corriente total sólo en las células que presentan constante de activación más rápida, este hecho podría deberse a la presencia de diversidad en las células de la pared vascular donde se verifica una contribución diferencial de la componente $I_{D R}$ en células provenientes del mismo segmento arterial. Además, en el grupo de células que presentan una cinética más lenta se encontró que 4-AP, aumenta la corriente total a valores de potenciales despolarizados, lo cual podría deberse a un efecto activador de la componente IBK $\mathrm{Ia}_{\mathrm{Ca}}$ de la corriente total de estas células. La 4-AP podría aumentar la corriente a través de canales $\mathrm{BK}_{\mathrm{Ca}}$ actuando por diversos mecanismos que han sido descriptos en la bibliografia. Se conoce que 4-AP, una base orgánica débil, es capaz de atravesar las membranas celulares y alcanzar concentraciones significativas en el medio intracelular. En el medio intracelular, que posee un $\mathrm{pH}$ menor al del medio extracelular, el equilibrio químico de la 4-AP se desplaza hacia su forma cargada tomando protones del medio con la consecuente alcalinización del mismo. Este hecho puede aumentar la actividad del canal $\mathrm{BK}_{\mathrm{Ca}}$ debido a la disminución del efecto bloqueante que pueden ejercer los iones $\mathrm{H}^{+}$por unión a sitios específicos de la proteína de canal como ha sido propuesto por Schubert y colaboradores (223). Estos autores encontraron que en células de músculo liso de arteria de la cola de rata, la alcalinización intracelular aumenta la actividad de los canales $\mathrm{BK}_{\mathrm{C} a}$. En coincidencia con este resultado, en los experimentos realizados sobre células de músculo liso de AMIH en este trabajo de Tesis se presentan evidencias electrofisiológicas que muestran activación de canales de tipo $\mathrm{BK}_{\mathrm{Ca}}$ como consecuencia de la alcalinización intracelular. Sin embargo, los datos bibliográficos relacionados con la acción del $\mathrm{pH}$ sobre los canales de $\mathrm{K}^{+}$son extensos y dispares. Por otro lado, se ha informado que la 4-AP puede generar liberación de $\mathrm{Ca}^{2+}$ de los depósitos intracelulares debido a efectos sobre estructuras de la membrana de los mismos. En estudios previos realizados en nuestro laboratorio hemos encontrado que, en arteria aorta de rata, la 4-AP produce contracción de anillos vasculares aislados mediante un mecanismo que involucra la liberación de $\mathrm{Ca}^{2+}$ desde depósitos intracelulares (224). El aumento de $\mathrm{Ca}^{2+}$ intracelular puede a su vez, activar canales $\mathrm{BK}_{\mathrm{Ca}}$ como ha sido descripto en algunos tipos celulares (214). Considerando estos mecanismos, es posible especular que los mismos podrían 
estar involucrados en el aumento que la 4-AP produce sobre la corriente total en algunas células de MLV de la AUH.

Los resultados obtenidos en condiciones de canal único están en concordancia con las propiedades informadas en la literatura para el canal BK en otros tipos de MLV. Así, el canal presentó una conductancia de canal único de $216 \pm 4$ o $124 \pm 4$ pS (configuración O-O) en gradiente de $\mathrm{K}^{+}$simétrico (130/130 mM) o asimétrico (130/5 mM), respectivamente, fue inhibido por la IBTX, y la probabilidad de apertura varía en función de la concentración de $\mathrm{Ca}^{2+}$ intracelular y del voltaje. El valor de conductancia iónica constituye un parámetro importante en la caracterización del canal iónico y en este caso se demostró en forma directa que el valor de conductancia aumenta cuando el gradiente de $\mathrm{K}^{+}$asimétrico se cambia por uno simétrico. Ambos valores de conductancia coinciden con los valores descriptos para canales $\mathrm{BK}_{\mathrm{Ca}}$ en diferentes tipos celulares en condiciones similares de registro de corriente (225). Por otro lado, se observó que el valor de conductancia iónica de $274 \pm 7$ pS obtenido en configuración 1-O con gradiente simétrico de $\mathrm{K}^{+}(130 / 130 \mathrm{mM})$ si bien es mayor del obtenido en configuración O-O con igual gradiente se encuentra en el rango de valores de conductancia informado en otros vasos humanos. Algunos ejemplos de los valores descriptos en la bibliografía son: 229 pS para el canal $\mathrm{BK}_{\mathrm{Ca}}$ en células de músculo liso de vena safena humana (226) y de arterias coronarias humanas (227) y 245 pS en células en cultivo de músculo liso de arteria pulmonar humana (144). La diferencia encontrada en los valores de conductancia iónica en I-O y O-O, ambos en gradiente simétrico $\mathrm{K}^{+}$, podría atribuirse, entre otros factores, a la configuración experimental y a la composición iónica en las soluciones intra y extracelulares utilizadas durante el registro de la corriente que varian levemente. Por ejemplo, se ha descripto que las concentraciones de $\mathrm{Na}^{+}$y $\mathrm{Mg}^{2+}$ internas pueden modificar la conductancia de este canal en células de MLV de vena porta y arterias coronarias de conejo (228) y este efecto ya había sido descripto anteriormente en otros tipos celulares $(229,230)$. Por otro lado, es importante señalar que según establece la Teoría de Campo Constante de Goldman, Hodgkin y Katz para el transporte de iones a través de una membrana, el valor de la corriente iónica depende en forma no lineal de la permeabilidad para ese ión, del gradiente de concentración del mismo y de la diferencia de potencial aplicado a los lados de la membrana. Por lo 
tanto, el valor empírico de conductancia iónica que se obtiene a partir de la relación I-V estará influenciado por estos y otros factores, indicando la complejidad de las propiedades de permeación de iones a través de la membrana plasmática. En particular, la atracción electrostática que ejercen las cargas presentes tanto en la proteína como en los fosfolípidos cercanos al canal puede generar variaciones de la concentración iónica en la región adyacente a la proteina formadora del poro (231). Por lo antes expuesto, es importante remarcar la importancia de conocer y explicitar las condiciones experimentales (configuración, iones presentes, gradiente de concentración de los mismos y rango de potencial) en las que se obtiene el valor de conductancia de un canal, especialmente cuando se realizan comparaciones entre ellos.

En base a la conductancia de canal único $(\gamma)$ y a la conductancia total máxima de la membrana para el canal $\mathrm{BK}_{\mathrm{Ca}}\left(\mathrm{G}_{\mathrm{total}}\right)$ es posible estimar la densidad de canales presentes en la membrana celular como:

\section{Densidad de canales $=G_{\text {total }} / \gamma$}

En nuestro caso se utilizaron para realizar este cálculo el valor de conductancia de canal único obtenido en configuración O-O en presencia de un gradiente fisiológico de $\mathrm{K}^{+}(124 \pm 4 \mathrm{pS})$ y el valor de conductancia total de la membrana para el canal $\mathrm{BK}_{\mathrm{Ca}}$ estimado a partir de la corriente macroscópica sensible a IBTX. El valor de $G_{\text {total }}$ expresado por unidad de capacitancia de membrana fue de 1207,98 $\pm 58,29$ pS/pF (figura 6B de "resultados"). Así, para las células de músculo liso de AUH se obtiene un valor de aproximadamente 10 canales/pF o 318 canales/célula considerando la capacitancia promedio de la membrana obtenida de estas células $(32.7 \pm 1.2 \mathrm{pF})$. Utilizando el valor de la capacitancia especifica para las membranas celulares $\left(1 \mu \mathrm{F} / \mathrm{cm}^{2}\right)(113)$, es posible calcular el número de canales $\mathrm{BK}_{\mathrm{Ca}}$ por unidad de área. A partir de nuestros datos experimentales surge que las células de AUH poseen 0,1 canales $/ \mu m^{2}$. Este valor, es similar al informado en otros tipos de músculo liso como en arterias coronarias de rata $\left(0.5\right.$ canales $\left./ \mu \mathrm{m}^{2}\right)(186)$, yeyuno de conejo $\left(2\right.$ canales $\left./ \mu \mathrm{m}^{2}\right)$ (232) 0 estómago de sapo $\left(1 \mathrm{canal} / \mu \mathrm{m}^{2}\right)$ (233) y es relativamente inferior al informado para las células de músculo liso de arterias coronarias humanas (aproximadamente de 4 canales $/ \mu \mathrm{m}^{2}$ ) (234). 
Se ha demostrado que la expresión de canales $\mathrm{BK}_{\mathrm{Ca}}$ en músculo liso de arterias coronarias humanas y de rata disminuye con la edad de los individuos y se piensa que este hecho tiene relación con cambios en la funcionalidad del vaso que determinarían el aumento de la incidencia de patologías como el espasmo coronario (186). Recientemente, Chanrachakul y colaboradores encontraron que la expresión de la subunidad $\alpha$ del canal $\mathrm{BK}_{\mathrm{Ca}}$ es menor en células de músculo liso de miometrio humano procedente de mujeres que tuvieron trabajo de parto respecto de las que no lo tuvieron. Así, tal vez la reducción de la expresión de subunidad $\alpha$ del canal $\mathrm{BK}_{\mathrm{Ca}}$ en el miometrio durante el trabajo de parto contribuya al mecanismo que desencadena la contracción uterina durante el parto (235). Por otro lado, se ha que descripto que la densidad de la corriente llevada por canales $\mathrm{BK}_{\mathrm{Ca}}$ es mayor en arteria aorta proveniente de ratas espontáneamente hipertensas con respecto a las normotensas, este hecho se interpreta como el resultado de un mecanismo de compensación estimulado por el estado patológico, que se opone a la mayor reactividad de las arterias hipertensas (185). También, en arteriolas cerebrales provenientes de ratas espontáneamente hipertensas, se ha demostrado que el canal $\mathrm{BK}_{\mathrm{Ca}}$ presenta una mayor expresión inducida por el aumento "in situ" de la presión sanguínea, lo que podría funcionar como un mecanismo de protección ante los vasoespasmos cerebrales (236). En general, parece ser que la expresión de los canales $\mathrm{BK}_{\mathrm{Ca}}$ se encuentra aumentada en la hipertensión, a diferencia de lo que ocurre con los canales tipo $K_{v}$, sobre los cuales se ha informado, en varios trabajos, una menor o igual expresión en vasos provenientes de organismos con esta patología respecto de los provenientes de organismos normotensos (130).

Considerando que la $\mathrm{AUH}$ no posee inervación autónoma (20), agentes circulantes o locales juegan un rol relevante en el control de la función contráctil de este vaso. Es muy probable que algunos de estos factores involucren en sus mecanismos de acción a canales de $\mathrm{K}^{+}$, los cuales pueden participar en la transducción de señales variando el potencial de membrana y la concentración de $\mathrm{Ca}^{2+}$ libre intracelular. Recientemente, mediante la realización de experimentos mecánicos, Lovren y Triggle informaron que canales $B K_{C a}$ y $K_{D R}$ participan en la relajación producida por $\mathrm{NO}$ en anillos de AUH precontraídos con 5-HT (79). Los resultados presentados en este trabajo de Tesis muestran que el nitroprusiato de sodio (SNP), dador de oxido nítrico (NO), y el Br-GMPc, análogo permeante del 
GMPc, son capaces de activar el canal $\mathrm{BK}_{\mathrm{Ca}}$ en células de músculo liso de $\mathrm{AUH}$ que conservan su citosol intacto. También informamos que NO y GMPc no son efectivas sobre canales aislados en segmentos de membrana (configuración 1-O), sugiriendo la ausencia de efectos directos de estas sustancias sobre el canal. Por lo tanto, estos resultados muestran que la actividad del canal $\mathrm{BK}_{\mathrm{Ca}}$ es regulada por la vía de señalización intracelular del NO, probablemente a través de activación de la enzima guanilato ciclasa y posterior fosforilación por PKG, y por lo tanto, apoyan los resultados obtenidos por Lovren y Triggle en segmentos intactos de la AUH.

Por otra parte, hemos demostrado en células de músculo liso de $\mathrm{AUH}$ la presencia de una corriente catiónica no selectiva y descripto sus propiedades y su participación en la función contráctil de esta arteria humana. Los resultados muestran que dicha corriente es llevada por cationes y en condiciones fisiológicas podría representar una importante vía de entrada de $\mathrm{Ca}^{2+}$ y $\mathrm{Na}^{+}$a la célula. La corriente macroscópica es independiente del tiempo y del voltaje y su relación I-V es lineal entre $-90 y+100 \mathrm{mV}$. El valor del potencial de reversión de esta corriente es muy cercano a $0 \mathrm{mV}$ como se espera para corrientes no selectivas. Esta corriente fue inhibida por $\mathrm{Gd}^{3+}(237,238), \mathrm{La}^{3+}$ y $\mathrm{Mg}^{2+}$, a concentraciones comúnmente utilizadas para bloquear canales de tipo CNS en músculo liso y en otros tipos celulares (190). La sensibilidad farmacológica y las características de la corriente coinciden con los datos presentados para corrientes mediadas a través de canales CNS en otros tipos de $\operatorname{MLV}(107,207,239)$, miométrio y músculo cardíaco $(240,241)$.

En relación con las propiedades de permeabilidad de estos canales, los resultados obtenidos a partir del estudio del corrimiento del potencial de reversión de la corriente CNS en condiciones bi-iónicas indican la siguiente serie de permeabilidades:

$$
\mathrm{Cs}^{+}>\mathrm{Na}^{+}>\mathrm{Li}^{+}=\mathrm{Ca}^{2+}=\mathrm{Ba}^{2+}>\text { Tris }^{+}
$$

Asi, al considerar la permeabilidad relativa entre $\mathrm{Na}^{+}$y $\mathrm{Ca}^{2+}$ (ambos presentes en las soluciones extracelulares en condiciones fisiológicas) obtuvimos que la permeabilidad del $\mathrm{Na}^{+}$es 1,3 veces mayor que la del $\mathrm{Ca}^{2+}$. Canales CNS 
con permeabilidades similares para el $\mathrm{Ca}^{2+}$ y otros cationes divalentes han sido informadas en varios tipos celulares $(107,201,243,244)$.

Eisenman propuso en 1962 (245), a partir de sus estudios sobre interacción electrostática en vidrios selectivos a distintos cationes monovalentes, la Teoría del equilibrio para la selectividad iónica para explicar la interacción entre una superficie de vidrio cargada negativamente y 5 cationes metálicos alcalinos diferentes. Este autor propuso que los iones disueltos en una solución acuosa se intercambian con iones unidos a sitios cargados negativamente de la superficie del vidrio en función de: 1. la energía electrostática de atracción entre el ión y el sitio cargado, que depende del radio del ión y del radio de sitio, y 2 . la energía de hidratación del ion. Considerando esta situación en uno de los extremos, donde el radio del sitio es muy amplio, la energía de interacción electrostática será baja para todos los cationes y el equilibrio de intercambio iónico dependerá sólo de la capacidad de los iones en solución para perder su capa de hidratación. Así, en esta situación denominada de sitio amplio o débil, el ion $\mathrm{Cs}^{+}$estaría favorecido ya que su energía de deshidratación es baja con respecto a otros iones como el $\mathrm{Na}^{+}$ y más aún, el $\mathrm{Li}^{+}$. En el otro extremo se ubicaría el caso en que los sitios tuvieran radios pequeños, aquí la energía de interacción electrostática sería alta para todos los iones y mucho mayor que la energía de deshidratación para cualquiera de ellos. En este caso denominado de sitio pequeño o fuerte los iones más pequeños podrán acceder más fácilmente al sitio para interaccionar con el mismo. Las situaciones intermedias entre estos dos casos extremos permiten calcular la energía de intercambio para los iones $\mathrm{Cs}^{+}, \mathrm{Rb}^{+}, \mathrm{K}^{+}, \mathrm{Na}^{+}$y $\mathrm{Li}^{+}$a distintos valores de radio del sitio, estableciéndose las distintas series de equilibrio para la afinidad de unión entre el sitio y los iones. Estas series fueron numeradas de la l $\left(\mathrm{Cs}^{+}>\mathrm{Rb}^{+}>\right.$ $\left.\mathrm{K}^{+}>\mathrm{Na}^{+}>\mathrm{Li}^{+}\right)$en el caso extremo del sitio amplio o débil a la $\mathrm{XI}\left(\mathrm{Li}^{+}>\mathrm{Na}^{+}>\mathrm{K}^{+}>\right.$ $\mathrm{Rb}^{+}>\mathrm{Cs}^{+}$) en el caso extremo del sitio pequeño o fuerte.

Este concepto general de Eisenman puede ser utilizado para analizar las series de permeabilidades de los canales catiónicos. En la AUH, la serie de permeabilidades encontrada $\left(\mathrm{Cs}^{+}>\mathrm{Na}^{+}>\mathrm{Li}^{+}\right)$para la corriente catiónica no selectiva se corresponde con la secuencia de permeabilidad para estos iones de las series I, II, III y IV de Eisenman, lo que indicaría que la selectividad estaría determinada en mayor medida por la capacidad de los iones de deshidratarse 
(situación de sitio amplio o débil) que por las interacciones entre sitios cargados del poro y los iones.

En células de MLV han sido descriptos canales CNS con valores de permeabilidad relativa muy similares entre si que se disponen en series de permeabilidades coincidentes con la demostrada en este trabajo. Así, ha sido informado por Bae y colaboradores, que el potencial de membrana de las células de músculo liso en la arteria pulmonar de conejo es regulado en parte por una corriente CNS con la siguiente serie de permeabilidad: $\mathrm{K}^{+}>\mathrm{Cs}^{+}>\mathrm{Na}^{+}>\mathrm{Li}^{+}$(116) correspondiente con la secuencia de permeabilidad para estos iones de las series III y IV de Eisenman. En la arteria mesentérica de cobayo, Setoguchi y colaboradores estudiaron las propiedades de un canal CNS sensible al estiramiento de la membrana celular, encontrando la misma serie de permeabilidad que la hallada por el grupo de Bae (107). En células de músculo liso de arteria coronaria porcina se informó la presencia de un canal activado por estiramiento con una mayor permeabilidad al $\mathrm{K}^{+}$que al $\mathrm{Na}^{+}$(246). En este estudio los autores muestran que este canal posee una serie de permeabilidad que corresponde a la serie III de Eisenman $\left(\mathrm{Rb}^{+}>\mathrm{K}^{+}>\mathrm{Cs}^{+}>\mathrm{Na}^{+}>\mathrm{Li}^{+}\right)$.

En el músculo cardíaco, específicamente en células de aurícula de rata, se ha descripto una corriente CNS activada por estiramiento con muy poca diferencia en los valores de permeabilidades relativas, las cuales se ubican en la siguiente serie: $\mathrm{Cs}^{+}>\mathrm{Na}^{+}>\mathrm{Li}^{+}(1,05: 1: 0,98)$, mientras que en el mismo tipo celular estos autores encontraron otra corriente basal, denominada de "background", que presenta la misma serie que en el caso anterior, pero con valores de permeabilidad relativa que difieren más entre sí que los obtenidos para el canal sensible al estiramiento $\left(\mathrm{Cs}^{+}>\mathrm{Na}^{+}>\mathrm{Li}^{+}=1,49: 1: 0,7\right)$ (247). Recientemente, Volk y colaboradores encontraron en células musculares de ventriculo izquierdo de rata un canal CNS, cuya estructura molecular probablemente sea una proteína tipo "polycystin-2-like". Este canal muestra muy poca diferencia en los valores de permeabilidad relativa entre distintos cationes monovalentes, los que se ubican en la siguiente serie de permeabilidad $\mathrm{Na}^{+}=\mathrm{K}^{+}>\mathrm{Cs}^{+}=\mathrm{Li}^{+}$(242).

Por otro lado, Prakriya y colaboradores diferenciaron, en células $T$ de leucemia humana (tipo Jurkat E6-1) dos tipos de canales CNS, uno activado por liberación de $\mathrm{Ca}^{2+}$ desde depósitos intracelulares y otro sensible a $\mathrm{Mg}^{2+}$; ambos difieren en sus valores de permeabilidad relativa, ya que el primero es más 
permeable al $\mathrm{Na}^{+}$que al $\mathrm{Cs}^{+}$y el segundo es más permeable al $\mathrm{Cs}^{+}$que al $\mathrm{Na}^{+}$ (248).

En el borde en cepillo de la placenta humana, también se ha descripto un canal CNS de baja conductancia con una serie de permeabilidades similar a la hallada para las células de músculo liso de AUH en este trabajo. La serie de permeabilidades encontrada es $\mathrm{Cs}^{+} \sim \mathrm{Rb}^{+}>\mathrm{Na}^{+} \sim \mathrm{K}^{+}>\mathrm{Li}^{+}$. No se conoce aún la implicancia fisiológica de este canal en el funcionamiento de la placenta (244).

Las células endoteliales de la vena umbilical humana poseen canales CNS en su membrana, estos canales son activados por histamina y son más permeables al $\mathrm{K}^{+}$que al $\mathrm{Na}^{+}(249)$.

Estos y otros ejemplos que se encuentran en la bibliografía muestran que los canales CNS siguen, por lo general, series de permeabilidades I-IV de Eisenman, lo que indicaría que es la energía de deshidratación de los cationes lo que limita la selectividad de los mismos. Este tipo de análisis sobre los canales CNS resulta interesante ya que aporta conocimiento sobre las propiedades del poro del canal y el mecanismo de permeación de iones a través del mismo, especialmente en aquellas células donde no se ha identificado aún la estructura molecular de los mismos.

En los últimos años se han logrado determinar en algunos casos que las proteínas TRP y proteínas tipo policistinas constituyen las estructuras proteicas formadoras de este tipo de canales iónicos. Así, los conocimientos sobre las características moleculares de estas proteínas, su expresión en distintos tejidos y la descripción de corrientes catiónicas no selectivas y sus roles fisiológicos avanzan, pero poseen hasta ahora, muy pocos puntos de encuentro.

En relación a las propiedades de la corriente CNS descripta en este trabajo los resultados muestran por un lado la secuencia de permeabilidad para diferentes cationes, lo cual permite conocer, como se detalló en los párrafos precedentes, las características de permeabilidad de estos canales y comparar estos con otros datos existentes. Por otro lado, se encontró que la corriente entrante macroscópica evocada a potenciales de membrana menores que $0 \mathrm{mV}$ y en presencia de concentraciones fisiológicas de $\mathrm{Na}^{+}$y $\mathrm{Ca}^{2+}$ disminuye cuando se elimina el $\mathrm{Na}^{+}$extracelular, y se reduce aún más cuando se eliminan $\mathrm{Na}^{+}$y $\mathrm{Ca}^{2+}$, indicando que estos dos cationes son iones portadores de esta corriente y podrían 
mediar un influjo de $\mathrm{Na}^{+}$y $\mathrm{Ca}^{2+}$ induciendo despolarización y contracción en las células de músculo liso.

El influjo de $\mathrm{Na}^{+}$y $\mathrm{Ca}^{2+}$ a través de canales CNS aumenta a valores de potencial de membrana negativos (mayor fuerza impulsora), por lo tanto, a valores de potencial de membrana de reposo la contribución de esta corriente despolarizante puede ser significativa, y en algunos casos se ha demostrado que es la responsable de mantener el potencial de las células de músculo liso en un valor entre - -60 y $-40 \mathrm{mV}$, alejado del valor teórico esperado (cercano a $-90 \mathrm{mV}$ ) si éste fuera sólo regulado por canales de $\mathrm{K}^{+}(116,243)$.

En la $\mathrm{AUH}$, los experimentos realizados en modo de fijación de corriente sugieren que el bloqueo de canales CNS es capaz de modificar el potencial de membrana de estas células, produciendo hiperpolarización. Existe además, la posibilidad de que la corriente despolarizante a través de canales CNS en condiciones de reposo indirectamente active la corriente a través de canales de $\mathrm{Ca}^{2+}$ operados por voltaje de tipo L. Si bien las curvas de activación descriptas para este tipo de canal en células musculares lisas de otros vasos muestran que la activación de estos canales es nula o muy baja a valores de potencial de membrana de reposo $(-60,-40 \mathrm{mV})(237)$, actualmente es posible especular con la posibilidad de que la corriente a través de canales tipo $L$ en el rango de potenciales denominado ventana de corriente, esté siempre activa y pueda estar contribuyendo al mantenimiento del potencial de membrana y sea modulada por factores hiper y despolarizantes (35).

Por otro lado, el influjo de $\mathrm{Na}^{+}$a través de canales CNS podría representar un mecanismo de regulación de la concentración de $\mathrm{Na}^{+}$intracelular en este tipo celular, tal como ha sido propuesto por Blaustein y colaboradores. Estos autores remarcan la importancia de posibles estructuras que puedan mediar un influjo de $\mathrm{Na}^{+}$en el músculo liso, ya que salvo pocas excepciones no se han descripto canales selectivos al $\mathrm{Na}^{+}$en este tipo celular. Los mismos autores demostraron que en células de músculo liso de arteria mesentérica de rata el $\mathrm{Na}^{+}$ingresa a través de canales CNS operados por la depleción de depósitos intracelulares (SOC) y que es removido rápidamente por la actividad de un subtipo específico de la bomba $\mathrm{Na} / \mathrm{K}\left(\alpha_{3}\right)$ en condiciones basales. Además, plantean que un aumento en la actividad de esta bomba, colocalizada en microdominios subsarcolemales con los canales tipo SOC y con el intercambiador $\mathrm{Na} / \mathrm{Ca}$ de la membrana 
plasmática, puede disminuir el gradiente de $\mathrm{Na}^{+}$disminuyendo así la extrusión de $\mathrm{Ca}^{2+}$ a través del intercambiador $\mathrm{Na} / \mathrm{Ca}$ y aumentando la concentración local de $\mathrm{Ca}^{2+}$ (237). Esta interesante hipótesis mecanística es sólo un ejemplo de la enorme complejidad de los mecanismos que regulan la función contráctil en el músculo liso.

\section{Función Contráctil de la AUH}

El estudio de la función contráctil del MLV utilizando registros de desarrollo de fuerza isométrica en anillos vasculares sometidos a un estiramiento inicial a 2 $\mathrm{gF}$ ha sido ampliamente utilizado y validado mediante experimentos en los cuales se prueba la acción de distintos estímulos sobre el tejido vascular. En los vasos que no poseen tono miogénico el estiramiento inicial del anillo genera como primera respuesta una relajación pasiva dada por la componente elástica de la pared del vaso, que luego de un período de estabilización se mantiene constante. Esta respuesta pasiva puede observarse en arterias como las arterias aorta o mesentérica de la rata (resultados obtenidos en nuestro laboratorio). En cambio, los anillos vasculares de AUH responden a ese estiramiento con una relajación inicial rápida seguida de una contracción más lenta que luego se estabiliza en el tiempo; obtuvimos entonces una respuesta contráctil activa que superó la relajación pasiva inicial. Las características de esta respuesta coinciden con las informadas para la respuesta miogénica típica que presentan las arteriolas, aunque recientemente, se ha descripto que la respuesta miogénica no es exclusiva de las arterias de pequeño calibre, encontrándose también expresada, en distinto grado, en arterias de mayor diámetro (250-252).

Los primeros indicios experimentales que permitieron plantear la hipótesis de que la respuesta al estiramiento observada en la AUH fuese una respuesta activa con características de respuesta miogénica fueron posteriormente apoyados por los resultados obtenidos mediante dos tipos diferentes de experimentos mecánicos que permitieron medir el desarrollo de fuerza en anillos vasculares y la resistencia al flujo en segmentos arteriales perfundidos. Del análisis de los mismos surgen las siguientes conclusiones parciales que avalan la idea preliminar: 
a. la respuesta contráctil al estiramiento en condiciones isométricas disminuye significativamente en ausencia de $\mathrm{Ca}^{2+}$ externo y es inhibida por $\mathrm{Gd}^{3+}, \mathrm{Mg}^{2+}$ y $\mathrm{La}^{3+}$ sugiriendo la presencia de un influjo de $\mathrm{Ca}^{2+}$ basal que mantiene la respuesta miogénica y al que probablemente contribuyen canales CNS, según sugieren los resultados obtenidos con los inhibidores de la corriente CNS. Además, esta respuesta fue también disminuida por nifedipina, hecho que sugiere la partícipación de canales de $\mathrm{Ca}^{2+}$ tipo $\mathrm{L}$ en el mantenimiento de este flujo basal de $\mathrm{Ca}^{2+}$.

b. las curvas tensión-longitud realizadas a diferentes concentraciones de $\mathrm{Ca}^{2+}$ extracelular indican que la respuesta contráctil depende del grado de estiramiento y de la concentración de $\mathrm{Ca}^{2+}$ externa como se espera para una respuesta de tipo miogénico. Este mismo efecto no pudo ser observado en otros vasos humanos como la vena safena o la arteria radial, ensayados anteriormente en nuestro laboratorio (observaciones no presentadas en este trabajo). La dependencia del estiramiento y del $\mathrm{Ca}^{2+}$ en la AUH desaparece cuando las curvas se obtienen en presencia de bloqueantes de canales CNS, lo que refuerza la idea de que este tipo de canal iónico participe en la respuesta miogénica.

c. En los experimentos con segmentos vasculares perfundidos a diferentes velocidades en presencia $\mathrm{O}$ ausencia de $\mathrm{Ca}^{2+}$ se observó que la resistencia de la arteria disminuye con el aumento de la velocidad en ambos casos, sin embargo en presencia de $\mathrm{Ca}^{2+}$ la caída es menor. Una explicación posible para este resultado podría ser que la caida de la resistencia de la arteria es menor en presencia de $\mathrm{Ca}^{2+}$ porque, en presencia de este ión se desarrolla una respuesta miogénica dependiente de $\mathrm{Ca}^{2+}$ que se opone a la relajación inducida, tanto por la componente elástica de la pared como por el efecto del cambio en el flujo sobre las células endoteliales (o del inglés relajación por shear stress, fenómeno al que nos referiremos mas adelante). En otras palabras, en la pared arterial un mismo estímulo estaría provocando directa 0 indirectamente dos mecanismos contráctiles opuestos, contracción miogénica y relajación (pasiva y activa) inducidos por modificación del flujo. En general, en las arteriolas la respuesta miogénica es muy importante y puede generar un efecto neto de vasoconstricción ante un aumento de la presión intravascular, y en las arterias de mayor diámetro que las arteriolas este efecto puede ser menos importante (18). 
d. La perfusión de segmentos arteriales a velocidad constante durante todo el experimento (aún a la velocidad mínima ensayada) representa un estímulo capaz de generar una respuesta contráctil activa o miogénica, tal como se pone en evidencia en el aumento de la resistencia de la arteria cuando se agrega $\mathrm{Ca}^{2+}$ a la solución de perfusión en arterias previamente perfundidas $\sin \mathrm{Ca}^{2}$. Este aumento de la resistencia es inhibido en forma parcial por $\mathrm{Gd}^{3+} \mathrm{y} \mathrm{Mg}^{2+}$ de la misma forma que fue observado en los demás experimentos. Este resultado además de poner en evidencia una respuesta activa dependiente del $\mathrm{Ca}^{2+}$ en la cual probablemente tengan un rol importante los canales CNS, podría también estar reflejando dos fenómenos adicionales: i. la presencia de un flujo de $\mathrm{Ca}^{2+}$ denominado capacitativo mediado por canales CNS de tipo SOC activados por la depleción del retículo sarcoplásmico generado por la perfusión de la arteria con solución KRB $\sin \mathrm{Ca}^{2+}$. ii. presencia del mecanismo denominado paradoja del calcio. En este mecanismo que ha sido demostrado en otros vasos (237) se propone que la ausencia de $\mathrm{Ca}^{2+}$ externo facilita el influjo de $\mathrm{Na}^{+}$a través de canales CNS despolarizando las células y abriendo canales de $\mathrm{Ca}^{2+}$ operados por voltaje, cuando se restituye el $\mathrm{Ca}^{2+}$, se observa una contracción debido a la entrada de $\mathrm{Ca}^{2+}$ a través de estos canales (237). Este fenómeno se explica en base a la presencia de canales CNS que tienen la propiedad de ser parcialmente bloqueados por el $\mathrm{Ca}^{2+}$ externo, aumentando su permeabilidad al $\mathrm{Na}^{+}$en ausencia de $\mathrm{Ca}^{2+}$. Si bien la presencia de estos dos mecanismos no fue explorada en detalle en este trabajo de Tesis, la hipótesis de que uno o ambos mecanismos estén contribuyendo a la respuesta contráctil descripta, se acompaña con el resultado que surge de comparar el valor de resistencia que alcanza la arteria cuando se restituye el $\mathrm{Ca}^{2+}$ externo con el obtenido en presencia de $\mathrm{Ca}^{2+}$ durante todo el experimento. Así, a una misma velocidad de perfusión los valores de resistencia en presencia de $\mathrm{Ca}^{2+}$ son mayores en los segmentos que fueron estabilizados en ausencia de $\mathrm{Ca}^{2+}$ que en los segmentos estabilizados en presencia de este ion. La discriminación y confirmación de la presencia de estos mecanismos en el MLV de la AUH, así como la importancia del influjo de $\mathrm{Na}^{+}$en la regulación de la función contráctil de estas células necesitan de mayores evidencias experimentales y quedan planteadas como futuros temas de estudio en este vaso. 
Por otro lado es importante discutir el hecho de que en los experimentos diseñados para indagar la participación de canales CNS en la respuesta miogénica de la arteria se ha utilizado en todos los casos $\mathrm{Gd}^{3+}$ como inhibidor de este tipo de canal. Numerosos trabajos describen la presencia de canales CNS utilizando $\mathrm{Gd}^{3+}$ como inhibidor y en este trabajo se demuestra que $\mathrm{Gd}^{3+}$ es capaz de inhibir la corriente CNS observada en células aisladas de músculo liso de la AUH. Algunas referencias bibliográficas sin embargo no consideran al $\mathrm{Gd}^{3+}$ como bloqueante selectivo y han informado que en otros tejidos $\mathrm{Gd}^{3+}$ es capaz de bloquear canales de $\mathrm{Ca}^{2+}$ de tipo $\mathrm{L}$ (253). En la AUH, los resultados que muestran que una dosis saturante de $\mathrm{Gd}^{3+}$ no modifica la contracción inducida por una solución despolarizante con alto $\mathrm{K}^{+}$, mientras que nifedipina sí induce relajación completa de la contracción, permiten descartar la posibilidad de que $\mathrm{Gd}^{3+}$ induzca su efecto relajante por bloqueo de canales de $\mathrm{Ca}^{2+}$ operados por voltaje.

El aumento de la concentración de $\mathrm{Mg}^{2+}$ extracelular produjo bloqueo de la corriente CNS en células aisladas y una inhibición sobre el tono miogénico en la $\mathrm{AUH}$. Si bien tampoco se considera al $\mathrm{Mg}^{2+}$ un bloqueante selectivo de canales CNS se ha demostrado en diferentes tipos celulares incluidas células de MLV, su capacidad de inhibir diferentes subtipos de esta familia de canales $(248,254)$. En particular se utiliza $\mathrm{Mg}^{2+}$ como inhibidor de la corriente capacitativa de $\mathrm{Ca}^{2+}$. Los resultados obtenidos con alto $\mathrm{Mg}^{2+}$ en la $\mathrm{AUH}$, podrían tener relevancia terapéutica ya que la misma dosis que es empleada terapéuticamente en pacientes con preeclampsia (255) se demostró efectiva para inhibir la corriente CNS y relajar el tono miogénico en la AUH. Por lo tanto, se puede especular que el $\mathrm{Mg}^{2+}$ administrado para prevenir las crisis epilépticas en pacientes eclámpticas (68) también podría afectar el flujo sanguíneo en la circulación feto-placentaria por acción directa sobre canales CNS en las células de músculo liso de la AUH.

El análisis de los resultados presentados hasta aquí permiten llegar a las siguientes conclusiones parciales acerca de la función contráctil de la $\mathrm{AUH}$ :

- la AUH es capaz de desarrollar tono miogénico en respuesta al estiramiento dependiendo de la concentración de $\mathrm{Ca}^{2+}$ externo.

- la corriente catiónica no selectiva caracterizada en este vaso participa en el desarrollo del tono miogénico.

- El tono miogénico puede ser inhibido en diferente grado por lantánidos como $\mathrm{Gd}^{3+}$ y $\mathrm{La}^{3+}$, por $\mathrm{Mg}^{2+}$ y por nifedipina. 
En cuanto al mecanismo por el cual la corriente CNS participa en el desarrollo de tono miogénico en la $\mathrm{AUH}$ se pueden plantear dos posibilidades que podrian incluso verificarse en forma simultánea: 1. como mediadora directa de un influjo de $\mathrm{Ca}^{2+}$ y 2. a través de su efecto despolarizante que activa canales de $\mathrm{Ca}^{2+}$ operados por voltaje permitiendo el influjo de $\mathrm{Ca}^{2+}$. Los resultados obtenidos avalarian la hipótesis de que estos dos mecanismos contribuyan al desarrollo de tono miogénico, ya que hemos demostrado que parte de la corriente puede ser transportada por $\mathrm{Ca}^{2+}$ en condiciones fisiológicas y además se ha observado que $\mathrm{Gd}^{3+}$ hiperpolariza las células y que el bloqueo de canales de $\mathrm{Ca}^{2+}$ operados por voltaje puede inhibir el tono miogénico.

El rol de canales CNS como vía directa de entrada de $\mathrm{Ca}^{2+}$ a la célula ha sido recientemente descripto en células de MLV de vena porta de conejo, por Inoue y colaboradores quienes reportaron una corriente CNS sensible a Gd ${ }^{3+}$ a través de un canal del subtipo TRPC6, el cual es 4 o 5 veces más permeable a $\mathrm{Ca}^{2+}$ que a los iones monovalentes (199). La corriente CNS descripta en este trabajo, en las células de músculo liso de $\mathrm{AUH}$, posee características similares a las informadas para la corriente a través de los canales TRPC6 en otros tipos celulares. Además, Welsh y colaboradores demostraron que este tipo de canales está involucrado en el mecanismo de despolarización miogénica y en el desarrollo del tono vascular (207). Por lo cual es posible plantear como hipótesis que la proteína TRPC6 pueda constituir la estructura molecular para el canal que produce la corriente CNS encontrada en AUH.

Así como planteamos y discutimos el rol despolarizante de la corriente CNS en el mecanismo de contracción miogénica, las corrientes de $\mathrm{K}^{+}$(IK $\mathrm{K}_{\mathrm{DR}}$ y IBK $\mathrm{K}_{\mathrm{Ca}}$ ) caracterizadas electrofisiológicamente en este vaso podrian también participar en la regulación de este mecanismo, aumentando el desarrollo de fuerza o disminuyéndolo según se induzca inhibición o activación de estas corrientes respectivamente. Nosotros hemos demostrado mediante experimentos mecánicos que la activación de canales $\mathrm{BK}_{\mathrm{Ca}}$, utilizando floretina, produjo relajación de la respuesta contráctil al estiramiento que se observa en esta arteria, y que el bloqueo de los mismos, con 2 mM de TEA, induce contracción. Esto sugiere que los canales iónicos de tipo $\mathrm{BK}_{\mathrm{Ca}}$, cuyas propiedades electrofisiológicas hemos puesto en evidencia en células aisladas y en segmentos de membrana, son funcionales en el tejido intacto y que estarian involucrados en la respuesta 
contráctil activa que induce el estiramiento en esta arteria. Si bien la concentración de TEA que produce este efecto en los anillos vasculares es mayor que la que produce el bloqueo de la corriente iónica ( 2 vs $1 \mathrm{mM}$, respectivamente), el valor es inferior a la dosis media de bloqueo (10 $\mathrm{mM}$ ) informada en el MLV para la corriente IK entre otras causas, a que las propiedades de difusión de la sustancia inhibidora en el tejido vascular no permitan que la misma alcance la concentración efectiva en el espacio extracelular en contacto con las membranas celulares de las células de músculo liso.

Con 4-AP no sé logró observar un efecto contrayente significativo en los anillos vasculares intactos de la $\mathrm{AUH}$. Este resultado puede interpretarse como el correlato mecánico de los efectos observados en los experimentos electrofisiológicos en configuración W-C, donde esta sustancia inhibe la corriente $K_{D R}$ en algunas células pero aumenta la corriente total en otro grupo de células. Si estos efectos contrapuestos se verifican en células del mismo segmento vascular, como hemos observado, el efecto mecánico resultante podría ser nulo. Por otro lado, la falta de efecto mecánico de la 4-AP en la fase estable de la respuesta activa inducida por el estiramiento, puede sugerir que la corriente IK $\mathrm{K}_{\mathrm{DR}}$ no está involucrada en el mantenimiento de la misma pero no descarta la posibilidad que la IK diferentes grados de estiramiento.

Es también importante tener en cuenta, en la interpretación de los efectos de sustancias inhibidoras de canales iónicos sobre la función contráctil del MLV, que la modificación del estado contráctil mediante la generación de contracción o relajación, si bien demuestra la funcionalidad de los mismos en el tejido intacto y orienta sobre el rol funcional de los mismos, no son suficientes para investigar el mecanismo de acción de una droga, debido a la gran cantidad de variables que se ponen en juego en el mecanismo de contracción y relajación. Como así tampoco se puede inferir acerca del efecto que producirian en el estado contráctil del vaso drogas que han sido ensayadas sobre corrientes iónicas. Con respecto a esto, Halliday y colaboradores encontraron que en aorta de rata los resultados electrofisiológicos obtenidos con TEA y 4-AP no se correlacionaron con los datos mecánicos obtenidos en anillos vasculares de ese vaso (256). 
En relación a la relajación vascular inducida por aumento del flujo que hemos citado precedentemente, es importante tener en cuenta que la pared de los vasos reacciona al estiramiento de diferentes maneras dependiendo de qué mecanismos se ponen en juego en cada caso particular. El estiramiento de la pared del vaso inducido por un aumento de la presión intravascular generaria, en principio, un incremento del diámetro del vaso por acción del componente elástico de la pared que cede, en forma pasiva, a esta fuerza. Por otro lado, dos procesos activos podrían sumarse al anterior para dar el efecto neto final del vaso: 1. la liberación de factores relajantes endoteliales en respuesta al esfuerzo de corte (o en inglés "shear strees") ejercido por el flujo sobre las células endoteliales y 2. el desarrollo de respuesta miogénica por parte de las células de músculo liso de la pared vascular en respuesta a un estiramiento de la pared vascular que determinaría la contracción de las células de MLV oponiéndose al aumento del diámetro.

En la $\mathrm{AUH}$, hemos encontrado que en presencia de $\mathrm{Ca}^{2+}$ en la solución de perfusión, el aumento del flujo (generado por un aumento de la velocidad de perfusión) disminuye la resistencia del vaso y que esta disminución es menor en presencia de L-NAME a todas las velocidades ensayadas. La diferencia entre los valores de resistencia al flujo obtenidos con y $\sin$ L-NAME es significativa entre la primera velocidad $(0,7)$ y las velocidades subsiguientes $(2,96 ; 5,27 ; 7,46$ y 8,70$)$, las cuales no muestran diferencias entre sí. Esto sugiere que a valores de velocidad de perfusión mayores que, aproximadamente, $1 \mathrm{ml} / \mathrm{min}$ en nuestras condiciones experimentales el efecto relajante activado por el aumento de flujo es el máximo. Estos resultados indicarian que el NO producido "in situ" por el vaso participa en el mecanismo que produce la disminución de la resistencia del vaso como respuesta al aumento del flujo. Por otro lado, en otra serie de experimentos utilizando también arterias perfundidas observamos que la presencia de un dador exógeno de NO (SNP) en la solución de perfusión disminuye la resistencia de la AUH con respecto al control a los distintos valores de velocidad de perfusión, y que este efecto fue inhibido por TEA $1 \mathrm{mM}$. Estos últimos resultados refuerzan la idea de que el NO puede mediar un efecto relajante en este vaso y sugiere que los canales $\mathrm{BK}_{\mathrm{Ca}}$ podrían estar involucrados en el mecanismo vasorrelajante del NO descripto en otros vasos $y$, en particular en esta arteria como ha sido 
descripto para anillos de AUH estimulados con 5-HT y análogos de tromboxano $A_{2}$ (79).

Además del NO, otros factores relajantes podrían producir disminución de la resistencia de la AUH. En particular, Klockenbusch y colaboradores en el año 1992 presentaron resultados mecánicos utilizando segmentos de AUH indicando que la $\mathrm{PGI}_{2}$ sería un factor relajante derivado del endotelio más importante que el NO (78). Si bien en esta Tesis se presentan resultados electrofisiológicos y mecánicos referidos a la acción del NO, focalizados principalmente en el efecto del mismo sobre canales de tipo $\mathrm{BK}_{\mathrm{Ca}}$, el objetivo central en este trabajo de investigación no comprende la acción de factores endoteliales, por esta razón no se continuó con la investigación del efecto de otros factores endoteliales sobre la resistencia de la $\mathrm{AUH}$. Se abordará, en el futuro, el estudio del rol y posibles mecanismos de acción de otros factores endoteliales relajantes (como prostagandina $\mathrm{PGI}_{2}$ ) y contrayentes (como endotelina). Los resultados presentados hasta aquí que muestran disminución de la resistencia de la $\mathrm{AUH}$ con el aumento del flujo conjuntamente con los resultados que muestran que el estiramiento de la pared vascular como único estímulo genera una contracción activa, ponen en evidencia la posibilidad de que el efecto de roce generado por el cambio en el flujo sumado al estiramiento de la pared del vaso inducen dos mecanismos contráctiles contrapuestos, relajación y contracción respectivamente, de los cuales según la importancia relativa de los mismos disminuirá o aumentara la resistencia del vaso. Existen pocos trabajos en la literatura que den un tratamiento conjunto a estos dos fenómenos, Kuo y colaboradores informaron que, en arterias coronarias porcinas, estas dos respuestas interaccionan y la magnitud de ambas depende del nivel del cambio de presión (257). Recientemente, han surgido trabajos con información acerca de las estructuras y las vías que transducen la señal de estiramiento desde la membrana celular al aparato contráctil de la célula. En estos trabajos se plantea que tanto proteínas de la matriz extracelular como integrinas, ubicadas en la membrana plasmática y los componentes del citoesqueleto estarían implicados en la transducción de este tipo de señales $(18,238)$.

Otra estructura de membrana capaz de inducir un influjo de $\mathrm{Ca}^{2+}$ y sobre la cual habíamos señalado que podría estar involucrada en el mantenimiento de la respuesta contráctil activa al estiramiento es el intercambiador $\mathrm{Na} / \mathrm{Ca} \circ \mathrm{NCX}$ (del 
inglés " $\mathrm{Na}^{+} / \mathrm{Ca}^{2+}$ exchanger") funcionando en su modo reverso. La activación de este transportador en modo reverso podría ser inducida en forma directa por el estiramiento, si bien no hay datos en la literatura que señalen esta propiedad (18), o en forma indirecta a través de la colocalización con otras estructuras que modifiquen el potencial de membrana y/o las concentraciones locales de $\mathrm{Na}^{+}$y $\mathrm{Ca}^{2+}$, así como por el efecto de fosforilación por proteínas quinasas (50). En otros tipos de MLV se ha informado que el NCX participa en la regulación de la función contráctil, generalmente funcionando en su modo directo, produciendo extrusión de $\mathrm{Ca}^{2+}$. Así, en arterias pulmonares de rata se demostró que la inhibición del NCX contribuye a la vasoconstricción producida por la hipoxia (258). Sin embargo, es poca la información sobre el rol del modo reverso del mismo en condiciones basales. En algunos trabajos se ha señalado que existe relación entre el efecto contráctil que produce la disminución del $\mathrm{Na}^{+}$extracelular y la actividad del modo reverso del NCX (259). Con respecto a esto, se ha demostrado que en arterias renales de rata la disminución severa del $\mathrm{Na}^{+}$extracelular produce una contracción que puede ser inhibida directamente por KB-R7943 y es independiente de la activación de canales de $\mathrm{Ca}^{2+}$ operados por voltaje y de canales de $\mathrm{Cl}^{-}$, sin embargo si la variación de $\mathrm{Na}^{+}$se realiza dentro de un rango fisiológico, la contracción es menor y depende de la activación de canales de $\mathrm{Ca}^{2+}$ operados por voltaje y de canales de $\mathrm{Cl}^{-}$. Esto sugiere que, al menos en este tejido, la actividad del modo reverso del NCX tiene un rol funcional en la entrada directa de $\mathrm{Ca}^{2+}$ dependiendo de la magnitud del cambio en la concentración de $\mathrm{Na}^{+}$extracelular (260). El mecanismo que surge a partir de ese trabajo sugiere que si la disminución del $\mathrm{Na}^{+}$extracelular se realiza dentro de un rango fisiológico la activación del modo reverso del intercambiador produce una corriente despolarizante neta (considerando una estequiometria $3 \mathrm{Na}^{+}: 2 \mathrm{Ca}^{2+}$ ) que activaría canales de $\mathrm{Cl}^{-}$y canales de $\mathrm{Ca}^{2+}$ operados por voltaje que contribuyen a la despolarización $y$, median el influjo de $\mathrm{Ca}^{2+}$ necesario para la contracción. Sin embargo, si la disminución de la concentración de $\mathrm{Na}^{+}$está fuera de los rangos fisiológicos, la entrada de $\mathrm{Ca}^{2+} \mathrm{y}$, por lo tanto, la contracción se independiza de otros transportadores y se daría, exclusivamente, a través del modo reverso del NCX.

En la AUH, nuestros resultados muestran que $5 \mu \mathrm{M}$ KB-R7943, un inhibidor específico del modo reverso del intercambiador $\mathrm{Na} / \mathrm{Ca}$ (261), relaja 
significativamente la respuesta miogénica e inhibe en forma parcial la contracción que induce una solución con bajo $\mathrm{Na}^{+}$extracelular. Estos resultados sumados al hecho de que el efecto contráctil que produce la disminución de la concentración de $\mathrm{Na}^{+}$externo no se verifica en ausencia de $\mathrm{Ca}^{2+}$ permiten proponer que el intercambiador $\mathrm{Na} / \mathrm{Ca}$, funcionando en modo reverso, contribuye a la respuesta miogénica mediando un influjo de $\mathrm{Ca}^{2+}$ y que el mismo puede ser estimulado disminuyendo la concentración de $\mathrm{Na}^{+}$externo. Este dato se correlaciona con los resultados obtenidos en el año 1991 por Sato y colaboradores que muestran que tanto la eliminación del $\mathrm{Na}^{+}$extracelular como la presencia de ouabaína (que aumentaría la concentración de $\mathrm{Na}^{+}$intracelular) producen contracción en segmentos helicoidales de AUH (262). Estos autores plantean que la acción del NCX es responsable de estos efectos basados en el hecho de que el amiloride, un bloqueante inespecifico del NCX, los inhibe; posteriormente demuestran en otro trabajo que la contracción inducida por disminución del $\mathrm{Na}^{+}$extracelular es menor en arterias umbilicales provenientes de neonatos cuyas madres han desarrollado preeclampsia durante el embarazo (263). Si asumimos que la disminución de $\mathrm{Na}^{+}$externo puede disminuir el modo directo del intercambiador y/o activar el modo reverso del mismo y que ambos efectos producirian contracción, la menor respuesta observada en los segmentos arteriales con preeclampcia podría tener varias explicaciones. Una hipótesis basada en nuestros resultados podría ser que la menor respuesta observada en segmentos con preeclampsia asociada se deba a una menor actividad del intercambiador $\mathrm{Na} / \mathrm{Ca}$ en su modo reverso, ya que hemos demostrado que el mismo contribuye al tono miogénico de la AUH funcionando en su modo reverso y se activa por efecto del bajo $\mathrm{Na}^{+}$. Sería interesante en el futuro indagar la validez de esta hipótesis examinando las características del tono miogénico y el efecto del inhibidor específico del modo reverso del NCX en arterias con patología eclámptica asociada. 


\section{Canal $\mathrm{BK}_{\mathrm{Ca}}$ y $\mathrm{pH}$ en la arteria mamaria interna humana (AMIH)}

La AMIH ha sido objeto de numerosos estudios que se han focalizado en su respuesta contráctil. Entre ellos, algunos han indagado la presencia y el rol de canales de $\mathrm{K}^{+}$en las células de MLV y la función endotelial de esta arteria. Se ha informado que los canales tipo $K_{\text {ATP }}$ están involucrados en la relajación inducida por levocromakalim en esta arteria, mientras que bloqueantes de otros tipos de canales de $\mathrm{K}^{+}$no modifican esta relajación (264).

Recientemente se ha demostrado la expresión del canal BK $\mathrm{C}_{\mathrm{Ca}}$ por métodos de biología molecular en las células de músculo liso de la $\mathrm{AMIH}$; mostrando además, que el 11,12-EET producido por el endotelio vascular activa la corriente de $\mathrm{W}$-C llevada por canales $\mathrm{BK}_{\mathrm{Ca}} \mathrm{y}$, consecuentemente, relaja el vaso (86). En concordancia con estos resultados, en este trabajo de Tesis se ha descripto un canal con una conductancia de $228 \pm 4$ pS en condiciones de $\mathrm{K}^{+}$simétrico (130 mM) sensible a IBTX y cuya probabilidad de apertura depende de la concentración intracelular de $\mathrm{Ca}^{2+}$ y del voltaje aplicado. Todas estas características son coincidentes con las informadas para el canal $\mathrm{BK}_{\mathrm{Ca}_{\mathrm{a}}}$ en células de músculo liso de otros vasos como se mencionó anteriormente para este canal en la AUH.

Por otro lado se demostró que este canal en la AMIH puede ser regulado por cambios en el pH. Los resultados obtenidos en configuración 1-O muestran que la alcalinización intracelular aumenta la probabilidad de apertura del canal y la acidificación la disminuye.

Son pocos los trabajos, hasta la fecha, que indagan la acción directa del pH sobre el canal BK $\mathrm{C}_{\mathrm{Ca}}$. En un estudio detallado, Shubert y colaboradores informaron el efecto de la variación del pH sobre la probabilidad de apertura de este canal en células de músculo liso de arteria de la cola de rata, con resultados coincidentes a los presentados en este trabajo para la AMIH. Estos autores encontraron que el aumento en la actividad del canal inducido por la alcalinización se debe a que en estas condiciones el canal muestra una mayor sensibilidad al $\mathrm{Ca}^{2+} \sin$ alterar su sensibilidad al voltaje, y proponen como mecanismo de acción que los protones podrían interaccionar con la proteina del canal ejerciendo un efecto inhibitorio dependiente de la concentración de $\mathrm{H}^{+}$(223). En otro trabajo realizado en 
músculo liso traqueal, Kume y colaboradores han informado que la acidosis modifica la conductancia del canal $\mathrm{BK}_{\mathrm{Ca}} \mathrm{e}$ induce un corrimiento de la curva de activación del canal hacia valores de potencial más hiperpolarizados (265). Estos efectos del pH podrian deberse a una modificación en la distribución de las cargas superficiales de la membrana que modifiquen las propiedades bioeléctricas de la proteína formadora del canal iónico.

Los resultados obtenidos en AMIH muestran que el valor de conductancia del canal no varía en función del cambio de $\mathrm{pH}$ y sí lo hace la probabilidad de apertura cuando se mantienen constantes el valor de potencial aplicado y la concentración de $\mathrm{Ca}^{2+}$. A la luz de la información precedente sería interesante, en el futuro, estudiar el mecanismo por el cual el cambio de $\mathrm{pH}$ afecta la probabilidad de apertura del canal $\mathrm{BK}_{\mathrm{Ca}}$ en este vaso.

Tal como se describió en la "Introducción", la modificación del pH extracelular $(\mathrm{pHe})$ puede inducir cambios en el estado contráctil de las células de músculo liso vascular. En este trabajo de Tesis se realizaron experimentos para examinar la acción de la modificación del pH externo e interno sobre la función contráctil de la $\mathrm{AMIH}$. El aumento del pHe contrae y su disminución relaja el tono basal de los anillos estirados isometricamente a $2 \mathrm{gF}$ sugiriendo que las variaciones en el pHe podrian afectar el diámetro de la AMIH "in situ". Si bien no ha sido estudiada en este vaso la respuesta del anillo al estiramiento (debido a que el número de experimentos realizados estuvo limitado por la poca cantidad de muestras disponibles) en los anillos sometidos al estiramiento se produce un desarrollo de fuerza que puede ser relajado por la disminución del pHe. Queda planteado como tema de futuras investigaciones indagar el hecho de que este tono pueda representar una respuesta de tipo miogénica y que ésta pueda ser modulada por el pH. En relación con esta posibilidad se ha reportado que, en arterias coronarias presurizadas de cobayo la acidosis produce vasodilatación y en este caso, se encontró que la activación de canales de $\mathrm{K}^{+}$sensibles al ATP está involucrada en el mecanismo de relajación (266).

El estudio de las propiedades contráctiles de la AMIH es de particular interés en el campo de la investigación clínica debido al hecho de que este vaso es ampliamente utilizado en la cirugía de revascularización miocárdica. Se ha informado que esta arteria presenta vasoespasmos, especialmente en las zonas más distales de su trayecto (últimos $3-4 \mathrm{~cm}$ antes de su bifurcación) que dificultan 
su manipulación quirúrgica (267). Este hecho hace que en el protocolo quirúrgico se incluya el uso de drogas vasodilatadoras de uso tópico que tiendan a minimizar los vasoespasmos en los segmentos que se utilizan como puentes aortocoronarios. Es importante remarcar entonces que el remanente quirúrgico que constituyó las muestras utilizadas en este trabajo proviene del extremo terminal de la $\mathrm{AMIH}$, o sea de la zona más proclive al desarrollo de vasoespasmos y que, entre las distintas drogas vasodilatadoras utilizadas durante la manipulación quirúrgica de la $\mathrm{AMIH}$, es frecuente la utilización de papaverina, una sustancia vasodilatadora inespecifica, que produce su efecto a través de distintos mecanismos como, inhibición de fosfodiesterasas (268), disminución del influjo de $\mathrm{Ca}^{2+}$ (269) e inhibición de la liberación de $\mathrm{Ca}^{2+}$ desde el retículo sarcoplásmico (270). La solución de papaverina comúnmente utilizada en forma tópica posee un valor de $\mathrm{pH}$ entre 5 y 3 (267), por lo tanto esta arteria, durante el procedimiento quirúrgico previo al momento en que comienza a cumplir su función de restablecimiento de flujo sanguíneo en el miocardio, se encuentra en contacto con una solución con pH muy bajo que podria alterar sus propiedades contráctiles futuras. Con respecto a esto, se ha informado que el bajo pH de la solución de papaverina produce daño endotelial (271) y apoptosis de células del endotelio como así también de las células de músculo liso (272). Por lo tanto, los posibles efectos que los cambios de $\mathrm{pH}$ puedan producir sobre las distintas estructuras involucradas en la contracción de las células de músculo liso de esta arteria adquiere mayor relevancia fisiológica.

Por otro lado, como se mencionó en la "introducción", se sabe que en el MLV, la variación del pHe produce una modificación considerable del $\mathrm{pH}$ intracelular (pHi) en el mismo sentido. Así, la reacción del vaso ante un cambio en el pHe tal vez se deba a los efectos de la modificación tanto del pHe como del pHi. En este trabajo, se evaluó, el efecto contráctil de sustancias que modifican el $\mathrm{pH}$ intracelular sin producir alteraciones del pH externo y se encontró que la alcalinización intracelular producida por una solución que contiene $20 \mathrm{mM}$ de $\mathrm{NH}_{4} \mathrm{Cl}$ contrae el vaso, mientras que la acidificación intracelular inducida por propionato de $\mathrm{Na}^{+}$en la misma concentración no logró producir un efecto significativo sobre el estado contráctil de la AMIH.

El hecho de que la alcalinización intracelular produzca activación de canales $\mathrm{BK}_{\mathrm{Ca}}$ en configuración I-O, y por otro lado induzca contracción en segmentos 
intactos del vaso, sugiere que el aumento del pH afecta, este tipo de canal iónico y otras estructuras involucradas en el mecanismo de contracción de este vaso favoreciendo el desarrollo de la misma. Se han descripto numerosas acciones del cambio de pHi sobre distintas estructuras relacionadas con el desarrollo de la contracción en las células de músculo liso. Por ejemplo, se sabe que el pH modula procesos relacionados con la homeostasis del $\mathrm{Ca}^{2+}$ intracelular como la liberación de $\mathrm{Ca}^{2+}$ del retículo sarcoplásmico a través de receptores de IP3 (273), la actividad de canales de $\mathrm{Ca}^{2+}$ operados por voltaje de la membrana plasmática (274) y la recaptación de $\mathrm{Ca}^{2+}$ por la bomba Ca-ATPasa del retículo sarcoplásmico (275). Es posible entonces que la activación de los canales $\mathrm{BK}_{\mathrm{Ca}}$, producida por el aumento del pHi. pueda actuar como un mecanismo limitante de la contracción.

La bibliografía referida al efecto neto del cambio de $\mathrm{pH}$ sobre el estado contráctil del músculo liso, es extensa y resulta controversial en algunos aspectos. Sin embargo, es claro que el efecto contráctil final que induce la modificación del $\mathrm{pH}$ depende de la importancia relativa de los mecanismos contráctiles o relajantes que este cambio produce en cada tipo de músculo liso y de las condiciones experimentales utilizadas en cada caso.

$\mathrm{Si}$ consideramos los resultados electrofisiológicos que muestran una regulación directa del $\mathrm{pH}$ sobre la actividad de canales $\mathrm{BK}_{\mathrm{Ca}}$ en las células de $\mathrm{AMIH}$, como una evidencia de uno de los efectos que el $\mathrm{pH}$ produce en estas células, así como los efectos contráctiles netos que genera en el tejido intacto podemos especular que estímulos fisiológicos como determinados agonistas, o condiciones patológicas relacionadas con cambios de $\mathrm{pH}$, podrian involucrar a este tipo de canal de $\mathrm{K}^{+}$que en respuesta a la alcalinización generaría hiperpolarización de la membrana celular y, a la acidificación, despolarización de la misma.

Las evidencias presentadas en este trabajo sobre las propiedades y modulación de la actividad de canales $\mathrm{BK}_{\mathrm{Ca}}$ en la $\mathrm{AMIH}$ provee además información útil para el estudio futuro de drogas vasodilatadoras que podrian tener como sitio de acción a este tipo de canal. 


\section{CONCLUSIONES FINALES}

El conjunto de datos presentados en este trabajo de investigación muestra inicialmente, algunos aspectos del conocimiento generado en el campo de la fisiología vascular, aporta nuevas evidencias experimentales acerca de la caracterización de estructuras de membrana que participan en la regulación de la función contráctil del MLV humano como mediadoras directas 0 indirectas del influjo de $\mathrm{Ca}^{2+}$ y finalmente, mediante la discusión de los resultados, presenta conclusiones parciales que permiten avanzar en la comprensión de los complejos mecanismos que intervienen en la regulación de la función contractil del MLV.

Un factor determinante de este proceso es la identificación de las estructuras celulares que participan en dicha función, la caracterización de sus propiedades, así como el conocimiento de los mecanismos implicados en la función. Los resultados electrofisiológicos aportan evidencias directas de las propiedades funcionales de los canales iónicos como mediadores de flujos iónicos y esto constituye un aspecto del conocimiento de estas estructuras. Los resultados mecánicos permiten observar el comportamiento del vaso ante determinadas intervenciones y especular sobre los posibles mecanismos que expliquen las respuestas netas obtenidas. Creemos que a partir del análisis global de este trabajo podemos aportar al conocimiento de la fisiología vascular, en este caso de la AUH y de la AMIH las siguientes conclusiones finales:

Las células de músculo liso de AUH poseen en su membrana canales CNS permeables al $\mathrm{Na}^{+}$y al $\mathrm{Ca}^{2+}$ con propiedades electrofisiológicas similares a las descriptas para este tipo de canal en músculo liso de otros vasos y en músculo liso no vascular. Estos canales están involucrados en la regulación del estado contráctil de este vaso representando una posible entrada de $\mathrm{Ca}^{2+}$ en la membrana de estas células. También describimos corrientes de $\mathrm{K}^{+}$con distintas componentes (IK $K_{D R}$ y IBK $\mathrm{IC}_{\mathrm{Ca}}$ )en la corriente total en estas células y, en particular, estudiamos las características del canal $\mathrm{BK}_{\mathrm{Ca}}$. Demostramos la existencia de tono miogénico en esta arteria y pusimos en evidencia el rol de dichos canales en el mantenimiento del mismo así como también la posible implicancia de otras estructuras como los canales de $\mathrm{Ca}^{2+}$ operados por voltaje y del intercambiador $\mathrm{Na} / \mathrm{Ca}$. Además indagamos la respuesta de este vaso al NO, encontrando que 
este activa el canal $\mathrm{BK}_{\mathrm{Ca}}$ y está implicado en la respuesta de este vaso al aumento del flujo produciendo vasodilatación. Así, los resultados presentados en este trabajo pueden ser importantes para el conocimiento de los mecanismos fisiológicos que regulan el flujo sanguíneo feto-placentario humano y las alteraciones que puedan producirse asociadas a ciertas patologías.

Con respecto a la $\mathrm{AMIH}$, se estudiaron las características del canal $\mathrm{BK}_{\mathrm{Ca}}$, su sensibilidad al $\mathrm{Ca}^{2+}$ y al voltaje, sobre el cual ha sido informado muy recientemente, por otros autores, su participación en el mecanismo de relajación por el factor hiperpolarizante endotelial. Además se puso en evidencia la sensibilidad de este canal a cambios del pH, encontrándose que la alcalinización lo activa y la acidificación lo inhibe. Además se indagó la respuesta del tejido intacto a la alcalinización intra y extracelular, encontrándose que ambas contraen este vaso, de forma que el efecto del $\mathrm{pH}$ sobre el canal $\mathrm{BK}_{\mathrm{Ca}}$ estaría contraponiendose al efecto contráctil neto observado en el tejido intacto. 


\section{REFERENCIAS}

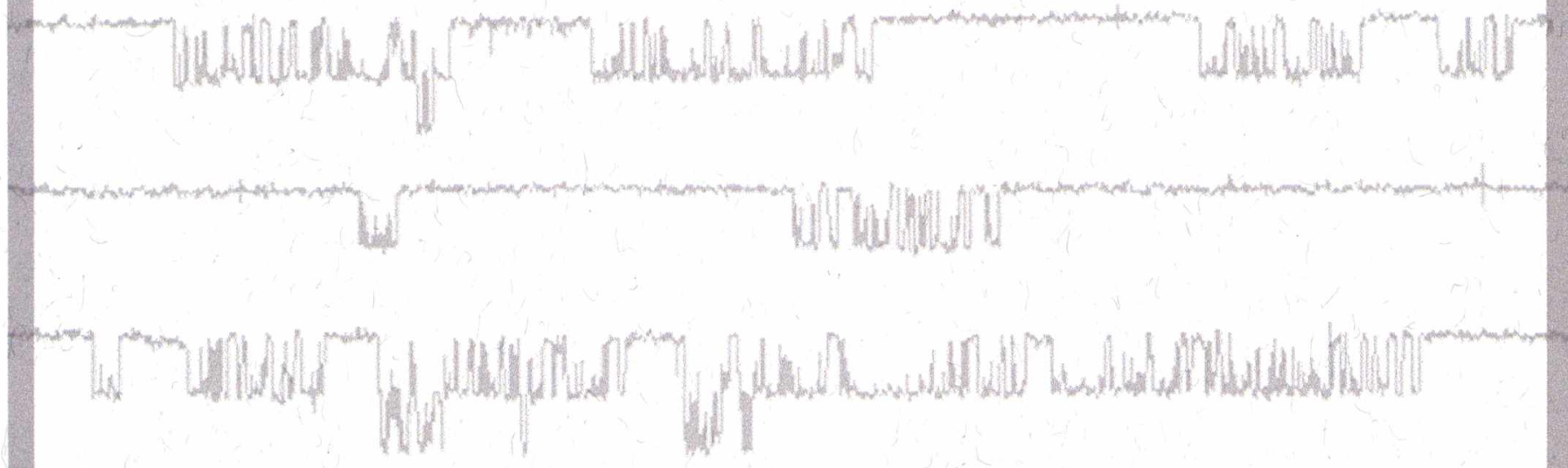




\section{REFERENCIAS}

1: Gende OA. Cap 31 en Cingolani HE, Houssay AB, "Fisiologia Humana", Editorial El Ateneo, 2000.

2: Cingolani HE. Cap 20 en Cingolani HE, Houssay AB, "Fisiología Humana", Editorial El Ateneo, 2000 .

3: Geneser F. "Histologia", Editorial Médica Panamericana, 2000.

4: Moncada S, Palmer RM, Higgs EA. Nitric oxide: physiology, pathophysiology, and pharmacology. Pharmacol Rev 43:109-142, 1991.

5: Gonzalez MC, Arribas SM, Molero F, Fernandez-Alfonso MS. Effect of removal of adventitia on vascular smooth muscle contraction and relaxation. Am J Physiol (Heart Circ Physiol) 280:H2876-2881, 2001.

6: Christ GJ, Spray DC, el-Sabban M, Moore LK, Brink PR. Gap junctions in vascular tissues. Evaluating the role of intercellular communication in the modulation of vasomotor tone. Circ Res 79:631-646, 1996.

7: National High Blood Pressure Education Program. The seventh report of the Joint National Committee on Prevention, Detection, Evaluation, and Treatment of High Blood Pressure.

8: Levy MN. Cap 23 en Berne RM, Levy MN, Knoeppen BM, Stanton BA, "Physiology", Editorial Mosby, 2004.

9: Cingolani HE. Cap 25 en Cingolani HE, Houssay AB, "Fisiologia Humana", Editorial El Ateneo, 2000 .

10: Packer CS. Changes in arterial smooth muscle contractility, contractile proteins, and arterial wall structure in spontaneous hypertension. Proc Soc Exp Biol Med 207:148-174, 1994.

11: Mc Minn RMH, Hutchings TR. Gran Atlas de Anatomia Humana. Wolfe Medical Publications, London, WI. EMALSA S.A., 1986.

12: Milesi V, Rebolledo A, Gomez Alvis A, Sanz N, Tommasi J, Drago A, Raingo J, Rinaldi GJ, Grassi de Gende AO. Structural and functional aspects of the human saphenous vein used as aorto-coronary graft in myocardial revascularization. Medicina (Buenos Aires) 61:481-490, 2001.

13: Kontos HA. Cap 46 en Bennet JC, Plum F "Cecil - Tratado de Medicina Interna", Editorial McGraw - Hill interamenicana, 1996.

14: Halpern W, Mongeon SA, Root DT. Stress, tension and myogenic aspects of small isolated extraparenchymal rat arteries. Publicado en: Smooth muscle contraction. Editado por NL Stephens NY 1984. Paginas 427-56.

15: Asano M, Masuzawa-Ito K, Matsuda T, Suzuki Y, Oyama H, Shibuya M, Sugita K. Increased $\mathrm{Ca}^{2+}$ influx in the resting state maintains the myogenic tone and activates charybdotoxinsensitive $\mathrm{K}^{+}$channels in dog basilar artery. J Cereb Blood Flow Metab 13:969-977, 1993.

16: Jain M, Dai HB, Carrozza JP, Selike FW, Morgan KG. Intrinsic tone as potential vascular reserve in conductance and resistance vessels. Circulation 94:1083-1088, 1996.

17: Bayliss WM. On the local reactions of the arterial wall to changes of internal pressure. $J$ Physiol (Lond) 28:220-231, 1902. 
18: Hill MA, Zou H, Potocnik SJ, Meininger GA, Davis MJ. Signal transduction in smooth muscle. Invited review: arteriolar smooth muscle mechanotransduction: $\mathrm{Ca} 2+$ signaling pathways underlying myogenic reactivity. J Appl Physiol 91:973-983, 2001.

19: Grassi de Gende, AO. Cap 29 en Cingolani HE, Houssay AB, "Fisiologia Humana", Editorial EI Ateneo, 2000.

20: Spivack M. The anatomic peculiarities of the human umbilical cord and their clinical significance. Am J Obstet Gynecol 52:387-401, 1946.

21: Wylam ME, Samsel RW, Schumacker PT, Umans JG. Extracellular calcium and intrinsic tone in the human umbilical artery. J Pharmacol Exp Ther 266:1475-1481, 1993.

22: Granger JP, Alexander BT, Bennett WA, Khalil RA. Pathophysiology of pregnancy-induced hypertension. Am J Hypertens 14:178S-185S, 2001.

23: Watras J. Cap 12 en Berne RM, Levy MN, Knoeppen BM, Stanton BA, "Physiology", Editorial Mosby, 2004.

24: Somlyo AP, Somlyo AV. "Smooth muscle structure and function.", en Fozard HA, "The heart and cardiovascular System", Ed. Raven Press, 1986.

25: Allen BG, Walsh MP. The biochemical basis of the regulation of smooth-muscle contraction. Trends Biochem Sci 19:362-368, 1994.

26: Stull JT, Gallagher PJ, Herring BP, Kamm KE. Vascular smooth muscle contractile elements. Cellular regulation. Hypertension 17:723-732, 1991.

27: Jiang H, Stephens NL. Calcium and smooth muscle contraction. Mol Cell Biochem 135:1-9, 1994.

28: Kanoh S, Ito M, Niwa E, Kawano Y, Hartshorne DJ. Actin-binding peptide from smooth muscle myosin light chain kinase. Biochemistry 32:8902-8907, 1993.

29: Lin P, Luby-Phelps K, Stull JT. Properties of filament-bound myosin light chain kinase. J Biol Chem 274:5987-5994, 1999.

30: Smith L, Su X, Lin P, Zhi G, Stull JT. Identification of a novel actin binding motif in smooth muscle myosin light chain kinase. J Biol Chem 274:29433-29438, 1999.

31: Wilson DP, Sutherland C, Walsh MP. $\mathrm{Ca}^{2+}$ activation of smooth muscle contraction: evidence for the involvement of calmodulin that is bound to the triton insoluble fraction even in the absence of Ca2+. J Biol Chem 277:2186-2192, 2002.

32: Mattiazzi AR. Cap 4 en Cingolani HE, Houssay AB, "Fisiologia Humana", Editorial El Ateneo, 2000 .

33: Sander KM. Mechanisms of calcium handling in smooth muscles. J Appl Physiol 91:14381449, 2001.

34: Fleischmann BK, Murray RK, Kotlikoff MI. Voltage window for sustained elevation of cytosolic calcium in smooth muscle cells. Proc Natl Acad Sci USA 91:11914-11918, 1994.

35: Gollasch M, Nelson MT. Voltage-dependent $\mathrm{Ca2}+$ channels in arterial smooth muscle cells. Kidney Blood Press Res 20:355-371, 1997.

36: Hermsmeyer K, Mishra S, Miyagawa K, Minshall R. Physiologic and pathophysiologic relevance of T-type calcium-ion channels: potential indications for T-type calcium antagonists. Clin Ther 19:18-26, 1997. 
37: Triggle DJ. Cardiovascular T-type calcium channels: physiological and pharmacological significance. J Hypertens 15:S9-15, 1997.

38: Schmitt R, Clozel JP, Iberg N, Buhler FR. Prevention of neointima formation by mibefradil after vascular injury in rats: comparison with ACE inhibition. Cardiovasc Drugs Ther 10:101-105, 1996.

39: Barritt GJ. Receptor-activated Ca2+ inflow in animal cells: a variety of pathways tailored to meet different intracellular Ca2+ signalling requirements. Biochem J 337:153-169, 1999.

40: Ehrlich BE, Kaftan E, Bezprozvannaya S, Bezprozvanny I. The pharmacology of intracellular $\mathrm{Ca}^{2+}$-release channels. Trends Pharmacol Sci. 15:145-149, 1994.

41: Mak DO, McBride S, Foskett JK. Inositol 1,4,5-trisphosphate activation of inositol trisphosphate receptor $\mathrm{Ca}^{2+}$ channel by ligand tuning of $\mathrm{Ca} 2+$ inhibition. Proc Natl Acad Sci USA 95:15821-15825, 1998.

42: Watras J, Bezprozvanny I, Ehrlich BE. Inositol 1,4,5-trisphosphate-gated channels in cerebellum: presence of multiple conductance states. J Neurosci 11:3239-3245, 1991.

43: lino M. Biphasic $\mathrm{Ca} 2+$ dependence of inositol 1,4,5-trisphosphate-induced $\mathrm{Ca}$ release in smooth muscle cells of the guinea pig taenia caeci. J Gen Physiol 95:1103-1122, 1990.

44: Lee HC, Aarhus R, Graeff R, Gurnack ME, Walseth TF. Cyclic ADP ribose activation of the ryanodine receptor is mediated by calmodulin. Nature 370:307-309, 1994.

45: Matsuda T, Takuma K, Baba A, $\mathrm{Na}(+)-\mathrm{Ca} 2+$ exchanger: physiology and pharmacology. Jpn J Pharmacol 74:1-20, 1997

46: Reeves JP. Na+/Ca2+ exchange and cellular $\mathrm{Ca} 2+$ homeostasis. J Bioenerg Biomembr 30:151-160, 1998.

47: Schulze D, Kofuji P, Hadley R, Kirby MS, Kieval RS, Doering A, Niggli E, Lederer WJ. Sodium/calcium exchanger in heart muscle: molecular biology, cellular function, and its special role in excitation-contraction coupling. Cardiovasc Res 27:1726-1734. 1993.

48: Wu C, Fry $\mathrm{CH} . \mathrm{Na}+/ \mathrm{Ca} 2+$ exchange and its role in intracellular $\mathrm{Ca} 2+$ regulation in guinea pig detrusor smooth muscle. Am J Physiol (Cell Physiol) 280:C1090-1096, 2001

49: Moore ED, Etter EF, Philipson KD, Carrington WA, Fogarty KE, Lifshitz LM, Fay FS. Coupling of the $\mathrm{Na}+/ \mathrm{Ca} 2+$ exchanger, $\mathrm{Na}+/ \mathrm{K}+$ pump and sarcoplasmic reticulum in smooth muscle. Nature 365:657-660, 1993.

50: Juhaszova M, Ambesi A, Lindenmayer GE, Bloch RJ, Blaustein MP. $\mathrm{Na}^{+}-\mathrm{Ca}^{2+}$ exchanger in arteries: identification by immunoblotting and immunofluorescence microscopy. Am J Physiol 266:C234-242, 1994.

51: Ohata H, Kawanishi T, Hisamitsu T, Takahashi M, Momose K. Functional coupling of the $\mathrm{Na}+/ \mathrm{Ca} 2+$ exchanger with $\mathrm{Ca} 2+$ release from intracellular stores in cultured smooth muscle cells of guinea pig ileum. Life Sci 58:1179-1187, 1996

52: Hisamitsu T, Ohata H, Kawanishi T, Iwamoto T, Shigekawa M, Amano H, Yamada S, Momose $\mathrm{K}$. A mechanism of $\mathrm{Ca} 2+$ release from $\mathrm{Ca} 2+$ stores coupling to the $\mathrm{Na}+/ \mathrm{Ca} 2+$ exchanger in cultured smooth muscle cells. Life Sci 69:2775-2787, 2001.

53: Schilling WP. TRP proteins: novel therapeutic targets for regional blood pressure control? Circ Res 88:256-259, 2001 
54: Sato K, Aoki K. Early and late contraction induced by ouabain in human umbilical arteries. $\mathrm{Br} \mathrm{J}$ Pharmacol 103:1525-1529, 1991.

55: Fernandez-Alfonso MS, Sanchez-Ferrer CF, Hernandez MC, Marin J. $\mathrm{Na}+/ \mathrm{Ca}+$ exchange mediation in the ouabain-induced contraction in human placental vessels. Gen Pharmacol 23:439444, 1992.

56: Austin C, Wray S. Interactions between $\mathrm{Ca}^{2+}$ and $\mathrm{H}^{+}$and functional consequences in vascular smooth muscle. Circ Res 86:355-363, 2000

57: Furukawa K, Ohshima N, Tawada-Iwata Y, Shigekawa M. Cyclic GMP stimulates $\mathrm{Na}+/ \mathrm{Ca} 2+$ exchange in vascular smooth muscle cells in primary culture. J Biol Chem 266:12337-12341, 1991. 58: Khoyi MA, Bjur RA, Westfall DP. Norepinephrine increases $\mathrm{Na}-\mathrm{Ca}$ exchange in rabbit abdominal aorta. Am J Physiol 261:C685-690, 1991.

59: Vigne P, Breittmayer JP, Duval D, Frelin C, Lazdunski M. The $\mathrm{Na}+/ \mathrm{Ca} 2+$ antiporter in aortic smooth muscle cells. Characterization and demonstration of an activation by phorbol esters. J Biol Chem 263:8078-8083, 1988

60: Shigekawa M, Iwamoto T, Wakabayashi S. Phosphorylation and modulation of the $\mathrm{Na}^{+}-\mathrm{Ca}^{2+}$ exchanger in vascular smooth muscle cells. Ann N Y Acad Sci 779:249-257, 1996.

61: Van Breemen C and Saida K. Cellular mechanisms regulating [ $\mathrm{Ca} 2+]$ i in smooth muscle. Annu Rev Physiol 51:315-329, 1989

62: Raeymaekers L, Eggermont JA, Wuytack F, Casteels R. Effects of cyclic nucleotide dependent protein kinases on the endoplasmic reticulum $\mathrm{Ca} 2+$ pump of bovine pulmonary artery. Cell Calcium 11:261-268, 1990.

63: Guerini D. The $\mathrm{Ca} 2+$ pumps and the $\mathrm{Na}+/ \mathrm{Ca} 2+$ exchangers. Biometals. 11:319-330, 1998.

64: Lee CH, Poburko D, Kuo KH, Seow CY, van Breemen C. Ca2+ oscillations, gradients, and homeostasis in vascular smooth muscle. Am J Physiol 282:H1571-1583, 2002.

65: Bayguinov O, Hagen B, Bonev AD, Nelson MT, Sanders KM. Intracellular calcium events activated by ATP in murine colonic myocytes. Am J Physiol 279:C126-135, 2000.

66: ZhuGe R, Sims SM, Tuft RA, Fogarty KE, Walsh JV Jr. Ca2+ sparks activate K+ and Clchannels, resulting in spontaneous transient currents in guinea-pig tracheal myocytes. J Physiol $513: 711-718,1998$.

67: Dadak C, Ulrich W, Sinzinger H. Morphological changes in the umbilical arteries of babies born to pre-eclamptic mothers: an ultrastructural study. Placenta 5:419-426, 1984

68: Johnstone FD, Ugaily-Thulesius L, Thulesius O, Nasrat AN. Umbilical artery reactivity and ultrastructural changes in pregnancy-induced hypertension and other complicated pregnancies. Clin Physiol 7:493-502, 1987.

69: Roberts JM, Taylor RN, Musci TJ, Rodgers GM, Hubel CA, McLaughlin MK. Preeclampsia: an endothelial cell disorder. Am J Obstet Gynecol 161:1200-1204, 1989

70: Haynes WG, Webb DJ. Endothelium-dependent modulation of responses to endothelin-I in human veins. Clin Sci (Lond) 84:427-433, 1993.

71: Pearson PJ, Vanhoutte PM. Vasodilator and vasoconstrictor substances produced by the endothelium. Rev Physiol Biochem Pharmacol 122:1-67, 1993. 
72: Ylikorkala O, Jouppila P, Kirkinen P, Vlinikka L. Maternal thromboxane, prostacyclin, and umbilical blood flow in humans. Obstet Gynecol 63:677-680, 1984.

73: Walsh SW. Preeclampsia: an imbalance in placental prostacyclin and thromboxane production. Am J Obstet Gynecol 152:335-340, 1985.

74: Fleming I, Gray GA, Stoclet JC. Influence of endothelium on induction of the L-arginine-nitric oxide pathway in rat aortas. Am J Physiol 264:H1200-1207, 1993.

75: Paya D, Maupoil V, Schott C, Rochette L, Stoclet JC. Temporal relationships between levels of circulating NO derivatives, vascular NO production and hyporeactivity to noradrenaline induced by endotoxin in rats. Cardiovasc Res 30:952-959, 1995

76: Lee MR, Li L, Kitazawa T. Cyclic GMP causes Ca2+ desensitization in vascular smooth muscle by activating the myosin light chain phosphatase. J Biol Chem 272:5063-5068, 1997.

77: Brophy CM, Whitney EG, Lamb S, Beall A. Cellular mechanisms of cyclic nucleotide-induced vasorelaxation. J Vasc Surg 25:390-397, 1997.

78: Klockenbusch W, Braun MS, Schroder H, Heckenberger RE, Strobach H, Schror K. Prostacyclin rather than nitric oxide lowers human umbilical artery tone in vitro. Eur $\mathrm{J}$ Obstet Gynecol Reprod Biol 47:109-115, 1992.

79: Triggle C, Lovren F. Nitric oxide and sodium nitroprusside-induced relaxation of the human umbilical artery. Br J Pharmacol 131:521-529, 2000.

80: Feletou M, Vanhoutte PM. Endothelium-dependent hyperpolarization of vascular smooth muscle cells. Acta Pharmacol Sin 21:1-18, 2000.

81: Campbell WB, Gebremedhin D, Pratt PF, Harder DR. Identification of epoxyeicosatrienoic acids as endothelium-derived hyperpolarizing factors. Circ Res 78:415-423, 1996.

82: Busse R, Edwards G, Feletou M, Fleming I, Vanhoutte PM, Weston AH. EDHF: bringing the concepts together. Trends Pharmacol Sci 23:374-380, 2002.

83: Popp R, Bauersachs J, Hecker M, Fleming I, Busse R. A transferable, beta-naphthoflavoneinducible, hyperpolarizing factor is synthesized by native and cultured porcine coronary endothelial cells. J Physiol 497:699-709, 1996.

84: Widmann MD, Weintraub NL, Fudge JL, Brooks LA, Dellsperger KC. Cytochrome P-450 pathway in acetylcholine-induced canine coronary microvascular vasodilation in vivo. Am J Physiol 274:H283-289, 1998

85: Quilley J, McGiff JC. Is EDHF an epoxyeicosatrienoic acid? Trends Pharmacol Sci 21:121124, 2000.

86: Archer SL, Gragasin FS, Wu X, Wang S, McMurtry S, Kim DH, Platonov M, Koshal A, Hashimoto K, Campbell WB, Falck JR, Michelakis ED. Endothelium-derived hyperpolarizing factor in human internal mammary artery is 11,12-epoxyeicosatrienoic acid and causes relaxation by activating smooth muscle BK(Ca) channels. Circulation 107:769-776, 2003.

87: Edwards G, Dora KA, Gardener MJ, Garland CJ, Weston AH. K+ is an endothelium-derived hyperpolarizing factor in rat arteries. Nature 396:269-272, 1998.

88: Vittone LB, Mundiña-Weilenmann C. Cap 23 en Cingolani HE, Houssay AB, "Fisiología Humana", Editorial El Ateneo, 2000. 
89: Toyofuku K, Nishimura J, Kobayashi S, Nakano H, Kanaide H. Effects of U46619 on intracellular $\mathrm{Ca}^{++}$concentration and tension in human umbilical artery. Am J Obstet Gynecol 172:1414-1421, 1995.

90: Kim YB, Yang BH, Piao ZG, Oh SB, Kim JS, Park K. Expression of Na+/HCO3- cotransporter and its role in $\mathrm{pH}$ regulation in mouse parotid acinar cells. Biochem Biophys Res Commun 304(4):593-598, 2003.

91: Romero MF, Fulton $\mathrm{CM}$, Boron WF. The SLC4 family of $\mathrm{HCO}_{3}{ }^{-}$transporters. Pflugers Arch 447:495-509, 2004.

92: Stamatas GN, Patrick CW Jr, McIntire LV. Intracellular pH changes in human aortic smooth muscle cells in response to fluid shear stress. Tissue Eng 3:391-403, 1997.

93: Neylon CB, Little PJ, Cragoe EJ Jr, Bobik A. Intracellular pH in human arterial smooth muscle. Regulation by $\mathrm{Na}+/ \mathrm{H}+$ exchange and a novel 5-( $\mathrm{N}$-ethyl- $\mathrm{N}$-isopropyl)amiloride-sensitive $\mathrm{Na}^{+}$- and $\mathrm{HCO}^{-}$-dependent mechanism. Circ Res 67:814-825, 1990.

94: Berk BC. Regulation of the $\mathrm{Na} / \mathrm{H}$ exchanger. Fliegel L, ed. Heidelberg, Germany, Springer, 1996

95: Albuquerque ML, Leffler $\mathrm{CW}$. $\mathrm{pHo}, \mathrm{pHi}$, and $\mathrm{PCO}_{2}$ in stimulation of IP3 and [Ca2+]c in piglet cerebrovascular smooth muscle. Proc Soc Exp Biol Med 219:226-234, 1998.

96: Smith JB, Dwyer SD, Smith L. Lowering extracellular pH evokes inositol polyphosphate formation and calcium mobilization. J Biol Chem 264:8723-8728, 1989.

97: lino S, Hayashi $\mathbf{H}$, Saito $H$, Tokuno $H$, Tomita T. Effects of intracellular $\mathrm{pH}$ on calcium currents and intracellular calcium ions in the smooth muscle of rabbit portal vein. Exp Physiol 79:669-680, 1994.

98: Smith GL, Austin C, Crichton C, Wray S. A review of the actions and control of intracellular pH in vascular smooth muscle. Cardiovasc Res 38:316-331, 1998.

99: Austin C, Wray S. The effects of extracellular $\mathrm{pH}$ and calcium change on force and intracellular calcium in rat vascular smooth muscle. J Physiol 488:281-291, 1995.

100: Apkon M, Boron WF. Extracellular and intracellular alkalinization and the constriction of rat cerebral arterioles. J Physiol 484:743-53, 1995.

101: Crichton CA, Templeton AG, Smith GL. Effect of altered bathing pH on calcium activated force in alpha toxin permeabilised rat portal vein and human umbilical artery. Cardiovasc Res 28:1378-1384, 1994

102: Klockner U, Isenberg G. Calcium channel current of vascular smooth muscle cells: extracellular protons modulate gating and single channel conductance. J Gen Physiol 103:665-678, 1994.

103: Brayden JE, Nelson MT. Regulation of arterial tone by activation of calcium-dependent potassium channels. Science 256:532-535, 1992.

104: Knot HJ, Nelson MT. Regulation of arterial diameter and wall [Ca2+] in cerebral arteries of rat by membrane potential and intravascular pressure. J Physiol 508:199-209, 1998.

105: Knot HJ, Nelson MT. Regulation of membrane potential and diameter by voltage-dependent $\mathrm{K}+$ channels in rabbit myogenic cerebral arteries. Am J Physiol 269:H348-355, 1995. 
106: Kotecha N, Potocnik SJ, Hill MA. Relationship between membrane potential and calcium entry in miogenic contraction of skeletal muscle arterioles. Proc Aust Physiol Pharmacol Soc 31: 88p, 2000.

107: Setoguchi M, Ohya Y, Abe I, Fujishima M. Stretch-activated whole-cell currents in smooth muscle cells from mesenteric resistance artery of guinea-pig. J Physiol 501:343-353, 1997.

108: Morris CE. Mechanosensitive ion channels. J Membr Biol 113:93-107, 1990.

109: Sjaastad MD, Nelson WJ. Integrin-mediated calcium signaling and regulation of cell adhesion by intracellular calcium. Bioessays 19:47-55, 1997.

110: Davis MJ, Hill MA, Signaling mechanisms underlying the vascular myogenic response. Physiol Rev. 79:387-423, 1999

111: Nelson MT, Quayle JM. Physiological roles and properties of potassium channels in arterial smooth muscle. Am J Physiol 268:C799-822, 1995.

112: Yuan XJ. Voltage-gated $\mathrm{K}+$ currents regulate resting membrane potential and $[\mathrm{Ca} 2+] \mathrm{i}$ in pulmonary arterial myocytes. Circ Res 77:370-378, 1995.

113: Hille B. Cap1 en Hille B, "Ionic channels of excitable membranes", Ed Sinauer, 1992.

114: Milesi V, Aiello EA, Rebolledo A, Gomez Alvis A, Grassi de Gende AO. Role of a Ca2+activated $\mathrm{K}+$ current in the maintenance of resting membrane potential of isolated, human, saphenous vein smooth muscle cells. Pflugers Arch 437:455-461, 1999.

115: Casteels R, Kitamura K, Kuriyama H, Suzuki H. The membrane properties of the smooth muscle cells of the rabbit main pulmonary artery. J Physiol; 271:41-61, 1977.

116: Bae YM, Park MK, Lee SH, Ho WK, Earm YE. Contribution of Ca2t-activated K+ channels and non-selective cation channels to membrane potential of pulmonary arterial smooth muscle cells of the rabbit. J Physiol 514:747-758, 1999.

117: Leblanc N, Leung PM. Indirect stimulation of $\mathrm{Ca}(2+)$-activated $\mathrm{Cl}$ - current by $\mathrm{Na}+/ \mathrm{Ca} 2+$ exchange in rabbit portal vein smooth muscle. Am J Physiol 268:H1906-1917, 1995.

118: Hirakawa Y, Gericke M, Cohen RA, Bolotina VM. $\mathrm{Ca}^{2+}$-dependent $\mathrm{Cl}^{-}$channels in mouse and rabbit aortic smooth muscle cells: regulation by intracellular $\mathrm{Ca}^{2+}$ and NO. Am J Physiol 277:H1732-1744, 1999.

119: Sakmann B, Neher E. Single channel recording, Ed. Plenum, 1995.

120: Hamill OP, Marty A, Neher E, Sackmann B, Sigworth FJ. Improved patch clamp techniques for high-resolution current readings from cells and cell-free membrane patches. Pflügers Arch 391:85-100, 1981.

121: Pallota BS, Blatz AL, Magleby KL. Cap 12 en Rudy B, Iverson LE, "Ion channels. Methods in enzymology vol. 207", Ed. Academic Press, 1992.

122: Clarke AL, Petrou S, Walsh JV Jr, Singer JJ. Site of action of fatty acids and other charged lipids on BKCa channels from arterial smooth muscle cells. Am J Physiol Cell Physiol. 2003 Mar;284:C607-19.

123: Latorre R, Labarca P. Potassium channels: diversity, assembly and differentila expression, en Evans JM, Hamilton TC, Longman SD, Stemp G, "Potassium channels and their modulators: from synthesis to clinical experience", Ed. Taylor and Francis, 1996. 
124: Korovkina VP, England SK. Detection and implications of potassium channels alterations. Vasc Pharmacol. 38:3-12. 2002.

125: Breitwieser GE. Mechanisms of K+ channel regulation. J Membr Biol 152:1-11, 1996.

126: Quayle JM, Nelson MT, Standen NB. ATP-sensitive and inwardly rectifying potassium channels in smooth muscle. Physiol Rev 77:1165-1232, 1997.

127: McCarron JG, Halpern W. Potassium dilates rat cerebral arteries by two independent mechanisms. Am J Physiol (Heart Circ Physiol) 28:H902-908, 1990.

128: Blumenthal EK, Kaczmarek LK. Structure and regulation of the MinK potassium channel. Neurochem Res 17:869-876, 1992.

129: Wain HM, Lush M, Ducluzeau F, Povey S. Genew: the human gene nomenclature database. Nucleic Acids Res 30:169-171, 2002.

130: Cox RH. Changes in the expression and function of arterial potassium channels during hypertension. Vascul Pharmacol 38:13-23, 2002.

131: Alon M. Voltage-dependent K+ (KV) Channels: A large and diverse family of membrane voltage regulators. Modulator 17:13-17, 2003.

132: Kaczorowski GJ, Garcia ML, Pharmacology of voltage-gated and calcium-activated potassium channels. Curr Opin Chem Biol 3:448-458, 1999.

133: Mandegar M, Remillard CV, Yuan JX. Ion channels in pulmonary arterial hypertension. Prog Cardiovasc Dis 45:81-114, 2002.

134: Archer SL, Huang JM, Reeve HL, Hampl V, Tolarova S, Michelakis E, Weir EK. Differential distribution of electrophysiologically distinct myocytes in conduit and resistance arteries determines their response to nitric oxide and hypoxia. Circ Res 78:431-442, 1996.

135: Gelband CH, Hume JR. Ionic currents in single smooth muscle cells of the canine renal artery. Circ Res 71:745-758, 1992.

136: Gelband CH, Ishikawa T, Post JM, Keef KD, Hume JR. Intracellular divalent cations block smooth muscle K+ channels. Circ Res 73:24-34, 1993.

137: Post JM, Gelband CH, Hume JR. [Ca2+]i inhibition of K+ channels in canine pulmonary artery. Novel mechanism for hypoxia-induced membrane depolarization. Circ Res 77:131-139, 1995.

138: Yuan XJ, Wang J, Juhaszova M, Golovina VA, Rubin LJ. Molecular basis and function of voltage-gated $\mathrm{K}+$ channels in pulmonary arterial smooth muscle cells. Am J Physiol 274:L621-635, 1998

139: Hille B. Cap5 en Hille B, "Ionic channels of excitable membranes", Ed Sinauer, 1992.

140: Levin G, Chikvashvili D, Singer-Lahat D, Peretz T, Thornhill WB, Lotan I. Phosphorylation of a $\mathrm{K}+$ channel alpha subunit modulates the inactivation conferred by a beta subunit. Involvement of cytoskeleton. J Biol Chem 271:29321-29328, 1996.

141: Maylie B, Bissonnette E, Virk M, Adelman JP, Maylie JG. Episodic ataxia type 1 mutations in the human Kv1.1 potassium channel alter hKvbeta 1-induced $\mathrm{N}$-type inactivation. J Neurosci 22:4786-4793, 2002.

142: Knot HJ, Brayden JE, Nelson MT. Calcium channels and potassium channels, en Bárány M, "Biochemistry of smooth muscle contraction", Ed. Academic Press, 1996. 
143: Gollasch M, Ried C, Bychkov R, Luft FC, Haller H. K+ currents in human coronary artery vascular smooth muscle cells. Circ Res 78:676-688, 1996.

144: Peng W, Karwande SV, Hoidal JR, Farrukh IS. Potassium currents in cultured human pulmonary arterial smooth muscle cells. J Appl Physiol 80:1187-1196, 1996.

145: Smirnov SV, Aaronson PI. $\mathrm{Ca}^{2+}$-activated and voltage-gated $\mathrm{K}^{+}$currents in smooth muscle cells isolated from human mesenteric arteries. J Physiol 457:431-454, 1992.

146: Aiello EA, Clement-Chomienne O, Sontag DP, Walsh MP, Cole WC. Protein kinase C inhibits delayed rectifier $\mathrm{K}+$ current in rabbit vascular smooth muscle cells. Am J Physiol 271:H109119, 1996.

147: Aiello EA, Malcolm AT, Walsh MP, Cole WC. Beta-adrenoceptor activation and PKA regulate delayed rectifier $\mathrm{K}+$ channels of vascular smooth muscle cells. Am J Physiol 275:H448459, 1998.

148: Yuan XJ, Tod ML, Rubin LJ, Blaustein MP. NO hyperpolarizes pulmonary artery smooth muscle cells and decreases the intracellular $\mathrm{Ca} 2+$ concentration by activating voltage-gated $\mathrm{K}+$ channels. Proc Natl Acad Sci USA 93:10489-10494, 1996.

149: Cox RH, Folander K, Swanson R. Differential expression of voltage-gated $\mathrm{K}^{+}$channel genes in arteries from spontaneously hypertensive and Wistar-Kyoto rats. Hypertension 37:1315-1322, 2001

150: Kohler M, Hirschberg B, Bond CT, Kinzie JM, Marrion NV, Maylie J, Adelman JP. Smallconductance, calcium-activated potassium channels from mammalian brain Science 273:17091714, 1996.

151: Chandy KG, Fantino E, Wittekindt O, Kalman K, Tong LL, Ho TH, Gutman GA, Crocq MA, Ganguli R, Nimgaonkar V, Morris-RosendahI DJ, Gargus JJ. Isolation of a novel potassium channel gene hSKCa3 containing a polymorphic CAG repeat: a candidate for schizophrenia and bipolar disorder? Mol Psychiatry 3:32-37, 1998.

152: Latorre R, Oberhauser A, Labarca P, Alvarez $\mathbf{O}$. Varieties of calcium-activated potassium channels. Annu Rev Physiol 51:385-399, 1989.

153: Plane F, Holland M, Waldron GJ, Garland CJ, Boyle JP. Evidence that anandamide and EDHF act via different mechanisms in rat isolated mesenteric arteries. Br J Pharmacol 121:15091511, 1997.

154: Zygmunt PM, Edwards G, Weston AH, Larsson B, Hogestatt ED. Involvement of voltagedependent potassium channels in the EDHF-mediated relaxation of rat hepatic artery. $\mathrm{Br} J$ Pharmacol 121:141-149, 1997.

155: Xia XM, Fakler B, Rivard A, Wayman G, Johnson-Pais T, Keen JE, Ishii T, Hirschberg B, Bond CT, Lutsenko S, Maylie J, Adelman JP. Mechanism of calcium gating in smallconductance calcium-activated potassium channels. Nature 395:503-507, 1998

156: Fanger CM, Ghanshani S, Logsdon NJ, Rauer H, Kalman K, Zhou J, Beckingham K, Chandy KG, Cahalan MD, Aiyar J. Calmodulin mediates calcium-dependent activation of the intermediate conductance KCa channel, IKCa1. J Biol Chem 274:5746-5754, 1999.

157: Pedersen KA, Schroder RL, Skaaning-Jensen B, Strobaek D, Olesen SP, Christophersen P. Activation of the human intermediate-conductance $\mathrm{Ca}^{2+}$-activated $\mathrm{K}^{+}$channel 
by 1-ethyl-2-benzimidazolinone is strongly $\mathrm{Ca}^{2+}$-dependent. Biochim Biophys Acta 1420:231-240, 1999.

158: Mieyal P, Fulton D, McGiff JC, Quilley J. NO-independent vasodilation to acetylcholine in the rat isolated kidney utilizes a charybdotoxin-sensitive, intermediate-conductance $\mathrm{Ca}^{++}$-activated $\mathrm{K}^{+}$channel. J Pharmacol Exp Ther 285:659-664, 1998.

159: Knaus HG, Garcia-Calvo M, Kaczorowski GJ, Garcia ML. Subunit composition of the high conductance calcium-activated potassium channel from smooth muscle, a representative of the mSlo and slowpoke family of potassium channels. J Biol Chem 269:3921-3924, 1994.

160: Meera P, Wallner M, Song M , Toro L. Large conductance voltage- and calcium-dependent $\mathrm{K}+$ channel, a distinct member of voltage-dependent ion channels with seven $\mathrm{N}$-terminal transmembrane segments (S0-S6), an extracellular $\mathrm{N}$ terminus, and an intracellular (S9-S10) C terminus. Proc Natl Acad Sci USA 94:14066-14071, 1997.

161: Wallner M, Meera P, Toro L. Determinant for beta-subunit regulation in high-conductance voltage-activated and $\mathrm{Ca}^{2+}$-sensitive $\mathrm{K}^{+}$channels: an additional transmembrane region at the $\mathrm{N}$ terminus. Proc Natl Acad Sci USA 93:14922-14927, 1996.

162: Schreiber $M$ and Salkoff L. A novel calcium-sensing domain in the BK channel. Biophys $J$ 73:1355-1363, 1997.

163: Hanner M, Vianna-Jorge R, Kamassah A, Schmalhofer WA, Knaus HG, Kaczorowski GJ, Garcia ML. The beta subunit of the high conductance calcium-activated potassium channel. Identification of residues involved in charybdotoxin binding. J Biol Chem 273:16289-16296, 1998.

164: Jan LY, Jan YN. Ways and means for left shifts in the MaxiK channel. Proc Natl Acad Sci USA 94:13383-13385, 1997.

165: Jaggar JH, Porter VA, Lederer WJ, Nelson MT. Calcium sparks in smooth muscle. Am J Physiol 278:C235-256, 2000.

166: Armstrong CM and Miller C. Do voltage-dependent $\mathrm{K}+$ channels require $\mathrm{Ca} 2+$ ? A critical test employing a heterologous expression system. Proc Natl Acad Sci USA 87:7579-7582, 1990.

167: Alon M. Large conductance Ca2+-dependent $\mathrm{K}+$ (BKca) Channels: Target for several pharmacological compounds. Modulator 17:10-11, 2003.

168: Zhou XB, Schlossmann J, Hofmann F, Ruth P, Korth M. Regulation of stably expressed and native BK channels from human myometrium by CGMP- and CAMP-dependent protein kinase. Pflügers Arch 436:725-734, 1998.

169: Gribkoff VK, Lum-Ragan JT, Boissard CG, Post-Munson DJ, Meanwell NA, Starrett JE Jr, Kozlowski ES, Romine JL, Trojnacki JT, Mckay MC, Zhong J, Dworetzky SI. Effects of channel modulators on cloned large-conductance calcium-activated potassium channels. Mol Pharmacol 50:206-217, 1996.

170: Koh DS, Reid G, Vogel W. Activating effect of the flavonoid phloretin on $\mathrm{Ca}^{2+}$-activated $\mathrm{K}^{+}$ channels in myelinated nerve fibers of Xenopus laevis. Neurosci Lett 165:167-170, 1994.

171: Valverde MA, Rojas P, Amigo J, Cosmelli D, Orio P, Bahamonde MI, Mann GE, Vergara

C, Latorre R. Acute activation of Maxi-K channels (hSlo) by estradiol binding to the beta subunit. Science 285:1929-1931, 1999. 
172: Brenner R, Perez GJ, Bonev AD, Eckman DM, Kosek JC, Wiler SW, Patterson AJ, Nelson MT, Aldrich RW. Vasoregulation by the beta1 subunit of the calcium-activated potassium channel. Nature 407:870-876, 2000.

173: Dick GM, Rossow CF, Smimov S, Horowitz B, Sanders KM. Tamoxifen activates smooth muscle BK channels through the regulatory beta 1 subunit. J Biol Chem 276:34594-34599, 2001.

174: Peng W, Michael JR, Hoidal JR, Karwande SV, Farrukh IS. ET-1 modulates KCa-channel activity and arterial tension in normoxic and hypoxic human pulmonary vasculature. Am J Physiol. 275:L729-739, 1998.

175: Brem AS, Bina RB, Mehta S, Marshall J. Glucocorticoids inhibit the expression of calciumdependent potassium channels in vascular smooth muscle. Mol Genet Metab 67:53-57, 1999.

176: Schubert R, Nelson MT. Protein kinases: tuners of the BKCa channel in smooth muscle. Trends Pharmacol Sci 22:505-512, 2001.

177: Toro L, Wallner M, Meera P, Tanaka Y. Maxi-K(Ca), a Unique Member of the Voltage-Gated K Channel Superfamily. News Physiol Sci 13:112-117, 1998.

178: Zhou XB, Arntz C, Kamm S, Motejlek K, Sausbier U, Wang GX, Ruth P, Korth M. A molecular switch for specific stimulation of the BKCa channel by CGMP and CAMP kinase. J Biol Chem 276:43239-43245, 2001.

179: Bregestovski PD, Printseva OYu, Serebryakov V, Stinnakre J, Turmin A, Zamoyski V. Comparison of $\mathrm{Ca2+-dependent} \mathrm{K}+$ channels in the membrane of smooth muscle cells isolated from adult and foetal human aorta. Pflügers Arch 413:8-13, 1988.

180 : Berczi V, Stekiel WJ, Contney SJ, Rusch NJ. Pressure-induced activation of membrane K+ current in rat saphenous artery. Hypertension 19:725-729, 1992.

181: Miura H, Wachtel RE, Liu Y, Loberiza FR Jr, Saito T, Miura M, Gutterman DD. Flowinduced dilation of human coronary arterioles: important role of $\mathrm{Ca}^{2+}$-activated $\mathrm{K}^{+}$channels. Circulation 103:1992-1998, 2001.

182: Stamler JS, Simon DI, Jaraki O, Osborne JA, Francis S, Mullins M, Singel D, Loscalzo J. S-nitrosylation of tissue-type plasminogen activator confers vasodilatory and antiplatelet properties on the enzyme. Proc Natl Acad Sci USA 89:8087-8091, 1992.

183: Bolotina V, Gericke M, Bregestovski P. Kinetic differences between $\mathrm{Ca}^{2+}$-dependent $\mathrm{K}^{+}$ channels in smooth muscle cells isolated from normal and atherosclerotic human aorta. Proc $\mathrm{R}$ Soc Lond B Biol Sci. 244:51-55, 1991.

184: Cox RH, Tulenko TN. Altered contractile and ion channel function in rabbit portal vein with dietary atherosclerosis. Am J Physiol 268:H2522-2530, 1995.

185: Rusch NJ, Liu Y, Pleyte KA. Mechanisms for regulation of arterial tone by $\mathrm{Ca}^{2+}$-dependent $K^{+}$channels in hypertension. Clin Exp Pharmacol Physiol 23:1077-1081, 1996.

186: Marijic J, Li Q, Song M, Nishimaru K, Stefani E, Toro L. Decreased expression of voltageand $\mathrm{Ca}^{2+}$-activated $\mathrm{K}^{+}$channels in coronary smooth muscle during aging. Circ Res 88:210-216. 2001.

187: Rusch NJ, De Lucena RG, Wooldridge TA, England SK, Cowley AW Jr. A Ca ${ }^{2+}$-dependent $\mathrm{K}^{+}$current is enhanced in arterial membranes of hypertensive rats. Hypertension 19:301-317, 1992. 
188: Kolias TJ, Chai S, Webb RC. Potassium channel antagonists and vascular reactivity in stroke-prone spontaneously hypertensive rats. Am J Hypertens 6:528-533, 1993.

189: Falcone JC, Granger HJ, Meininger GA. Enhanced myogenic activation in skeletal muscle arterioles from spontaneously hypertensive rats. Am J Physiol 265:H1847-1855, 1993.

190: Halaszovich CR, Zitt C, Jungling E, Luckhoff A. Inhibition of TRP3 channels by lanthanides. Block from the cytosolic side of the plasma membrane. J Biol Chem 275:37423$37428,2000$.

191: Minke B, Cook B. TRP channel proteins and signal transduction. Physiol Rev 82:429-472, 2002.

192: Clapham DE, Runnels LW, Strubing C. The TRP ion channel family. Nat Rev Neurosci. 2:387-396, 2001.

193: Gonzalez-Perrett S, Kim K, Ibarra C, Damiano AE, Zotta E, Batelli M, Harris PC, Reisin IL, Arnaout MA, Cantiello HF. Polycystin-2, the protein mutated in autosomal dominant polycystic kidney disease (ADPKD), is a Ca2+-permeable nonselective cation channel. Proc Natl Acad Sci USA 98:1182-1187, 2001.

194: Assaf AR, Lapane KL, McKenney JL, McKinlay S, Carleton RA. Coronary heart disease surveillance: field application of an epidemiologic algorithm. J Clin Epidemiol 53:419-426, 2000.

195: Hoyer J, Distler A, Haase W, Gogelein H. Ca2+ influx through stretch-activated cation channels activates maxi $\mathrm{K}+$ channels in porcine endocardial endothelium. Proc Natl Acad Sci USA 91(6):2367-2371, 1994.

196: Wang YX, Kotlikoff MI. Signalling pathway for histamine activation of non-selective cation channels in equine tracheal myocytes. J Physiol 523:131-138, 2000.

197: Lee HK, Shuttleworth CW, Sanders KM. Tachykinins activate nonselective cation currents in canine colonic myocytes. Am J Physiol 269:C1394-1401, 1995.

198: Kume H, Takagi K. Involvement of G proteins between receptors and $\mathrm{KCa}$ channels in the regulation of airway tone by the autonomic nervous system. Nihon Kyobu Shikkan Gakkai Zasshi 33:116-124, 1995.

199: Inoue R, Okada T, Onoue H, Hara Y, Shimizu S, Naitoh S, Ito Y, Mori Y. The transient receptor potential protein homologue TRP6 is the essential component of vascular alpha(1)adrenoceptor-activated $\mathrm{Ca}^{2+}$-permeable cation channel. Circ Res 88:325-332, 2001.

200: Valdecantos P, Briones R, Moya P, Germain A, Huidobro-Toro JP. Pharmacological identification of P2X1, P2X4 and P2X7 nucleotide receptors in the smooth muscles of human umbilical cord and chorionic blood vessels. Placenta 24:17-26, 2003.

201: Loirand G, Pacaud P. Mechanism of the ATP-induced rise in cytosolic Ca2+ in freshly isolated smooth muscle cells from human saphenous vein. Pflügers Arch 430:429-436, 1995.

202: Cario-Toumaniantz C, Loirand G, Ladoux A, Pacaud P. P2X7 receptor activation-induced contraction and lysis in human saphenous vein smooth muscle. Circ Res 83:196-203, 1998.

203: Parekh AB, Penner R. Store depletion and calcium influx. Physiol Rev 77:901-930, 1997.

204: Poteser M, Wakabayashi I, Rosker C, Teubl M, Schindl R, Soldatov NM, Romanin C, Groschner K. Crosstalk between voltage-independent $\mathrm{Ca} 2+$ channels and L-type $\mathrm{Ca} 2+$ channels 
in A7r5 vascular smooth muscle cells at elevated intracellular $\mathrm{pH}$ : evidence for functional coupling between L-type Ca2+ channels and a 2-APB-sensitive cation channel. Circ Res 92:888-896, 2003. 205: Sinkins WG, Estacion M, Schilling WP. Functional expression of TrpC1: a human homologue of the Drosophila Trp channel. Biochem J 331:331-339, 1998.

206: Ng LC, Gurney AM. Store-operated channels mediate Ca2+ influx and contraction in rat pulmonary artery. Circ Res 89:923-929, 2001.

207: Welsh DG, Morielli AD, Nelson MT, Brayden JE. Transient receptor potential channels regulate myogenic tone of resistance arteries. Circ Res 90:248-250, 2002.

208: Golovina VA. Cell proliferation is associated with enhanced capacitative $\mathrm{Ca}^{2+}$ entry in human arterial myocytes. Am J Physiol 277:C343-349, 1999.

209: Klockner U. Intracellular calcium ions activate a low-conductance chloride channel in smoothmuscle cells isolated from human mesenteric artery. Pflügers Arch 424:231-237, 1993.

210: Neher E. Cap 6 en Rudy B, Iverson LE, "Ion channels. Methods in enzymology vol. 207", Ed. Academic Press, 1992.

211: Kajioka S, Kitamura K, Kuriyama H. Guanosine diphosphate activates an adenosine 5'triphosphate-sensitive $\mathrm{K}+$ channel in the rabbit portal vein. J Physiol 444:397-418, 1991.

212: Langton PD, Nelson MT, Huang Y, Standen NB. Block of calcium-activated potassium channels in mammalian arterial myocytes by tetraethylammonium ions. Am J Physiol 260:H927934, 1991.

213: Hille B. Cap13 en Hille B, "Ionic channels of excitable membranes", Ed Sinauer, 1992.

214: Carl A, Lee HK, Sanders MK. Regulation of ion channels in smooth muscles by calcium. Am J Physiol 271:C9-34, 1996.

215: Tiritilli A. Effects of magnesium on human umbilical arteries: role of intracellular calcium stores. Pharmacology. 57:295-304, 1998.

216: Okatani Y, Taniguchi K, Sagara Y. Amplifying effect of endothelin-1 on serotonin-induced vasoconstriction of human umbilical artery. Am J Obstet Gynecol 172:1240-1245, 1995.

217: Caldwell RA, Clemo HF, Baumgarten CM. Using gadolinium to identify stretch-activated channels: technical considerations. Am J Physiol 275:C619-C621, 1998.

218: Lacampagne A, Gannier F, Argibay J, Gamier D, Le Guennec JY. The stretch-activated ion channel blocker gadolinium also blocks L-type calcium channels in isolated ventricular myocytes of the guinea-pig. Biochim Biophys Acta 1191:205-208, 1994.

219: Nelson MT. Ca2+-activated porassium channels and ATP-sensitive potassium channels as modulators of vascular tone. Trends Cardiovasc Med 3:54-60, 1993.

220: Austin C, Wray S. A quantitative study of the relation between intracellular $\mathrm{pH}$ and force in rat mesenteric vascular smooth muscle. Pflügers Arch 427:270-276, 1994.

221: Schwartz SM, Campbell GR, Campbell JH. Replication of smooth muscle cells in vascular disease. Circ Res 58:427-444, 1986.

222: Schwarz TL, Tempel BL, Papazian DM, Jan YN, Jan LY. Multiple potassium-channel components are produced by alternative splicing at the Shaker locus in Drosophila. Nature 331:137-142, 1988. 
223: Schubert R, Krien U, Gagov H. Protons inhibit the BK(Ca) channel of rat small artery smooth muscle cells. J Vasc Res 38:30-38, 2001.

224: Raingo J, Milesi V, Gómez Alvis A, Rebolledo A, Speroni F, Grassi A. Participación del retículo sarcoplásmico en la respuesta contráctil a 4-aminopiridina en aorta de rata. XLV Reunión anual de la Sociedad Argentina de Investigación Clínica. Medicina (Buenos Aires) 60:745, 2000.

225: Carl A, Lee HK, Sanders KM. Regulation of ion channels in smooth muscles by calcium. Am J Physiol. 271:C9-34, 1996.

226: Zhang H, Li P, Almassi GH, Nicolosi A, Olinger GN, Rusch NJ. Single-channel and functional characteristics of a $\mathrm{KCa}$ channel in vascular muscle membranes of human saphenous veins. J Cardiovasc Pharmacol 28:611-617, 1996.

227: Strobaek D, Christophersen P, Dissing S, Olesen SP. ATP activates $\mathrm{K}$ and $\mathrm{Cl}$ channels via purinoceptor-mediated release of $\mathrm{Ca} 2+$ in human coronary artery smooth muscle. Am J Physiol 271:C1463-1471, 1996

228: Morales E, Cole WC, Remillard CV, Leblanc N. Block of large conductance $\mathrm{Ca}^{2+}$-activated $\mathrm{K}^{+}$channels in rabbit vascular myocytes by internal $\mathrm{Mg}^{2+}$ and $\mathrm{Na}^{+}$. J Physiol 495:701-716, 1996.

229: Marty A. Blocking of large unitary calcium-dependent potassium currents by internal sodium ions. Pflügers Arch 396:179-181, 1983.

230: Yellen G. Relief of $\mathrm{Na}^{+}$block of $\mathrm{Ca}^{2+}$-activated $\mathrm{K}^{+}$channels by external cations. J Gen Physiol 84:187-199, 1984.

231: Latorre R, Labarca P, Naranjo D. Cap 32 en Rudy B, Iverson LE, "Ion channels. Methods in enzymology vol. 207", Ed. Academic Press, 1992.

232: Benham CD, Bolton TB. Spontaneous transient outward currents in single visceral and vascular smooth muscle cells of the rabbit. J Physiol 381:385-406, 1986.

233: Singer JJ, Walsh JV Jr. Characterization of calcium-activated potassium channels in single smooth muscle cells using the patch-clamp technique. Pflügers Arch 408:98-111, 1987.

234: Tanaka Y, Meera P, Song M, Knaus HG, Toro L. Molecular constituents of maxi KCa channels in human coronary smooth muscle: predominant alpha + beta subunit complexes. J Physiol 502:545-557, 1997.

235: Chanrachakul B, Matharoo-Ball B, Turner A, Robinson G, Broughton-Pipkin F, Arulkumaran S, Khan RN. Immunolocalization and protein expression of the alpha subunit of the large-conductance calcium-activated potassium channel in human myometrium. Reproduction 126:43-48, 2003.

236: Liu Y, Hudetz AG, Knaus HG, Rusch NJ. Increased expression of Ca2+-sensitive K+ channels in the cerebral microcirculation of genetically hypertensive rats: evidence for their protection against cerebral vasospasm. Circ Res 82:729-737, 1998.

237: Arnon A, Hamlyn JM, Blaustein MP. $\mathrm{Na}^{+}$entry via store-operated channels modulates $\mathrm{Ca}^{2+}$ signaling in arterial myocytes. Am J Physiol 278:C163-C173, 2000.

238: Hamill OP, Mcbride DW Jr. The pharmacology of mechanogated membrane ion channels. Pharmacol Rev 48:231-252, 1996. 
239: Trepakova ES, Gericke M, Hirakawa Y, Weisbrod RM, Cohen RA, Bolotina VM. Properties of a native cation channel activated by $\mathrm{Ca}^{2+}$ store depletion in vascular smooth muscle cells. J Biol Chem 276:7782-7790, 2001.

240: Zhang YH, Youm JB, HK Sung, Lee SH, Ryu SY, Lee SH, Ho WK, Earm YE. Stretchactivated and background non-selective cation channels in rat atrial myocytes. J Physiol 523:607619, 2000.

241: Miyoshi H, Yamaoka K, Garfield RE, Okhama K. Identification of a non-selective cation channel current in myometrial cells isolated from pregnant rats. Pflügers Arch 447:457-464, 2004. 242: Volk T, Schwoerer AP, Thiessen S, Schultz JH, Ehmke H. A polycystin-2-like large conductance cation channel in rat left ventricular myocytes. Cardiovasc Res 58:76-88, 2003.

243: Rhee JC, Rhee PL, Park MK, So I, Uhm DY, Kim KW, Kang TM. Muscarinic receptors controlling the carbachol-activated nonselective cationic current in guinea pig gastric smooth muscle cells. Jpn J Pharmacol 82:331-337, 2000.

244: Llanos P, Henriquez M, Riquelme G. A low conductance, non-selective cation channel from human placenta. Placenta 23:184-191, 2002.

245: Eisenman G. Cation selective glass electodes and their mode of operation. Biophys J 2:259323, 1962.

246: Davis MJ, Donovitz JA, Hood JD. Stretch-activated single-channel and whole cell currents in vascular smooth muscle cells. Am J Physiol 262:C1083-1088, 1992.

247: Zhang YH, Youm JB, Sung HK, Lee SH, Ryu SY, Ho WK, Earm YE. Stretch-activated and background non-selective cation channels in rat atrial myocytes. J Physiol 523: 607-619, 2000.

248: Prakriya M, Lewis RS. Separation and characterization of currents through store-operated CRAC channels and Mg2+-inhibited cation (MIC) channels. J Gen Physiol 119:487-507, 2002.

249: Nilius B. Permeation properties of a non-selective cation channel in human vascular endothelial cells. Pflügers Arch 416:609-611, 1990.

250: Asano M, Masuzawaito K, Matsuda T, Suzuki Y, Oyama H, Shibuya M, Sugita K. Functional role of charybdotoxin-sensitive $\mathrm{K}+$ channels in the resting state of cerebral, coronary and mesenteric arteries of the dog. J Pharmacol Exp Ther 267:1277-1285, 1993.

251: Asano M, Nomura Y, Ito K, Uyama Y, Imaizumi Y, Watanabe M. Increased function of voltage-dependent $\mathrm{Ca}^{++}$channels and $\mathrm{Ca}^{++}$-activated $\mathrm{K}^{+}$channels in resting state of femoral arteries from spontaneously hypertensive rats at prehypertensive stage. J Pharmacol Exp Ther 275:775-783, 1995.

252: Jain M, Dai HB, Carrozza JP, Sellke FW, Morgan KG. Intrinsic tone as potential vascular reserve in conductance and resistance vessels. Circulation 94:1083-1088, 1996.

253: Lacampagne A, Gannier F, Argibay J, Garnier D, Le Guennec JY. The stretch-activated ion channel blocker gadolinium also blocks L-type calcium channels in isolated ventricular myocytes of the guinea-pig. Biochim Biophys Acta 1191:205-208, 1994.

254:Yoshimura M, Oshima T, Matsuura H, Ishida T, Kambe M, Kajiyama G. Extracellular $\mathrm{Mg}^{2+}$ inhibits capacitative $\mathrm{Ca}^{2+}$ entry in vascular smooth muscle cells. Circulation 95: 2567-2572, 1997. 
255: Repke JT, Power ML, Holzman GB, Schulkin J. Hypertension in pregnancy and preeclampsia. Knowledge and clinical practice among obstetrician-gynecologists. J. Reprod. Med. 47: 472-476, 2002.

256: Halliday FC, Aaronson PI, Evans AM, Gurney AM. The pharmacological properties of K+ currents from rabbit isolated aortic smooth muscle cells. Br J Pharmacol 116:3139-3148, 1995.

257: Kuo L, Chilian WM, Davis MJ. Interaction of pressure- and flow-induced responses in porcine coronary resistance vessels. Am J Physiol 261:H1706-1715, 1991.

258: Wang YX, Dhulipala PK, Kotlikoff MI. Hypoxia inhibits the $\mathrm{Na}(+) / \mathrm{Ca}(2+)$ exchanger in pulmonary artery smooth muscle cells. FASEB J 14:1731-1740, 2000.

259: Fowler BC, Carmines PK, Nelson LD, Bell PD. Characterization of sodium-calcium exchange in rabbit renal arterioles. Kidney Int 50:1856-1862, 1996.

260: Schweda F, Seebauer H, Kramer BK, Kurtz A. Functional role of sodium-calcium exchange in the regulation of renal vascular resistance. Am J Physiol Renal Physiol 280:F155-161, 2001.

261: Amran MS, Homma N, Hashimoto K. Pharmacology of KB-R7943: a Na+-Ca2+ exchange inhibitor. Cardiovasc Drug Rev 21:255-276, 2003.

262: Sato K, Aoki K. Early and late contraction induced by ouabain in human umbilical arteries. $\mathrm{Br}$ J Pharmacol 103:1525-1529, 1991.

263: Sato K, Kojima M, Dohi Y. Depressed sodium-calcium exchange in human umbilical arteries from women with preeclampsia. J Cardiovasc Pharmacol 26:328-332, 1995.

264: Gojkoviic Bukarica L, Kazic T, Sajic Z, Djukanovic B, Panic G, Peric M, Bojic M. The effects of levcromakalim and pinacidil on the human internal mammary artery. Fundam Clin Pharmacol 11:550-560, 1997.

265: Kume H, Takagi K, Satake T, Tokuno H, Tomita T. Effects of intracellular pH on calciumactivated potassium channels in rabbit tracheal smooth muscle. J Physiol 424:445-457, 1990.

266: Ishizaka H, Gudi SR, Frangos JA, Kuo L. Coronary arteriolar dilation to acidosis: role of ATP-sensitive potassium channels and pertussis toxin-sensitive $G$ proteins. Circulation 99:558-563, 1999

267: Rosenfeldt FL, He GW, Buxton BF, Angus JA. Pharmacology of coronary artery bypass grafts. Ann Thorac Surg 67:878-888, 1999.

268: Martin W, Furchgott RF, Villani GM, Jothianandan D. Depression of contractile responses in rat aorta by spontaneously released endothelium-derived relaxing factor. J Pharmacol Exp Ther 237:529-238, 1986.

269: Huddart H, Saad KH. Papaverine-induced inhibition of electrical and mechanical activity and calcium movements of rat ileal smooth muscle. J Exp Biol 86:99-114, 1980.

270: Brading AF, Burdyga TV, Scripnyuk ZD. The effects of papaverine on the electrical and mechanical activity of the guinea-pig ureter. J Physiol 334:79-89, 1983.

271: Cooper GJ, Gillot T, Parry EA, Kennedy A, Wilkinson GA. Papaverine injures the endothelium of the internal mammary artery. Cardiovasc Surg 3:553-555, 1995.

272: Gao YJ, Yang H, Teoh K, Lee RM. Detrimental effects of papaverine on the human internal thoracic artery. J Thorac Cardiovasc Surg 126:179-185, 2003. 


\section{REFERENCIAS}

273: Tsukioka M, lino M, Endo M. pH dependence of inositol 1,4,5-trisphosphate-induced Ca2+ release in permeabilized smooth muscle cells of the guinea-pig. J Physiol 475:369-375, 1994.

274: Klockner U, Isenberg G. Calcium channel current of vascular smooth muscle cells: extracellular protons modulate gating and single channel conductance. J Gen Physiol 103:665-678, 1994.

275: Grover AK, Samson SE. Coronary artery acidosis: pH and calcium pump stability. Am J Physiol 265:H1486-1492, 1993. 